\title{
En

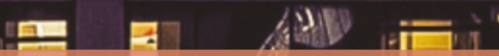 \\ Estrategias para la consecución del trabajo decente y sostenible en la empresa
}

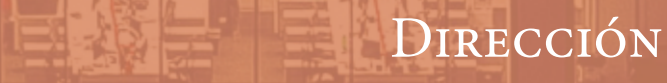

\section{E. M. Blázquez Agudo}

\section{Pérez del Prado}

Editorial Dykinson

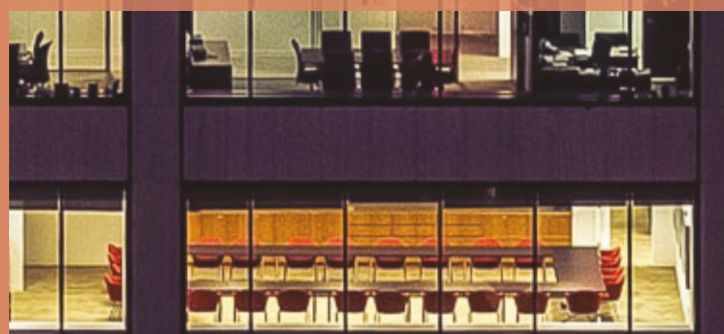

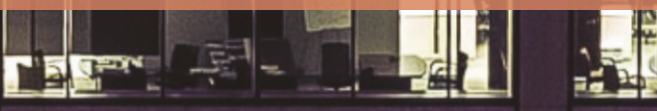

iil
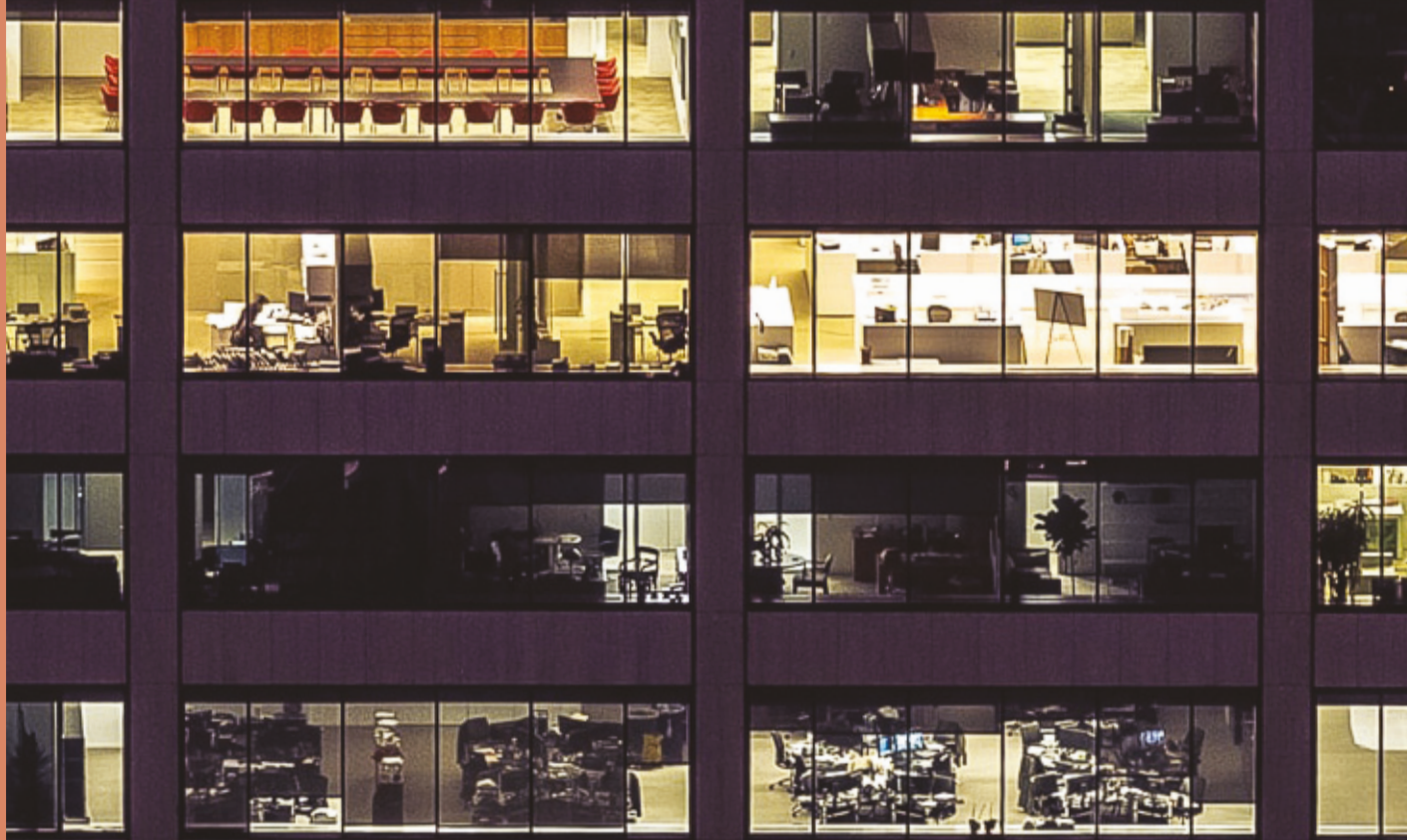

ESTRATEGIAS PARA LA CONSECUCIÓN DEL TRABAJO DECENTE Y SOSTENIBLE EN LA EMPRESA 

ESTRATEGIAS PARA LA CONSECUCIÓN DEL TRABAJO DECENTE Y SOSTENIBLE EN LA EMPRESA

E. M. Blázquez Agudo

D. Pérez del Prado

(Directores)

DYKINSON

2019 
(C) 2019 Autores

Motivo de cubierta:

Foto de Vladimir Kudinov disponible en Unsplash.com

Editorial Dykinson

c/ Meléndez Valdés, 61 - 28015 Madrid

Tlf. (+34) 915442846

E-mail: info@dykinson.com

http://www.dykinson.com

Preimpresión: TALLERONCE

ISBN: 978-84-1324-447-1

Depósito Legal: M-35786-2019

Versión electrónica disponible en e-Archivo

http://hdl.handle.net/10016/29106

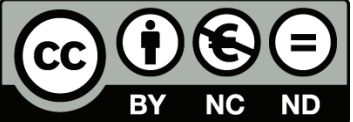

Licencia Creative Commons Atribución-NoComercial-SinDerivadas 3.o España 


\section{ÍNDICE}

Eva M. ${ }^{a}$ Blázquez Agudo, Daniel Pérez del Prado

PRÓLOGO ......................................

Magdalena Díaz Gorfinkiel, María Gema Quintero Lima

ESTRATEGIAS DE PREVENCION DE LA POBREZA LABORAL ......

1. El fenómeno social de la pobreza. 2. La paradoja de la pobreza laboral. 2.1. Variables sociales condicionantes de la pobreza. 2.2. Variables jurídico-laborales. 3. Estrategias y propuestas de actuación. 3.1. En relación con las políticas laborales. 3.1.1. Los ingresos. 3.1.2. Otras condiciones laborales. 3.1.3. La vigilancia pública. 3.2. En relación con políticas de protección social en sentido amplio. 4. Nuevas formas de gobernanza: el papel de los agentes sociales y de la sociedad civil. 5 . Consideraciones finales. 6. Bibliografía.

Tania García-Sedano, Vanesa Zorrilla-Muñoz, M. ${ }^{a}$ Silveria Agulló-Tomás APROXIMACIÓN AL TRABAJO FORZOSO E INFANTIL DESDE UNA PERSPECTIVA INTERDISCIPLINAR E INTERNACIONAL ..........

1. Introducción. Magnitud de los fenómenos y necesidad de investigación y evaluación. 2. Aproximación al trabajo forzoso. 2.1. Formas contemporáneas de esclavitud y trabajo forzoso. 2.2. La Agenda 2030 y la Meta 8.7. 2.3. El trabajo forzoso. 2.3.1. Convenio sobre el trabajo forzoso, 1930. 2.3.2. Convenio sobre la abolición del trabajo forzoso, 1957. 2.3.3. Protocolo de 2014 relativo al Convenio sobre el trabajo forzoso. 2.3.4. Otros Convenios. 2.4. El trabajo forzoso como finalidad del delito de trata de seres humanos. 3. Aproximación al trabajo infantil. 3.1. El trabajo infantil como problema psicosocial y sociopolítico. 3.2. Método y claves de la meta-evaluación de programas. 3.3. Resultados de la meta-evaluación del Programa "Edúcame Primero, Colombia". 4. Conclusiones. 5. Bibliografía. 6. Jurisprudencia. 
Patricia Nieto Rojas

EL INCREMENTO DE LOS NIVELES EDUCATIVOS DE LAS PERSONAS CON DISCAPACIDAD COMO FACTOR DE EMPLEABILIDAD . . .

1. Baja cualificación y personas con discapacidad. Un binomio consolidado. 2. El horizonte: el incremento de los niveles de cualificación como mecanismo de inclusión laboral. 3. El incremento del número de estudiantes con discapacidad en los programas de educación no obligatoria. 3.1. En los estudios de formación profesional. 3.2. En los estudios universitarios. 4. El futuro: el incremento de la cualificación de las personas con discapacidad como condición para el aumento de su empleabilidad. 5. Bibliografía

Ana Belén Muñoz Ruiz

DERECHOS FUNDAMENALES EN EL PLANO INTERNACIONAL: UNA INTRODUCCIÓN . . . . . . . . . . . . . . . . . . . . . .

1. Los derechos fundamentales en las fuentes internacionales generales.

1.1. La Carta de las Naciones Unidas. 1.2. La Declaración Universal de Derechos Humanos. 1.3. Los Pactos de 1966. 2. El sistema universal especializado de los derechos humanos laborales: la Organización Internacional del Trabajo. 3. Bibliografía.

Daniel Pérez del Prado

LAS CLÁUSULAS LABORALES COMO HERRAMIENTA PARA LOGRAR EL OBJETIVO DEL TRABAJO DECENTE . . . . . . . . . . . .

1. Introducción: el debate sobre las externalidades negativas del libre comercio en las condiciones de trabajo. 2. La progresiva incorporación de cláusulas laborales en los tratados comerciales internacionales. 2.1. Concepto y morfología de las cláusulas laborales. 2.2. La implantación de las cláusulas laborales. 2.3. Efectos y eficacia de las cláusulas laborales desde el plano económico. 3. Las cláusulas laborales como garantía del trabajo decente. 4. Bibliografía.

Marta García Mandaloniz

UNA ESTRATEGIA GLOBAL PARA LA FORMALIZACIÓN EMPRESARIAL Y LABORAL . . . . . . . . . . . . . . . . . . . . . . . .

1. Un entorno de informalidad: las causas y los efectos .1.1. Los efectos de la informalidad. 1.2. Las causas de la informalidad. 2. La informalidad versus la formalidad: un entorno de competencia desleal. 3. Las desventajas de la informalidad son las ventajas de la formalidad: para el empresario, el trabajador, el Estado y la sociedad. 4. Los componentes 
clave de una estrategia hacia la formalización. 4.1. Un sistema electrónico eficiente de inscripción empresarial. 4.2. Un sistema de incentivos fiscales y laborales. 4.3. Un conjunto de medidas de sensibilización para desenraizar la cultura de la informalidad. 5. Hacia la formalización en un entorno digital y global. 6 . Bibliografía.

Ofelia de Felipe Vila

TRABAJO DECENTE E IGUALDAD DE GÉNERO. DÉFICITS DE TRABAJO DECENTE Y ACCIÓN SINDICAL . . . . . . . . . . . . . . . .

1. Relación entre trabajo decente e igualdad de género. 2. Estado del trabajo en el mundo. 3. Impacto de género en la Globalización. 4. Las cadenas globales de cuidado. 5. Pistas para la acción sindical internacional. 6. El compromiso sindical con el trabajo decente, igualdad de género y Agenda 2030. 7. Bibliografía. 



\section{PRÓlogo}

La presente obra surge de la labor desarrollada en el grupo de cooperación "Trabajo decente y sostenible" de la Universidad Carlos III de Madrid <www. uc3m.es/cooperacion/trabajo-decente-sostenible>. Este grupo tiene como objetivo principal analizar, desde un enfoque interdisciplinar, la situación y perspectivas del trabajo decente como Objetivo de Desarrollo Sostenible en el marco de la Agenda 2030, así como formular propuestas para su consecución. Desde un plano más concreto, su labor científica se dirige, entre otros, a la sensibilización social sobre la necesidad de que el trabajo sea decente y sostenible, la difusión de buenas prácticas y la formulación de propuestas para alcanzar este objetivo, la creación de flujos de reflexión entre la universidad y la sociedad para buscar soluciones a los problemas que plantea la implantación de un sistema de trabajo sostenible a nivel mundial, la potenciación de la responsabilidad social corporativa, etc.

Dentro de los proyectos promovidos por el grupo se encuentra la "Escuela de trabajo decente: formación online para el apoyo de la acción sindical en Colombia para erradicar el trabajo informal", que ha sido financiado en el marco de la XI Convocatoria de ayudas para Proyectos de Cooperación de la Universidad Carlos III de Madrid. Su objetivo principal ha sido desarrollar una plataforma de formación online para cuadros sindicales en Colombia con el fin de colaborar en la conformación de mecanismos que permitan mejorar las condiciones de trabajo en aquel país, como vía para la consecución de las metas relativas al de trabajo decente. En particular, se ha tratado de dotar de herramientas de aplicación sobre el concepto de trabajo decente, en colaboración con los trabajadores y con las empresas, desde las prioridades marcadas desde la OIT. Además, esta iniciativa se ha enmarcado en el programa de actividades y acciones del centenario de la OIT en Colombia, que tenía como una de las líneas de actuación destacadas el impulso de la formalidad del trabajo.

Aunque los materiales del curso han sido fundamentalmente digitales, pues se ha articulado a través de vídeos grabados por cada uno de los autores que luego se han complementado con reuniones en "streaming" para la resolución de dudas, nos parecía que merecía la pena plasmar todo ese trabajo por escrito, dotándole de un mayor peso científico. Así pues, el lector encontrará aquí una colección de estudios que desde una perspectiva mixta docente- 
investigadora han pretendido abordar el fenómeno del trabajo decente desde sus muy diversas manifestaciones.

Así, el primero de ellos se centra precisamente en el binomio trabajo-pobreza. Las profesoras Díaz Gorfinkiel y Quintero Lima abordan la pobreza como fenómeno social para, a partir de ahí detenerse en la cada vez más habitual paradoja del trabajo de los pobres o, si se prefiere, de los trabajadores pobres. En efecto, el trabajo no es hoy, en muchos casos, una garantía para escapar de la pobreza. Al contrario, cada vez son más frecuentes los casos de trabajadores pobres cuyos ingresos les sitúan por debajo del nivel que separa la pobreza de una vida más decente. De ahí la importancia de las estrategias y propuestas que formulan con el objetivo de, a través del trabajo decente, revertir el proceso de expansión de la pobreza y la desigualdad.

Pero si la pobreza es un mal generalizado que presenta su cara más cruda en determinados países, algo parecido ocurre con el trabajo forzoso e infantil. Aunque este es un problema especialmente importante en los países subdesarrollados y en vías de desarrollo, no es una realidad de la que escapen los países desarrollados. A este particular reto del trabajo decente se dedica el capítulo de las profesoras García Sedano, Zorrilla Muñoz y Agulló Tomás. En él no solamente se hace un especial esfuerzo por destacar el modo en que los avances en la erradicación de estas dos formas particulares de explotación contribuyen, entre otros, a la consecución del objetivo del trabajo decente, sino que desde una perspectiva interdisciplinar e internacional se analiza el modo en que han de enfocarse los programas dirigidos a su completa eliminación.

De otra parte, para alcanzar el objetivo del trabajo decente y sostenible es necesario prestar atención a la diversidad. En este sentido, el trabajo de la profesora Nieto Rojas es especialmente valioso, pues no solamente se centra en un colectivo que presenta graves dificultades de acceso al empleo y, cuando así ocurre, para tener unas condiciones de trabajo dignas, sino en la herramienta más eficaz para conseguir que esto no ocurra. En efecto, la formación es probablemente una de las políticas de empleo más eficaces y eficientes, pero deviene en una herramienta crucial de integración laboral y social cuando se trata de personas con discapacidad. Las múltiples facetas y valor que la formación tienen se ponen al descubierto cuando se afirma que «articular políticas concertadas en torno a criterios y objetivos comunes de mejora de la calidad y la equidad, especialmente cuando el sistema educativo y formativo no solo aparece como garante del cumplimiento del derecho constitucional 
a la educación sino que esta cualificación es el principal mecanismo para la provisión y desarrollo de competencias y cualificaciones profesionales, con proyección en el derecho constitucional al trabajo de las personas con discapacidad».

Esta especial vinculación entre el trabajo decente y otros derechos humanos es especialmente valiosa, como vemos, en los casos de las personas con discapacidad, aunque también las trasciende. Tan es así, que no es que la garantía del trabajo decente repercuta positivamente en otros derechos para el conjunto de la ciudadanía, sino que va más allá de las fronteras de cualquier país. De ahí la necesidad, como ya se ha mencionado, de analizar el modo en que desde la perspectiva internacional puede contribuirse a alcanzar el objetivo del trabajo decente o conexión con otros derechos. Los capítulos de los profesores Muñoz Ruiz y Pérez del Prado desarrollan esta estrategia desde el plano general y particular respectivamente. Así, mientras que en el primer caso se discute como el Derecho internacional sirve de herramienta de garantía de los derechos fundamentales, en el segundo se centra en el instrumento particular de las cláusulas sociales, que persiguen el mismo objetivo, pero en el marco de los tratados de libre comercio, que tanto impacto tienen en las condiciones laborales y sociales de los distintos países del Globo.

Sin embargo, el trabajo decente se manifiesta también en los extremos. De ahí la necesidad de ir de lo general a lo particular, de los Estados y las relaciones internacionales a la empresa. Ésta es la sugerente propuesta de la profesora García Mandaloniz, que nos propone una estrategia global hacia la formalización, esto es, conectando el plano internacional con el ecosistema particular que es la empresa, delinea con precisión los caminos a seguir para pasar de la informalidad a la formalidad en el trabajo. En este mismo ámbito, aunque desde un plano completamente diferente, de Felipe reflexiona en el último capítulo acerca de la mejor forma de alcanzar el trabajo decente y la igualdad de género desde la perspectiva sindical.

En suma, el presente libro recoge desde una perspectiva interdisciplinar y multifocal las múltiples manifestaciones que el trabajo tiene hoy en día, proponiendo vías para avanzar hacia el trabajo decente, de tal forma que nos situemos en 2020 en un mundo con condiciones de trabajo mejores y más sostenibles.

Eva Ma . Blázquez Agudo

Daniel Pérez del Prado 



\title{
ESTRATEGIAS DE PREVENCION DE LA POBREZA LABORAL
}

\author{
Magdalena DÍAZ GORFINKIEL \\ Universidad Carlos III de Madrid \\ María Gema QUINTERO LIMA \\ Universidad Carlos III de Madrid
}

\begin{abstract}
RESUMEN: La pobreza laboral resulta, como la pobreza en sí misma, una realidad multidimensional, resultado de la conjunción de aspectos sociales, pero, sobre todo, de esquemas regulatorios del mercado de trabajo y de las formas de protección social. De ahí que la propuesta de estrategias para la prevención de la pobreza de los trabajadores pobres, considerados en un sentido amplio, requiera abordar la prospección de causas mediatas e inmediatas de generación de la pobreza en el trabajo. Entre éstas destacan aquellas ligadas a la regulación de instituciones laborales tales como las formas de contratación, la jornada de trabajo, la cuantía del salario y condiciones anejas como la formación o la salud laboral. A partir de esto se pueden proponer algunas acciones políticas de reversión de la flexibilización de las relaciones laborales y de mejora racional de los sistemas de protección social dentro de un marco general de una nueva Gobernanza del Trabajo.
\end{abstract}

Palabras clave: trabajador pobre, contratación temporal, trabajo parcial, salario mínimo.

SUMARIO: 1 . El fenómeno social de la pobreza. 2. La paradoja de la pobreza laboral. 2.1. Variables sociales condicionantes de la pobreza. 2.2. Variables jurídico-laborales. 3. Estrategias y propuestas de actuación. 3.1. En relación con las políticas laborales. 3.1.1. Las modalidades contractuales y los ingresos. 3.1.2. Otras condiciones laborales. 3.1.3. La vigilancia pública 3.3. En relación con políticas de protección social en sentido amplio. 4. Nuevas formas de gobernanza: el papel de los agentes sociales y de la sociedad civil. 5. Consideraciones finales. 6. Bibliografía

\section{Strategies for preventing work poorness}

ABSTRACT: Poverty at work, as well as poverty itself, constitutes a multidimensional reality that results from the interaction of social aspects, but above all it is related to labour market regulations and forms of social protection. Hence, the proposal of strategies for the prevention of poverty among the working poor in 
a broad sense requires addressing the identification of immediate and long-term causes of poverty at work. Among them the regulation of labour institutions such as ways of recruitment, work time, wages and related conditions such as training or occupational health can be found. From these variables it is, therefore, possible to propose some political measures to reverse the easing of labour relations and to rationally improve social protection systems, related to new Labour Governance as a framework.

Key words: working poor, temporary work, part-time work, minimum wage.

\section{El fenómeno social de la pobreza}

Cada día en el devenir de nuestra cotidianeidad hacemos frente a diversas situaciones de pobreza. Tanto en nuestra experiencia directa -al pasear por las calles o entablar conversaciones- como de manera indirecta -a través de las noticias o relatos de procesos ocurridos- nos enfrentamos a realidades vitales que se alejan de los estándares de una vida digna que se asumen socialmente. El hecho de convivir, en mayor o menor grado, con esta realidad de fragilidad y vulnerabilidad no significa que deba normalizarse ni considerarse una realidad ineludible. Se considera un hecho ampliamente demostrado que la presencia de significativos niveles de pobreza y exclusión generan importantes consecuencias para el funcionamiento de la sociedad. La dificultad de acceso a los recursos para garantizar una vida con niveles básicos de calidad y dignidad no sólo afecta al desarrollo personal de los individuos que lo sufren sino también impacta a nivel grupal generando desigualdad y falta de cohesión social. Así el último documento del gobierno español centrado en la prevención y lucha contra la pobreza ${ }^{1}$ señala precisamente que "Las sociedades más desiguales afrontan múltiples problemas en los ámbitos educativo y sanitario, pero también sufren de altos niveles de violencia, baja confianza social y desafección política". En definitiva, se transmite la idea de que las relaciones entre ciudadanos que se encuentran atravesadas por desigualdades permanentes y notorias generan dificultades en la interacción cotidiana, así como en el mantenimiento de condiciones mínimas que no requieran de intervenciones de emergencia por parte de los gobiernos. Estas intervenciones no sólo se producen desde una perspectiva colectiva sino también individual

1 MINISTERIO DE SANIDAD, CONSUMO Y BIENESTAR SOCIAL, 'Estrategia nacional de prevención y lucha contra la pobreza y exclusión social 2019-2023’, 2019, p. 33. 
al generar la pobreza falta de autoestima, de bienestar mental y sentimientos de exclusión en las personas, lo que en definitiva se ha dado en llamar un menor bienestar subjetivo ${ }^{2}$.

Los costes de la pobreza y la necesidad de buscar alternativas para disminuir el fenómeno han sido reconocidos tanto a nivel de cada uno de los distintos Estados como a nivel supranacional. Teniendo en cuenta el ámbito nacional español se puede señalar que desde el año 2001 los distintos gobiernos han implementado los denominados Planes Nacionales de Acción para la Inclusión Social y que en el año 2019 se aprobó la primera estrategia nacional a este respecto: la Estrategia nacional de prevención y lucha contra la pobreza y exclusión social 2019-2023. Este nuevo acercamiento al fenómeno venía siendo demandado por las distintas entidades sociales que trabajan en el sector, por considerar que la centralidad social de la cuestión de la pobreza y la exclusión social requería de una consideración amplia de la desigualdad acompañada, en consecuencia, de una extensa batería de medidas interrelacionadas y con incidencia en numerosos ámbitos sociales. Se debe señalar, además, que esta aproximación se encuentra integrada dentro de las estrategias actuales de la Unión Europea. Esta institución, a partir del establecimiento de la Estrategia 2020, convirtió el eje de la lucha contra la pobreza en uno de los ejes de acción fundamental en aras de la consecución del crecimiento y del empleo en esta zona geográfica. Además de la Unión Europea, desde una perspectiva supranacional se puede mencionar el papel de las Naciones Unidas, organismo impulsor de los denominados Objetivos de Desarrollo Sostenible (ODS) que establecen líneas de actuación en diversos ámbitos sociales con objeto de erradicar la pobreza y construir sociedades más inclusivas que favorezcan el desarrollo global. El Objetivo 1, por ejemplo, se concentra explícitamente en la erradicación de la pobreza a nivel mundial por considerarla, además de una cuestión de niveles de vida digno, un condicionante del respeto de los derechos humanos ${ }^{3}$. Por su parte, el objetivo número 8 se concentra en el ámbito laboral y su meta es la consecución del trabajo decente y el crecimiento económico para conseguir que la idea de empleo vaya unida a la de progreso e igualdad social. Se debe señalar que esta perspectiva de Naciones

2 EUROFOUND, In-work poverty in the EU, Publications Office of the European Union, Luxemburgo, 2017.

3 La descripción pormenorizada de los 17 objetivos de desarrollo sostenible se puede encontrar en la página web correspondiente de Naciones Unidas: https://www.un.org/ sustainabledevelopment/es/ 
Unidas no es algo novedoso de la Nueva Agenda 2030, ya que la reducción de la pobreza fue el Primero de los Objetivos del Milenio en el año 2015, y el trabajo decente como concepto se fragua ya en 1999 (en el seno de la Organización Internacional del Trabajo - OIT). Lo novedoso, entonces, reside en que la erradicación de la pobreza (ODS 1) y el trabajo decente (ODS 8) se engloban en un contexto de crecimiento sostenible y componen un programa universal de transformación global, que se sustenta en la alianza de todos los eventuales actores implicados (como se señala en el ODS 17).

En esta línea toman sentidos dos enfoques, el primero relativo a remover las situaciones de pobreza a través del trabajo, y el segundo -que resulta de una constatación postmoderna como la de la propia paradoja de la pobreza laboral- relacionado con suprimir, o al menos reducir, el número de trabajadores pobres.

\section{La paradoja de la pobreza laboral}

Históricamente se pueden admitir varias premisas respecto al funcionamiento social. La primera reconoce que el trabajo se conforma como un bien asociado a la obtención de recursos, no cualesquiera sino, en primer lugar, recursos de subsistencia. Por lo tanto, el trabajo responde a una necesidad de supervivencia. La segunda, en consecuencia, hace referencia a que el notrabajo se asimila a la exclusión social. De ahí que, en épocas modernas, entre las políticas de prevención de la exclusión estaban las políticas que incluían medidas de inserción laboral. Todo en un marco ius-filosófico en el que el trabajo es un elemento de dignificación del individuo. Pero esas dos premisas actualmente se han visto desdibujadas a contrario, en el sentido de que hoy junto al trabajador-que-se-vuelve-pobre-y-resulta-excluido se encuentran las personas-que-aunque-trabajan-sufren-riesgo-de-exclusión, porque -y manténgase esta idea- hoy la exclusión está ligada al trabajo también bajo una polimorfa precariedad laboral. De esta suerte, junto a las clásicas estrategias de dinamización laboral de las personas activas se hace preciso desarrollar estrategias de prevención de la pobreza laboral, la que afecta a los trabajadores que, a pesar de tener un empleo y a veces como consecuencia de ello, se encuentran en situación de riesgo de exclusión social. Los efectos incluso llegan más allá de su propia orbita vital, alcanzando al hogar mismo y al resto de sus cohabitantes. 


\subsection{Variables sociales condicionantes de la pobreza}

Puede considerarse que los distintos sistemas sociales nacionales presentan algunos condicionantes generales de la situación de pobreza en general y del desarrollo de la pobreza en particular. Sin que se pretenda hacer un análisis exhaustivo sirva, simplemente, con dejarlos anotados.

Se puede comenzar señalando que algunos condicionantes responden a la realidad macroeconómica del país, de suerte que el nivel de desarrollo, el producto interior bruto, los niveles de deuda externa, la tasa de dependencia de exportaciones e importaciones de bienes, servicios y materias primas y/o la (in)existencia de mercados regionales organizados en torno a instituciones supranacionales constituyen un marco claro para mayores o menores umbrales de pobreza. Y, ligado a lo anterior, se presentan como especialmente predeterminantes las variables geopolíticas, en lo que se refiere al tipo de sistemas políticos actuales y pretéritos, al tipo de relaciones diplomáticas con otras potencias, a los niveles de transparencia pública, a la existencia de conflictos sociales o bélicos internos o circundantes. Variables todas que se amalgaman con la localización geográfica y sus consecuencias (el tipo recursos autóctonos disponibles o la predisposición a desastres naturales resultan paradigmáticos).

Lo anterior, en suma, puede explicar de una parte el tipo de mercado de trabajo y de otra la modalidad de organización social. Respecto a la generación de pobreza, ésta sería consecuencia de los tipos de sectores productivos preponderantes, del desarrollo tecnológico, del tipo de inversión público-privada/nacional-extranjera, de la tasa de empleo y la de desempleo, y también sería función de variables sociodemográficas. La edad de la población activa, por ejemplo, puede predeterminar colectivos en este grupo con edades muy jóvenes, maduras o muy envejecidas, con o sin inserción laboral femenina, con o sin predominancia de población autóctona o extranjera. Pero, quizás, uno de los elementos más sensibles que explican la pobreza se relaciona con el nivel formativo y la adecuación de la formación a las necesidades del mercado productivo. La infracualificación profesional, la sobrecualificación, la obsolescencia tecnológica o las brechas digitales, por puntualizar, condicionarían, según el tipo de economía productiva de que se trate, una mano de obra más o menos estratégica en termino de costes sociales empresariales, lo que repercutiría directamente en el precio del trabajo y, por ende, en la eventual pobreza laboral en términos cuantitativos. 
Por lo que respecta al papel de las mujeres en el trabajo, junto a los niveles formativos, las culturas sociales del cuidado y la responsabilización públicoprivada, incide significativamente en la tasa de empleo, y en el tipo de empleo. Porque la asunción de las labores de cuidado del hogar, de los menores, de los ancianos y personas discapacitadas, frena los procesos educativos y los proyectos profesionales de las mujeres, al mismo tiempo que condiciona su participación en el mercado, tanto más cuanto menor sea el grado de desarrollo de servicios sociales. Así, el coste-beneficio del trabajo femenino en el hogar seria función de su nivel salarial y de la disponibilidad (gratuidad, precio, calidad) de instrumentos de cuidado externos al hogar.

\subsection{Variables jurídico-laborales}

Hablar de la existencia de los trabajadores pobres exige, entonces, introducir la idea de la precariedad laboral, lo que presupone analizar las eventuales causas de dicha precarización del trabajo. Esto resulta ser de suma complejidad, y por lo tanto no es cuestión aquí tratarlo sino de un modo accidental, especialmente porque la precariedad actual no se puede explicar linealmente, por responder a una multiplicidad de causas que están muy imbricadas y se retroalimentan bidireccionalmente con la propia precariedad. Y lo mismo es predicable de su causalidad.

Se deben distinguir, en primer lugar, causas exógenas al mundo del trabajo, que se vinculan a las crisis económicas y financieras mundiales, así como a la globalización y la transnacionalización de los mercados de bienes y servicios, y por ende de trabajo. Todas estas cuestiones se enmarcan en contextos internos, propios de la organización asimétrica e ineficiente de los sectores productivos, del desarrollo urbano, de situaciones macroeconómicas particulares y de inercias históricas de tipo político y/o socioeconómico, porque hay muchos sectores productivos que han devenido arcaicos, hay sectores sobredimensionados, hay sectores nuevos y otros nichos productivos sin cubrir. A lo anterior se sumaría, como causa ideológica más clara, la preponderancia presente de teorías económica ligadas al neoliberalismo, con efectos en racimo.

En el panorama específico del trabajo, por otra parte, se pueden identificar algunas otras causas de la pauperización de los trabajadores que tienen carácter endógeno, como pudieran ser la edad de la población, los déficit de formación y cualificación/recualificación profesional de los trabajadores y la rigidez de competencias y habilidades generalizada de los trabajadores, la 
insensibilidad a las perspectivas de género, la existencia de ciertas culturas económico-empresariales ineficientes, así como el debilitamiento de la acción colectiva o el raquitismo de instrumentos de control laboral y de protección social, por señalar las más evidentes.

En efecto, solo muy recientemente se ha conseguido visualizar la formación, tanto previa al trabajo como la inicial en el trabajo y la formación a lo largo de toda la vida, como un objetivo integrado en las políticas de empleo. Y si bien formalmente si ha habido conexiones jurídicas efectivas entre formación y empleabilidad, en realidad no hay una idea fuerza materializada en la percepción del trabajo desde una perspectiva de causa-efecto con la cualificación.

El diseño de formas jurídicas del trabajo ancladas en esquemas -que se podrían considerar patriarcales-, genera un subtipo de pobreza laboral referida a las mujeres trabajadoras. Respecto de ellas, la ausencia de políticas de conciliación efectiva, el peso de los estereotipos de cuidado sin avances en corresponsabilidad familiar entre géneros o los efectos de procesos formativos feminizados generan una realidad laboral en el que conforman un colectivo con condiciones laborales aún más precarias que las de los varones en situaciones equiparables.

En paralelo, parecen preponderantes las ideologías empresariales sustentadas únicamente en la idea del beneficio. $\mathrm{Y}$ a pesar de su existencia nominal, la Responsabilidad Social de la empresa parece ausente de modo generalizado.

Las herramientas de las relaciones laborales colectivas es posible que no estén siempre desarrolladas en su nivel óptimo, en la doble vertiente de la vigilancia del cumplimiento normativo del empresariado y de la representación de los intereses de los trabajadores en la empresa, y en la vertiente de la negociación de normas convencionales vinculantes. Junto a lo anterior, desde los poderes públicos, tanto normativa como financieramente, y vinculado a los ajustes del gasto en orden a su viabilidad financiera se han venido privando de margen de actuación a los instrumentos públicos de control (inspección laboral) del cumplimiento efectivo de la regulación laboral, así como se ha frenado la vía expansiva de la protección social y los distintos sistemas implicados (de salud, de servicios sociales y el propio de Seguridad Social).

Entre las variables jurídico-laborales parece haber un consenso generalizado respecto a que la pauperización de los trabajadores guarda una relación muy directa con la estabilidad contractual, que a su vez tiene un efecto en el nivel de ingresos derivado. Y esa inestabilidad contractual se manifiesta 
tanto en la duración de los contratos cuanto en la duración de la jornada de esos contratos, lo cual se refleja en un género de debilidad salarial. Sin embargo, esa pauperización puede entenderse que tenga diferentes grados, de ahí que se haya de advertir de que el trabajador pobre stricto sensu no es una realidad idéntica al trabajador con poco salario, si bien el bajo salario puede conducir con cierta facilidad a una situación de riesgo de pobreza. Pero ni el trabajador temporal necesariamente ha de tener un bajo salario, ni el trabajador a tiempo parcial ha de ser necesariamente pobre (si acumula distintas jornadas parciales o su salario a tiempo parcial reúne ciertas características). Además, también es plausible que los trabajadores indefinidos y a jornada completa tengan un salario bajo. $\mathrm{O}$, dicho de otro modo, la pobreza en el trabajo puede tener como causa la regulación jurídica que el legislador haga de la temporalidad/la parcialidad de la contratación laboral, pero, sin embargo, no es una condición única ni indivisible. El salario (su cuantía, conformación, efectividad, garantía) sí parece ser un elemento originario o coadyuvante de una eventual situación de pobreza, pero otras condiciones laborales pueden serlo igualmente.

La pobreza en el trabajo, a la vista de los elementos que sirven de objeto de análisis en las distintas aproximaciones estadísticas, se conforma como una realidad multidimensional, que incorpora elementos jurídicos plausibles diversos: la regulación del salario, el tipo de contratación -temporal-, la parcialidad de la jornada, la protección de la salud laboral, los niveles de formación y de empleabilidad de los trabajadores, o el modelo de protección social establecido (especialmente en lo relativo al desempleo y a la protección de la familia, por señalar algunos evidentes). La temporalidad conforma solo parte de las causas, y la conformación de la precariedad va más allá del tipo del contrato. En abstracto, la existencia de un vínculo jurídico contractual de carácter no permanente no habría de suponer, por sí mismo, una causa de pobreza. Sería la baja intensidad laboral, y no la temporalidad estrictamente -porque cabría que un sujeto trabajador tuviera sucesivos contratos temporales con el mismo o distintos empleadores sin solución de continuidad, lo que se podría traducir en una regularidad de ingresos- la generadora una situación de pobreza/riesgo de pobreza en un contexto de pleno empleo. Por el contrario, sí puede conducir a esa situación indeseada la ausencia de otros tipos de percepciones patrimoniales de origen privado --rentas-- y otras percepciones bajo la forma de subsidios públicos, así como la situación familiar global del sujeto. 
Si a esa relación entre contrato temporal-ausencia de otras rentas (que no sean las salariales que no toman en consideración las situaciones familiares) se le une una jornada de trabajo a tiempo parcial, entonces la intersección de las normatividades de cada realidad puede tener efectos laborales y sociales en clave de pobreza-no pobreza con manifestaciones polimorfas. De una parte, porque las modalidades contractuales se condicionan en ocasiones por la situación familiar de cada sujeto (la parcialidad ligada a la existencia de responsabilidades familiares es paradigmática) y de otra porque las modalidades contractuales condicionan los ingresos salariales (el contrato a tiempo parcial genera salarios parciales) y condicionan eventuales percepciones públicas (cierta concatenación de contratos temporales inhibe el despliegue de la protección por desempleo). Por último, la situación familiar puede condicionar eventuales percepciones públicas (prestaciones familiares y otro tipo de prestaciones asistenciales en las que las cargas familiares pueden ser condicionantes, por ejemplo) que complementan bajos salarios y mantienen el umbral de rentas disponible en niveles estándares.

Sin perjuicio de lo anterior, habría algunos elementos de la regulación de la contratación temporal que podrían actuar (individualmente contemplados, y/o cumulativamente) como factores explicativos de un eventual riesgo de pobreza. En algunas legislaciones, como la española, las modalidades contractuales temporales se sustentan, con carácter general, en el principio de causalidad. No obstante, en algunos casos, esa causalidad es solo formal o tiene carácter difuso, lo que podría justificar una temporalidad permanente. Del mismo modo, en ocasiones la causalidad es tan compleja que genera zonas de incertidumbre jurídica aprovechada por los agentes jurídicos (empresarios) para llevar a cabo una interpretación laxa y /o situaciones de fraude en la contratación. A lo anterior se une que la causalidad no se refiere necesariamente a las necesidades económicas de la empresa, sino que se vinculan con objetivos genéricos de política de empleo (como sucede en los contratos formativos).

Junto a la duración (temporal) del contrato la posibilidad de duración reducida de la jornada podría contribuir a una situación de riesgo de pobreza de los trabajadores, especialmente cuando se pactan pocas horas porque lo permita la regulación del trabajo a tiempo parcial, pero también cuando se realicen de facto horas sin remunerar ni pactadas complementariamente, lo que impide la compatibilidad con otro/s contratos o actividades remuneradas. Junto a la regulación de la contratación temporal, el diseño normativo 
del trabajo a tiempo parcial puede quedar articulado en el principio de flexibilidad empresarial, que conduce a una indefinición real de las horas de trabajo pactadas y, por lo tanto, a una imprevisibilidad practica de los ingresos salariales. En efecto, las regulaciones que se pueden hacer del tiempo parcial pueden ser de varios tipos: las rígidas exigen una determinación inicial de la jornada que solo excepcionalmente puede ampliarse, y sin aproximarse nunca a una jornada ordinaria en sentido estricto, y las más laxas, en las que inicialmente se fija estimativamente un número de horas de trabajo relativamente bajo pero que puede ampliarse sobrevenidamente, con mayor o menor preaviso, atendiendo a las necesidades productivas y organizativas de la empresa, con jornadas que pueden aproximarse mucho a la ordinaria comparable, y sin especiales contraprestaciones ligadas a esa disponibilidad del tiempo de trabajo.

La flexibilidad tendría una última manifestación en la fase final de la relación jurídico-laboral, o, dicho de otro modo, en la regulación de la extinción del contrato por voluntad empresarial. Esto explica, de una parte, los niveles de aquiescencia de los trabajadores en situaciones de incumplimiento empresarial y, por otra, la fluctuación de las tasas de desempleo, porque el debilitamiento de la causalidad del despido, la reducción o eliminación de las cuantías indemnizatorias y el aligeramiento de las exigencias formales favorece el recurso, en mayor o menor medida, a la institución extintiva. Cuanto más flexible sea la salida del mercado de trabajo seguramente menor será la reticencia individual al ejercicio empresarial de las restantes formas de flexibilidad y mayor será la tendencia empresarial a recurrir al despido para resolver fluctuaciones, a veces coyunturales, de las necesidades económicoproductivas. Si lo anterior se adereza con recortes en la acción colectiva, el resultado es el del incremento de las tasas de desempleo, con los efectos derivados de une eventual insuficiencia de los sistemas de protección social.

Cuando, junto a lo anterior, no hay una regulación paralela para asegurar la solvencia vital de los trabajadores el resultado es la pobreza laboral. Y cuando se habla de esa regulación paralela se estaría pensado en esquemas prestacionales de cobertura de rentas durante contratos temporales o de complementos generales de las bajas jornadas de trabajo, así como de normas de ingresos mínimos con salarios interprofesionales o profesionales suficientes y acordes a la situación económica nacional, en normas de prevención de riesgos laborales acordes a las especificidades de los trabajadores temporales y a tiempo parcial, por señalar las más evidentes. 


\section{Estrategias y propuestas de actuación}

A la vista de lo que se acaba de mencionar, la existencia del fenómeno de la pobreza, y en concreto la consolidación de la denominada pobreza laboral como una realidad cada vez más extendida ${ }^{4}$, conllevaría una necesidad de emprender acciones específicas para hacerles frente. Las sociedades, a nivel global, no pueden permitirse la consolidación de formas precarias de trabajo que conlleven a la exclusión social sin emprender medidas que tengan como objeto superar las desigualdades que se generan. Ya varios autores han explicado que la precariedad laboral no repercute exclusivamente en ese ámbito, sino que se extiende a todos los ámbitos de vida ${ }^{5}$ y esta precarización de la existencia es algo que el desarrollo actual no debería permitirse, ni a nivel colectivo ni a nivel individual. Tanto más cuanto ya comienza a evidenciarse un evento nefasto de la precariedad laboral, y por ende de la pobreza en su distinta tipología, en la salud de los sujetos ${ }^{6}$.

Conviene, entonces, esbozar algunas propuestas en torno al desarrollo de políticas, programas y herramientas orientados a mejorar la situación de los trabajadores y sus condiciones laborales.

\subsection{En relación con las políticas laborales}

El ámbito de las políticas laborales conforma una esfera de incidencia central en el proceso de mejora de las condiciones de trabajo de las personas. La

4 La existencia de trabajadores pobres en países emergentes o en desarrollo sería comprensible en su contexto (según la OIT (2019) 300 millones de trabajadores en el mundo se encuentran en situación de pobreza extrema, es decir que cuentan con menos de 1,9 dólares al día) pero no resultan tan comprensibles en el marco de Estados con economías desarrolladas. Según los datos del Instituto Nacional de Estadística español, en junio de 2019, el porcentaje de trabajadores pobres es del 16\%, dos puntos más que en 2018. Además, uno de cada cinco españoles, el 21,5\% de la población, vive en riesgo de pobreza o exclusión social con unos ingresos inferiores a 8.871 euros al año, una situación que afecta al 26,2 \% de los menores de 16 años (ver https://www.ine.es/jaxiT3/Tabla. htm?t=10011).

5 CANDIL MORENO, D., "En la cuerda floja: un estudio sobre la precariedad laboral", Intersticios. Revista sociológica de pensamiento crítico, vol.10, núm. 2, 2016, pp. 123-133.

6 ARIAS-URIONA, A. M. y ORDÓÑEZ, J. C., "Factores de precariedad laboral y su relación con la salud de trabajadores asalariados y con contrato en Bolivia”, en Revista Panamericana de Salud Pública , 2018 (https://doi.org/10.26633/ RPSP.2018.98). 
normativa existente en este ámbito ha constituido, históricamente, la referencia de actuación dentro del mismo, y los importantes cambios acaecidos en las últimas décadas no han hecho más que reforzar esta situación. Como señala la OIT $^{7}$ los últimos años han sido testigo de cambios en las formas de trabajo que han afectado a las relaciones 'típicas' de empleo. Estos cambios han sido estimulados, principalmente, por el desarrollo tecnológico y las nuevas formas de organización laboral pero también por la búsqueda de una mayor flexibilidad laboral y una consolidación de las mujeres en el mercado de trabajo (con la consecuente creación de condiciones de trabajo más precarias). Estas nuevas realidades laborales demandan nuevas formas de hacerles frente ya que los riesgos de experimentar pobreza y precariedad son mayores en las personas con empleos no estándar, y en las mujeres.

Varios autores señalan las limitaciones que tradicionalmente presentan las políticas laborales ya que, en primer lugar, se han desarrollado de manera muy escasa ${ }^{8}$ dirigiéndose de manera generalista a abordar la pobreza en su conjunto ${ }^{9}$ y careciendo un diseño específico en relación a cada mercado laboral y su funcionamiento. En segundo lugar, se señala que el foco de estas políticas se ha concentrado casi exclusivamente en la idea de la empleabilidad, es decir el acceso al empleo, pero olvidando las condiciones de trabajo y vida que se ofrecían y señalando que el acceso a un empleo no es sinónimo de integración social o el acceso a una vida digna ${ }^{10}$. Esto, en último término, ha llevado a garantizar la competencia económica global de la producción frente a la protección económica y social de los trabajadores ${ }^{11}$. Las políticas centradas en la activación de desempleados han llegado incluso a convertir el proceso social de precarización en una responsabilidad individual ${ }^{12}$, suponiendo que las mejoras en las competencias de los demandantes de empleo tendrán que llevarlos automáticamente a la mejora de su situación. En consecuencia, por

7 OIT, Preliminary concept note on non-standard forms of employment, Grupo sobre la seguridad y el desempeño del mercado de trabajo, Servicio de Mercados Laborales Inclusivos, Relaciones Laborales y Condiciones de Trabajo (INWORK), Ginebra, 2013.

8 BANYULS LLOPIS, J., RECIO ANDREU, A., "Pobreza laboral en España: causas y alternativas políticas", en Anuario IET de Trabajo y Relaciones Laborales, vol. 4, 2017, pp. 135-149.

9 EUROFOUND, In-work poverty in the EU, cit.

10 Ibidem

11 CASTRO, C., "Presentación. La precariedad laboral y más allá”, en Cuadernos de Relaciones Laborales, vol. 37, núm. 1, 2019, pp. 11-29.

12 Ibidem. 
tanto, se deberían desarrollar políticas laborales específicas e inclusivas que tengan como objetivo la consecución de empleos de calidad.

Las nuevas políticas de empleo han reformar los enfoques ya que, en algunos casos, como en España, por ejemplo, han supuesto un potente condicionante de la existencia de contratación temporal y a tiempo parcial (desde sus inicios en la década de los ochenta y hasta la actualidad). Paradójicamente, en cierto momento se observó que esas políticas habían conducido a una polarización del mercado y que esa dualidad generaba fuertes distorsiones. Se desarrolló una autoconciencia legislativa respecto a los defectos estructurales del mercado de trabajo ocasionados por la contratación temporal estimulada por las regulaciones normativas precedentes. Se convirtió en objetivo de las políticas de empleo ya no tanto promover la contratación temporal en clave de empleo sino frenar los efectos de esa dualidad (trabajadores indefinidos-temporales a tiempo completo-parcial) mediante la incentivación de la contratación indefinida/a tiempo completo y la desincentivación de la temporal/a tiempo parcial (reformas de los años 2010 y 2012) en orden a frenar la dualidad del mercado y/o el uso abusivo de la contratación temporal. Esto sin dejar de utilizar la jornada flexible y la regulación laxa del trabajo a tiempo parcial como formas óptimas para solventar la crisis del empleo. Paralelamente, sin embargo, se ha mantenido una síncopa incongruente: la inserción de ciertos colectivos (desempleados, mujeres, jóvenes, discapacitados, entre otros) a través de la contratación temporal y no siempre de tipo formativo.

Los efectos de esa esquizofrenia jurídica resultan ser exponencialmente dañinos en términos de riesgo de pobreza, tanto más cuanto las políticas contra la temporalidad no han tenido hasta el momento un objetivo de frenar la pauperización de los trabajadores ni luchar contra los distintos tipos de pobreza ligada al trabajo. Las políticas de empleo han tratado de promover el empleo (crear empleo) pero, por efecto, han generado índices de temporalidad exageradas que, en una segunda fase, han configurado nuevos objetivos reformistas (frenar el incremento de la precariedad en el empleo). Pareciera llegado el momento socio-teórico óptimo para diseñar nuevas políticas públicas de lucha, no contra la pobreza y la inserción social de los desempleados sino contra la pobreza de los trabajadores empleados, en clave preventiva y reparadora y a través de la articulación de políticas de empleo de calidad.

En esta dirección, la aplicación de políticas laborales debería incidir en dos cuestiones fundamentales: el aumento de la formalidad laboral y el control de la flexibilidad. En cuanto a lo primero, la formalidad, los datos de varias 
zonas del mundo ${ }^{13}$ reflejan unos altos índices de informalidad que implican la falta de acceso de estos trabajadores a cualquier tipo de protección social (a excepción de las que sean prestaciones universales) y a la demanda de implantación de cualquier tipo de derechos laborales. El trabajo informal deja a los trabajadores a merced de las coyunturas socioeconómicas y a la discrecionalidad de los empleadores. Como señala Maurizio ${ }^{14}$ se deberían implementar políticas públicas específicas que reduzcan los costes de la formalidad, a través de la reducción de la cotización empresarial, por ejemplo, o que incremente el coste de la informalidad, fundamentalmente a través de sanciones económicas, que debieran representar un coste importante para la empresa para que se vea orientada a evitarlas. Para el caso español Oxfam ${ }^{15}$ señala, por ejemplo, que se debería "penalizar significativamente, a través de las cotizaciones sociales, a las empresas que abusan, o establecer una penalización por cada contrato firmado en fraude de ley y no una multa fija”. Así si se observa la existencia sin contrato, o con contrato, pero con una rotación temporal superior a la esperada o con una parcialidad mayor de lo que precisa el sector empresarial al que pertenece la empresa, cabría vincular consecuencias sancionadoras administrativas proporcionales al número de casos detectados y no a un global calculado de manera abstracta. La implantación de la sanción podría realizarse a través de una multa específicamente o a través del aumento de las cotizaciones sociales de sus trabajadores.

Junto a lo anterior, una labor de prospección y diagnóstico proporcionaría datos muy fiables de aquellos sectores productivos y áreas geográficas en los que la informalidad resulta ser la regla general provocando situaciones de inequidad entre las empresas cumplidoras y las incumplidoras (dumping social). De un modo añadido, la informalidad priva de derechos sociales a las personas trabajadoras afectadas, cuya invisibilidad jurídica conlleva, incluso, una merma de ingresos fiscales y de contribuciones sociales a la Seguridad

13 Los datos de la OIT (2019) ponen de manifiesto que hay 2.000 millones de personas que viven de la economía sumergida en todo el mundo, "y esto implica que se vean privados de condiciones de trabajo dignas", lo que supone un ensanchamiento de la brecha social. Concretamente, entre 1980 y 2016 el 1\% más rico de la población aumentó sus ingresos en un 27\%, mientras que el 50\% más pobre los incrementó un $12 \%$.

14 MAURIZIO, R., "Formas atípicas de empleo en América Latina: incidencia, características e impactos en la determinación salarial", Series Condiciones de Trabajo y Empleo n 76, OIT, Ginebra, 2016.

15 OXFAM, Voces contra la precariedad: mujeres y pobreza laboral en Europa. Oxfam Internacional, Barcelona, 2018, p. 57. 
social. Y esto no sería tan relevante de no ser porque, en consecuencia, no solo hay una ineficiencia sistémica en clave de sostenibilidad de los sistemas de Seguridad Social, sino que, además, generará la pobreza prestacional de las personas afectadas por la informalidad, que bien no podrán acceder a prestaciones o percibirán prestaciones muy insuficientes.

Las políticas laborales habrían de actuar no solo en la vertiente del afloramiento del empleo sino también en la de la flexibilidad de las condiciones laborales. Se aduce que una de las causas de la pobreza laboral ha sido la flexibilización de la regulación de derechos y obligaciones laborales, especialmente en lo que se refiere al diseño de la contratación de duración determinada y de trabajo a tiempo parcial. Pero también se han hecho aún más flexibles las facultades empresariales de organización del trabajo (de la movilidad funcional y geográfica, de la gestión del tiempo de trabajo, a través de la distribución irregular de la jornada, la parametrización anual de la jornada máxima, o la acumulación de los descansos obligatorios), así como las facultades de alternación de las condiciones laborales inicialmente previstas en el contrato individual o, incluso en los instrumentos convencionales y pactados colectivamente.

\subsubsection{Los ingresos}

Junto a los demás elementos de la relación laboral, el salario se ve afectado, a su vez, por esa tendencia a la modificación flexible y reductora/moderadora. Entre otras cuestiones, se han limitado las fórmulas de revalorización salarial, se han debilitado las garantías del salario y se ha cercenado los instrumentos de la autonomía colectiva amplo sensu. En efecto, en un marco normativo proclive las situaciones generales de crisis han servido de argumento para las políticas empresariales de ajuste de los costes laborales, para la moderación/congelación salarial, para el descuelgue salarial y para la reducción del potencial de los instrumentos de garantía del salario. Y todo en un marco de atomización de la negociación colectiva patológica que opta por la preponderancia de una unidad de negociación del nivel empresarial, y una concomitante desaparición del sujeto clásico de compensación de la debilidad contractual del trabajador individualmente considerado (el de la representación unitaria y/o sindical). En este sentido, parece haber un cambio de paradigma en el que la visión marxista del conflicto inherente a las relaciones laborales se ha sustituido por mecanismos de diálogo entre representantes 
de trabajadores y empresarios con un fin común, como es de la viabilidad sistémica, el fin de la crisis y la atenuación de sus efectos negativos, así como el de la competitividad de las empresas como exigencia sine qua non de lo anterior, lo que ha debilitado el ímpetu de la exigibilidad de derechos laborales. Lo relevante en esta situación es, en síntesis, la confusión entre las esferas puramente jurídicas y las económico-financieras que han hecho, en suma, que se haya producido una infravaloración del salario como contrapartida económica y jurídica porque se ha desvinculado el valor real de la prestación laboral con su remuneración efectiva. De ahí que el trabajador, a pesar de tener trabajo, pueda llegar a ser hoy un ciudadano poco remunerado (con el incumplimiento del mandato constitucional referido a la suficiencia del salario - art. $35 \mathrm{CE}$ ). El salario puede ya no ser un instrumento de garantía vital del trabajador y su familia, sino que puede existir y al mismo tiempo el trabajador puede ser sujeto de una situación de pobreza y de exclusión. En orden a superar este escenario, las políticas de elevación del salario mínimo interprofesional o profesional pueden suponer un vector esencial de freno a la pobreza laboral (tal como se señala en la sección pertinente).

Junto a esa proyección de los ingresos, cabría otra complementaria, la relativa a la posibilidad de instaurar impuestos negativos para los trabajadores de bajos ingresos salariales. O lo que es lo mismo, cabría complementar a través del sistema fiscal la renta de aquellas personas que se encuentran por debajo de un cierto nivel de ingresos. Esta idea ha estado presente en la agenda política en España durante los últimos debates electorales, e incluso se ha expandido a un impuesto negativo más generalista que no tenga en cuenta únicamente las rentas del trabajo sino también a aquellas personas sin ingresos o que los reciben de transferencias monetarias públicas (más cercano a la idea de una renta básica garantizada).

\subsubsection{Otras condiciones laborales}

Volviendo a la cuestión de la restricción de la flexibilidad, se ha de insistir en la necesidad de redefinir el trabajo a tiempo parcial. En el diseño teórico primigenio, el trabajo a tiempo parcial se contemplaba como una institución optima de freno de la rigidez contractual y de contestación de las necesidades sociales de las personas trabajadoras. Se le atribuían, entonces, tres funcionalidades: serviría para repartir del empleo y la consiguiente creación de empleo que discurre en paralelo, serviría para favorecer la conciliación de la vida 
laboral y la personal y familiar y serviría para dotar al empresario de mayor flexibilidad organizativa para favorecer la competitividad y la productividad empresarial. Estas tres funcionalidades podrían imbricarse, a priori, de un modo muy coherente por ser compatibles y generar efectos beneficiosos en términos socioeconómicos, en la medida en que aúnan intereses complejos de distintos sujetos (trabajadores y empresarios) en planos estrictamente individuales (la conciliación personal, el acceso o el mantenimiento de un puesto de trabajo, la flexibilidad organizativa de los recursos humanos de la empresa), pero también colectivos (las políticas públicas de empleo para provocar el dinamismo de un mercado de trabajo con menores tasas de desempleo y mayores tasas de actividad y de empleo, y de transiciones hacia la jubilación más dulcificadas). Sin embargo, como consecuencia de las sucesivas reformas flexibilizadoras, y en un contexto de crisis económica del siglo XXI, el trabajo a tiempo parcial ha acabado siendo señalado como una de las causas esenciales de la pobreza de los trabajadores, así como de la precariedad general del empleo.

Desde esas dos ópticas, la más individual (aunque con incidencia colectiva) y la social o colectiva, el trabajo a tiempo parcial ha supuesto una perversión socioeconómica de las funcionalidades teórico-abstractas que pretendía cumplir esta modalidad de empleo porque no es claro que se hayan creado empleos, o al menos estables y de calidad, no se posibilita la conciliación, sino al contrario es posible que se haya perjudicado en distintas dimensiones. Además, sólo sirve de herramienta de gestión instantánea a falta de planificación y ejercicio responsable de la actividad empresarial.

En todo caso, se ha de señalar cómo esta evolución normativa ha conducido a estos efectos (algo que se ha explicado de forma relativamente rauda para no desviar el eje expositivo) como consecuencia del proceso paralelo y concomitante que ha sufrido la contratación temporal, como contrapunto a la contratación indefinida. A la vista de ese diagnóstico sucinto, quizás sea posible aventurar algunos elementos de reforma que resulten estratégicos para corregir las disfuncionalidades de la figura y la reconduzcan a su potencial optimizado. Es preciso garantizar la voluntariedad real del trabajo a tiempo parcial, en el momento de la contratación, pero también en lo relativo al desarrollo de jornadas superiores a las pactadas inicialmente. Para evitar situaciones de fraude y abuso, para una formalidad total, el establecimiento de obligaciones de registro de jornada puede resultar eficaz, pues lo que se registra se visibiliza y se ha de remunerar/cotizar. 
La flexibilidad de la determinación del tiempo de trabajo no ha de ser ilimitada, y esto sirva tanto para el tiempo parcial como para el tiempo completo. De ahí que, junto al registro, el derecho a una jornada previsible y la garantía efectiva de los descansos, resultan líneas de reforma que interesaría explorar, junto con el fortalecimiento y la renovación de los instrumentos de conciliación entre vida laboral y personal. Los derechos de formación, y recualificación profesional, junto con los derechos derivados de una correcta prevención de los riesgos laborales en la empresa, son ámbitos que plantearían una eventual reducción de la depauperización laboral. En efecto, si se pergeñan derechos formativos que se traduzcan en obligaciones empresariales de conservación del talento y de la empleabilidad de las plantillas como freno al uso abusivo de la temporalidad laboral y se conserva la salud de los trabajadores, no solo la física, sino la también la salud mental, se permitiría reducir el impacto en términos de vulnerabilidad económica y social que puedan generar los bajos salarios o las condiciones de trabajo flexibles. No ha de concebirse la formación, sin embargo, como una cuestión genérica, sino que se hace necesario adaptar la formación de las personas a la realidad productiva demandada. Por lo tanto, en primer lugar, se debería garantizar un nivel formativo mínimo a todas las personas para dotarlas de las herramientas suficientes para desenvolverse en el mercado laboral. En segundo lugar, se debería potenciar el desarrollo de la formación profesional para adaptar esta formación a las demandas del mercado y así garantizar trabajadores que posean las capacidades prácticas que puedan aplicarse de manera efectiva. En esta misma línea se debería potenciar la acreditación de competencias profesionales como forma de reconocer oficialmente los conocimientos adquiridos por la experiencia laboral y vías no formales de formación. A través de este proceso, así como de la formación continua, se podría conseguir una mayor flexibilidad en la formación de los trabajadores, adecuándolo rápidamente a las necesidades que el mercado pueda generar, así como animando a las personas excluidas del mercado laboral a participar en él.

En todo lo anterior, como elemento mainstreamming evidente, se hace precisa una perspectiva de género. Sin minusvalorar el potencial de los elementos anteriores, el esencial de cualesquiera reformas tendría que apoyarse en la asunción de una perspectiva de género transversal. En efecto, en sus formulaciones teóricas, el contrato a tiempo parcial sería una figura contractual que se adaptaría muy bien a las circunstancias de ciertos colectivos sociales que desean compatibilizar la actividad productiva con otro tipo de activida- 
des. Y así la voluntariedad esencial del trabajo a tiempo parcial se explicaría vehementemente, tanto más cuanto se trate de contratos a tiempo parcial con alto porcentaje de horas ${ }^{16}$, y celebrados por tiempo indefinido. Porque en estos casos, especialmente si se pactan inicialmente y responden a una previsibilidad y regularidad relativas, se mantiene el objetivo de lograr un equilibrio razonable entre la vida laboral y las responsabilidades familiares ${ }^{17}$.

\subsubsection{La vigilancia pública}

Cualquier política pública pecaría de una ingenuidad voluntarista impropia del papel interventor de las administraciones implicadas si no se establecieran mecanismos firmes de control del cumplimiento normativo. De ahí que una política anexa a las anteriores habría de centrarse en el reforzamiento material y jurídico de los órganos de la inspección laboral con la finalidad de garantizar la efectiva fiscalización de las empresas. De un modo más concreto, la inspección de trabajo debiera dotarse de recursos humanos y monetarios con el objetivo de conseguir el cumplimiento de las normativas laborales de cada país. La existencia de un marco de sanciones claras y significativas, así como de incentivos por el correcto cumplimiento de la norma son instrumentos útiles para la consecución de un sector empresarial respetuoso con las garantías de los trabajadores. La idea de la falta de inspección lleva a que, en los casos de querer incumplir la legislación, se propague una sensación de impunidad que deja la decisión del respeto de los derechos en manos de cada actor social. Cuestión similar ocurre en los casos en que las sanciones no son proporcionales a la falta, es decir que se demuestra más rentable infligir la legislación y pagar por ello que respetarla (bonus malus). La noción de una vigilancia proporcional y sistemática ayuda a estimular el cumplimiento de las normativas, cuestión que también puede ser estimulada por la creación de incentivos que coloquen a las empresas, social o monetariamente, en un lugar privilegiado.

En relación con la fiscalización, se debe incidir de manera especial en la

16 Esto es lo que ha venido sucediendo en aquellos países con altas tasas de empleo femenino a tiempo parcial, como sería el caso de los países nórdicos . Vid. KJELDSTAD, R. Y HYMOEN, R., "Empleo a tiempo parcial y género: el trabajador o el puesto de trabajo como factor clave”, en Revista Internacional del Trabajo, vol. 131, núm. 1-2, 2012, p. 93.

17 SALLADARRE, F., HLAIMI, S. B. "Las mujeres y el trabajo a tiempo parcial en los países europeos”, en Revista Internacional del Trabajo, vol. 133 (2014), núm. 2. 
inspección de determinados tipos de empresa como las empresas multiservicio o de cesión de trabajadores, así como en la vigilancia de las cadenas de descentralización productiva. En efecto, las relaciones triangulares de empleo donde se terceriza la contratación de personal presentan mayores posibilidades de precarizar las condiciones de trabajo ya que la responsabilidad de su cumplimiento se desdibuja en las cadenas de contratación. Esta forma de contratación, además, repercute en mayor medida en los colectivos más desfavorecidos, como mujeres, jóvenes e inmigrantes, que acceden a puestos de trabajo con peores condiciones de partida y con menores posibilidades de negociación de sus derechos.

Otro eje de actuación de los poderes públicos se podría establecer incidiendo en el comportamiento empresarial a través de formas de procedimiento no punitivas. De un modo más preciso, la intervención del funcionamiento empresarial puede estimular la generalización de condiciones dignas de empleo a través de las compras públicas o las etiquetas sociales. La red de administraciones y organismos públicos se conforma como un importante demandante de recursos de las empresas privadas, y esta demanda podría ligarse al correcto funcionamiento de estas empresas en cuanto al respeto de condiciones laborales y salariales dignas. Se debería priorizar la contratación de empresas que establezcan salarios vivibles (registros de salarios) y, en definitiva, que tengan una postura que contribuya a la disminución de la precariedad laboral. Además, en clara relación con esto, las propias entidades públicas deberían aumentar sus partidas dedicadas a financiar los recursos humanos para convertirse en ejemplos de la lucha contra la precariedad laboral. Por otra parte, la relación con las empresas se debería establecer a partir de la promoción de etiquetas sociales o etiquetas de calidad, es decir distintivos que atesoren el respeto de los aspectos laborales y sociales fundamentales. Los requisitos de estos distintivos deberían encontrarse claramente establecidos en la línea de la construcción de empleo decente y todas aquellas empresas que deseen establecer contratos con los organismos públicos deberán estar en posesión de esta etiqueta.

\subsection{En relación con políticas de protección social en sentido amplio}

Así las cosas, admitido que el mundo empresarial está sujeto a situaciones de crisis, parece que el Estado del Bienestar, y de un modo más concreto los 
sistemas de protección social serían el colchón que frena la caída de las condiciones de existencia. Pero las dinámicas globales también han afectado a esa función de Estado, que ha sido conducido a una situación crítica en la que ya no mantiene su clásico papel de seguridad y se encuentra en proceso de ser re-etiquetado como papel de aseguramiento/securización y de contrapunto a la flexibilidad.

En la actualidad, si el trabajador (pobre) se ve inmerso en una situación de necesidad contributiva (enfermedad, vicisitudes varias, jubilación) el sistema, que ha frenado su vis expansiva protectora, posiblemente no le proteja suficientemente, tanto más cuando consten lagunas de cotización que sean consecuencia de periodos prolongados de inactividad laboral o de actividad laboral irregular o fraudulenta y/o se sumen periodos de infracotización, y/o se atesoren largos periodos de cotización a tiempo parcial. Se debe apuntar que tampoco desde el sistema de protección social se salvaguarda al trabajador -flexiblemente- expulsado del mercado de trabajo ya que se mantiene muy fuerte la contrapartida pública contributiva, en decir el vínculo prestación por desempleo-cotización previa y se reduce la extensión de la protección del desempleado cuantitativa (prestaciones más bajas y de menor duración) y cualitativamente (sujeto a controles excesivos y causas de extinción y suspensión estrictas, sin derechos reales tendentes a la ocupabilidad y la empleabilidad). Como consecuencia de lo primero, si la contributividad se intensifica, y el salario ya se ha visto afectado a la baja, cabría que el trabajador pobre o cuasi-pobre, se convierta en un desempleado subsidiado pobre o cuasi pobre sin que la asistencialización de las prestaciones pueda evitarlo. Es verdad que se han potenciado las prestaciones ligadas al desempleo y más directamente a la exclusión con nuevas formas (desde el sistema público estatal y desde las autonomías con las rentas básicas reformadas), con nuevos requisitos y nuevas duraciones, pero no resultan suficientes, y se ven afectada la tasa de cobertura/de protección.

Desde la perspectiva de las políticas activas de empleo, se ha 'modernizado' el sistema de la intermediación laboral, pero eso, sin embrago, ha supuesto en realidad una externalización/privatización de esta. Sobre argumentos de eficiencia se ha potenciado la inserción profesional con sustento lucrativo, y se han dado nuevos roles a las agencias de colocación a las Empresas de Trabajo Temporal, al tiempo que han disminuido los recursos materiales y financieros y se ha incrementado los argumentos de incapacidad de los sistemas públicos de empleo estatales, autonómicos y locales. Lo que sumado a la regulación del 
mercado laboral aumenta el riesgo de ser una persona trabajadora en riesgo de pobreza. En idéntica dirección discurren los esquemas asegurativos contributivos de la vejez. El mantra de la sostenibilidad financiera de los sistemas públicos de pensiones ha conducido a reformas normativas para alargar la vida laboral (que, si se refiere a un trabajador pobre, prolonga en realidad la situación de pobreza laboral) y a reformas que ahondan en la proporcionalidad estricta entre contribución y prestación, de suerte que la pauperización salarial conduce a una pauperización prestacional, entre otros efectos. Por otra parte, desde los sistemas públicos de salud también se ha desinflado el colchón de protección de los trabajadores y sus familias, mientras que la prevención de la enfermedad y la promoción de la salud han ido desdibujando su presencia en las empresas (donde la prevención de riesgos deviene coste necesario involuntario desganado) y en las propias administraciones sanitarias en las que la acción preventiva y curativa se han sometido a regímenes de eficiencia y eficacia, y no tanto de preservación y recuperación de la salud, ni a un tratamiento integral de la salud psico-física. En resumen, como consecuencia de la situación económica se mantiene que el tránsito al trabajo resulta difícil, y como consecuencia de las reformas laborales, la inserción laboral en muchas ocasiones en un tránsito a la precariedad como trabajador.

A partir de esta situación, el desarrollo de políticas sociales amplias que garanticen el acceso a recursos para la experiencia de una vida digna se constituye en un ámbito de desarrollo fundamental para el funcionamiento social. Las realidades laborales se insertan en unas dinámicas más amplias, entre otras cosas de salud o de acceso a la vivienda, que son esenciales para la eliminación de la pobreza y de la exclusión social y que conforman un ámbito de acompañamiento fundamental de las políticas laborales. En términos generales, los distintos Estados deberían desarrollar una estructura básica de servicios públicos que garanticen el acceso a los ámbitos educativos, sanitarios y sociales fundamentales. En esta línea la Estrategia nacional de prevención y luch a contra la pobreza y exclusión social aprobada por el Gobierno de España en 2019 señala entre sus metas el hecho de "consolidar un sistema de servicios públicos sanitarios, educativos y sociales, universales y de calidad, que acompañen y protejan a las personas a lo largo de su ciclo vital y profundicen en combatir las desigualdades", reflejando que sin un sistema institucional de acceso a los recursos básicos se convierte en una tarea imposible disminuir la desigualdad social.

Además del desarrollo de servicios públicos transversales de calidad, se 
puede mencionar de manera concreta la necesidad de implementar políticas que apoyen el funcionamiento de las familias a través, principalmente, de la creación de escuelas públicas de calidad para todos los niveles de escolarización y con catálogos ampliados de servicios auxiliares (alimentación y actividades extraescolares y de apoyo escolar) y, por otro lado, mediante el desarrollo de un sistema efectivo y real de atención de las situaciones de dependencia de las personas dependientes que, a falta de una red integral de servicios sociales de atención sociosanitaria, acaban al cuidado de los hogares, y por ende de las personas trabajadoras y/o desempleadas que en él convivan.

En otro orden de cosas, aunque referido también a la transversalidad de ciertas políticas, se puede señalar la necesidad de desarrollar políticas sociales generales que favorezcan el positivo desarrollo del ámbito laboral. Ejemplo de esto podrían ser las políticas migratorias, las cuales deberían potenciar la regularización de los y las migrantes como forma, entre otras cosas, de evitar la explotación laboral. Distintos estudios señalan que la población extranjera y/o inmigrante se constituye en uno de los colectivos con mayor presencia tanto en el empleo atípico como en la economía irregular. La normativa de extranjería podría llevar, de manera directa o indirecta, a la aceptación de la precariedad laboral, y vital, como única forma de conseguir a medio plazo una situación jurídica regular en el país de destino.

En términos concretos se pueden señalar tres líneas de actuación de interés desde las políticas sociales. La primera de ellas se refiere a las cuestiones relacionadas con la garantía de ingresos, la segunda con el blindaje de sistemas de protección social suficientes para proteger contra las situaciones de necesidad y la tercera con el reforzamiento de sistemas públicos de salud. En cuanto a la línea relacionada con los ingresos, se puede señalar que las transferencias monetarias desde las administraciones públicas pueden constituir una medida protectora fundamental contra la pobreza y exclusión social. El propio Ministerio de Sanidad, Consumo y Bienestar social español ${ }^{18}$ señala que este tipo de transferencias no contributivas se erigen en una herramienta clave para atacar las situaciones de ingresos bajos y mejorar la renta disponible en una unidad familiar. Se pueden organizar a través de complementos a mínimos, que completen ingresos disponibles a través del mercado, o del establecimiento de un ingreso mínimo vital encauzados a través de subsidios

18 MINISTERIO DE SANIDAD, CONSUMO Y BIENESTAR SOCIAL, 'Estrategia nacional de prevención y lucha contra la pobreza y exclusión social 2019-2023’, 2019, p. 33. 
o diversas prestaciones, como la prestación de jubilación o desempleo. En ambos casos el objetivo último consiste en garantizar una vida digna a todas las personas a través del desarrollo de un sistema de garantías de ingresos, el cual también trae aparejado un debate respecto a las formas idóneas de implantación para evitar convertirse, entre otras cosas, en una subvención a las malas condiciones salariales de las empresas.

En la línea de garantizar una mínima cuantía monetaria a los individuos, se considera importante establecer un salario mínimo relacionado con la idea de salario vivible ${ }^{19}$, en el sentido de que su cuantía se establezca no en función de una cifra en abstracto sino en relación a las exigencias monetarias que se experimentan en cada sociedad. Los ingresos disponibles deben encontrarse acordes a los costes de vida, ya que la precariedad laboral y vital se encuentran estrechamente relacionadas con la insuficiencia salarial. Algunos autores incluso plantean la idoneidad de establecer salarios mínimos locales para poder ajustarlos de manera más precisa a la situación socioeconómica del contexto o la introducción de un debate relativo a los determinantes del salario con objeto de mejorar la situación de los empleos de bajos salarios ${ }^{20}$. Esto último podría hacerse a través de un aumento directo del salario, así como de un aumento de las cuotas a la Seguridad Social o un endurecimiento del tratamiento fiscal de las empresas que fomentan malas condiciones laborales y salariales.

La segunda línea de acción se concreta en el fortalecimiento de los sistemas de seguridad social en todas sus vertientes respecto de los distintos pisos de protección. Esta sería una línea de acción sobre la que aquí se indicarán algunas ideas-fuerza. En primer lugar, no debería perderse la centralidad del esquema mismo que subyace al sistema: la protección suficiente para superar las situaciones de riesgo de pobreza derivada de una merma de ingresos y/o un incremento de gastos. Ese principio general ha sufrido la embestida de la obsesiva búsqueda de la eficiencia económica y la sostenibilidad financiara, y ha permutado su papel en la relación objetivo-herramienta. La vertiente financiera no ha dejar de ser esencial, pero es instrumental a la finalidad objeto del sistema y, por lo tanto, no podría justificar reformas regresivas. Antes al contrario, la realidad de la pobreza laboral, debería ser un acicate para conformar sistemas solventes para subvenir a las situaciones de necesidad

19 EUROFOUND (2017). In-work poverty in the EU, cit.

20 BANYULS LLOPIS, J., RECIO ANDREU, A, “Pobreza laboral en España: causas y alternativas políticas", cit. 
derivadas de mercados de trabajo ineficientes y/o normativas defectuosas. Las vertientes contributivas y asistenciales no debieran confundirse, y quizás sí deberían actuar de modo realmente complementario, con fuentes de financiación separadas.

Esto sería especialmente estratégico en lo relativo a la promoción del empleo. Una vez diseñado un mercado de trabajo más decente (en los términos del ODS 8 y de la OIT), el objetivo esencial de erradicación de la pobreza pasa por la inserción en el mercado o, rectius, la reinserción cuando la persona trabajadora pobre se ha visto expulsada. Para esas dos finalidades se apunta como una buena fórmula de acción política la de aunar de una forma imbricada, e indisoluble incluso, la garantía de ingresos con fórmulas eficaces de orientación, recualificación e inserción en el mercado a través de servicios de orientación y empleo ${ }^{21}$. O, dicho de otro modo, la pobreza derivada del no-trabajo necesita ser cubierta como situación de necesidad a través de subsidios o rentas mínimas pero que estén cohonestadas con acciones para la reinserción de la persona trabajadora en el mercado de un modo duradero y con garantías de no quedar incluido en un género de samsara de la desocupación regular. De ahí que tanto la vertiente monetaria como de servicios debería prolongarse en tanto se alcanza la situación de salida del círculo de la pobreza.

Por último, los sistemas públicos de salud son condicionantes del nivel de aptitud física y mental de la población ocupada y desocupada. De modo que deberían actuar para prevenir las patologías ligadas a la pobreza, además de para curarlas. Y no solo en la vertiente física, sino mental. Y en esta función, la intervención de las empresas, desde el desarrollo de acciones de protección de la salud laboral de los trabajadores es crucial. Y solo será preciso hacer una afirmación: la precariedad laboral se considera un factor de riesgo laboral agudizado, como demuestra la tasa de incidencia de accidentes laborales graves o muy graves entre los trabajadores temporales, por ejemplo, o entre los trabajadores en situación de informalidad o irregularidad. En las empresas, la vulnerabilidad es función de las intensidades protectoras (tipos de equipos de protección, modalidades de información y formación en prevención de riesgos laborales) respecto de la morfología de las plantillas (temporales, subcontratadas, a tiempo parcial...).

21 OIT, What Works promoting pathways to decent work, Ginebra, 2019. (https:// www.ilo.org/wcmsp5/groups/public/--dgreports/--inst/documents/publication/ wcms_724049.pdf) 


\section{Nuevas formas de gobernanza: el papel de los agentes socia- les y de la sociedad civil}

La organización colectiva de los trabajadores se ha constituido históricamente en un elemento primordial para equilibrar las relaciones desiguales de poder que se originan en el ámbito de la producción laboral. Las normativas sobre libertad sindical y negociación colectiva han permitido que los trabajadores actúen de manera conjunta con objeto de influir positivamente en sus condiciones laborales ${ }^{22}$. La presencia sindical en los espacios de trabajo, por tanto, se constituye en un factor importante de actuación, así como de garantía de observación del cumplimiento de un mínimo estándar de condiciones laborales dignas. Esta forma de negociación laboral, sin embargo, se ha ido modificando en las últimas décadas en función de las transformaciones acaecidas en las formas de producción y las relaciones laborales, lo que ha conducido a un debilitamiento en la capacidad de los sindicatos en los procesos de negociación colectiva y un estímulo de la gestión individual del malestar laboral y social ${ }^{23}$.

Las formas de producción económica se están modificando en favor de un aumento de la economía de trabajo esporádico que se encuentra basada en formas alternativas a la contratación tradicional. Hasta ahora no se ha mencionado expresamente, pero la denominada 'gig economy' tiene el potencial de modificar las formas de organización y realización del trabajo, incentivando la flexibilidad, la deslocalización y las relaciones individuales a través de un soporte tecnológico. Estas formas de trabajo alteran no sólo la composición de los sectores económicos sino también la relación colectiva entre los empleados y sus formas de interactuar con los empleadores. La normativa que regula el empleo y la representación sindical, sin embargo, sigue basado en la estructura tradicional de relación de trabajo típica, sin haberse podido producir aún una adaptación profunda de las formas de articulación colectiva a la nueva realidad socioeconómica. Las personas con empleos no estándar representan un desafío para la representación sindical por una variada gama de razones, entre las que destacan la dificultad de llegar a ellos por

22 HANNAH, J. y LAND-KAZLAUSKAS, C., "Representación, voz y negociación colectiva: la sindicalización en la economía del trabajo esporádico y por encargo", Series Condiciones de Trabajo y Empleo no 94, Ginebra, 2018, OIT.

23 CASTRO, C., "Presentación. La precariedad laboral y más allá”, en Cuadernos de Relaciones Laborales, vol. 37, núm. 1, 2019, pp. 11-29. 
su forma de trabajo aislado y una menor identificación de sus compañeros como colectivo, así como de sus empleadores como un vértice esencial de la relación laboral. Todos estos procesos de indefinición se insertan, además, en un aumento del riesgo de pobreza laboral, generado tanto por los cambios del sistema capitalista global como, precisamente, por la falta de identificación y resolución de estas nuevas formas de relaciones laborales. Los beneficios y costes de las nuevas formas de trabajo están aún por determinar y, por el momento, resulta enormemente controvertido su desarrollo e implantación en la dinámica social. Reflejo de esta incertidumbre en la interpretación de las nuevas relaciones laborales pueden ser las sentencias con distintas interpretaciones que se han producido en España al respecto de las plataformas laborales digitales y su relación con los trabajadores (Glovo y Deliveroo entre otras).

Los cambios en la estructura económica y la organización laboral modifican sustancialmente las posibilidades de actuación sindical y de organización colectiva, por lo que los sindicatos se encuentran abocados a investigar nuevas formas de acción y actuación. Johnston y Land-Kazlauskas ${ }^{24}$ proponen, por ejemplo, el desarrollo de foros en línea que sirvan de soporte y relación entre los trabajadores de plataformas que no coinciden físicamente en un espacio. De esta manera se podrían generar redes de apoyo y de intercambio de información que faciliten el establecimiento de condiciones laborales respetuosas para todas las personas trabajadoras. Así mismo, los autores sugieren la posibilidad de desarrollar normativa a nivel municipal (como ilustran con el caso de los camioneros en Seattle) como forma de reforzar la organización colectiva teniendo en cuenta los contextos específicos. En base a esta idea de flexibilidad y deslocalización, también se propone como estímulo a la organización sindical el aplicar una perspectiva transversal que aspire a movilizar los intereses de trabajadores, que se refiere tanto a la coordinación de la movilización de todos los trabajadores implicados en los eslabones de una cadena de producción como a la alianza con asociaciones de los territorios donde se insertan las cadenas ${ }^{25}$. La idea de trasfondo de todas estas opciones reside en movilizar a las personas trabajadoras de una manera más flexible

24 HANNAH, J. y LAND-KAZLAUSKAS, C., "Representación, voz y negociación colectiva: la sindicalización en la economía del trabajo esporádico y por encargo", Series Condiciones de Trabajo y Empleo no 94, Ginebra, 2018, OIT..

25 CASTRO, C., "Presentación. La precariedad laboral y más allá”, en Cuadernos de Relaciones Laborales, vol. 37, núm. 1, 2019, pp. 11-29. 
y generando alianzas que superen las tradicionales de la empresa y/o de un espacio de producción determinado. En la actualidad la gestión de la solidaridad laboral debe verse impulsada por una doble vertiente que tenga en cuenta tanto que la producción se realiza a nivel global como que se aplica a unas realidades sociales muy determinadas (globalización). Por último, en esta línea de acción internacionalizada se debe señalar las incipientes estrategias de los sindicatos por establecer negociaciones internacionales con empresas transnacionales enmarcadas en los denominados Acuerdos Marco Globales.

En la vertiente normativa también se hace preciso redimensionar el valor de las normas negociadas, lo que demanda dar un nuevo papel a la negociación colectiva. Al hablar de las condiciones laborales ligadas a la pobreza laboral, hasta ahora apenas se ha hecho mención de ella, pero (y sin que sea algo exclusivo del contrato a tiempo parcial) la negociación colectiva (en su dimensión puramente normativo-convencional pero también proyectada hacia los derechos y deberes de los representantes de los trabajadores en las empresas) adquiere una relevancia esencial. De una parte, el legislador en las sucesivas reformas laborales ha venido ofreciendo a la negociación colectiva un papel ambivalente y contradictorio de garante (si opta por regular la cuestión) al mismo tiempo que de adalid de la aceptabilidad de los pequeños vectores de flexibilidad que sumativamente han conducido a la precariedad y la desprotección de los trabajadores. De otra parte, la negociación colectiva no ha respondido homogénea ni unívocamente a una única finalidad congruente de protección de los derechos de los trabajadores temporales, o a tiempo parcial o de ciertos colectivos habitualmente ausentes (jóvenes, mujeres, personas con discapacidad, inmigrantes, personas LGTBI, por señalar algunos). En efecto, se ha producido una relativa desafección de los representantes de los trabajadores respectos de la protección de derechos e intereses de los trabajadores atípicos y, viceversa. Unida a la temporalidad, la parcialidad conforma una amalgama de realidades multiplicadas en las que la flexibilidad excesiva de la jornada, junto a parcialidad extrema, llega a invisibilizar a las personas trabajadoras. Los representantes unitarios o sindicales de los trabajadores en la empresa (si los hubiera) no tienen la capacidad real de poder actuar las facultades estatutariamente reconocidas y, por ende, en los procesos de reivindicación del cumplimiento de la normativa laboral podrían ignorar los intereses del colectivo de trabajadores a tiempo parcial y aún más en los procesos de negociación de pactos o convenios. Algo semejante se produce respecto de las personas trabajadoras vinculadas con contratos de duración determi- 
nada en la medida que esas dos realidades contractuales afectan con mayor incidencia a ciertos colectivos, por lo que mayor proyección social tendrán los defectos representatividad/representación. De ahí la necesidad de reformar (para reforzar y proteger) el papel de esa representación de los trabajadores en la empresa.

En el ámbito de las políticas públicas, en aras a una Gobernanza real de los cambios, se hace preciso reubicar a los agentes sociales (sindicatos y asociaciones de empresarios) que deberían tener un nuevo rol de agentes dinamizadores del empleo responsable y el Trabajo Decente, que sea la base de un sistema de protección social solvente (porque hay contribuciones debidas). De suerte que, por ejemplo, se sustituyera la obsesión normativa por los planes de fomento (incentivado, subvencionado) de la contratación con condicionamientos cualesquiera vacíos de efectividad, por el diálogo social y el trazado de planes de empleo, de formación y de inserción de colectivos vulnerables dialogados, bilateral o tripartitamente en los que los sistemas de rentas mínimas condicionadas puedan ser, incluso, gestionados por esos agentes sociales, o por otros actores de la sociedad civil (entes de formación, entidades del tercer sector o de la economía social...).

A lo anterior habría de añadirle otro ámbito de acción, (que es a la vez causa en un bucle difícil de frenar): el de resolver la situación de desafección de la clase trabajadora de los sindicatos. Las teorías neoliberales han cuajado socialmente y explican el individualismo preponderante, en el que el sujeto no se percibe como ente laborator, sino como ciudadano y consumidor. $\mathrm{Y}$ en esa trasmutación, omite la necesidad de la organización colectiva como instrumento de gestión de la producción y de los equilibrios de intercambio.

\section{Consideraciones finales}

El trabajo no-decente, se erige, entonces, como el paradigma de los efectos que puede generar la combinación, por una parte, de las situaciones macroeconómicas y financieras que provocan reformas laborales coyunturales y sucesivas del mercado laboral complejo y, de otra, de un modus operandi socialmente irresponsable de las empresas, de los propios trabajadores, y de todos sus representantes. Efectos tales como la precariedad del empleo y la pauperización de los trabajadores, pero en especial de colectivos especialmente vulnerables, como son las mujeres (y los jóvenes). En este sentido, se señala que la falta de análisis prospectivo y de evaluación periódica de las 
reformas normativas puede conducir a la superposición de efectos perniciosos por la acumulación incongruente de aspectos normativos laborales y de Seguridad Social que, por ende, a veces nihilizan los objetivos legislativos progresistas, como ha sucedido con el objetivo de crear empleo a través de cualesquiera regulaciones de flexibilización de las relaciones laborales.

En tercer lugar, es un modelo que permite reclamar la necesidad de dotar de mayor profundidad a la intervención eficaz y efectiva, de control disuasorio y sancionador, de la inspección de trabajo y de la Seguridad Social. No solo mediante el reforzamiento de recursos humanos y materiales disponibles, sino también mediante un giro en la regulación sustantiva de ciertas obligaciones empresariales y de ciertos derechos de los trabajadores que resultan intrínsecamente ineficaces. Por último, la (des)regulación y la (in)aplicación de la normativa referida al trabajo es un arquetipo de la presencia de una visión patriarcal del trabajo, centrada en tipologías contractuales históricamente masculinas, que omite las perspectivas de género y que, cuando lo ha hecho, ha sido para perpetuar funciones de endoculturización de las tareas de cuidado femeninas.

La consecuencia de todo lo anterior es que la regulación postmoderna del trabajo ha contribuido intensamente a la creación del precariado ${ }^{26}$ como la nueva clase social que, si bien comparte conciencia de clase con el proletariado, está sometida a condiciones diferentes, propias de la era de la flexibilidad. Y así, la organización del trabajo es, precisamente, una de las grandes cuestiones a normalizar en este maltrecho Estado del "malestar"

En el ámbito laboral podría partirse de una hipótesis fáctica: la aplicación de las legislaciones relativa a la contratación laboral corre el riesgo de un uso desorbitadamente fraudulento en las empresas. De ahí que, hoy, la causa de la pobreza en el trabajo no sería en sí misma solo la normativa de la contratación temporal, sino el uso que en la práctica se ha hecho de ella. A ello contribuye una legislación tendencialmente dispositiva que desconoce la cultura empresarial ligada a la búsqueda del vericueto legal para realizar un arbitraje rentable del cumplimiento/incumplimiento de la norma. Todo aderezado con un sistema imperfecto de control administrativo del cumplimiento laboral por las empresas.

26 CASTRO, C., "Presentación. La precariedad laboral y más allá”, Cuadernos de Relaciones Laborales, vol. 37, núm. 1, 2019, pp. 11-29.

27 MANZANERA-ROMÁN, S.; ORTIZ GARCÍA, P. y OLAZ CAPITÁN, A. J., "Trabajo y flexibilidad laboral en un escenario de crisis económica: situación en el caso español”, Revista Internacional de Ciencias Sociales, número 36, 2017, p. 15. 


\section{Bibliografía}

ARIAS-URIONA, A.M. Y ORDÓÑEZ, J.C.. "Factores de precariedad laboral y su relación con la salud de trabajadores asalariados y con contrato en Bolivia”, en Revista Panamericana de Salud Pública, 2018 (https://doi.org/10.26633/ RPSP.2018.98).

BANYULS LLOPIS, J.; RECIO ANDREU, A. "Pobreza laboral en España: causas y alternativas políticas", en Anuario IET de Trabajo y Relaciones Laborales, Vol. 4, 2017, pp.135-149.

CANDIL MORENO, D. "En la cuerda floja: un estudio sobre la precariedad laboral", Intersticios. Revista sociológica de pensamiento crítico, vol. 10, núm. 2, 2016, pp. 123-133.

CASTRO, C. "Presentación. La precariedad laboral y más allá", Cuadernos de Relaciones Laborales, vol. 37, núm. 1, 2019, pp. 11-29.

EUROFOUND. In-work poverty in the EU, Publications Office of the European Union, Luxemburgo. 2017.

JOHNSTON, H.Y LAND-KAZLAUSKAS, C.. "Representación, voz y negociación colectiva: la sindicalización en la economía del trabajo esporádico y por encargo", Series Condiciones de Trabajo y Empleo núm. 94, 2018, Ginebra, OIT.

KJELDSTAD, R. Y HYMOEN, R "Empleo a tiempo parcial y género: el trabajador o el puesto de trabajo como factor clave", Revista Internacional del Trabajo, vol. 131, número 1-2, 2012

MANZANERA-ROMÁN, S. ORTIZ GARCÍA, P.Y OLAZ CAPITÁN, Á. J. “Trabajo y flexibilidad laboral en un escenario de crisis económica: situación en el caso español”, Revista Internacional de Ciencias Sociales, número 36, 2017.

MAURIZIO, R. Formas atípicas de empleo en América Latina: incidencia, características e impactos en la determinación salarial, Series Condiciones de Trabajo y Empleo núm. 76, 2016, Ginebra, OIT.

MINISTERIO DE SANIDAD, CONSUMO Y BIENESTAR SOCIAL. 'Estrategia nacional de prevención y lucha contra la pobreza y exclusión social 2019-2023'. 2019

OIT. Preliminary concept note on non-standard forms of employment, Grupo sobre la seguridad y el desempeño del mercado de trabajo, Servicio de Mercados Laborales Inclusivos, Relaciones Laborales y Condiciones de Trabajo (INWORK), Ginebra. 2013.

OIT What Works promoting pathways to decent work. Ginebra (https://www.ilo.org/wcmsp5/groups/public/---dgreports/--- 2019 inst/documents/publication/wcms_724049. pdf)

SALLADARRE, F., HLAIMI, S. B. "Las mujeres y el trabajo a tiempo parcial en los países europeos", Revista Internacional del Trabajo, vol. 133, núm. 2., 2014.

STANDING, G. El precariado: una nueva clase social, Barcelona: Ediciones de Pasado y Presente, 2013 



\title{
APROXIMACIÓN AL TRABAJO FORZOSO E INFANTIL DESDE UNA PERSPECTIVA INTERDISCIPLINAR E INTERNACIONAL ${ }^{1}$
}

\author{
Tania GARCÍA-SEDANO \\ Universidad Carlos III de Madrid \\ Vanesa ZORRILLA-MUÑOZ \\ Universidad Carlos III de Madrid \\ Ma Silveria AGULLÓ-TOMÁS \\ Universidad Carlos III de Madrid
}

\begin{abstract}
RESUMEN: Este capítulo se estructura en el abordaje de dos cuestiones. La primera desarrolla el trabajo forzoso como forma contemporánea de esclavitud y su regulación en el ámbito internacional, regional e hispano-colombiano. La segunda, expone un análisis de meta-evaluación para el caso concreto del trabajo infantil. En particular, se analiza el Programa "Edúcame primero, Colombia", proyecto de intervención socio-educativa frente al trabajo infantil en todos los sectores laborales. Desde este prisma, el programa (con implementación primero en Colombia, y recientemente en otros países) constituye un ejemplo de intervención para la prevención del trabajo infantil a partir de la educación desde edades tempranas.
\end{abstract}

Palabras clave: trabajo forzoso, trabajo infantil, enfoque jurídico, enfoque social, meta-evaluación, programas para la erradicación.

SUMARIO: 1. Introducción. Magnitud de los fenómenos y necesidad de investigación y evaluación. 2. Aproximación al trabajo forzoso. 2.1. Formas contemporáneas de exclavitud y trabajo forzoso. 2.2. La Agenda 2030 y la Meta 8.7. 2.3. El trabajo forzoso. 2.4. El trabajo forzoso como finalidad del delito de trata de seres humanos. 3. Aproximación al trabajo infantil. 3.1. El trabajo infantil como problema psicosocial y sociopolítico. 3.2. Método y claves de la meta-evaluación de programas. 3.3. Resultados de la meta-evaluación del Programa "Edúcame Primero, Colombia” 4. Conclusiones. 5. Bibliografía. 6. Jurisprudencia

\section{Approach to forced work and child labour from an interdisciplinary and international perspective.}

1 Las autoras están muy agradecidas a Christopher Alvarado Carrasco y Georgiana Livia Cruceanu por su apoyo y colaboración en la búsqueda de información para el tratamiento del trabajo infantil realizado en este capítulo. 
ABSTRACT: This chapter is structured in addressing two issues. The first section develops forced labour as a contemporary form of slavery and its regulation in the international, regional and Hispanic-Colombian frame. The second part exposes a meta-evaluation analysis for the specific case of child labour. In particular, the "Edúcame Primero, Colombia" Program is evaluated, which is a socio-educational intervention project against child labour in all sectors. From this perspective, the program (with the first implementation in Colombia, and recently in other countries) is an example of intervention for the prevention of child labour based on education from the childhood..

Key words: forced labour, child labour, legal focus, social focus, meta-evaluation analysis, erradication programs.

\section{Introducción. Magnitud de los fenómenos y necesidad de in- vestigación y evaluación}

Según la Organización Internacional del Trabajo (en adelante OIT) ${ }^{2}, 40,3$ millones de personas han sido víctimas de formas contemporáneas de esclavitud y 24,9 millones han realizado trabajos forzosos (datos del 2016) y, es destacable, que ninguna región del mundo está libre de la misma. Sin embargo, las estadísticas tienden a menospreciar la magnitud del fenómeno, que varía de un modo muy considerable entre sectores económicos y regiones geográficas ${ }^{3}$. El trabajo forzoso suscita un gran interés a nivel internacional desde diversas perspectivas, tanto desde una aproximación jurídica como económica-social.

Por otra parte, el trabajo forzoso infantil expone a millones de niños/as a graves violaciones de derechos humanos. $\mathrm{La} \mathrm{OIT}^{4}$ (2016) estima que, en el mundo, 152 millones son víctimas del trabajo infantil, donde casi la mitad, 73 millones, están en situación de trabajo infantil peligroso. Es por ello que, entre las acciones emprendidas por parte de la Asamblea General de las Naciones Unidas y otras entidades relevantes, la erradicación del trabajo forzoso y el trabajo infantil constituye un eje principal de acción, donde urge que la

2 OIT. Walk Free Foundation. Global estimates of modern slavery: forced labour and forced marriage. Exexutive Summary. Geneva, 2017. p.9-10.

3 Boohla, U. Naciones Unidas. Asamblea General. Las formas contemporáneas de la esclavitud, incluidas sus causas y consecuencias. 2018. Documento: A/73/139. Párrafo 8.

4 OIT. Walk Free Foundation. Global estimates of modern slavery: forced labour and forced marriage. Exexutive Summary. Geneva, 2017. p.9-10. 
comunidad internacional implemente actividades que ayuden a la erradicación del trabajo forzoso y el trabajo infantil. Además, la Asamblea General de las Naciones Unidas ha declarado el 2021 como Año Internacional para la Erradicación del Trabajo Infantil.

Partiendo de este contexto, se constata la necesidad de investigación con mayor profundidad tanto de la regulación como de la evaluación de algunos de los programas existentes para combatir esta situación sociopolítica y psicosocial.

\section{Aproximación al trabajo forzoso}

2.1. Formas contemporáneas de esclavitud y trabajo forzoso

La razón de comenzar por esta cuestión se ubica en razones de índole conceptual; es fundamental subrayar que el trabajo forzoso ha sido considerado una forma contemporánea de esclavitud. Así, aunque el concepto de formas contemporáneas de esclavitud carece de un contenido equívoco, se utiliza como un término en el que se conglomeran todas las formas de explotación extrema del ser humano 5 .

No obstante, existe consenso en que la esclavitud, las prácticas análogas a la misma como la servidumbre por deudas, la servidumbre de la gleba y el matrimonio forzado, el trabajo forzoso, y la trata de seres humanos son formas contemporáneas de esclavitud ${ }^{6}$.

5 Bales, K., \& Robbins, P. T. "No one shall be held in slavery or servitude": A critical analysis of international slavery agreements and concepts of slavery. Human Rights Review, Vol. 2, N. ${ }^{2}$ 2, 2001, pp. 18-45. Plant, R. Modern slavery: The concepts and their practical implications. International Labour Organization, Geneva. 2014. p.1. Shahinian, G. Informe de la Relatora Especial sobre las formas contemporáneas de la esclavitud, incluidas sus causas y consecuencias. 2008. Documento no A/HRC/9/20. Párrafo 38.

Scarpa, S. Contemporary forms of slavery. STUDY Requested by the DROI committee. Policy Department for External Relations Directorate General for External Policies of the Union PE. December 2018. p.11.

6 Boohla, U. Naciones Unidas. Asamble General. Las formas contemporáneas de la esclavitud, incluidas sus causas y consecuencias. 2015. Documento: A/HRC/36/43. Párrafo 7.

Boohla, U. Naciones Unidas. Asamblea General. Las formas contemporáneas de la esclavitud, incluidas sus causas y consecuencias. 2015. Documento: A/HRC/27/53.

Sentencia de la Corte Interamericana de Derechos Humanos, caso trabajadores de la hacienda Brasil verde vs. Brasil, de fecha 20 Octubre de 2016.Párrafo 219.

Sentencia Tribunal Europeo de Derechos Humanos, caso de Rantsev c. Chipre y Rusia, de fecha 7 de enero de 2010. Demanda no 25965/04.Párrafo 281. 
En todo caso, es un concepto que ha llegado para quedarse. Así, la agenda 2030 de Naciones Unidas supone un paso más en la consolidación del uso de este concepto.

\subsection{La Agenda 2030 y la Meta 8.7}

La Agenda para el desarrollo para después de 2015 fue aprobada por la Asamblea General de Naciones Unidas y, dentro de la misma, se incardinan los 17 Objetivos de Desarrollo Sostenible y las 169 metas, conexas, de carácter integrado e indivisible ${ }^{7}$ que tienen como objetivo hacer realidad los derechos humanos de todas las personas y alcanzar la igualdad entre los géneros y el empoderamiento de todas las mujeres y niñas. Para ello ambos conjugan las tres dimensiones del desarrollo sostenible: económica, social y ambiental.

Por lo que se refiere al objeto de este capítulo, la meta 8.7 de la Agenda $2030^{8}$ establece: "adoptar medidas inmediatas y eficaces para erradicar el trabajo forzoso, poner fin a las formas contemporáneas de esclavitud y la trata de personas y asegurar la prohibición y eliminación de las peores formas de trabajo infantil, incluidos el reclutamiento y la utilización de niños/as soldados, y, de aquí a 2025, poner fin al trabajo infantil en todas sus formas”.

Se debe destacar que constituye una Meta que no puede ser interpretada de forma aislada si no que se complementa con otros objetivos y metas como por ejemplo la Meta 5.2. Eliminar todas las formas de violencia contra todas las mujeres y las niñas en los ámbitos público y privado, incluidas la trata y la explotación sexual y otros tipos de explotación.

En el marco de la Meta 8.7 de los Objetivos de Desarrollo Sostenible se hace un llamamiento para la adopción de medidas inmediatas y eficaces con miras a erradicar el trabajo forzoso, poner fin a las formas modernas de esclavitud y la trata de seres humanos, y asegurar la prohibición y eliminación de todas las formas de trabajo infantil, incluido el reclutamiento y la utilización de niños/as soldados, como una medida esencial para lograr el trabajo

7 Naciones Unidas. Asamblea General. Proyecto de documento final de la cumbre de las Naciones Unidas para la aprobación de la agenda para el desarrollo después de 2015. Documento: A/69/L.85. Párrafo 18

8 OIT. Principios y derechos fundamentales en el trabajo: Retos y oportunidades. Conferencia Internacional del Trabajo, 106. ${ }^{\text {a }}$ reunión, Ginebra. 2017. Párrafo 29. p.11.

Naciones Unidas. Asamblea General. Proyecto de documento final de la cumbre de las Naciones Unidas para la aprobación de la agenda para el desarrollo después de 2015. Documento: A/69/L.85.Meta 8.7. 
decente para todos, el empleo pleno y productivo, y el crecimiento económico incluyente y sostenido.

La enorme relevancia del objeto de la meta 8.7 requiere evitar la duplicación de esfuerzos e implantar las mejores soluciones a mayor escala9. Los compromisos de eliminar el trabajo infantil, el trabajo forzoso, las formas modernas de esclavitud y la trata de seres humanos sólo podrán cumplirse si se concilian y coordinan todos los esfuerzos mediante un conocimiento integrado, acciones coordinadas, la formulación eficaz de políticas y el uso eficiente de los recursos ${ }^{10}$.

En esa línea, se presentó la Alianza $8.7^{11}$ que constituye una iniciativa multipartita toda vez que cuenta con la colaboración de los gobiernos, las organizaciones de empleadores/as y de trabajadores/as, los organismos de las Naciones Unidas, las organizaciones regionales, los socios para el desarrollo, el sector privado, las organizaciones de la sociedad civil, la comunidad académica, los expertos, los medios de comunicación y otros actores, con el fin de apoyar el logro de la Meta 8.7.

La Alianza se concentrará, fundamentalmente, en cuatro ámbitos: coordinar mejor la investigación y el intercambio de conocimientos, estimular la innovación, incrementar y movilizar los recursos.

\subsection{El trabajo forzoso}

Desde el prisma del derecho internacional de los derechos humanos, la Declaración Universal de Derechos Humanos, de 1948, dispone en su artículo 4 que "[n]adie estará sometido a esclavitud ni a servidumbre" y que "la esclavitud y la trata de esclavos están prohibidas en todas sus formas". El Pacto

9 OIT. Departamento de Gobernanza y Tripartismo. Alianza 8.7 de los ODS Concertar esfuerzos a escala mundial para erradicar el trabajo infantil y el trabajo forzoso, las formas modernas de esclavitud y la trata de seres humanos. Proyecto para consulta. Ginebra, 2016. p.2-4.

10 En el contexto colombiano adquiere especial virtualidad el Auto 92 del año 20o8, de fecha 14 de abril de dos mil ocho 2008, Ponente: Ilmo, Sr. Manuel José Cepeda Espinosa, en que se tutelaron los derechos de algunas mujeres víctimas de desplazamiento forzoso en Colombia, fallando que Colombia debía acatar las normas internacionalmente ratificadas y ordenó la creación de hasta 13 programas para evitar la repetición de situaciones como la juzgada.

11 OIT. Información actualizada sobre la Alianza 8.7 de la Agenda 2030 para el Desarrollo Sostenible. Ginebra, 2019. 
Internacional de Derechos Civiles y Políticos, de 1966, dispone en su artículo 8.1 y 8.2 que "[n]adie estará sometido a esclavitud", que "la esclavitud y la trata de esclavos estarán prohibidas en todas sus formas", y que "[n]adie estará sometido a servidumbre".

En los ámbitos regionales europeos e interamericano la proscripción del trabajo forzoso se encuentra tanto en el Convenio Europeo de Derechos $\mathrm{Hu}-$ manos, artículo 4, como en la Convención americana de derechos humanos, artículo 6.

En el texto Constitucional español no se encuentran más referencia al trabajo o servicio forzoso que la prevista en el artículo 25 párrafo 2 de la Constitución que establece la proscripción del mismo en el ámbito penitenciario ${ }^{12}$. De manera implícita el artículo 35 de la Constitución ${ }^{13}$ se refiere a esta materia cuando establece: «Todos los españoles tienen el deber de trabajar y el derecho al trabajo, a la libre elección de profesión u oficio, a la promoción a través del trabajo y a una remuneración suficiente para satisfacer sus necesidades y las de su familia, sin que en ningún caso pueda hacerse discriminación por razón de sexo. La ley regulará un estatuto de los trabajadores».

Por su parte, la Constitución Colombiana proscribe en su artículo 17: "Se prohíbe la esclavitud, la servidumbre y la trata de personas en todas sus formas”.

En el ámbito de la OIT, la prohibición del trabajo forzoso es uno de los Principios y Derechos Fundamentales que se recogen en la Declaración de la OIT de 1998 relativa a los principios y derechos fundamentales en el trabajo ${ }^{14}$. Ello significa que todos los Estados, miembros de la citada organización internacional, deben promover y hacer cumplir la erradicación del trabajo forzoso independientemente de si han ratificado o no los Convenios $\mathrm{n}^{0} 29 \mathrm{y} \mathrm{n}^{0} 105$.

\subsubsection{Convenio sobre el trabajo forzoso, 1930}

Uno de los mayores reconocimientos que debe otorgarse al Convenio $\mathrm{n}^{0}$

12 Canosa Usera, R., "La prohibición de la esclavitud y del trabajo forzado: un ejemplo de integración entre Tratados Internacionales” en García Roca, J. Santolaya, P. (coords.) La Europa de los Derechos. Centro de Estudios Políticos y Constitucionales, Madrid, 2005. p. 134.

13 López Rubia, M.E.. "Prohibición de la esclavitud y del trabajo forzoso" en Ordeñana Gezuraga, Ixusko (dir.). La carta de los derechos fundamentales de la Unión Europea y su reflejo en el ordenamiento jurídico español. Thomson Reuters, Cizur Menor. 2014.p.113.

14 Declaración de la OIT relativa a los principios y derechos fundamentales en el trabajo, de 1998. 
29 de 1930 es que proporciona una definición de trabajo forzoso ${ }^{15}$. Según el Convenio 29 de la OIT relativo al trabajo forzoso u obligatorio, artículo segundo párrafo 1, es: "A los efectos del presente Convenio, la expresión 'trabajo forzoso u obligatorio' designa todo trabajo o servicio exigido a un individuo bajo la amenaza de una pena cualquiera y para el cual dicho individuo no se ofrece voluntariamente".

El Tribunal Europeo de Derechos Humanos, en el asunto Van der Mussele contra Bélgica ${ }^{16}$, al constatar que el artículo 4 párrafo 2 del Convenio Europeo de Derechos Humanos pese a prohibir el trabajo forzoso ${ }^{17}$, no proporciona una definición del concepto de trabajo forzoso. Además, subrayó que el Convenio $\mathrm{n}^{0} 29$ es un instrumento vivo y por lo tanto debe ser interpretado de manera dinámica, a la luz de las prácticas predominantes en los Estados democráticos. Con posterioridad, en el asunto Siliadin contra Francia ${ }^{18}$, el Tribunal ratificó lo ya expuesto en Van der Mussele, esto es que el Convenio $\mathrm{n}^{\circ}$ 29 de la OIT constituye la referencia para la construcción de una definición el trabajo forzoso.

Para concluir, el propio Convenio establece excepciones a la definición

15 Ley Colombiana 23 de 1967, junio 14, por la cual se ratifican varios Convenios Internacionales del Trabajo, adoptados por la Conferencia Internacional del Trabajo en las Reuniones $14^{\mathrm{a}}$ (1930), 23 ${ }^{\mathrm{a}}$ (1937), 30 ${ }^{\mathrm{a}}$ (1947), 40 ${ }^{\mathrm{a}}$ (1957) y $45^{\mathrm{a}}(1961)$.

16 Sentencia Tribunal Europeo de Derechos Humanos, Van der Mussele c. Bélgica, de fecha de 23 de noviembre de 1983. Demanda $n^{\circ}$ 8919/80.Párrafo 32: “There is in fact a striking similarity, which is not accidental, between paragraph 3 of Article 4 (art. 4-3) of the European Convention and paragraph 2 of Article 2 of Convention No. 29. Paragraph 1 of the last-mentioned Article provides that "for the purposes" of the latter Convention, the term "forced or compulsory labour" shall mean "all work or service which is exacted from any person under the menace of any penalty and for which the said person has not offered himself voluntarily". This definition can provide a starting-point for interpretation of Article 4 (art. 4) of the European Convention."

17 Sentencias Tribunal Europeo de Derechos Humanos, caso, Stummer vs Austria, de fecha 7 de julio de 2011. Demanda n ${ }^{0}$ 37452/o2 . Párrafo 117.

18 Sentencia Tribunal Europeo de Derechos Humanos Siliadin vs Francia, de fecha 26 de Julio de 2005, Demanda $\mathrm{n}^{0}$ 73316/01.Párrafo 116: "[T] here is in fact a striking similarity, which is not accidental, between paragraph 3 of Article 4 of the European Convention and paragraph 2 of Article 2 of Convention No. 29. Paragraph 1 of the last-mentioned Article provides that "for the purposes" of the latter convention, the term "forced or compulsory labour" shall mean "all work or service which is exacted from any person under the menace of any penalty and for which the said person has not offered himself voluntarily". 
de trabajo. Así, no será trabajo forzoso ${ }^{19}$ el Servicio militar obligatorio; las Obligaciones cívicas normales; el Trabajo penitenciario (respetando ciertas condiciones $)^{20}$; el Trabajo realizado en casos de fuerza mayor, es decir, guerra, siniestros o amenaza de siniestros (como incendios, inundaciones, hambre y temblores) y los Pequeños trabajos comunales (dentro de una comunidad).

\subsubsection{Convenio sobre la abolición del trabajo forzoso, 1957}

El Convenio $\mathrm{n}^{0} 105$ establece que: “Todo Miembro de la Organización Internacional del Trabajo que ratifique el presente Convenio se obliga a suprimir y a no hacer uso de ninguna forma de trabajo forzoso u obligatorio: a) como medio de coerción o de educación política o, como castigo por tener o expresar determinadas opiniones políticas o, por manifestar oposición ideológica al orden político, social o económico establecido; b) como método de movilización y utilización de la mano de obra con fines de fomento económico; c) como medida de disciplina en el trabajo; d) como castigo por haber participado en huelgas; e) como medida de discriminación racial, social, nacional o religiosa".

\subsubsection{Protocolo de 2014 relativo al Convenio sobre el trabajo forzoso}

El propio Protocolo reconoce que su adopción obedece a la detección de lagunas en la aplicación de los Convenios de 1930 y 1957, surgidas del trans-

19 Artículo 2, párrafo 2.

20 Sentencia del Tribunal Constitucional de fecha 20 de mayo de 2002, STC 116/92, que versa: «Aunque en la demanda no se desarrolle, debe entenderse que la primera de las alegaciones parte de la comprensión de que no puede constituir infracción la negativa a realizar un trabajo que se considera «forzado», porque tal tipificación sería contraria a la Constitución, lo que permite subsumir esta denuncia en la vulneración del art. 25.2 CE. Pues bien, esta alegación no tiene tampoco fundamento; se afirma en la demanda que del art. 25.2 CE se deduce que el trabajo en prisión es un derecho del interno, no una obligación, y que lo contrario será tanto como admitir los trabajos forzados, prohibidos por el precepto constitucional. Frente a ello cabe decir que lo que la Administración penitenciaria exigió al recurrente fue, sencillamente, la limpieza que por turno le correspondía de parte de las zonas comunes de su módulo, prestación contemplada en el art. 29 de la Ley Orgánica general penitenciaria. Parece obvio insistir en que la prestación solicitada al recurrente de realizar la limpieza de parte de las zonas comunes de su módulo que por turno le correspondía no puede ser considerada, a los efectos del art. 25.2 CE, como un «trabajo forzoso». La negativa a su cumplimiento fue lo que fundamentó la sanción impuesta». 
curso del tiempo y cambios socioeconómicos, así como de la urgencia de eliminar la lacra que significa la existencia de trabajo forzoso en cualquiera de sus manifestaciones ${ }^{21}$.

Se trata de un instrumento jurídicamente vinculante que insta a que los Estados adopten medidas relativas a la prevención, protección y de reparación para hacer efectiva la obligación de suprimir el trabajo forzoso establecida por el Convenio núm. 29. De este modo, el Protocolo ofrece una respuesta integral y actualizada para abordar todas las manifestaciones del trabajo forzoso ${ }^{22}$.

\subsubsection{Otros Convenios}

No se puede concluir sin hacer referencia a otros Convenios de la OIT que complementan la lucha contra el trabajo forzoso. En ese sentido, son destacables el Convenio sobre las peores formas de trabajo infantil, 1999 ( $\left.{ }^{\circ} 182\right)$, el Convenio sobre los/as trabajadores/as migrantes (revisado) 1949 (núm. 97), el Convenio sobre las personas trabajadoras migrantes (disposiciones complementarias), 1975 (núm. 143), el Convenio sobre las agencias de empleo privadas, 1997 (núm. 181), o el Convenio sobre las trabajadoras y los trabajadores domésticos, 2011 (núm. 189), entre otros.

En relación con las peores formas de trabajo infantil es preciso hacer dos indicaciones. La primera es que no toda forma de trabajo infantil es una peor forma de trabajo infantil ${ }^{23}$. En ese sentido, el artículo 44 de la Constitución Política de Colombia consagra, entre otros derechos fundamentales de los niños/as, los derechos a la vida, la integridad física, la salud y la seguridad social; los menores serán protegidos contra explotación laboral o económica y contra trabajos riesgosos, y menciona igualmente que los derechos de los niños/as prevalecen sobre los derechos de los demás. Por su parte, el artículo 53 sobre principios mínimos fundamentales, instaura la protección al trabajador menor de edad.

21 Comoyasehaindicadoennotaapiedepágina,elProtocolohasidoratificadoporEspaña, Instrumento de ratificación. «BOE» núm. 309, de 21 de diciembre de 2017. No ha sido así en el caso colombiano.

22 El artículo 1 párrafo 2 insta a la adopción de una Política y un Plan de acción nacionales a fin de: "lograr la supresión efectiva y sostenida del trabajo forzoso u obligatorio que prevea la adopción de medidas sistemáticas por parte de las autoridades competentes”.

23 El Artículo 3 del Convenio de la OIT sobre la prohibición de las peores formas de trabajo infantil y la acción inmediata para su eliminación, 1999 (núm. 182), define las peores formas de trabajo de menores. 
La Ley 1098 del 8 de noviembre de 2006 por la cual se expide el Código de la Infancia y la Adolescencia, estableció en su artículo 37 como libertad fundamental de los/as niños/as y adolescentes, la de escoger profesión u oficio y estableció una jornada especial para los menores de edad, así: los mayores de 15 años y menores de 17 pueden trabajar en jornadas diurnas máximo de 6 horas diarias y 30 a la semana y hasta las 6:00 p.m².

La segunda cuestión, el reclutar a un menor para las fuerzas armadas ha sido considerado como una forma de esclavitud por la Corte Interamericana de Derechos Humanos en el asunto Vargas Areco vs Paraguay de fecha 26 de Septiembre de 2006, basándose en una recomendación general sobre la erradicación del reclutamiento y la participación de niños/as en conflictos arma$\operatorname{dos}^{25}$. En dicha Recomendación la Comisión señala:" pese a que la mayoría de los países miembros de la Organización de Estados Americanos establece en su legislación un mínimo de 18 años para el reclutamiento militar obligatorio, subsisten en este aspecto prácticas violatorias de los derechos humanos de los niños/as que la Comisión considera pura y simplemente situaciones similares a la esclavitud y servidumbre forzada".

La ley 599 de 2000 del Código Penal Colombiano tipifica el delito de reclutamiento determinando en su artículo 162 que será reclutamiento ilícito ${ }^{26}$ : "El que, con ocasión y en desarrollo de conflicto armado, reclute menores de dieciocho (18) años o los obligue a participar directa o indirectamente en las hostilidades o en acciones armadas, incurrirá en prisión de seis (6) a diez (10) años y multa de seiscientos (600) a mil (1.00o) salarios mínimos legales mensuales vigentes".

\subsection{El trabajo forzoso como finalidad del delito de trata de se- res humanos}

En el ámbito de Naciones Unidas, se suscribió la Convención de Naciones Unidas contra la Delincuencia Organizada Transnacional que constituye el Instrumento central de una estrategia destinada a atacar aspectos estructurales de la delincuencia organizada trasnacional ${ }^{27}$. La Convención se com-

24 Artículo 114.

25 Corte Interamericana de Derechos humanos. Informe Anual, 1999. Capítulo 6: Recomendación sobre la erradicación del reclutamiento y la participación de niños en conflictos armados. 2000.

26 El ordenamiento jurídico español no contiene ninguna mención en ese sentido.

27 Naciones Unidas. Consejo Económico y Social. Comité Especial encargado de ela- 
plementa con el Protocolo de las Naciones Unidas para Prevenir, Reprimir y Sancionar la Trata de Personas, Especialmente Mujeres y Niños/as; Protocolo de las Naciones Unidas contra el Contrabando de Migrantes por Tierra, Mar y Aire y el Protocolo de las Naciones Unidas contra la fabricación y el tráfico ilícito de armas de fuego.

El artículo 3 del Protocolo de Palermo para prevenir, reprimir y sancionar la trata de personas, especialmente mujeres y niños $/ \mathrm{as}^{28}$, define el fenómeno que se está tratando estableciendo que ${ }^{29}$ : "Por "trata de personas" se entenderá la captación, el transporte, el traslado, la acogida o la recepción de personas, recurriendo a la amenaza o al uso de la fuerza u otras formas de coacción, al rapto, al fraude, al engaño, al abuso de poder o de una situación de vulnerabilidad o a la concesión o recepción de pagos o beneficios para obtener el consentimiento de una persona que tenga autoridad sobre otra, con fines de explotación.

Esa explotación incluirá, como mínimo, la explotación de la prostitución ajena $u$ otras formas de explotación sexual, los trabajos o servicios forzados, la esclavitud o las prácticas análogas a la esclavitud, la servidumbre o la extracción de órganos ${ }^{30 "}$.

borar una convención contra la delincuencia organizada transnacional. Examen del proyecto de convención contra la delincuencia organizada transnacional. Informe de la reunión preparatoria oficiosa del comité especial intergubernamental de composición abierta sobre la elaboración de una Convención internacional amplia contra la delincuencia organizada transnacional. Celebrada en BUENOS AIRES del 31 de Agosto al 4 de Septiembre de 1998. Documento A/AC.254/3. Párrafo 14.

28 Publicado en Diario Oficial de la Unión Europea $n^{0} 262$ de fecha 22 de Septiembre de 2006 y Boletín Oficial del Estado de fecha 11 de Diciembre de 2003. En el ordenamiento jurídico colombiano, por Ley 800 de 2003: "Por medio de la cual se aprueban la "Convención de las Naciones Unidas contra la Delincuencia Organizada Transnacional" y el "Protocolo para Prevenir, Reprimir y sancionar la Trata de Personas, especialmente Mujeres y Niños, que complementa la Convención de las Naciones Unidas contra la Delincuencia Organizada Transnacional", adoptados por la Asamblea General de las Naciones Unidas el quince (15) de noviembre de dos mil (200o)". La Ley 985 de 2005 (agosto 26) Diario Oficial No. 46.015 de 29 de agosto de 2005, por medio de la cual se adoptan medidas contra la trata de personas y normas para la atención y protección de las víctimas de la misma y el Decreto 1069 de 201412 de Junio de 2014 que reglamenta parcialmente la Ley 985 de 2005 .

29 Es un criterio unánime el afirmar que el concepto normativo de trata se gesta en este concepto internacional.

30 Párrafo 281. La trata de seres humanos, tal y como se define en el Protocolo de 
Es destacable que este Protocolo ha logrado consensuar las finalidades del delito de trata de seres humanos ${ }^{31}$.

\section{Aproximación al trabajo infantil \\ 3.1. El trabajo infantil como problema psicosocial y sociopolíti-} co

Dentro de los convenios indicados con anterioridad, se prevén distintas obligaciones que se han ido implementando a fin de erradicar el trabajo forzoso en cualquiera de sus formatos y tipologías. En la línea de la acción preventiva y social, una de las grandes apuestas de Colombia (y otras entidades internacionales) viene siendo la erradicación del trabajo infantil a través de fórmulas de formación, en particular, desde una base común y temprana, como es la infancia y la adolescencia. En este sentido, cabe destacar que el trabajo infantil y el trabajo forzoso están relacionados, ya que la mitad de las personas trabajadoras son niños/as, siendo el trabajo forzoso, además, una de las peores formas de trabajo infantil ${ }^{32}$. Desde este eje, una de las for-

las Naciones Unidas contra la Trata y en el Convenio del Consejo de Europa sobre lucha contra la trata de seres humanos, se halla prohibida en el artículo 4 del Convenio Europeo para la protección de los Derechos Humanos y de las Libertades fundamentales, sin que sea necesario que sea calificada como esclavitud, servidumbre o trabajo forzoso " $L$ a trata de seres humanos, por su propia naturaleza y finalidad de explotación, se basa en el ejercicio de los poderes atribuidos al derecho de propiedad. Trata a los seres humanos como mercancías que se compran y se venden y son sometidos a trabajos forzosos, a menudo por escaso o ningún pago, por lo general en la industria del sexo, pero también en otras. Esto implica una estrecha vigilancia de las actividades de las víctimas, cuyos movimientos se limitan a menudo. Conlleva el uso de la violencia y las amenazas contra las víctimas, que viven y trabajan en condiciones míseras”.

31 En el contexto de la Unión Europea merece destacarse el papel de la Directiva 2011/36/UE que sigue la estela del Protocolo de Palermo. Si bien, que con un enfoque más victimocéntrico que el Protocolo. En el contexto colombiano, uno de los principales avances regionales está representado por la Declaración de Ministros de Trabajo contra la Trata de Personas y el Trabajo Forzoso, firmada en Brasilia en el año 2015 en el marco de la reunión de Ministros de Trabajo del MERCOSUR. En el ámbito de las relaciones bilaterales, se encuentra en vigencia un acuerdo con Colombia con el objetivo de fortalecer las acciones de coordinación y cooperación conjunta, para la prevención e investigación del delito de Trata de Personas, y la asistencia y protección de las víctimas del mismo.

32 Desde la Confederación Sindical Internacional (2008), también se distingue la diferencia entre el trabajo forzoso en menores del trabajo meramente infantil: "Un niño que 
mas preventivas con mayor eficacia para la erradicación del trabajo infantil arranca de la intervención y formación desde tempranas edades. Siguiendo esta línea, este capítulo también tiene como objetivo clave una evaluación de programas aplicados en Colombia.

\subsection{Método y claves de la meta-evaluación de programas}

Como en otros trabajos previos de las autoras, la evaluación de programas también se ha realizado en este caso a través de un proceso de meta-evaluación. Este acercamiento consiste (entre las distintas funciones y acepciones de la meta-evaluación tratadas posteriormente) en un proceso de evaluación de informes que otros/as evaluadores/as han realizado. La finalidad es ofrecer una aproximación a un tipo de evaluación y a una de las fases básicas de cualquier evaluación como es "la consulta y la evaluación sistemática lo que ya otros han evaluado”. Además, esta meta-evaluación concreta puede servir como botón de muestra para conocer la situación de trabajo forzoso infantil en Colombia desde la existencia de evaluación de programas para reducir la esclavitud infantil y como referente para la inclusión psicosocial. El proceso utilizado parte de la búsqueda de documentos e informes publicados (que no son muy numerosos, de ahí la dificultad metodológica) con rigor científico. De esta manera, la meta-evaluación ha permitido ir un paso más allá de la investigación existente (documentación y datos algo más accesibles), a la evaluación de programas (menor accesibilidad, que no significa ausencia como ha sido el caso), foco de este estudio, que pretenden aminorar el problema de trabajo infantil en Colombia. El objeto de las meta-evaluaciones suele ser información de distinto tipo (datos, discursos), interpretaciones, recomendaciones y todo ello suele reflejarse en los informes de evaluación, sea en formato más breve

trabaja no es necesariamente un trabajador forzoso. Mientras el niño trabaje por voluntad propia, sin coacción ni amenaza de pena, los daños producidos corresponderán exclusivamente al trabajo infantil, no al trabajo forzoso. Dejando de lado algunas dificultades prácticas a la hora de determinar cómo puede un niño acceder a trabajar voluntariamente en sectores de naturaleza peligrosa o nociva (como el de la explotación sexual comercial, por ejemplo) y centrándonos en aquellas situaciones en las que no cabe duda de que los/as niños/as son trabajadores/as forzosos, se hace patente que los/as niños/as son el colectivo más vulnerable en relación con el trabajo forzoso." Por su parte, Save the Children expone que los trabajos forzosos infantiles son: "Trabajos que son mental, física y moralmente peligrosos para su bienestar y que les impiden, además, disfrutar de su derecho a ir a la escuela.". 
(resumen en artículos académicos publicados) o en formato extenso (informes completos publicados o no), como ha sido el caso de este estudio.

Siguiendo a Agulló y Topa ${ }^{33}$ y Agulló $^{34}$, las ventajas y limitaciones de la Meta-evaluación son varias y, al igual que el meta-análisis, puede aplicarse y se aplica como técnica en la meta-evaluación de programas sociales, por ejemplo. La meta-evaluación es un enfoque más general (no solo una técnica) que se sigue y aplica en diversas áreas: evaluación, psicología social y organizacional, sociología, ciencias políticas, gestión, entre otras. También es llamada "Evaluación secundaria" o "Auditoria de evaluación”, aunque el término "meta-evaluación", introducido por Scriven, es el más comúnmente utilizado. Este autor fue pionero y defensor de este enfoque inaugurando un nuevo lenguaje y términos como "meta-evaluation", "evaluación libre de objetivos", "evaluación formativa y sumativa", entre otros ${ }^{35}$. Scriven afirma que el personal evaluador tiene la obligación profesional de que todas las evaluaciones propuestas o finalizadas se evalúen de forma competente y rigurosa. Para ello recomienda su "Key Evaluation Checklist" de 18 puntos ${ }^{36}$ que aquí no se dispone de espacio para describir. Además, Scriven enfatiza algunas soluciones a nivel socio-organizacional como la meta-evaluation o la evaluación libre de objetivos ${ }^{37}$.

Stufflebeam fue también pionero de la "Meta-evaluation", apoyando la

33 Agulló, M.S. y Topa, G. “Técnicas de investigación en Psicología Social y de las Organizaciones: El meta-análisis y el grupo de discusión”, en Palací, F.J. (coord.), Psicología de la Organización. Madrid: Pearson-Prentice Hall (pp. 55-72), 2005. ISBN: 978-84-2054340-6.

34 Agulló, M.S., "Evaluando programas desde un enfoque psicosociológico", Encuentros en Psicología Social, Vol. 1, No. 3, 2003, pp. 159-164.

35 Shadish, W. R., Ragsdale, K., Glaser, R. R., \& Montgomery, L. M. (1995). The efficacy and effectiveness of marital and family therapy: A perspective from meta-analysis. Journal of marital and Family Therapy, Vol. 21, No. 4, 1995, pp. 345-360.

Stufflebeam, D.L. y Shinkfield, A.J. Evaluación sistemática. Guía teórica y práctica. Madrid: Paidós y MEC, 1987.

36 Scriven, M. An introduction to metaevaluation. Educational products report, Vol. 2, No. 5,1968 , pp. 36-38.

Scriven, M. The evaluation of college teaching. National Dissemination Center, Syracuse University School of Education, 1980.

37 Véase también Shadish, W.R., Cook, T.D. \& Leviton, L.C., Foundations of program evaluation: Theories of practice. Sage, 1991, pp. 81-83;

Stufflebeam, D.L. y Shinkfield, A.J. Evaluación sistemática. Guía teórica y práctica. Madrid: Paidós y MEC, 1987, pp. 348-351. 
consideración de este enfoque para asegurar y probar la calidad de las evaluaciones ${ }^{38}$. Entre las meta-evaluaciones realizadas, Lipsey y Wilson ${ }^{39}$ destacan por realizar 300 meta-análisis de programas basados en comportamiento psicológico e intervenciones educativas. La mayor parte de meta-evaluación ha sido aplicada en áreas como terapia familiar ${ }^{40}$, prevención de salud mental $^{41}$ y educación ${ }^{42}$, entre otros/as.

Otra definición expone que "la meta-evaluación implica una revisión de la evidencia existente sobre la efectividad de un programa social desde evaluaciones previas" 43 . Patton desarrolla e incluye el rol de "sintetizador, metaevaluador y cluster leader" en los roles básicos de evaluación cuando el objetivo es sintetizar resultados desde múltiples evaluaciones y juzgar la calidad de las mismas ${ }^{44}$. También lo resumen así, de manera similar, Stufflebeam y Shinkfield ${ }^{45}$ y, Díaz y Rosales ${ }^{46}$.

38 Stufflebeam, D.L. Metaevaluation. Kalamazoo: Western Michigan University, The Evaluation Center. 1974.

39 Lipsey, M. W., \& Wilson, D. B., The efficacy of psychological, educational, and behavioral treatment: Confirmation from meta-analysis. American psychologist, 1993, Vol. $48, \mathrm{~N}^{\mathrm{o}} .12, \mathrm{p} .274$.

40 Shadish, W. R., Ragsdale, K., Glaser, R. R., \& Montgomery, L. M. (1995). The efficacy and effectiveness of marital and family therapy: A perspective from meta-analysis. Journal of marital and Family Therapy, Vol. 21, No. 4, 1995, pp. 345-360.

41 Durlak, J.A., Wells, A.M., Evaluation of indicated preventive intervention (secondary prevention) mental health programs for children and adolescents. American journal of community psychology, 1998, Vol. 26, No. 5, pp. 775-802.

42 Borman, G. D., \& D’Agostino, J. V. Title I and student achievement: A meta-analysis of federal evaluation results. Educational Evaluation and Policy Analysis, 1996, Vol. 18, $N^{o}$. 4, pp. 309-326.

Masachs, R. C., Maroto, J. L. S. F., \& Berciano, S. G., "Evaluación de programas educativos en museos: Una nueva perspectiva.” Bordón. Revista de pedagogía, 2017, Vol. 69, No. 1, pp. 45-65.

Pérez-González, J. C., "Propuesta para la evaluación de programas de educación socioemocional." Electronic Journal of Research in Education Psychology, 2017, Vol. 6, №. 15, pp. 523-546.

43 Freeman, H.E., Rossi, P.H. \& Lipsey, M. Lipsey. Evaluation: A systematic approach. Sage Publications, 1993, p. 253.

44 Patton, M. Utilization-Focused Evaluation. London: Sage, 1996, pp.126-129.

45 Stufflebeam, D.L. y Shinkfield, A.J. Evaluación sistemática. Guía teórica y práctica. Madrid: Paidós y MEC, 1987, pp. 52-53.

46 Díaz Jiménez, L., \& Rosales, R. Metaevaluación: evaluación de la evaluación de políticas, programas y proyectos sociales. Agora. 2003. 
En muchas ocasiones se considera la meta-evaluación como un tipo concreto de evaluación que valora la calidad de la labor que realizan los/as profesionales o entidades más vinculadas a la evaluación. El objetivo suele ser el mejorar y perfeccionar los trabajos de evaluación realizados, y promoción de una mayor difusión y comprensión de los mismos. Lo que parece claro es que hay distintas perspectivas y la meta-evaluación puede ser de diferentes tipos (sumativa, formativa, de impacto, eficacia, etc.). Por ejemplo: 1) la meta-evaluación como primera fase de revisión que todo estudio evaluativo debe realizar; 2) evaluación de otra evaluación; 3) Análisis y/o resumen de resultados de varias evaluaciones, critica de informes evaluativos. Por ejemplo, la revisión de evaluaciones en un periodo constituye un elemento básico. Dentro de este formato, Wholey et al. evaluó 15 programas de 4 agencias norteamericanas entre 1968-1969. Evaluó tanto la organización de programas, como la calidad de las evaluaciones, informes finales y problemas de comunicación y posterior uso de resultados); 4) Algunas veces se trata de repetir un estudio acabado, re-analizando los datos y; 5) Revisiones externas de evaluaciones internas, principalmente ${ }^{47}$.

En general, los tipos de evaluación pueden ser, según el contenido: análisis de informe/s final/es (de resultados), revisión de procesos técnicos o metodológicos seguidos (de procesos), aspectos organizacionales o previos (de diseño), utilización de la evaluación (de impacto). A su vez, puede utilizarse la evaluación de otra evaluación como parte del proceso, tal y como planteó Wholey. Aún existe un debate acerca de la meta-evaluación como tipo de evaluación o simplemente como primera fase de revisión. Los/as autores se decantan por la opción de la "meta-evaluación" como tipo de evaluación en sí misma, pues no se trata de hacer una revisión (la típica en las primeras fases de evaluación; esta es obvio que debe hacerse) sino de evaluar las evaluaciones de manera sistemática, siguiendo unos criterios y técnicas específicas con el fin de obtener información contrastable y novedosa. Por ejemplo, Agulló ${ }^{48}$ y Agulló et al. ${ }^{49}$ en sus trabajos de evaluación, detectaron la escasez de

47 Wholey, J. S., Nay, J. N., Scanlon, J. W., \& Schmidt, R. E. (1975). Evaluation: When is it really needed. Evaluation, 1975, Vol. 2, No. 2, pp. 89-93.

48 Agulló, M.S. Metaevaluation of support programmes for informal carers of elderly people. University of North London (dissertation-tesina de Master en "Evaluation and Social Research"). 2001-2002

49 Agulló, M.S., Zorrilla, V. y Gómez, V. "Investigación y Evaluación sobre género/ feminismo y envejecimiento/vejez”, editorial del monográfico, coordinación, publicación de 2 artículos y de una nota de investigación en el número 21 de la Revista Prisma Social 
evaluaciones sobre programas relacionados con el apoyo a cuidadores/as de personas mayores y, confirmaron que no había ninguna meta-evaluación al respecto. Es decir, comprobaron que no existía ninguna "evaluación de evaluaciones" de programas de apoyo informal a cuidadores en España, aunque sí las hay en otras áreas y en países anglosajones. Pauta similar (en cuanto a escasez de meta-evaluaciones y evaluaciones) ocurre en relación a los programas frente al trabajo forzoso y esclavitud en Colombia, que centran la atención de este capítulo.

A pesar de las dificultades de acceso a los informes completos, se pudo realizar la meta-evaluación y los resultados se han obtenido desde documentos clave en relación al Programa "Edúcame Primero, Colombia". Se trata de un programa-proyecto de intervención socio-educativa para la prevención del trabajo infantil llevado a cabo, inicialmente, por un consorcio liderado por Partners of Americas y apoyado por el Departamento de Trabajo de los Estados Unidos (USDOL) y la Oficina de Trabajo Infantil, Trabajo Forzoso y Trata de Seres Humanos (OCFD). El análisis parte de dos informes centrales: por un lado, el informe de evaluación de resultados del propio Acuerdo Cooperativo número IL-16574-07-75-K $\mathrm{K}^{50}$ y por otro, de los resultados del "Proyecto de cooperación internacional entre la Universidad de Sevilla y la Universidad del Norte" ${ }^{51}$.

Los criterios seguidos para esta meta-evaluación se han adaptado de trabajos previos (véase bibliografía de las autoras). Se han aplicado análisis de aspectos positivos y criterios evaluativos sobre los siguientes puntos:

1) Objeto y objetivos de la evaluación: planteados, consecución o no, claridad, planificados, realistas, etc.

"Envejecimiento y Género. Investigación y Evaluación de Programas", $2^{0}$ trimestre, Junio 2018. ISSN: 1989-3469. http://revistaprismasocial.es/issue/view/146

50 Hasbún, J. Evaluación final independiente del proyecto Erradicación del trabajo infantil a través de la educación en Colombia: Edúcame Primero Colombia. 2010. Consultado el 19 de Septiembre de 2019. https://www.dol.gov/sites/dolgov/files/ILAB/evaluation_type/final_evaluation/Colombia_TBP_feval_SPAN_o.pdf

51 Maya-Jariego, I. y Palacio, J.E., Educáme Primero Colombia. Proyecto de cooperación internacional entre la Universidad de Sevilla y la Universidad del Norte. 2012. Consultado el 19 de Septiembre: http://personal.us.es/isidromj/php/wp-content/ uploads/2012/10/Catálogo_barranquilla.pdf

Holgado, D., Santolaya, F., Maya-Jariego, I., Cueto, R. M., \& Anaya, R. H., Preparación comunitaria y organizativa contra el trabajo infantil en tres colegios de barrios periféricos de Lima (Perú). Apuntes de Psicología, 2015, Vol. 33, №. 3, pp. 103-116. 
2) Diseño de evaluación: tipo de evaluación aplicada, criterios, tiempo (duración o cronograma), desde cuándo se aplica, recursos, etc.

3) Método: técnicas, instrumentos, muestra, etc.

4) Agentes implicados en la evaluación: partes involucradas que participan o no, quienes evalúan, colaboradores y facilitadores/as, financiadores, organizadores, etc..

5) Resultados: formato y presentación adecuada, claridad, partes, por ejemplo.

6) Contraste con otras evaluaciones: referencias bibliográficas, webs, etc.

7) Recomendaciones (dos tipos: las que ofrece el informe y por parte de las autoras): si son concretas, claras, jerarquizadas, por ejemplo.

8) Otros aspectos a considerar: posible financiación, transparencia en el presupuesto y otros puntos del programa.

\subsection{Resultados de la meta-evaluación del Programa "Edúcame Primero, Colombia"}

El Programa, entre otras "etiquetas" que podrían definirlo, y desde una meta-evaluación positiva con la que podremos concluir, ha tenido una evaluación participativa, contextual, interna y externa, de resultados, de cobertura, eficacia, sumativa y pluralista. Sin embargo, no se percibe que se haya realizado una evaluación, de diseño, de impacto o de eficiencia, pero se presume que así ha sido a juzgar por la alta calidad de los resultados y su vigencia actual. De acuerdo con Seibel ${ }^{2}$ y Holgado et al..$^{53}$, esta evaluación sirve como ejemplo validado de implementación de programas basado en la evidencia, esto es, que ha demostrado ser eficaz y efectivo en diversos contextos; ha sido monitorizado y evaluado en sucesivas aplicaciones mostrando su capacidad de ajuste a diferentes ámbitos de aplicación, y cuenta con un respaldo suficiente por partes de organizaciones para su implementación. Además, consideramos que se enmarca claramente en la intervención psicoeducativa y social; en este sentido, afecta al desarrollo futuro e impacto psicosocial y, dentro de la línea de este capítulo, contribuye a la disminución y erradicación del trabajo forzoso y esclavitud moderna.

52 Seibel, N.L., Using Evidence-Based Programs to Support Children and Families Experiencing Homelessness. Needham, MA: Conrad N. Hilton Foundation. 2011.

53 Holgado, D., Santolaya, F., Maya-Jariego, I., Cueto, R. M., \& Anaya, R. H., Preparación comunitaria y organizativa contra el trabajo infantil en tres colegios de barrios periféricos de Lima (Perú). Apuntes de Psicología, 2015, Vol. 33, No. 3, pp. 103-116 
Entre los objetivos que se muestran específicos, medibles, planificados y claros, destacan los siguientes: conocer y entender la problemática del trabajo infantil e, incrementar la sensibilización de todos los agentes educadores y formadores, como son padres y familias, maestros/as y, líderes y actores clave de la comunidad que forman parte de los "Espacios para Crecer" (en adelante EpC) y "Espacios para Emprender" (EpE).

El método aplicado en la primera evaluación fue de tipo cualitativa, basada en la triangulación de informantes y de los métodos de recolección de datos. Se aplicaron sesiones focales grupales, entrevistas grupales, entrevistas individuales, así como entrevistas a personal de diversos EpC (en total ocho) y EpE (en total 3). En total, se implicaron un total de 250 personas. En una segunda evaluación, se ha encontrado que el programa fue aplicado a tres de los grandes municipios de la Costa de Colombia, que son Cartagena, Barranquilla, and Santa Marta. Entre los 172 espacios (EpC y EpE) utilizados, se llevaron a cabo entrevistas y diversos grupos de discusión con 8 de los facilitadores que participaron en la aplicación del programa, con 40 profesores/as de los centros educativos en los que se implementaron los espacios y con 38 familias cuyos hijos participaron en alguno de los espacios, durante los tres años de aplicación de los mismos (2008-2010).

Por otra parte, se realizó un grupo de discusión en el que se trataron los temas abordados en las entrevistas individuales (no se concreta el número de participantes y, tampoco se puede saber si se refiere a grupo de discusión, entrevistas grupales u otra modalidad de técnica de investigación). Con las familias se realizaron entrevistas semiestructuradas a uno de sus miembros, en las que se les preguntaba por la experiencia de la participación del menor en el programa, la percepción del contexto comunitario, la relación y la implicación de la familia en la educación de los menores y la relación de los progenitores con los facilitadores y profesionales vinculados al programa. Por último, al profesorado se le aplicó una breve encuesta sobre sus percepciones del trabajo infantil desde el sistema educativo, el grado de conciencia que tiene acerca del problema, la metodología didáctica que utilizan con el alumnado y el conocimiento sobre el programa y su implementación en los centros educativos. Para la selección del entrevistado/a se basó en su papel como informante clave. Asimismo, a la hora de elegir a los facilitadores aplicaron el criterio de la Fundación Universidad Norte. Para las familias y profesorado se tuvo en cuenta el criterio de los facilitadores. En esta segunda evaluación, se realizó una metodología mixta. 
Los agentes financiadores durante el primer informe evaluado fueron los Partners of Americas, el USDOL y la OCFD. En el segundo informe evaluado, el proyecto parte de agentes de voluntariado, en particular, la Universidad de Sevilla y la Universidad del Norte. Es de destacar la participación en el programa con el apoyo de becas de Formación Solidaria, la financiación de proyectos y estancias de investigación de Cooperación al Desarrollo desde España, y la colaboración entre la Universidad del Norte y la Universidad de Sevilla, otros proyectos de voluntariado y cooperación enmarcados en esta línea, y programas de investigación pre- y post-doctoral. Este pluralismo en la participación ha ido asentando las bases para el éxito y la continuidad del programa.

Otro de los puntos clave en la meta-evaluación ha sido conocer el origen, recorrido y evolución del programa. Cabe subrayar que el programa partió de la necesidad constatada desde distintos organismos internacionales para luchar contra el trabajo infantil. La recopilación de experiencias previas permitió detectar una veintena de "buenas prácticas" que, posteriormente, fueron adaptadas y aplicadas en distintos países, entre ellos Colombia. El apoyo institucional en este país desde 2008 se tradujo en una amplia cobertura en su implementación (ha alcanzado a más de 20.000 niños/as), redujo la prevalencia del trabajo infantil y aumentó la sensibilización e implicación de distintos agentes sociales en las zonas de intervención contra el trabajo infantil (evaluación de Hasbún ${ }^{54}$ ).

Previa a la implementación del programa "Edúcame Primero, Colombia", existen iniciativas en Centroamerica, en particular, el programa "Primero Aprendo" (2004-2008) impulsado por el Departamento de Trabajo de los Estados Unidos. Este programa incluía en su implementación actividades de colaboración con gobiernos locales, organizaciones no gubernamentales y familias. De este programa se pudieron recabar 14 prácticas educativas con resultados positivos en lo que respecta a la intervención de trabajo infantil. Los resultados de este programa fueron relevantes para las iniciativas que se llevaron a cabo en República Dominicana y en Colombia.

A su vez, los resultados de Colombia facilitaron la continuidad del programa en otras zonas (tanto de Colombia como en Perú y Honduras, p.e.) una

54 Hasbún, J. Evaluación final independiente del proyecto Erradicación del trabajo infantil a través de la educación en Colombia: Edúcame Primero Colombia. 2010. Consultado el 19 de Octubre de 2019. https://www.dol.gov/sites/dolgov/files/ILAB/evaluation_type/final_evaluation/Colombia_TBP_feval_SPAN_o.pdf 
vez finalizado el apoyo internacional al mismo (véase informes posteriores55).

En los resultados obtenidos relativos a la erradicación del trabajo forzoso en Colombia, cabe comentar los siguientes:

a. Las EpC y EpC son sistemas que impactan en la reducción del trabajo infantil y, por ende, en la del trabajo forzoso. En particular, porque demostraron la eficacia en la mejora del rendimiento académico y de conducta en alumnos/as. De esta forma, si bien no se pudo asegurar la reducción del trabajo infantil, sí que existe un acercamiento al interés de la escuela, disminuyendo así el riesgo de deserción y evasión de las clases, lo que, a su vez puede evitar el acercamiento al trabajo forzoso u obligado a partir de una conciencia de su propias emociones y apego al sistema educativo. En definitiva y como afirman Winrock International ${ }^{56}$ y Holgado et al. (2015, ibíd.), los centros escolares constituyen un espacio de prevención ${ }^{57}$. Algunos de los testimonios recuperados de familiares muestran los beneficios "milagrosos" y satisfacción sobre los resultados obtenidos a partir de las EpC y EpE:

"Yo tengo aquí a mi hijo. Antes, cuando yo tenía que venir a la escuela, yo pasaba mucha vergüenza porque mi hijo no se portaba bien y era una mal estudiante. Era famoso por las malas conductas. Era muy violento y vivía peleando. Por eso me daba vergüenza

55 Holgado, D., Santolaya, F., Maya-Jariego, I., Cueto, R. M., \& Anaya, R. H., Preparación comunitaria y organizativa contra el trabajo infantil en tres colegios de barrios periféricos de Lima (Perú). Apuntes de Psicología, 2015, Vol. 33, No. 3, pp. 103-116.

Holgado Ramos, D., Maya-Jariego, I., Ramos Vidal, I., \& Palacio Sañudo, J. (2014). El papel de los facilitadores en la implementación de los "Espacios para Crecer": evaluación formativa del programa con menores trabajadores "Edúcame Primero, Colombia". Universitas Psychologica, 2014, Vol. 13, No. 4, pp. 1441-1459, https://doi.org/10.11144/ Javeriana.UPSY13-4.pfie

Maya-Jariego, I. y Palacio, J.E., Educáme Primero Colombia. Proyecto de cooperación internacional entre la Universidad de Sevilla y la Universidad del Norte. 2012. Consultado el 19 de Octubre: http://personal.us.es/isidromj/php/wp-content/uploads/2012/10/ Catálogo_barranquilla.pdf

Maya-Jariego, I., y Holgado, D., From Barranquilla to Lima in reducing child labor: Lessons in community action. Global Journal of Community Psychology Practice, 2014, Vol. 5, No. 2, pp. 1-6.

56 Winrock International, Best Practices in Preventing and Eliminating Child Labor through Education. Arlintong, VA: Winrock International Empowerment and Civic Engagement Unit. 2008.

57 Bekele, A. \& Boyden, J. Combating Child Labour. Ginebra: International Labour Organization. 1998. 
venir a la escuela porque me señalaban como esa mala madre de fulano y yo me tapaba la cara para que no me reconocieran. Hoy mi hijo es otro, le va bien en la escuela, y se porta muy bien. Abandonó el mal comportamiento. Ya no tengo que esconderme cuando vengo a la escuela." (Madre, Barranquilla, Beneficiaria de EpC, Programa Edúcame Primero Colombia).

"Yo estoy sorprendida del cambio de mi hija. Se ve más segura, no discute conmigo como lo hacía antes. Es más cariñosa con sus hermanos y conmigo. Es un cambio enorme que le ha ocurrido. En su escuela le va muy bien, con calificaciones excelentes que yo nunca me imaginé que iba a poder ver eso en mi hija." (Madre, Cartagena, Beneficiaria de EpC, Programa Edúcame Primero Colombia).

"Yo tengo a mis dos hijas aquí. Una de ellas, casi no hablaba antes. Ahora habla mucho y bien. Les va bien en la escuela y les gusta mucho venir al EpC. Ellas ayudaban antes en los cultivos. Ya nosotros decidimos que sólo estudien para que después puedan tener un mejor futuro que el nuestro. La vida es muy dura aquí, pero nosotros estamos dispuestos a sacrificarnos por ellas.” (Padre, Samacá, Beneficiario de EpC, Programa Edúcame Primero Colombia).

b. El programa trabajó con beneficiarios/as procedentes de poblaciones desarraigadas y excluidas, entre ellos/as, indígenas y otras etnias. Estas personas han sido muy susceptibles a que sus hijos/as pudieran llegar a participar de una forma u otra en el colectivo armado y, por tanto, formar parte de trabajos forzosos relacionados con esta índole.

c. El programa trabajó también con beneficiarios/as retirados/as de explotación sexual comercial y, además, en zonas con presencia de altos niveles de violencia, tolerancia de trabajo sexual infantil, regiones de extrema pobreza y delincuencia.

Entre las recomendaciones principales del programa, procede mencionar las siguientes:

a. El programa sirvió como base para el planteamiento de acciones de seguimiento y escenarios de sensibilización. De esta forma, se pudo continuar con la implantación de otros programas como el Programa Vivo Jugando que implementaron todas las ONG subcontratadas por Mercy Corps.

b. El impacto que generó el programa verificó que se habían obtenido beneficiarios en dos índoles: por una parte, los propios menores, ya que son retirados de trabajos de explotación y forzoso o, son prevenidos de estos. Por otra parte, la actitud positiva de educadores/as y familiares de sus hijos/as hacia el estudio, lo que favorece que los/as menores puedan distanciarse de las formas de trabajo de explotación. En definitiva, aflora un sentimiento de posibilidad de que sus hijos/as pueden alcanzar una vida mejor. 
c. La necesidad de continuar investigando, de evaluar o meta-evaluar la aplicación de estos programas en Colombia, así como en otros países. También se observa una necesidad de indagar desde otras perspectivas, como puede ser la de género e intergeneracional y, a través de distintos niveles de participación ${ }^{58}$. La necesidad de perspectiva de género, e incluso feminista, en evaluaciones previas (véase bibliografía de las autoras) se ha constatado también en este caso.

Como prueba de la "actualidad" y futura aplicabilidad y las múltiples bondades del programa en Colombia, ha sido la posterior aplicación en Perú ${ }^{59}$ y la que se está desarrollando en la actualidad en Honduras ${ }^{60}$. Cabe destacar que para la transferencia del programa a Perú, se seleccionaron y adaptaron aquellos contenidos centrales del programa que demostraron efectividad en Colombia ${ }^{61}$ (Holgado et al, 2015: 105): 1) Creación de espacios seguros de aprendizaje para niños/as trabajadores/as o en riesgo de trabajar ("Espacios para crecer”). Se trata de talleres que pretendían amortiguar el impacto del trabajo infantil sobre el desarrollo social, emocional y académico del niño/a; y mejorar su experiencia en el contexto educativo. Se desarrollaron a través de sesiones independientes en un horario alternativo a la jornada escolar, en coordinación con el centro educativo y las familias. 2) La sensibilización del profesorado y de las familias sobre el impacto del trabajo en el desarrollo del niño/a así como la formación y asistencia técnica en estrategias de diagnóstico e intervención en esta problemática psicosocial y socio-política. 3) La

58 Zorrilla-Muñoz, V., García-Sedano, T. y Alvarado, C., El trabajo forzoso desde una perspectiva de género, intergeneracional e internacional. En IV Congreso Internacional de Jóvenes Investigadorxs con perspectiva de Género. 24-26 de Junio de 2019. Consultado el 19 de Octubre de 2019: http://portal.uc3m.es/portal/page/portal/inst_estudios_genero/archivo_eventos/Congreso_Jovenes_Investigadorxs_genero

59 Maya-Jariego, I., y Holgado, D., From Barranquilla to Lima in reducing child labor: Lessons in community action. Global Journal of Community Psychology Practice, 2014, Vol. 5, No. 2, pp. 1-6.

Márquez, E., Holgado, D., \& Maya-Jariego, I. (2019). Innovation, Dosage and Responsiveness in the Implementation of the Program "Edúcame Primero Perú" for Reducing Child Labour. Applied Research in Quality of Life, 2019, Vol. 14, No. 3, pp. 617-636.

60 La presentación del programa se puede ver en: https://evoluntas.wordpress. com/2019/o2/o6/educame-primero-en-honduras/

61 Holgado, D., Santolaya, F., Maya-Jariego, I., Cueto, R. M., \& Anaya, R. H., Preparación comunitaria y organizativa contra el trabajo infantil en tres colegios de barrios periféricos de Lima (Perú). Apuntes de Psicología, 2015, Vol. 33, №. 3, pp. 103-116. 
implementación de estrategias de mediación entre el contexto educativo y comunitarios y las agencias públicas, mediante (a) la implicación de familias y profesorado en la aplicación del programa,(b) la mejora de la preparación comunitaria, (c) la identificación de líderazgo comunitario y (d) de la creación de coaliciones entre los distintas agentes sociales, para la prevención.

En cuanto a la financiación del programa, llama la atención que en la meta-evaluación realizada no se ha encontrado el presupuesto, sin embargo se presupone que ha existido financiación, dada la continuidad y el éxito del programa. Tampoco se ha tenido acceso al cronograma e hitos clave relacionados con actividades de trabajo, estudio de viabilidad, resultados de efectividad o impacto posterior, entre otros aspectos (que quizás si están presentes en informes o anexos no publicados pero no se han detectado).

Entre las estrategias que deberían aplicarse a este tipo de programas, cabe destacar las siguientes por parte de los/as facilitadores/as: 1) Disponer de una permanencia de los niños/as mayor (en todo caso, superior a un año); 2) Dar una mayor libertad a los facilitadores a la hora de utilizar el material; 3) Rediseñar el material utilizado en función de los resultados del EpC y de la experiencia previa de implementación; 4) Permitir el asesoramiento y participación de otros profesionales en la implementación del programa; 5) Proponer estrategias sistematizadas y previas de difusión del programa y sus resultados; 6) Realizar un adecuado plan de evaluación del programa; y las recomendaciones o sugerencias por parte del equipo internacional de evaluadores: 1) Seguimiento de la implementación del programa; y 2) Recogida de datos objetivos sobre los resultados, como podría ser el abandono de las actividades laborales de los/as niños/as participantes.

En la línea mencionada sobre la necesidad de incorporar una clara perspectiva de género en la evaluación de programas analizados, procede enfatizar también el imperativo de incorporar un lenguaje no generizado e inclusivo, tanto en los documentos jurídicos referenciados (no han sido modificados a fin de respetar la literalidad de las normativas y convenios) como en los informes de evaluación. El lenguaje, aunque para algunas voces/autores es un aspecto secundario, también puede ser fundamental para mostrar y recordar la necesidad de igualdad intergénero a diferentes niveles: desde el lenguaje y discursos, hasta las prácticas y programas más aplicados. 


\section{Conclusiones}

La erradicación de las formas contemporáneas de esclavitud y entre ellas del trabajo forzoso requiere un abordaje multidisciplinar. Así, el derecho penal no parece una herramienta que unilateralmente pueda poner fin a este fenómeno. No obstante, parece preciso, tanto para Colombia como para España, ratificar convenios internacionales e implementarlos en sus respectivos ordenamientos. Se constata que el trabajo infantil continúa siendo un problema y reto psicosocial y sociopolítico por resolver. Además, es un ejemplo de exclusión psicosocial, de la falta de investigación y respeto por otras culturas y contextos, y de necesidad de priorizar la sostenibilidad de determinados entornos/países más desfavorecidos. El programa analizado (desde sus distintas versiones e informes meta-evaluados) constituye un referente frente al trabajo infantil, por la defensa de la educación de los menores como prioridad indudable. En este sentido, destaca la necesidad de continuar potenciando la implentación, evaluación y/o meta-evaluación de programas de este tipo en beneficio de los diferentes agentes sociales, especialmente para la población infantil y, en definitiva, para la toda ciudadanía en su conjunto.

\section{Bibliografía}

Agulló, M.S. Metaevaluation of support programmes for informal carers of elderly people. University of North London (dissertation-tesina de Master en "Evaluation and Social Research"). 2001-2002.

Agulló, M.S. y Topa, G. "Técnicas de investigación en Psicología Social y de las Organizaciones: El meta-análisis y el grupo de discusión”, en Palací, F.J. (coord.), Psicología de la Organización. Madrid: Pearson-Prentice Hall (pp. 55-72). 2005. ISBN: 978-84-205-4340-6.

Agulló, M.S., "Evaluando programas desde un enfoque psicosociológico", Encuentros en Psicología Social, Vol. 1, No. 3, 2003, pp. 159-164.

Agulló, M.S., Zorrilla, V. y Gómez, V. "Investigación y Evaluación sobre género/ feminismo y envejecimiento/vejez”, editorial del monográfico, coordinación, publicación de 2 artículos y de una nota de investigación en el número 21 de la Revista Prisma Social "Envejecimiento y Género. Investigación y Evaluación de Programas", $2^{\circ}$ trimestre, Junio 2018. ISSN: 1989-3469. http://revistaprismasocial.es/issue/view/146

Bales, K., \& Robbins, P. T. (2001). "No one shall be held in slavery or servitude": A critical analysis of international slavery agreements and concepts of slavery. Human Rights Review, Vol. 2, N. ${ }^{0}$ 2, 2001, pp. 18-45. 
Bekele, A. \& Boyden, J. Combating Child Labour. Ginebra: International Labour Organization. 1998.

Boohla, U. Naciones Unidas. Asamblea General. Las formas contemporáneas de la esclavitud, incluidas sus causas y consecuencias. 2018. Documento: A/73/139. Párrafo 8.

Boohla, U. Naciones Unidas. Asamblea General. Las formas contemporáneas de la esclavitud, incluidas sus causas y consecuencias. 2015. Documento: A/ HRC/36/43. Párrafo 7.

Boohla, U. Naciones Unidas. Asamblea General. Las formas contemporáneas de la esclavitud, incluidas sus causas y consecuencias. 2015. Documento: A/ $\mathrm{HRC} / 27 / 53$.

Borman, G. D., \& D’Agostino, J. V. Title I and student achievement: A metaanalysis of federal evaluation results. Educational Evaluation and Policy Analysis, 1996, Vol. 18, $N^{\circ} .4$, pp. 309-326.

Canosa Usera, R., "La prohibición de la esclavitud y del trabajo forzado: un ejemplo de integración entre Tratados Internacionales" en García Roca, J. Santolaya, P. (coords.) La Europa de los Derechos. Centro de Estudios Políticos y Constitucionales, Madrid, 2005. p. 134.

Confederación Sindical Internacional. Miniguía de acción. Trabajo forzoso. 2008. Consultado el 19 de Septiembre de 2019. https://www.ituc-csi.org/IMG/pdf/ mini_guide_CL_final_ES-2.pdf

Corte Interamericana de Derechos Humanos. Informe Anual, 1999. Capítulo 6: Recomendación sobre la erradicación del reclutamiento y la participación de niños en conflictos armados. 2000.

Corte Interamericana de Derechos Humanos. Sentencia del caso trabajadores de la hacienda Brasil verde $v s$. Brasil, de 20 Octubre de 2016. Párrafo 219.

Díaz Jiménez, L., \& Rosales, R. Metaevaluación: evaluación de la evaluación de políticas, programas y proyectos sociales. Agora. 2003.

Durlak, J.A., Wells, A.M., Evaluation of indicated preventive intervention (secondary prevention) mental health programs for children and adolescents. American journal of community psychology, 1998, Vol. 26, No .5 , pp. 775-802.

Freeman, H.E., Rossi, P.H. \& Lipsey, M. Lipsey. Evaluation: A systematic approach. Sage Publications, 1993.

Hasbún, J. Evaluación final independiente del proyecto Erradicación del trabajo infantil a través de la educación en Colombia: Edúcame Primero Colombia. 2010. Consultado el 19 de Septiembre de 2019. https://www.dol.gov/ sites/dolgov/files/ILAB/evaluation_type/final_evaluation/Colombia_TBP_ feval_SPAN_o.pdf

Holgado Ramos, D., Maya-Jariego, I., Ramos Vidal, I., \& Palacio Sañudo, J., El papel de los facilitadores en la implementación de los "Espacios para Crecer": 
evaluación formativa del programa con menores trabajadores "Edúcame Primero, Colombia”. Universitas Psychologica, 2014, Vol. 13, No. 4, pp. 14411459, https://doi.org/10.11144/Javeriana.UPSY13-4.pfie

Holgado, D., Santolaya, F., Maya-Jariego, I., Cueto, R. M., \& Anaya, R. H., Preparación comunitaria y organizativa contra el trabajo infantil en tres colegios de barrios periféricos de Lima (Perú). Apuntes de Psicología, 2015, Vol. 33, №. 3, pp. 103-116.

Lipsey, M. W., \& Wilson, D. B., The efficacy of psychological, educational, and behavioral treatment: Confirmation from meta-analysis. American psychologist, 1993, Vol. 48, $\mathrm{N}^{0} .12$.

López Rubia, M.E., "Prohibición de la esclavitud y del trabajo forzoso" en Ordeñana Gezuraga, Ixusko (dir.). La carta de los derechos fundamentales de la Unión Europea y su reflejo en el ordenamiento jurídico español. Thomson Reuters, Cizur Menor. 2014. p.113.

Masachs, R. C., Maroto, J. L. S. F., \& Berciano, S. G., "Evaluación de programas educativos en museos: Una nueva perspectiva." Bordón. Revista de pedagogía, 2017, Vol. 69, No. 1, pp. 45-65.

Maya-Jariego, I. y Palacio, J.E., Educáme Primero Colombia. Proyecto de cooperación internacional entre la Universidad de Sevilla y la Universidad del Norte. 2012. Consultado el 19 de Septiembre: http://personal.us.es/isidromj/ php/wp-content/uploads/2012/10/Catálogo_barranquilla.pdf

Maya-Jariego, I., y Holgado, D., From Barranquilla to Lima in reducing child labor: Lessons in community action. Global Journal of Community Psychology Practice, 2014, Vol. 5, No. 2, pp. 1-6.

Márquez, E., Holgado, D., \& Maya-Jariego, I. (2019). Innovation, Dosage and Responsiveness in the Implementation of the Program "Edúcame Primero Perú" for Reducing Child Labour. Applied Research in Quality of Life, 2019, Vol. 14, No. 3, pp. 617-636.

Naciones Unidas. Consejo Económico y Social. Examen del proyecto de convención contra la delincuencia organizada transnacional. Informe de la reunión preparatoria oficiosa del comité especial intergubernamental de composición abierta sobre la elaboración de una Convención internacional amplia contra la delincuencia organizada transnacional. Buenos Aires. 1998. Documento A/AC.254/3. Párrafo 14.

Naciones Unidas. Asamblea General. Proyecto de documento final de la cumbre de las Naciones Unidas para la aprobación de la agenda para el desarrollo después de 2015. Documento: A/69/L.85.Meta 8.7.

OIT. (1998). Declaración de la OIT de 1998 relativa a los principios y derechos fundamentales en el trabajo. https://www.ilo.org/declaration/lang-es/index.htm 
OIT. Departamento de Gobernanza y Tripartismo. Alianza 8.7 de los ODS Concertar esfuerzos a escala mundial para erradicar el trabajo infantil y el trabajo forzoso, las formas modernas de esclavitud y la trata de seres humanos. Proyecto para consulta. Ginebra, 2016. p.2-4.

OIT. Estimaciones mundiales sobre el trabajo infantil: Resultados y tendencias 2012-2016. Informe de 19 de Septiembre de 2017. http://www.oit.org/global/ publications/books/WCMS_651815/lang--es/index.htm

OIT. Walk Free Foundation. Global estimates of modern slavery: forced labour and forced marriage. Exexutive Summary. Geneva, 2017. p. 9-10.

OIT. Principios y derechos fundamentales en el trabajo: Retos y oportunidades. Conferencia Internacional del Trabajo, 106. ${ }^{a}$ reunión, Ginebra, 2017. Párrafo 29. p.11. Naciones Unidas. Asamblea General. Proyecto de documento final de la cumbre de las Naciones Unidas para la aprobación de la agenda para el desarrollo después de 2015. Documento: A/69/L.85.Meta 8.7.

OIT. Información actualizada sobre la Alianza 8.7 de la Agenda 2030 para el Desarrollo Sostenible. Ginebra, 2019.

Patton, M., Utilization-Focused Evaluation. London: Sage, 1996.

Pérez-González, J. C., "Propuesta para la evaluación de programas de educación socioemocional." Electronic Journal of Research in Education Psychology, 2017, Vol. 6, No. 15, pp. 523-546.

Plant, R. Modern slavery: The concepts and their practical implications. International Labour Organization, Geneva. 2014. p.1.

Save the Children. Trabajo Forzoso Infantil. Consultado el 19 de Septiembre de 2019. https://www.savethechildren.es/trabajo-ong/proteccion-infantil/violencia-contra-la-infancia/trabajo-infantil-forzoso

Seibel, N.L., Using Evidence-Based Programs to Support Children and Families Experiencing Homelessness. Needham, MA: Conrad N. Hilton Foundation. 2011.

Shadish, William R., Thomas D. Cook, and Laura C. Leviton. Foundations of program evaluation: Theories of practice. Sage, 1991.

Shadish, W. R., Ragsdale, K., Glaser, R. R., \& Montgomery, L. M. (1995). The efficacy and effectiveness of marital and family therapy: A perspective from meta-analysis. Journal of marital and Family Therapy, Vol. 21, No . 4, 1995, pp. 345-360.

Shahinian, G. Informe de la Relatora Especial sobre las formas contemporáneas de la esclavitud, incluidas sus causas y consecuencias. 2008. Documento $\mathrm{n}^{\mathrm{O}}$ A/HRC/9/20. Párrafo 38.

Scarpa, S. Contemporary forms of slavery. STUDY Requested by the DROI committee. Policy Department for External Relations Directorate General for External Policies of the Union PE. December 2018. p.11. 
Scriven, M. An introduction to metaevaluation. Educational products report, Vol. 2, $\mathrm{N}^{\mathrm{o}}$. 5, 1968, pp. 36-38.

Scriven, M. The evaluation of college teaching. National Dissemination Center, Syracuse University School of Education, 1980.

Stufflebeam, D.L. Metaevaluation. Kalamazoo: Western Michigan University, The Evaluation Center. 1974.

Stufflebeam, D.L. y Shinkfield, A.J. Evaluación sistemática. Guía teórica y práctica. Madrid: Paidós y MEC, 1987.

Wholey, J. S., Nay, J. N., Scanlon, J. W., \& Schmidt, R. E. (1975). Evaluation: When is it really needed. Evaluation, 1975, Vol. 2, No. 2, pp. 89-93.

Winrock International, Best Practices in Preventing and Eliminating Child Labor through Education. Arlintong, VA: Winrock International Empowerment and Civic Engagement Unit. 2008.

Zorrilla-Muñoz, V., García-Sedano, T. y Alvarado, C., El trabajo forzoso desde una perspectiva de género, intergeneracional e internacional. En IV Congreso Internacional de Jóvenes Investigadorxs con perspectiva de Género. 2426 de Junio de 2019. Consultado el 19 de Septiembre de 2019: http://portal. uc3m.es/portal/page/portal/inst_estudios_genero/archivo_eventos/Congreso_Jovenes_Investigadorxs_genero

\section{Juridisprudencia}

Corte Interamericana de Derechos Humanos. Sentencia del caso trabajadores de la hacienda Brasil verde vs. Brasil, de 20 Octubre de 2016. Párrafo 219.

Corte Interamericana de Derechos Humanos. (2016). Sentencia del caso trabajadores de la hacienda Brasil verde vs. Brasil, de 20 Octubre. Párrafo 219.

Tribunal Europeo de Derechos Humanos. Sentencia del caso Van der Mussele c. Bélgica, del 23 de noviembre de 1983. Demanda no 8919/80.

Tribunal Constitucional. Sentencia STC 116/92, de 20 de mayo.

Tribunal Europeo de Derechos Humanos. Sentencia del caso Siliadin vs Francia, de 26 de Julio de 2005. Demanda $\mathrm{n}^{0}$ 73316/01.

Tribunal Europeo de Derechos Humanos. Sentencia del caso de Rantsev c. Chipre y Rusia, de 7 de enero de 2010. Demanda ${ }^{0}$ 25965/04. Párrafo 281.

Tribunal Europeo de Derechos Humanos. Sentencia del caso de Rantsev c. Chipre y Rusia, de 7 de enero de 2010. Demanda $n^{0}$ 25965/04.

Tribunal Europeo de Derechos Humanos. Sentencia del caso Stummer vs Austria, de 7 de julio de 2011. Demanda $n^{0}$ 37452/o2. 



\title{
EL INCREMENTO DE LOS NIVELES EDUCATIVOS DE LAS PERSONAS CON DISCAPACIDAD COMO FACTOR DE EMPLEABILIDAD
}

\author{
Patricia NIETO ROJAS \\ Universidad Carlos III de Madrid
}

\begin{abstract}
RESUMEN: La Organización Mundial de la Salud y el Banco Mundial estiman que mil millones de personas experimentan alguna forma de discapacidad, y lamentablemente muchas de estas personas abandonan prematuramente la escolarización obligatoria. Estos datos evidencian las múltiples barreras a la educación que enfrentan muchas de las personas con discapacidad, que incluyen: falta de accesibilidad, tanto en términos de edificios escolares físicamente inaccesibles como de materiales de aprendizaje inadecuados, discriminación y prejuicio que impide que las personas con discapacidad accedan a la educación en igualdad de condiciones. Sin embargo, el incremento de los niveles de cualificación de las personas con discapacidad es el factor de mayor incidencia para garantizar el tránsito a su empleabilidad.
\end{abstract}

Palabras clave: igualdad, discapacidad, educación, empleo, barreras a la educación.

SUMARIO: 1. Baja cualificación y personas con discapacidad. Un binomio consolidado. 2. El horizonte: el incremento de los niveles de cualificación como mecanismo de inclusión laboral. 3. El incremento del número de estudiantes con discapacidad en los programas de educación no obligatoria. 3.1. En los estudios de formación profesional. 3.2. En los estudios universitarios. 4. El futuro: el incremento de la cualificación de las personas con discapacidad como condición para el aumento de su empleabilidad. 5. Bibliografía.

\section{The increase of educational level of people with disabilities as emplo- yability factor.}

ABSTRACT: The World Health Organisation and the World Bank estimate that one billion people experience some form of disability and it's very often persons with disabilities leave school early without transitioning to secondary school and beyond. These facts and figures reflect barriers to education faced by many people with disabilities, which include: lack of accessibility, both in terms of physically inaccessible school buildings and unsuitable learning materials discrimination 
and prejudice which prevents people with disabilities from accessing education on equal terms. However, the increase in the levels of qualification of persons with disabilities is the factor with the greatest incidence to guarantee their insertion in the labor market..

Key words: equality, disability, education, employment, barriers to education.

\section{Baja cualificación y personas con discapacidad. Un binomio consolidado}

La OECD ${ }^{1}$ advierte de que un mayor nivel educativo reporta mejores perspectivas laborales, mejores ingresos y se asocia con una mejor autopercepción de salud, capital social y participación política. En promedio, en los países de la OCDE, el 13,7\% de aquellas personas que no alcanzaban el nivel de secundaria superior estaban desempleadas mientas que esta tasa se situaba en un 5,3\% en los individuos con educación terciaria y en un $8 \%$ entre aquellos que contaban con educación secundaria superior o post- secundaria no terciaria. Indubitada la correlación existente entre nivel formativo e inserción laboral, el art. 27 de la Convención Internacional sobre los Derechos de las Personas con Discapacidad (2006) reconoce el derecho de las personas con discapacidad "a tener la oportunidad de ganarse la vida mediante un trabajo libremente elegido o aceptado en un mercado y un entorno laborales que sean abiertos, inclusivos y accesibles”, cobrando especial interés a los efectos aquí analizados los dos últimos apartados de dicho precepto que instan a permitir que las personas con discapacidad tengan acceso efectivo a programas generales de orientación técnica y vocacional, servicios de colocación y formación profesional y continua y abogan por incrementar las oportunidades de empleo y promoción profesional de las personas con discapacidad en el mercado laboral.

El objetivo del modelo social consagrado por la Convención es asegurar a las personas con discapacidad la igualdad de oportunidades tanto en el acceso al sistema educativo como en el tránsito hacia el empleo.

Como veremos, la legislación española también reconoce a la educación como una de las herramientas que habría de posibilitar "que el enfoque de la

1 Organization for Economic Cooperation and Development. Education at a Glance Interim Report: Update of Employment and Educational Attainment Indicators. January, 2015 . 
discapacidad desde los derechos humanos sea una realidad. Por eso es muy importante no solo que las legislaciones estatales presten atención a la educación en derechos humanos"2 sino que en el marco de esta reflexión no puede obviarse la importancia de la educación como factor de integración social. El modelo social propugna un cambio radical del concepto mismo de discapacidad: el problema no reside en la persona, sino en la propia sociedad y en las bases sobre las que esta se ha edificado, por cuando dificultan o impiden a determinadas personas -que no obedecen a estos estándares dominantes- el ejercicio de sus derechos ${ }^{3}$.

Sin embargo, las conclusiones del informe "La situación de las personas con discapacidad en España. Informe Olivenza 2016”, elaborado por el Observatorio Estatal de la Discapacidad, son muy elocuentes a este respecto, habida cuenta que el nivel educativo de las personas con discapacidad es comparativamente bajo respecto al de las personas sin discapacidad, siendo necesario revertir esta situación, especialmente porque a mayor nivel de estudios, la tasa de actividad de este colectivo es más alta: mientras que la tasa de actividad de las personas con discapacidad sin estudios es de apenas un $6,9 \%$, la de aquellos con estudios superiores es del 59,3\%. Respecto a la tasa de actividad de las personas con discapacidad que cuentan con estudios superiores, esta es un 56\% más alta que la media de todo el colectivo, reduciéndose por tanto las diferencias con la población sin discapacidad ${ }^{4}$. De los datos expuestos es evidente la necesidad de incrementar el nivel de cualificación de las personas con discapacidad para reducir así las desigualdades todavía existentes no solo en el acceso sino en el mantenimiento en el mercado de trabajo, pues aunque son diversos los tratados y convenios internacionales relativos a los derechos humanos que proclaman el derecho a la educación -entre otros, el artículo 26 de la Declaración Universal de Derechos Humanos (1948), la Convención relativa a la Lucha contra las Discriminaciones en la Esfera de la Enseñanza (1960), la Convención sobre los Derechos del Niño (1989) y

2 De Asís Roig, R., "El encaje de la Convención Internacional sobre los Derechos de las Personas con Discapacidad”, en Arenas Escribano, F., Cabra de Luna, M. A. (eds.) Comentarios al Texto Refundido de la Ley General de derechos de las personas con discapacidad y de su inclusión social, La Ley; CERMI, Madrid, 2015, p. 84.

3 VALDÉs DAL-RÉ, F., "Derechos en serio y personas con discapacidad: una sociedad para todos”, en Lahera Forteza, J., Valdés Dal-Ré, F. (eds.) Relaciones laborales de las personas con discapacidad, Biblioteca Nueva, Madrid, 2005, p. 372.

4 Huete García, A.; Jiménez Lara, A. (EDs.), Informe Olivenza 2016 sobre la situación de la discapacidad en España, Observatorio Estatal de la Discapacidad, Olivenza, 2016, p. 270. 
el artículo 24 de la ya referida Convención Internacional sobre los Derechos de las Personas con Discapacidad (2006)5-, una primera aproximación a los datos relativos al nivel educativo de las personas con discapacidad en España nos permite afirmar que dos tercios de las personas con discapacidad tenían en 2012 (según datos de la Encuesta de Integración Social y Salud) un nivel educativo bajo que alcanza, como máximo, la educación secundaria de primera etapa (de estos, el 7,3\% serían analfabetos, tasa 12 veces mayor que en la población). En el otro lado de la pirámide, un 18,3\% alcanza educación secundaria de segunda etapa y un 15,3\% estudios superiores. Las diferencias con las personas sin discapacidad son importantes en esta variable, toda vez que el peso de las personas con educación superior es entre las personas sin discapacidad dos veces mayor (34,8\% del total) mientras que el peso relativo de las personas con educación primaria o inferior es menos de la mitad (10,4\% frente a $23 \%$ de las personas con discapacidad $)^{6}$.

También en el Informe del mercado de Trabajo de las personas con discapacidad, elaborado por el Ministerio, se advierte del diferencial educativo de este colectivo y así "los considerados analfabetos según el INE (aquellos que no poseen estudios acreditados), entre las personas con discapacidad son casi el $7 \%$ mientras que en el resto de la población en edad laboral suponen el $0,5 \%$. En el otro extremo, las personas sin discapacidad doblan porcentualmente a las personas con discapacidad en cuanto a tener acreditados estudios superiores. Los que sólo tienen estudios primarios, representan casi el 26\% en los que tienen discapacidades mientras que, en el resto de la población, no llegan al 11\%"7, siendo en la educación secundaria donde el acercamiento

5 En el párrafo segundo del art. 24 expresamente se contempla que para hacer efectivo el derecho a la educación los Estados parte se comprometen a que "las personas con discapacidad no queden excluidas del sistema general de educación por motivos de discapacidad, y que los niños y las niñas con discapacidad no queden excluidos de la enseñanza primaria gratuita y obligatoria ni de la enseñanza secundaria por motivos de discapacidad”. También la Recomendación sobre el desarrollo de los recursos humanos, 2004 (núm. 195), de la OIT adoptada en Ginebra, 92 ${ }^{\mathrm{a}}$ reunión CIT (17 junio 2004) señala como deber de los Estados “desarrollar estrategias, medidas y programas en materia de igualdad de oportunidades a fin de promover y poner en práctica actividades de formación para las mujeres, grupos específicos, sectores económicos y personas con necesidades especiales, con el objetivo de reducir las desigualdades".

6 Huete García, A.; Jiménez Lara, A. (eds.), Informe Olivenza 2016 sobre la situación de la discapacidad en España, cit., p. 303.

7 Servicio Público Empleo Estatal, Informe del Mercado de Trabajo de las Personas 
entre ambas poblaciones es mayor, no llegando a los 5 puntos de diferencia. Respecto a los datos acumulados sobre alumnos que cursan Ciclos Formativos de Formación Profesional, o Programas de Cualificación Profesional (Inicial o en Centros de Educación Especial), suponen una ínfima parte del número total de alumnos con necesidades educativas especiales escolarizados en la educación secundaria obligatoria, por lo que la mayoría de ellos tampoco accede a estas opciones de enseñanza.

Si centrásemos el foco en las personas con discapacidad intelectual, los datos son aún más desalentadores o, al menos, esa es la conclusión alcanzada en el observatorio ODISMET. En él, se destaca que el 28,5\% de la población con discapacidad intelectual carece de formación en comparación con la media del $3,5 \%$ del resto de la población con discapacidad ${ }^{8}$. Paralelamente, es la población que está cursando más estudios (12,6\%), un $82 \%$ por encima de la media del colectivo, quizás por la mayor prolongación de su etapa formativa y el menor acceso al empleo. A la luz de los datos expuestos, es evidente que las posibilidades de inserción laboral, así como el acceso a empleos de mayor calidad se incrementan con mayores niveles de cualificación y, sin embargo, el nivel educativo de las personas con discapacidad es notablemente inferior al de las personas sin discapacidad.

El tipo de discapacidad es la variable que con mayor intensidad determina el nivel de instrucción alcanzado, siendo las mujeres con discapacidad visual las mejor formadas en líneas generales y las más próximas a los niveles de las mujeres sin discapacidad mientras que en el extremo contrario, la discapacidad intelectual es la que presenta peores niveles formativos ${ }^{9}$. Entre las personas con discapacidad intelectual, muchos de los entornos educativos que ofrecen formación reglada presentan barreras en la comunicación y en el acceso a la información que no se mencionan en las estadísticas sobre educación y discapacidad intelectual y, sin embargo, los datos arrojan resultados muy evidentes pues mientras que casi el 100\% de los alumnos con discapacidad visual o más del 90\% del alumnado con discapacidad auditiva estudia en centros ordinarios, entre los alumnos con discapacidades intelectuales o del desarrollo la cifra se reduce al $77,2 \%{ }^{10}$.

con Discapacidad Estatal. Datos 2015., Ministerio de Empleo y Seguridad Social, Madrid, 2016, p. 16.

8 ODISMET, Informe general. La situación de las personas con discapacidad en el mercado laboral, Fundación ONCE, Madrid, 2015, p. 105.

9 Ibid., p. 119.

10 Plena inclusión MAdRId, La formación como oportunidad de inclusión de las personas con discapacidad intelectual, Plena Inclusión Madrid, Madrid, 2017. 
Al tiempo las personas con discapacidad pueden tener incentivos en prolongar sus estudios en parte por la coexistencia de factores cruzados: dificultades de acceso al mercado de trabajo y desincentivos a trabajar por la dificultad para compatibilizar pensiones/salario si bien no es fácil determinar qué alcance tiene esta afirmación a la luz de la ausencia de datos estadísticos concluyentes a este respecto.

Una de las características de las personas con discapacidad sobre la que existe consenso en la literatura es su menor nivel educativo. Esto no es sólo consecuencia de la mayor prevalencia de la discapacidad en las edades superiores (en general, las personas de más edad tienen en promedio niveles de estudio más bajos) sino que diversos trabajos indican que las propias discapacidades (principalmente en el caso de las intelectuales) generarían ese bajo nivel de estudios. A mayor abundamiento, en las encuestas específicas de discapacidad, con una definición de discapacidad acorde a la Clasificación Internacional del Funcionamiento, de la Discapacidad y de la Salud (CIF), se encuentra un mayor peso del analfabetismo que en el caso de las fuentes de información vinculadas al certificado de discapacidad. Esto nos puede estar indicando que son aquellas personas que padecen una discapacidad, pero que carecen del correspondiente certificado, las que experimentan en mayor medida un déficit educativo, y por ende una mayor probabilidad de desconexión con el mercado de trabajo, de ahí que compartamos que en "aras de conseguir una mayor integración educativa y laboral de este colectivo ${ }^{11}$ ", no debiese condicionarse el apoyo formativo a la posesión del certificado de discapacidad sino que se tendría que extender este apoyo a toda aquella persona que tuviese alguna necesidad específica de apoyo educativo, pues aunque práctica totalidad de legislaciones nacionales contemplan, entre los principios rectores de su normativa educativa, la equidad y la igualdad de oportunidades, haciendo operativa la Convención de Naciones Unidas sobre los derechos de las personas con discapacidad, y atendiendo al Objetivo de Desarrollo Sostenible número $4^{12}$ y, más concretamente a la meta quinta de este objetivo (4.5: de aquí a 2030, eliminar las disparidades de género en la educación y asegurar el acceso igualitario a todos los niveles de la enseñanza y la formación profesional para las personas vulnerables, incluidas las personas con discapacidad, los pueblos indígenas y

11 Rodríguez, V., "El empleo de las personas con discapacidad en España: quo venis, quo vadis”, Panorama Social, vol. 26, 2017, p. 53.

12 Objetivo 4: Garantizar una educación inclusiva, equitativa y de calidad y promover oportunidades de aprendizaje durante toda la vida para todos 
los niños en situaciones de vulnerabilidad), y a lo establecido en la declaración de la Agenda 2030. Sin embargo, de los datos referidos en este epígrafe podemos concluir la escasa materialización de este derecho lo que dificulta enormemente el tránsito a la empleabilidad de las personas con discapacidad.

Para revertir esta situación, se ha impulsado el plan de inclusión del alumnado con necesidades educativas especiales $2018-2020^{13}$, cuyos ámbitos de actuación están dirigidas al contexto social y familiar, a la atención educativa del alumnado, a los centros docentes, al profesorado y otros profesionales de la educación, y, en lo que aquí interesa, a la formación a lo largo de la vida e inserción laboral. Veremos si su aprobación incrementa la empleabilidad de las personas con discapacidad y un indicador muy relevante para esta evaluación en relación con las enseñanzas no obligatorias será el porcentaje de estudiantes con discapacidad que cursa satisfactoriamente estudios no obligatorios y cuál es la tasa de inserción laboral tras la finalización de estos.

\section{El horizonte: el incremento de los niveles de cualificación como mecanismo de inclusión laboral}

$\mathrm{El}$ art. 3 de la Convención consagra, como uno de sus principios generales, la igualdad de oportunidades. Una de las vías para materializar este principio se contiene en el art. 27.1 del referido texto que reconoce el derecho de las personas con discapacidad a trabajar en igualdad de condiciones que los demás, lo que incluye el derecho a tener la oportunidad de ganarse la vida mediante un trabajo libremente elegido o aceptado en un entorno laboral que sea abierto, inclusivo y accesible a las personas con discapacidad. Para la consecución de este propósito es necesario incrementar sus niveles de cualificación, habida cuenta de la correlación existente entre el nivel de cualificación alcanzado y la inserción laboral. Seguidamente, el artículo 24, párrafo 1, de la Convención señala que los Estados Miembros deben asegurar el cumplimiento del derecho a la educación de las personas con discapacidad a través de un sistema de educación inclusiva, entendiendo que este derecho "abarca una transformación en la cultura, la política y la práctica en todos los entornos educativos, sean estos formales o informales, para dar cabida a las diferentes necesidades e identidades de cada estudiante"14.

13 https://www.educacionyfp.gob.es/prensa/actualidad/2018/05/20180508-inclu. html (fecha de consulta: 8/10/2019).

14 Comité sobre los Derechos de las Personas con Discapacidad, Comentario general $n^{o}$ 
También en el ámbito comunitario son múltiples los documentos que enfatizan en la importancia de las transiciones efectivas entre el sistema educativo y el sistema productivo para que las personas con discapacidad puedan ejercer sus derechos de forma plena. Sirvan, a modo de paradigma, los objetivos enumerados en la Estrategia Europea sobre Discapacidad 2010-2020: un compromiso renovado para una Europa sin barreras.

El referido documento estratégico, tras un exhaustivo análisis de los precedentes existentes y una ronda de consultas a los Estados Miembros, ha identificado ocho ámbitos primordiales de actuación que sustentarán y orientarán la actuación estratégica, a saber: accesibilidad, participación, igualdad, empleo, educación y formación, protección social, sanidad y acción exterior. Tal como recoge la Estrategia, con la accesibilidad se persigue el acceso de las personas con discapacidad, en las mismas condiciones que el resto de la población ${ }^{15}$, en todos los ámbitos de la sociedad, materializándose esta exigencia en la necesidad de garantizar el apoyo necesario para asegurar su transición efectiva desde el aprendizaje escolar hasta la formación profesional y, finalmente, hasta su incorporación a entornos laborales ${ }^{16}$.

Sin perjuicio de la responsabilidad de los Estados respecto al contenido de los planes de estudios y la organización de los sistemas educativos, la Comisión respaldará el objetivo de una educación y formación inclusivas en el marco de la iniciativa «Juventud en movimiento» y además difundirá más información sobre los niveles educativos y las oportunidades que se ofrecen a las personas con discapacidad, facilitando su participación en el programa de aprendizaje permanente. Esta actuación se respaldará además mediante la estrategia «ET 2020» que se configura como el marco estratégico para la cooperación europea en educación y formación.

Por su parte, los esfuerzos nacionales debiesen ir encaminados, en primer lugar, a suprimir las barreras jurídicas y organizativas que se presentan a las personas con discapacidad en los sistemas generales de educación y de aprendizaje permanente; en segundo lugar, a apoyar oportunamente una educación inclusiva, un aprendizaje personalizado y una identificación tem-

4 (2016). Artículo 24. Derecho a la Educación Inclusiva., Naciones Unidas. Convención sobre los Derechos de las Personas con Discapacidad, 2016, p. 3.

15 Polonio de Dios, G., "La discapacidad desde la perspectiva del estado social”, 2016, Universidad de Córdoba, Córdoba, p. 272.

16 Comité sobre los Derechos de las Personas con Discapacidad, Comentario general $n^{o}$ 4 (2016). Artículo 24. Derecho a la Educación Inclusiva., cit., p. 4. 
prana de necesidades especiales y, en tercer lugar, a facilitar una formación y un apoyo adecuados a los profesionales que trabajan en todos los niveles educativos ${ }^{17}$. En las sociedades avanzadas, el sistema educativo es mucho más que una herramienta para impartir conocimiento, sino que se configura como un "agente de socialización clave, que distribuye capital cultural, modelos de comportamiento, relaciones personales, vínculos, expectativas sobre la propia vida y la de quienes nos rodean"18.

En la normativa española contempla que todo el alumnado con necesidad especifica de apoyo educativo ha de ver garantizada su permanencia en el sistema educativo-art. 3.8 LOE- $^{-19}$. Ahora bien, las medidas de atención a la diversidad, innegablemente necesarias para lograr el mantenimiento de los estudiantes con discapacidad en el modelo educativo, dependen en gran parte los proyectos de los centros pues, de conformidad con el artículo 121 de la $\mathrm{LOE}^{20}$, serán estos los que recogerán la forma de atención a la diversidad del alumnado. Es cierto que el art. $71 \mathrm{LOE}^{21}$ encomienda a "las Administraciones educativas asegurar los recursos necesarios para que los alumnos y alumnas que requieran una atención educativa diferente a la ordinaria, por presentar necesidades educativas especiales, por dificultades específicas de aprendizaje, TDAH, por sus altas capacidades intelectuales, por haberse incorporado tarde al sistema educativo, o por condiciones personales o de historia escolar, puedan alcanzar el máximo desarrollo posible de sus capacidades personales y, en todo caso, los objetivos establecidos con carácter general para todo el alumnado". Sin embargo, los datos son elocuentes, y así si se analizan los datos procedentes del Ministerio de Educación, referida a las estadísticas de las enseñanzas no universitarias se constata que del total de alumnos con necesidades educativas especiales, 139.448 alumnos estaban escolarizados en centros ordinarios $(80,2 \%)$ y 34.439 alumnos en centros o unidades de educación especial (19,8\%), siendo este dato objeto de fundadas críticas pues

17 COM (2010) 636 final. Estrategia Europea sobre Discapacidad 2010-2020: un compromiso renovado para una Europa sin barreras.

18 Huete García, A., "Las personas con discapacidad en la escuela. Luces y sombras del proceso de inclusión educativa en España”, Panorama Social, vol. 26, 2017, p. 97.

19 De Araoz SÁnchez-Dopico, I., "La configuración del derecho a la educación inclusiva”, en Pérez Cayo, L. (ed.) Discapacidad, Tercer Sector e Inclusión Social, CERMI, Madrid, 2010, p. 253.

20 LO 3/2006, de 3 de mayo, de Educación (BOE 4.5.2006).

21 En la modificación aprobada en la LO 8/2013, de 9 de diciembre, para la mejora de la calidad educativa (BOE 10.12.2013). 
"igual de importante que un acceso al sistema en igualdad de condiciones es el aseguramiento de la permanencia y progresión del alumnado con necesidades educativas en el Sistema Educativo cuyo logro incumbe a las Administraciones Educativas" 22 .

Conforme al artículo 24, párr. 2, apdo. a), de la Convención, las personas con discapacidad no deben quedar excluidas del sistema general de educación por motivos de discapacidad, sino que las autoridades educativas les deben garantizar los apoyos y ajustes necesarios. Para materializar este mandato, el Comité sobre los Derechos de las Personas con discapacidad ${ }^{23}$ dictó su Observación General núm. 4 (2016) sobre el derecho a la educación inclusiva, la cual parte de la consideración del derecho a la educación como el derecho de todas las personas a aprender en un sistema educativo que haya sido diseñado teniendo en cuenta las necesidades de todas las personas, incluidas las personas con discapacidad, en donde todos los centros educativos acogen a todos los estudiantes, independientemente de sus condiciones físicas, intelectuales, sociales, lingüísticas u otras. No se trata solo de brindar una educación de calidad, sino también de cambiar las actitudes de discriminación para crear sociedades inclusivas, que respeten y valoren las diferencias y la dignidad de todas las personas por igual. Sin embargo, las elevadas tasas de abandono escolar temprano y el reducido número de estudiantes con discapacidad cursando satisfactoriamente enseñanzas no obligatorias exigen acciones públicas y privadas $^{24}$ que reviertan esta situación, actuando sobre las barreras actitudinales que, en ocasiones, ponen en peligro la inclusión plena de los alumnos.

Para favorecer la empleabilidad de este colectivo y mejorar paralelamente sus niveles de cualificación se han de impulsar reformas en la normativa laboral, en particular en la regulación de la formación profesional para el empleo, y esta reforma también habría de abogar por una perspectiva inclusiva tanto en el diseño como en la ejecución de los programas formativos. Algún informe señala a este respecto que del total de personas con discapacidad entre 16 y 64 años (1.774.800) solo el 6,9\% de ellos (122.800) se encontraban cursando algún tipo de estudio, en el momento de la medición mientras que

22 Araoz SÁnchez-Dopico, I., "Insuficiencias de la regulación del derecho a la educación inclusiva en la legislación española”, en Cayo Pérez Bueno, L. (ed.) 2003-2012: 10 años de legislación sobre no discriminación de personas con discapacidad en España: estudios en homenaje a Miguel Ángel Cabra de Luna, Cinca, Madrid, 2012.

23 Disponible en: http://repositoriocdpd.net:808o/handle/123456789/1865

24 Araoz SÁnchez-Dopico, I., "Insuficiencias de la regulación del derecho a la educación inclusiva en la legislación española”, cit. 
el dato para la población general se situaba en el $18,5 \%^{25}$ y aunque estas cifras parecen evidenciar una menor predisposición hacia la formación profesional para el empleo por parte del colectivo también cabe inferir mayores barreras y dificultades para acceder a procesos formativos.

En ocasiones, una pequeña adaptación curricular, una disposición del aula determinada, la utilización de recursos didácticos específicos y adecuados, la modificación o diversificación de los tipos de actividades, la aplicación de métodos variados que apoyen los diferentes estilos de aprendizaje (ejemplos todos ellos de ajustes perfectamente asumibles) permitirían incrementar el número de participantes en estas acciones formativas, tanto las impulsadas por los centros de educación de personas adultas, dependientes de la Administración educativa, como las que se imparten en el marco del modelo de la formación profesional para el empleo, dependientes de la Administración laboral.

En el ordenamiento jurídico español, la noción de "ajustes razonables" se contempla en el artículo 2 del RD Legislativo 1/2013, de 29 de noviembre, por el que se aprueba el Texto Refundido de la Ley General de derechos de las personas con discapacidad y de su inclusión social, al lado de la noción de "accesibilidad universal” y es el artículo 63 de esa misma ley el que considera que "se entenderá que se vulnera el derecho a la igualdad de oportunidades de las personas con discapacidad, definidas en el artículo 4.1, cuando, por motivo de o por razón de discapacidad, se produzcan discriminaciones directas o indirectas, discriminación por asociación, acosos, incumplimientos de las exigencias de accesibilidad y de realizar ajustes razonables, así como el incumplimiento de las medidas de acción positiva legalmente establecidas".

También en el marco de la Estrategia Europea 2020, que sitúa el éxito escolar y la mejora de los niveles educativos como una de las prioridades fundamentales para la próxima década, se aboga por poner en marcha mecanismos y recursos necesarios para disminuir los porcentajes de abandono escolar de las personas con discapacidad; abandono que, en demasiadas ocasiones, obedece a la falta de adaptación y de recursos. Entre las medidas prioritarias están las dirigidas a disponer de indicadores sobre niveles educativos que ofrezcan información precisa para tener una radiografía completa sobre la situación de las personas con discapacidad, tanto en el entorno educativo como en el mercado de trabajo. Este mandato también se contiene en el Pacto Eu-

25 Casanova Rodríguez, M. A, "De la educación especial a la inclusión educativa. Estado de la cuestión y retos pendiente”, Participación educativa. Revista cuatrimestral del Consejo Escolar del Estado, vol. 11, 2011, p. 27. 
ropeo de la Discapacidad promovido por el Foro Europeo de la Discapacidad, $\mathrm{EDF}$, que incluye entre sus prioridades la igualdad de acceso y oportunidades en materia de educación ${ }^{26}$.

De los datos expuestos es evidente que el modelo de educación integradora es más una aspiración que una forma de describir exactamente la situación española que se caracteriza por importantes pérdidas de oportunidades para los alumnos con discapacidad. Esta distancia entre la teoría -incluso si está plasmada en las normas- y la práctica ha sido constatada por distintos informes que se han realizado sobre educación y discapacidad y en las reivindicaciones de los distintos colectivos afectados ${ }^{27}$. El modelo educativo no está garantizando la progresión del alumnado con necesidades educativas especiales en el entorno de la formación reglada, siendo aún menos visible su presencia en el sistema de formación profesional para el empleo.

Cuando finaliza la educación obligatoria, "finaliza la educación" de las personas con discapacidad mientras que para el resto de la población sí que se está impulsando el aprendizaje a lo largo de toda la vida y, a este respecto, algunos estudios ${ }^{28}$ señalan que el " $69,5 \%$ indican haber experimentado barreras en el acceso a estos programas formativos, siendo las causas mayormente aludidas las vinculadas a razones de tipo económico. Dicho motivo resulta más coherente si recordamos la baja intensidad laboral de este colectivo", siendo los jóvenes quienes menos obstáculos encuentran en sus procesos formativos (25\%). Si a los anteriores datos le unimos que el alumnado con necesidades educativas especiales sufre un elevado fracaso escolar, entenderemos porque muchos de estos estudiantes, normalmente con la aquiescencia familiar y tras la recomendación de los equipos de orientación pedagógica de los centros, son dirigidos hacia módulos profesionales en centros de educación especial o Programas de Cualificación Profesional Inicial que no necesariamente garantizan el tránsito hacia la empleabilidad. Esta misma conclusión se alcanza por el Comité sobre los Derechos de las Personas con Discapacidad, en el Informe de la investigación relacionada con España bajo el artículo 6 del Protocolo Facultativo, hecho público el 4 de junio de 2017. En

26 Sanz Escudero, M. J., "Trayectoria del CERMI en materia educativa”, Participación educativa. Revista cuatrimestral del Consejo Escolar del Estado, vol. 11, 2011, p. 157.

27 LEMa AÑon, C., "El impacto en la educación de la Convención de la ONU sobre los Derechos de las Personas con Discapacidad”, en Casanova Rodríguez, M. J. (ed.) Educación y personas con discapacidad: presente y futuro, ONCE, Madrid, 2009, p. 65.

28 ODISMET, Informe general. La situación de las personas con discapacidad en el mercado laboral, cit., p. 80. 
él se destaca que "las dificultades a las que se enfrentan los estudiantes con discapacidad se resuelven de manera ad hoc, y el destino del estudiante con discapacidad depende en la mayoría de los casos de la voluntad de sus padres, y del personal administrativo, educativo y de inspección involucrado, más no de la realización de su derecho a la educación inclusiva y de calidad"29.

Sin embargo, es evidente que un modelo productivo de éxito exige un sistema de formación profesional que no solo promueva la adquisición y actualización de conocimientos, sino que mejore las perspectivas de empleo estable y de calidad de todos los trabajadores, significadamente de aquellos que tienen más dificultad para acceder a él. Y aunque ciertamente el artículo 3.k) de la Ley 30/2015 de 9 de septiembre, por la que se regula el Sistema de Formación Profesional para el empleo en el ámbito laboral, establece que en el diseño de todas las acciones formativas se tomarán las medidas necesarias para favorecer la accesibilidad y participación de las personas con discapacidad, concretando el art. 5.2 RD 694/2017 ${ }^{30}$ este derecho, los datos de participación anualmente publicados por la Fundación Estatal por el Empleo nos permiten afirmar que este compromiso no se está cumpliendo. Pero es que, además, es sintomático del escaso interés que tiene la Fundación en este colectivo que en las estadísticas de participación en estos programas no desagregue este dato y, por tanto, no se puede conocer cuál ha sido el grado de utilización de estos recursos por las personas con discapacidad ${ }^{31}$.

Aunque el art. 31.1 de la Ley de Empleo reconoce a los trabajadores con discapacidad como uno de los colectivos prioritarios en la acción gubernamental, previendo que a fin de facilitar el acceso a la oferta de formación profesional para el empleo de los trabajadores con mayores dificultades de mantenimiento del empleo o de inserción laboral, las Administraciones Públicas competentes podrán establecer prioridades para su participación en las acciones formativas, de los datos hechos públicos por la Fundación Estatal concluimos con dos disfunciones en relación a este objetivo, es decir, en relación a la utilización de este tipo de recursos por las personas con discapacidad.

29 Puede consultarse el texto del informe en: http://tbinternet.ohchr.org/_layouts/ treatybodyexternal/TBSearch.aspx?Lang=en\&TreatyID=4\&DocTypeCategoryID=7 (fecha de consulta: 17/7/2019)

30 RD 694/2017, de 3 de julio, por el que se desarrolla la Ley 30/2015, de 9 de septiembre, por la que se regula el Sistema de Formación Profesional para el Empleo en el ámbito laboral (BOE 5.7.2017).

31 http://www.fundae.es/publicaciones/visor?reportPath=rptSerieso9 (fecha de consulta: 31/10/2019) 
De un lado, en las propuestas remitidas por las empresas o por las entidades de formación a la Fundación Estatal para que esta participe en su financiación, el hecho de contener alguna referencia a los trabajadores con discapacidad es valorado positivamente en la baremación de la solicitud, pero, en ningún caso, es condición de participación en la convocatoria. Sin embargo, si realmente se quiere incrementar la participación de estos trabajadores, tendría que reservarse un porcentaje de las plazas ofertadas a personas con discapacidad y solo en el caso de que estas no participasen en la acción programada, las mismas se liberarían.

De otro lado, a pesar de que los trabajadores con discapacidad son uno de los colectivos identificados por la Estrategia Española de Activación para el Empleo $^{32}$, y la mejora de su empleabilidad forma parte de los objetivos estratégicos establecidos en el Plan Anual de Política de Empleo ${ }^{33}$, así como de las propuestas y recomendaciones formuladas en el escenario plurianual de la formación profesional para el empleo, los datos referidos obligan a la revisión de estas acciones formativas, especialmente los programas de alternancia dirigidos a este colectivo, máxime cuando estos sistemas de formación dual son los que plantean una mayor estabilidad en relación al mantenimiento de los trabajadores con discapacidad en el mercado de trabajo.

No parece además que tenga mucho sentido que la normativa en materia de empleo califique como un colectivo homogéneo al de las personas con discapacidad, pues en su seno existe una multiplicidad de situaciones que han de ser valoradas a la hora de diseñar los itinerarios formativos que garanticen su tránsito a la empleabilidad. Llegados a este punto, convendremos en la importancia de revisar la multiplicidad de programas de formación y empleo existentes, algunos impulsados desde el tejido asociativo, otros desde las autoridades educativas, otros desde los Servicios Sociales, para no solo tratar de darles una cierta unidad, sino para conseguir que la participación en ellos no sea simplemente un recurso temporal, sino que garanticen el tránsito a la empleabilidad, a ser posible en el mercado ordinario.

En demasiadas ocasiones, estos programas formativos no están concebi-

$32 \mathrm{RD}$ 1032/2017, de 15 de diciembre, por el que se aprueba la Estrategia Española de Activación para el Empleo 2017-2020 (BOE 16.12.2017).

33 Resolución de 12 de marzo de 2019, de la Secretaría de Estado de Empleo, por la que se publica el Acuerdo del Consejo de Ministros de 8 de marzo de 2019, por el que se aprueba el Plan Anual de Política de Empleo para 2019, según lo establecido en el artículo 11.2 del texto refundido de la Ley de Empleo, aprobado por el Real Decreto Legislativo 3/2015, de 23 de octubre (BOE 15·3.2019). 
dos como una transición hacia el mercado laboral abierto, pues no han sido diseñados con estrategias que faciliten la inclusión social y laboral. El Comité sobre los Derechos de las Personas con Discapacidad, en el Informe de la investigación relacionada con España bajo el artículo 6 del Protocolo Facultativo, hecho público el 4 de junio de 2017 "notó la percepción de varios de los padres entrevistados en el sentido que un taller protegido es el mejor de los casos ya que representantes de la administración les han recomendado "no tener muchas expectativas", y que su hijo o hija podría "quedarse en casa para el resto de su vida" 34 .

Sentado lo anterior, se ha de recordar que las personas con discapacidad no solo sufren problemas con relación al mercado de trabajo, sino también en otros campos de su vida, como la vivienda, la familia, la salud, etc. Estamos ante un colectivo muy heterogéneo que, en demasiadas ocasiones, no se encuentra preparado para incorporarse directamente al mercado de trabajo, sino que su inserción requiere la participación en actuaciones que incrementen su empleabilidad. Para este perfil, suele resultar muy positivo un paso previo como es el empleo con apoyos, cuyo objetivo es permitir a las personas con especiales dificultades de empleabilidad acceder y mantenerse en el mercado laboral. Se debe abogar, al tiempo, por la necesidad de medidas específicas y claramente individualizadas, toda vez que muchos de estos trabajadores cuentan con un bajo nivel de empleabilidad. En muchos casos, son personas que han abandonado prematuramente la formación reglada y que, tras su experiencia negativa, sienten rechazo a espacios formales de formación, debiendo desarrollar metodologías flexibles que permitan retomar el interés y la motivación hacia el aprendizaje mediante objetivos progresivos y alcanzables, que les hagan tomar conciencia de sus capacidades.

Un paso en esta dirección, aun con todas las cautelas planteadas, es el espacio formativo que se puede desarrollar dentro de los Centros Especiales de Empleo. A este respecto, el convenio colectivo general de centros y servicios de atención a personas con discapacidad ${ }^{35}$ dedica un capítulo integro a la formación, reconociendo el derecho de los trabajadores incorporados en su ámbito funcional "a ver facilitada la realización de estudios para la obtención de títulos académicos o profesionales reconocidos oficialmente, a la realización de

34 Considerando 69 del Informe que puede consultarse en: http://tbinternet.ohchr. org/_layouts/treatybodyexternal/TBSearch.aspx?Lang=en\&TreatyID=4\&DocTypeCateg oryID $=7$

35 BOE 9.10.2012. 
cursos de perfeccionamiento profesional organizados por la propia empresa u otros organismos, así como a recibir una oferta formativa, estructurada en módulos formativos, vinculada a la obtención de los certificados de profesionalidad y al reconocimiento de competencias profesionales en el marco del Sistema Nacional de Cualificaciones y Formación Profesional". Seguidamente el convenio define la formación como un "factor básico para incrementar la motivación y la integración de los trabajadores y trabajadoras y crear un mecanismo eficaz e indispensable para articular la promoción es la formación. En consecuencia, la formación habrá de pasar a un primer plano en la preocupación de la empresa, por lo que ésta se compromete a vincular la formación a los distintos procesos de la carrera de los trabajadores/as y a la promoción".

Ahora bien, algunas investigaciones sobre la valoración de los usuarios de la actividad formativa desarrollada en su seno ${ }^{36}$ calificaban a la misma como "escasa" y esta circunstancia pone de manifiesto "la necesidad de reformular su función y de asegurar que su existencia responde al objetivo de mejorar la empleabilidad de las personas" ${ }^{37}$, debiendo garantizarse en la certificación oficial de las competencias adquiridas en todos los programas formativos impulsados en estos centros. El fundamento de esta certificación es dotar al participante de un sistema de acreditación de las enseñanzas adquiridas que debiese favorecer su empleabilidad. Evidentemente este requerimiento supone un reto para el tejido asociativo, cuya importancia en la impartición de acciones formativas dirigidas a las personas con discapacidad es innegable, pues exige que tanto en el diseño como la impartición de formación se efectúen teniendo presente cuáles son los requisitos exigidos por el catálogo nacional de cualificaciones para su certificación.

\section{El incremento del número de estudiantes con discapacidad en los programas de educación no obligatoria}

La promoción de la educación inclusiva es una de las áreas prioritarias establecidas por la Estrategia Europea para la Discapacidad 2010-2020, ofre-

36 De Asís Roig, R. (Dir.)., Impacto de la aplicación de la Convención de Naciones Unidas para los derechos de las personas con discapacidad en la regulación de los centros especiales de empleo, Universidad Carlos III de Madrid. Instituto Bartolomé de las Casas, Getafe, 2015, p. 88.

37 KPMG, Presente y futuro de los centros especiales de empleo, Fondo Social Europeo; Ministerio de Empleo y Seguridad Social; Fundación Once, Madrid, 2013, p. 88. 
ciendo para ello vías alternativas, formatos innovadores de Formación Profesional, más aprendizaje basado en el trabajo (prácticas de empresa), etc.

La Agencia Europea para el Desarrollo de Educación Especial ha publicado un estudio sobre las competencias en la enseñanza inclusiva en $2012^{38}$ en el que identifica cuatro competencias necesarias para incrementar la eficacia de los programas de formación no obligatoria y, por tanto, el número de estudiantes con discapacidad que cursa satisfactoriamente estudios no obligatorios.

Estas cuatro competencias se centrar en valorar la diversidad del aprendiz, apoyar a los aprendices, trabajar con otros y continuar el desarrollo profesional en un marco de aprendizaje durante toda la vida. Los estudiantes con dificultades de aprendizaje necesitan, por tanto, tener un plan de estudio personal que incluya prácticas de empresa adaptadas a ellos, y por otra parte es necesario formar a las empresas para apoyar a dicho colectivo.

\subsection{En los estudios de formación profesional}

En el estado español, el RD 1529/2012 da la posibilidad de establecer un contrato de formación y aprendizaje entre una empresa ordinaria y un trabajador con discapacidad. La figura que adquiere un especial interés para garantizar el éxito de estos programas es la de los preparadores laborales puesto que los tutores de las empresas puede que no tengan la formación suficiente para afrontar con éxito las mayores dificultades de inserción laboral de los estudiantes con discapacidad.

Dada la amplitud con la que define en el art. 2.2 RD 870/200 $7^{39}$ las posibles tareas que pueden asumir estos profesionales en relación a la orientación y acompañamiento individualizado en el puesto de trabajo, entendemos que cabría extender este acompañamiento también a la actividad formativa lo que no solo debiese incrementar el número y motivación de jóvenes con discapacidad que pudieran obtener un título de educación secundaria postobligatoria sino que, al menos, en línea de principios, debiera mejorar la corresponsabilidad del tejido empresarial con la inserción laboral de trabajadores con discapacidad. Sin embargo, ha de tenerse en cuenta que el reglamento diseña

38 https://www.european-agency.org/sites/default/files/OoPSummaryReport_ES.pdf

39 Real Decreto 870/2007, de 2 de julio, por el que se regula el programa de empleo con apoyo como medida de fomento de empleo de personas con discapacidad en el mercado ordinario de trabajo (BOE 14.7.2017). 
el empleo con apoyo como una medida para la integración en el mercado ordinario de trabajo para personas con discapacidad con especiales dificultades de integración, concretamente las que cumplan los requisitos contenidos en el art. 3.1 RD 870/2007, lo que limita notablemente su aplicación práctica.

Respecto a la concreción de esta actuación, la primera acción pasaría por la suscripción de un convenio de colaboración entre la empresa y alguna asociación, fundación u otra entidad sin ánimo de lucro, mediante la cual la empresa que va a contratar al trabajador con discapacidad va a contar con la figura del preparador laboral en el centro de trabajo del primero con el fin último de facilitar su adaptación social y laboral (art. 2.1 RD 870/2007). La función de este convenio es garantizar que el preparador pueda acompañar, de forma individualizada y en el mismo puesto de trabajo al destinatario final del programa. Esta medida de inserción se concibe con carácter temporal y merece una valoración muy positiva por varios motivos: de un lado, porque favorece el acceso al mercado ordinario no sólo desde un entorno protegido sino también desde la situación de inactividad (art. 3.1); de otro, por su carácter gratuito para la empresa ordinaria (art. 4); y finalmente por el hecho de que se exija que los preparadores acrediten un nivel mínimo de formación y una experiencia de al menos un año en actividades de integración laboral de personas con discapacidad (art. 7), debiendo dedicar un porcentaje mínimo de su jornada a cada trabajador con discapacidad en función del grado y de sus dificultades de integración. El problema que se aprecia es el desconocimiento por parte de las empresas de este concreto mecanismo de inserción lo que requiere, por parte del Gobierno, campañas de difusión del empleo con apoyo y de buenas prácticas al respecto ${ }^{40}$.

Además del convenio con la entidad para impulsar la figura del preparador laboral, las empresas que quieran participar en estos programas de alternancia tendrán que suscribir un convenio de colaboración con la entidad de enseñanza en los términos contenidos en el art. 31 RD 1529/2002. Este convenio contemplará, como mínimo, los siguientes aspectos: a) el programa de formación; b) el número de participantes; c) el régimen de becas; d) la jornada y horario en el centro y en la empresa y e) las condiciones que de-

$40 \mathrm{El}$ poco uso de esta figura se ha lamentado certeramente en el informe elaborado por el Observatorio de la Discapacidad, denominado "Estudio sobre la realidad, situación, dimensión y tendencias del empleo con apoyo en España en el horizonte del año 2020" disponible en: https://www.observatoriodeladiscapacidad.info/wp-content/uploads/2018/o5/ Informe-OED-ECA-v3.pdf (fecha de consulta: 31/10/2019) 
ben cumplir empresas, alumnos, profesores y tutores. Si realmente se quieren revalorizar las prácticas académicas externas de los estudiantes, tanto en la formación profesional reglada como en el ámbito universitario, la función del tutor en la empresa no puede dejarse en manos del voluntarismo, sino que debe reconocerse de un modo significativo esta actividad, bien a través de un complemento salarial específico bien a través del reconocimiento de crédito horario para la asunción de esta función.

\subsection{En los estudios universitarios}

El modelo dual de Formación Profesional, que se aplica tanto a los ciclos formativos de Grado Medio como de Grado Superior, y que combina la formación teórica en los centros de enseñanza con la formación práctica en la empresa, pretende no solo adecuar la formación profesional a la realidad actual del mercado de trabajo sino incrementar la inserción laboral y la empleabilidad de los titulados. A la luz de los positivos resultados en términos de inserción laboral de los egresados en formación profesional ${ }^{41}$, se ha de abogar por implementar la formación dual en el ámbito universitario ${ }^{42}$, lo cual cobra especial importancia para los estudiantes con discapacidad. Según datos de la Fundación ONCE, las personas con discapacidad solo están representadas en un 1,3\% en los estudios universitarios de grado y el porcentaje es aún inferior cuando hablamos de estudiantes de máster, posgrado o doctorado, porcentaje alejadísimo del pretendido por la Estrategia Europea 2020 que hablaba de un horizonte de un $40 \%$.

Estos datos demuestran que, a pesar del esfuerzo realizado por las universidades españolas en los últimos años para promover la diversidad y mejorar el acceso y permanencia de todas las personas con necesidades especiales en la universidad, aún resulta necesario adoptar medidas de acción positiva para reducir el abandono escolar temprano, fomentar el acceso y garantizar una formación superior adaptada. La Comunicación de la Comisión al Parlamento Europeo, al Consejo, al Comité Económico y Social Europeo y al Comité

41 Véanse los datos desagregados por nivel de estudios en las páginas 45 y siguientes del informe editado por el Ministerio de Educación y disponible en el siguiente enlace: https://cutt.ly/Aebg9Sz (fecha de consulta: 30/10/2019).

42 Arrieta Idiakez, F. J., "La formación dual en el ámbito universitario como alternativa a los retos planteados por la industria 4.o en cuanto a la empleabilidad de los jóvenes", en Mella Méndez, L. (ed.), 2018, p. 6 del ejemplar multicopiado. 
de las Regiones, de 30 de mayo de 2017, sobre una agenda renovada de la UE para la educación superior ${ }^{43}$, parte de un dato: "se está incrementando la demanda de personas altamente capacitadas y socialmente comprometidas, y esta demanda también está cambiando. En el período que va hasta 2025, se prevé que la mitad de los puestos de trabajo requieran cualificaciones de alto nivel" lo que exige a los poderes públicos eficacia y eficiencia en el diseño de los programas curriculares, incluyendo en ellos la atención a la diversidad como una materia nuclear para que los estudiantes sean capaces de responder a los retos de un nuevo modelo productivo.

Para ello, se fijan cuatro prioridades de actuación: 1) abordar los futuros casos de inadecuación de las capacidades y promover la excelencia en el desarrollo de capacidades; 2) crear unos sistemas de educación superior integradores y conectados; 3) velar por que las instituciones de educación superior contribuyan a la innovación; y 4) apoyar unos sistemas de educación superior eficaces y eficientes, y en este último objetivo es donde mejor se evidencia la necesidad de incrementar el número de estudiantes con discapacidad que culminan con éxito sus estudios postobligatorios.

De acuerdo con las directrices europeas, la eficacia del modelo educativo exige una financiación adecuada, de ahí que solo quepa valorar de manera altamente positiva que haya una partida específica de financiación para los estudiantes con discapacidad dentro de los programas de movilidad Erasmus+, impulsados en el seno de instituciones de educación superior ${ }^{44}$. Estas entidades, al firmar la Carta Erasmus de Educación Superior, se comprometen a garantizar la igualdad de acceso y oportunidades a los participantes de todas las procedencias y concretamente los estudiantes pueden beneficiarse de los servicios de apoyo que ofrecen las instituciones de acogida a los miembros de su personal y a sus propios estudiantes. Además, los participantes con problemas físicos, mentales o de salud pueden optar a financiación adicional con el fin de compensar las dificultades específicas a las que se enfrentan los participantes: alojamiento adaptado, asistencia durante los viajes, atención médica, equipos de apoyo, adaptación del material didáctico, acompañante para estudiantes o personal con discapacidad. Ahora bien, los datos de la Comisión Europea de 2015 a este respecto son elocuentes: los estudiantes con discapacidad representan tan sólo el 1\% de las movilidades totales dentro del

$43 \mathrm{COM} / 2017 / 0247$ final.

44 https://ec.europa.eu/programmes/erasmus-plus/opportunities/individuals/ physical-mental-conditions_es 
programa Erasmus+, y más concretamente, el o,16\% en movilidades de Educación Superior.

\section{El futuro: el incremento de la cualificación de las personas con discapacidad como condición para el aumento de su emplea- bilidad}

En España, el sistema de formación profesional del ámbito laboral se caracteriza por ser un sistema complejo con múltiples administraciones públicas competentes. Esta propia complejidad demanda articular políticas concertadas en torno a criterios y objetivos comunes de mejora de la calidad y la equidad, especialmente cuando el sistema educativo y formativo no solo aparece como garante del cumplimiento del derecho constitucional a la educación sino que esta cualificación es el principal mecanismo para la provisión y desarrollo de competencias y cualificaciones profesionales, con proyección en el derecho constitucional al trabajo de las personas con discapacidad.

Como se ha tratado de argumentar en este capítulo, uno de las mayores dificultades para su aprehensión es que las fuentes de información comúnmente utilizadas para análisis sociales, como son el panel Encuesta de Condiciones de Vida (diseñado desde EUROSTAT) o la Encuesta de Población Activa, no proporcionan información acerca de la existencia de alguna discapacidad en los encuestados, haciendo imposible conocer las trayectorias de formación de los adultos con discapacidad debido a la imposibilidad de identificar al colectivo $^{45}$, y también se ha de lamentar que, desde la Fundación Estatal para la Formación para el Empleo, no se desagregue el dato de participantes ni la trayectoria de estos, teniendo en cuenta esta variable. Esta misma conclusión se alcanza en la enseñanza reglada, pues aunque la legislación recuerda que la educación constituye un instrumento de mejora de la condición humana y de la vida colectiva y la LOE establece, en su Título Preliminar, que los principios en los que se inspira el sistema educativo son, entre otros: la equidad, la igualdad de derechos y de oportunidades, la no discriminación y la inclusión educativa, estos objetivos no han sido conseguidos en el sistema educativo

45 Necesidad ya detectada y criticada hace algunos años, Calero Martínez, J.; FerNÁNDEZ GuTiERrez, M., "Programas de gasto destinado a la educación inclusiva de personas con discapacidad: descripción y estimación del coste de nuevas medidas”, en Casanova Rodríguez, M. J. (ed.) Educación y personas con discapacidad: presente y futuro, ONCE, Madrid, 2009, p. 263. 
español. Esta disfunción también ha sido advertida por el Comité sobre los Derechos de las Personas con Discapacidad, el cual ha hecho público el 4 de junio de 2017, un "informe de la investigación relacionada con España bajo el artículo 6 del Protocolo Facultativo"46, centrado en examinar las presuntas violaciones graves o sistemáticas del artículo 24 (derecho a la educación) de la Convención por España, a saber, la alegada exclusión estructural y segregación de las personas con discapacidad del sistema educativo general por motivos de discapacidad, desde 2011 (fecha del examen del informe inicial del Estado parte) hasta la fecha de adopción del informe, es decir, junio de 2017.

A este respecto, "el Comité considera que la información disponible revela violaciones al derecho a la educación inclusiva y de calidad principalmente vinculadas a la perpetuación, pese a las reformas desarrolladas, de las características de un sistema educativo que continua excluyendo de la educación general, particularmente a personas con discapacidad intelectual o psicosocial y discapacidades múltiples, con base en una evaluación anclada en un modelo médico de la discapacidad y que resulta en la segregación educativa y en la denegación de los ajustes razonables necesarios para la inclusión sin discriminación en el sistema educativo general. Esta situación de segregación, respecto a la cual el Comité hizo referencia en sus observaciones finales sobre España en 2011, continúa afectando, como entonces, a alrededor de un 20\% de las personas con discapacidad, con repercusiones adversas para su inclusión en la sociedad".

Aunque el artículo 74, párr. 5, de la Ley Orgánica para la mejora de la calidad educativa establece que las administraciones educativas deben facilitar que los "estudiantes con necesidades educativas especiales" continúen su escolarización de forma adecuada, y adaptar las condiciones en las que las evaluaciones establecidas por esa Ley se llevan a cabo, el Comité lamenta "la poca atención prestada a ese tema, pues la gran mayoría de personas con discapacidad se ve obligada a abandonar sus estudios después de la educación secundaria". A su juicio, "el sistema de enseñanza postobligatorio no está suficientemente adaptado para las personas con discapacidad. Una cantidad significativa de personas con discapacidad decide entonces cursar estudios postobligatorios a distancia, para evitar las dificultades de accesibilidad e inclusión de las universidades presenciales" 47 . Como hemos

46 http://tbinternet.ohchr.org/_layouts/treatybodyexternal/TBSearch.aspx?Lang= en\&TreatyID $=4 \&$ DocTypeCategoryID $=7$

47 Véase la página 14 del informe: http://tbinternet.ohchr.org/_layouts/treatybodyexternal/TBSearch.aspx?Lang=en\&TreatyID=4\&DocTypeCategoryID=7 
señalado, después de la etapa de escolarización obligatoria (21 años), existen pocas oportunidades para que los estudiantes con discapacidad ejerzan su derecho a la participación e inclusión social y cuando existen, son rutas segregadas tales como talleres protegidos, centros de ocupación, o la permanencia en casa o en un centro de día, que recibe a personas con discapacidad de entre 17 y 70 años ${ }^{48}$.

\section{Bibliografía}

Araoz Sánchez-Dopico, I., "Insuficiencias de la regulación del derecho a la educación inclusiva en la legislación española”, en Cayo Pérez Bueno, L. (ed.) 20032012: 10 años de legislación sobre no discriminación de personas con discapacidad en España: estudios en homenaje a Miguel Ángel Cabra de Luna, Cinca, Madrid, 2012, pp. 325-340.

ARRIETA IDIAKEz, F. J., "La formación dual en el ámbito universitario como alternativa a los retos planteados por la industria 4.0 en cuanto a la empleabilidad de los jóvenes”, en Mella Méndez, L. (ed.), 2018.

BÉzou, C., "Le commerce, les clauses sociales et les normes du travail", en Deblock, C. (ed.) L'Organisation mondiale du commerce: où s'en va la mondialisation?, Les Editions Fides, 2002.

Calero Martínez, J.; Fernández Gutierrez, M., "Programas de gasto destinado a la educación inclusiva de personas con discapacidad: descripción y estimación del coste de nuevas medidas”, en Casanova Rodríguez, M. J. (ed.) Educación y personas con discapacidad: presente y futuro, ONCE, Madrid, 2009, pp. 237-265.

Casanova Rodríguez, M. A, "De la educación especial a la inclusión educativa. Estado de la cuestión y retos pendiente", Participación educativa. Revista cuatrimestral del Consejo Escolar del Estado, vol. 11, 2011.

Comité sobre los Derechos de las Personas con Discapacidad, Comentario general $n^{\circ} 4$ (2016). Artículo 24. Derecho a la Educación Inclusiva., Naciones Unidas. Convención sobre los Derechos de las Personas con Discapacidad, 2016.

Correa Carrasco, M., Acuerdos marco internacionales: de la responsabilidad Social Empresarial a la autonomía colectiva transnacional, Tirant lo Blanch, Valencia, 2016.

De Araoz Sánchez-Dopico, I., "La configuración del derecho a la educación inclusiva”, en Pérez Cayo, L. (ed.) Discapacidad, Tercer Sector e Inclusión Social, CERMI, Madrid, 2010.

48 Véase la página 5 dela respuesta emitida por el Estado español, cuya documentación está disponible en el siguiente enlace: http://tbinternet.ohchr.org/_layouts/treatybodyexternal/ Download.aspx?symbolno=CRPD\%2fC\%2f20\%2f3\&Lang=en 
De Asís Roig, R., "El encaje de la Convención Internacional sobre los Derechos de las Personas con Discapacidad", en Arenas Escribano, F., Cabra de Luna, M. A. (eds.) Comentarios al Texto Refundido de la Ley General de derechos de las personas con discapacidad y de su inclusión social, La Ley; CERMI, Madrid, 2015.

De Asís Roig, R. (Dir.)., Impacto de la aplicación de la Convención de Naciones Unidas para los derechos de las personas con discapacidad en la regulación de los centros especiales de empleo, Universidad Carlos III de Madrid. Instituto Bartolomé de las Casas, Getafe, 2015.

Delors, J., Programa de la Comisión para 1986. Discurso ante el Parlamento Europeo, Parlamento Europeo, Estrasburgo, 1986.

Doumbia-Henry, C.; Gravel, E., "Acuerdos de libre comercio y derechos laborales. Evolución reciente”, Revista Internacional del Trabajo, vol. 125, n. ${ }^{\circ} 3,2006$, pp. 207-231.

ELLIOTT, K. A., The ILO and Enforcement of Core Labor Standards, Peterson Institute for International Economics, 2000.

FernáNDEz Scrimieri, B., "Derechos sociales y globalización: soluciones multilaterales", Información Comercial Española, ICE: Revista de economía, n. ${ }^{\circ} 785$, 2000, pp. 69-80.

Gordo GonZÁlez, L., La representación de los trabajadores en las empresas transnacionales, Tirant lo Blanch, Valencia, 2017.

Guamán Hernández, A., "Cláusulas laborales en los acuerdos de libre comercio de nueva generación: una especial referencia al contenido laboral del TPP, CETA y TTIP”, Estudios financieros. Revista de trabajo y seguridad social: Comentarios, casos prácticos : recursos humanos, n. ${ }^{\circ}$ 398, 2016, pp. 83-112.

Guerrero Romera, C., Formación ocupacional de las personas con discapacidad psíquica, Ariel, Barcelona, 2002.

Gutiérrez Hurtado, F. J.; Lobejón Herrero, L. F., “Cláusulas sociales, comercio internacional y derechos laborales. La perspectiva de los países subdesarrollados", Revista de Economía Crítica, vol. 7, n..$^{\circ}$ [object Attr], 2009, pp. 55-73.

Huete García, A., "Las personas con discapacidad en la escuela. Luces y sombras del proceso de inclusión educativa en España”, Panorama Social, vol. 26, 2017.

Huete García, A.; Jiménez Lara, A. (eds.), Informe Olivenza 2016 sobre la situación de la discapacidad en España, Observatorio Estatal de la Discapacidad, Olivenza, 2016.

KPMG, Presente y futuro de los centros especiales de empleo, Fondo Social Europeo; Ministerio de Empleo y Seguridad Social; Fundación Once, Madrid, 2013.

Krugman, P. R., "New Thinking about Trade Policy", en Krugman, P. R. (ed.) Stra- 
tegic Trade Policy and the New International Economics, MIT Press, Cambridge (Massachusetts), 1986, pp. 1-22.

Lema AÑon, C., "El impacto en la educación de la Convención de la ONU sobre los Derechos de las Personas con Discapacidad”, en Casanova Rodríguez, M. J. (ed.) Educación y personas con discapacidad: presente y futuro, ONCE, Madrid, 2009, pp. 31-35.

Lim, H., The Social Clause: Issues and Challenges, OIT, Geneva.

Lobejon Herrero, L. F., "Pasado, presente y futuro de la cláusula social. El papel de la Organización Mundial del Comercio.”, Información Comercial Española, ICE: Revista de economía, vol. 843.

Marshald, S.; Fenwick, C., "Labour law and trade policy", en Labour Regulation and Development, Edward Elgar Publishing, 2016.

Maskus, K. E., Should Core Labor Standards Be Imposed Through International Trade Policy?, World Bank Publications, 1999.

Muntaner, S., "Las cláusulas sociales en el libre comercio: del TTIP al caso de Hunduras", SEGÚN ANTONIO BAYLOS..., fecha de consulta 7 febrero 2017, en http://baylos.blogspot.com.es/2015/04/las-clausulas-sociales-en-el-libre. html.

ODISMET, Informe general. La situación de las personas con discapacidad en el mercado laboral, Fundación ONCE, Madrid, 2015.

OECD, Trade, Employment and Labour Standards, Organisation for Economic Co-operation and Development, Paris, 1996.

OIT, Assessment of Labour Provisions in Trade and Investment Arrangements., ILO, Geneva, 2016.

OIT, Dimensiones sociales de los acuerdos de libre comercio., International Labour Office, Geneva, 2013.

OIT, Handbook on assessment of labour provisions in trade and investmnt arrangements, OIT, Geneva, 2016.

OIT, Informe sobre el trabajo en el mundo 2009, International Labour Office, Geneva, 2010.

ONU, Impact of globalization on the achievement of the internationally agreed development goals, including the Millennium Development Goals, ONU, Nueva York, 2008.

Pérez DEl PRADo, D., "Cláusulas laborales y libre comercio: el papel de la OIT Dialnet”, en Futuro del Trabajo: Trabajo decente para todos, Ministerio de Trabajo y Seguridad Social, Madrid, 2017.

Plena INCLUSIÓn MAdRID, La formación como oportunidad de inclusión de las personas con discapacidad intelectual, Plena Inclusión Madrid, Madrid, 2017.

Polonio De Dios, G., "La discapacidad desde la perspectiva del estado social", 2016, Universidad de Córdoba, Córdoba. 
RICARDO, D., Principios de economía política y tributación, Pirámide, Madrid, 2003.

Rivera Sánchez, J.R., La cláusula laboral en los acuerdos de libre comercio, Tirant lo Blanch, Valencia, 2018.

Rodríguzz, V., "El empleo de las personas con discapacidad en España: quo venis, quo vadis", Panorama Social, vol. 26, 2017.

SAnz Escudero, M. J., "Trayectoria del CERMI en materia educativa", Participación educativa. Revista cuatrimestral del Consejo Escolar del Estado, vol. 11, 2011.

Servicio Público Empleo Estatal, Informe del Mercado de Trabajo de las Personas con Discapacidad Estatal. Datos 2015., Ministerio de Empleo y Seguridad Social, Madrid, 2016.

Stern, R., Labor Standards and Trade Agreements, Research Seminar in International Economics, University of Michigan, 2003.

Stiglitz, J. E., Microeconomía, $2^{\text {a }}$ Edición inglesa, Ariel, Barcelona, 2001.

UNCTAD (ed.), Investor nationality: policy challenges, United Nations, New York Geneva, 2016.

VALDÉS DAL-RÉ, F., "Derechos en serio y personas con discapacidad: una sociedad para todos", en Lahera Forteza, J., Valdés Dal-Ré, F. (eds.) Relaciones laborales de las personas con discapacidad, Biblioteca Nueva, Madrid, 2005.

VAlor MarTínez, C., "Cláusulas sociales: análisis de la afinidad de objetivos con el movimiento por el comercio justo", Boletín económico de ICE, Información Comercial Española, n. ${ }^{\circ}$ 2882, 2006, pp. 39-54. 


\title{
DERECHOS FUNDAMENALES EN EL PLANO INTERNACIONAL: UNA INTRODUCCIÓN
}

\author{
Ana Belén MUÑOZ RUIZ \\ Universidad Carlos III de Madrid
}

\begin{abstract}
RESUMEN: Las fuentes de regulación de los derechos fundamentales en el plano internacional han tenido y tienen una especial incidencia sobre el nivel de protección de los trabajadores especialmente en aquellos países con escaso desarrollo en este tema. En este capítulo se analizan con detalle las fuentes internacionales generales y también las especializadas destacando la labor desarrollada por la OIT.
\end{abstract}

Palabras clave: fuentes internacionales, derechos fundamentales, trabajadores, OIT

SUMARIO: 1. Los derechos fundamentales en las fuentes internacionales generales. 1.1. La Carta de las Naciones Unidas. 1.2. La Declaración Universal de Derechos Humanos. 1.3. Los Pactos de 1966. 2. El sistema universal especializado de los derechos humanos laborales: la Organización Internacional del Trabajo.

\section{Human rights at International level: an introduction}

ABSTRACT: The legal sources on human rights at International level have a special incidence on the protection level of the employees, in particular, in those countries with less development in this topic. In this chapter we will analyse the International general sources as well as the special sources highlighting the role of ILO.

Keyword: International sources, human rights, employees, ILO

\section{Los derechos fundamentales en las fuentes internacionales generales}

El sistema universal general de los derechos humanos viene constituido por la Carta de las Naciones Unidad y también por la Carta Internacional de Derechos Humanos que comprende a la Declaración Universal de Derechos 
Humanos (DUDH), el Pacto Internacional de Derechos Civiles y Políticos (PIDCP), sus Protocolos Facultativos, y el Pacto Internacional de Derechos Económicos, Sociales y Culturales (PIDESC).

\subsection{La Carta de las Naciones Unidas}

El conjunto integrado por la Declaración Universal y los dos Pactos de Nueva York suele citarse como la "Carta internacional de derechos humanos". Mientras la Declaración Universal se concibe desde el sujeto individual al que se reconocen derechos, los Pactos, y en particular el de Derechos Económicos, Sociales y Culturales, asumen en primer lugar la dimensión social de la persona $^{1}$. Ambas disposiciones vienen a conformar un catálogo básico de los derechos fundamentales entendidos éstos como el núcleo básico, ineludible e irrenunciable del status jurídico del individuo. Como seguidamente será objeto de análisis, dentro de dicho género es posible aislar una serie de derechos fundamentales de contenido netamente laboral, los que podrían calificarse como derechos sociolaborales fundamentales, inherentes al desarrollo mismo de las relaciones laborales. Esta formulación tiene dos implicaciones trascendentales: en primer lugar, el reconocimiento de que todos los trabajadores son titulares de unos derechos fundamentales, que configuran la proyección de su dignidad humana ${ }^{2} \mathrm{y}$, en segundo término, la interrelación de estos derechos fundamentales con la libertad del trabajador como ser humano.

La Carta de las Naciones Unidas fue aprobada en la ciudad de San Francisco el 26 de junio de 1945. Se trata de un documento de carácter obligatorio para los Estados Miembros. Básicamente, la Carta regula el marco institucional de las Naciones Unidas. También, establece entre sus fines la promoción y el respeto universal de los derechos humanos y libertades fundamentales de las personas, sin hacer distinción por motivos de raza, sexo, idioma o religión (art. 55 c). La cláusula de respeto se reitera a lo largo del articulado de la Carta. Pero no se define de forma precisa en el contenido de los derechos humanos ${ }^{3}$.

1 A. SAIZ ARNAIZ, La apertura constitucional al derecho internacional y europeo de los derechos humanos. El art. 10.2 de la Constitución Española, Madrid, CGPJ, 1999, p. 126.

2 J.J. VAN DER VER, La liberté, motif juridique dans l'Organisation International du Travail, Revue des Droits de l'Homme, 1975, VII, 4, p. 871.

3 CANESSA MONTEJO, M.F., Los derechos humanos laborales en el Derecho Internacional, Tesis Doctoral, Getafe, Universidad Carlos III de Madrid, 2006, pp. 126 y 127. 


\subsection{La Declaración Universal de Derechos Humanos}

La Declaración Universal de Derechos Humanos es "el primer instrumento jurídico mundial que recoge un conjunto de principios en los que se consagran los derechos y libertades fundamentales del ser humano, reconocidos por la comunidad internacional y fundamentados en la dignidad e igualdad del género humano".

La Declaración no es un Tratado. Por tanto, no se trata de un instrumento jurídicamente vinculante para los Estados partes del mismo ${ }^{4}$. El valor moral, político y jurídico del contenido de la Declaración ha sido afirmado en diversos documentos en el seno de la Comunidad internacional. La Declaración se configura como obligatoria ad intra en la actuación de los órganos legislativos y ejecutivos del sistema internacional 5 . Esta afirmación se fundamenta en los siguientes argumentos. Por un lado, fue proclamada por la Asamblea General de las Naciones Unidas el 10 de diciembre de 1948 como un documento de alcance moral, pues representaba el "ideal común por el que todos los pueblos y naciones deben esforzarse", asegurando "su reconocimiento y aplicación universales y efectivos" entre todos los pueblos, por encima de las distintas ideologías y criterios sobre el origen y la naturaleza de los derechos humanos"6. En segundo término, en los Pactos del 1966, en concreto, en los Preámbulos, se reiteran los principios contenidos en la Declaración Universal en materia de derechos humanos7. En tercer lugar, en la Proclamación de Teherán de 1968 (refrendada por más de 120 Estados) se afirmó que la Declaración Universal "enuncia una concepción común a todos los pueblos de los derechos iguales e inalienables [...] y la declara

4 Se trata de más bien de una Recomendación que no tiene fuerza de ley, ORAA, J., La Declaración Universal de Derechos Humanos, en AA.VV. (Dir. F. Gómez ISA), La protección internacional de los derechos humanos en los albores del siglo XXI, Bilbao, Universidad de Deusto, 2003, pp. 149 y 150.

5 VILLAN DURAN, C., La Declaración Universal de Derechos Humanos en la Práctica de las Naciones Unidas, en AAVV., (Ed. A. Blanc Altemir), La protección internacional de los derechos humanos a los cincuenta años de la Declaración Universal, Madrid, Tecnos, 2001, p. 59

6 VILLAN DURAN, C., La Declaración Universal de Derechos Humanos en la Práctica de las Naciones Unidas, cit., p. 51.

7 Pero, como ha advertido la doctrina, la Declaración Universal prima el desarrollo de los derechos civiles y políticos en detrimento de los derechos económicos, sociales y culturales, VILLAN DURAN, C., La Declaración Universal de Derechos Humanos en la Práctica de las Naciones Unidas, cit., pp. 52 y 53. 
obligatoria para la comunidad internacional". Posteriormente, la Declaración de Viena señaló que: "constituye una meta común para todos los pueblos y todas las naciones", por lo que "es fuente de inspiración y ha sido la base en que se han fundado las Naciones Unidas para fijar las normas contenidas en los instrumentos internacionales de derechos humanos, en particular el Pacto Internacional de Derechos Civiles y Políticos y el Pacto Internacional de Derechos Económi-

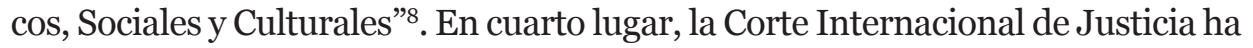
confirmado el carácter jurídico y obligatorio de la Declaración Universal ${ }^{9}$. Y, en fin, la Asamblea General reconoció que la DUDH “establece la medida común del progreso para todos los pueblos y naciones", siendo además "la fuente de inspiración y la base de los avances ulteriores en la esfera de los derechos humanos". En otro lugar, la Asamblea fue más explícita al afirmar "la validez permanente de los principios y normas enunciados en los principales instrumentos relativos a la protección internacional de los derechos humanos, particularmente la Declaración Universal de Derechos Humanos [...] Párr. 1 del Preámbulo de la Resolución 52/115 de la Asamblea General, aprobada el 12 de diciembre de $1997^{10}$.

De todo lo expuesto, es fácil convenir que la Declaración constituye "un elemento clave de la estructura constitucional del Derecho Internacional contemporáneo"11. Este reconocimiento del valor jurídico de la Declaración Universal por parte de la Comunidad Internacional ha sido respaldado por el Tribunal Constitucional español en numerosas sentencias, donde se ha tomado en consideración los contenidos de la Declaración. Todo ello contribuye a proyectar el carácter normativo de todos sus contenidos ${ }^{12}$.

8 Sin embargo, la Declaración de Viena omite pronunciarse sobre el valor jurídico de la Declaración Universal quizás, porque, en la fecha de la Declaración de Viena no se alcanzó el consenso necesario, VILLAN DURAN, C., La Declaración Universal de Derechos Humanos en la Práctica de las Naciones Unidas, en AAVV., (Ed. A. Blanc Altemir), cit., p. 57.

9 Se trataba del fallo dictado el 24 de mayo de 1980 relativo al personal diplomático y consular de los Estados Unidos en Teherán. Se dijo por parte de la Corte Internacional que el hecho de mantener ilegalmente privados de su libertad a seres humanos y someterlos a presiones físicas, es incompatible con los principios fundamentales enunciados en la Declaración Universal de los Derechos Humanos, VILLAN DURAN, C., La Declaración Universal de Derechos Humanos en la Práctica de las Naciones Unidas, cit., p. 58.

10 VILLAN DURAN, C., La Declaración Universal de Derechos Humanos en la Práctica de las Naciones Unidas, en AAVV., (Ed. A. Blanc Altemir), cit., p. 58.

11 CARRILLO SALCEDO, J.A., Soberanía de los Estados y derechos humanos en Derecho Internacional contemporáneo, Madrid, Tecnos, 1995, p. 174.

12 Se ha aplicado la Declaración Universal en materias como: la prohibición de tratos 


\subsection{Los Pactos de 1966}

En 1966 se aprobaron dos Pactos: el Pacto de Derechos Civiles y Políticos y el Pacto de Derechos Económicos, Sociales y Culturales ${ }^{13}$. El primero de ellosel Pacto Internacional de Derechos Civiles y Políticos- fue aprobado el 16 de diciembre de 1966 (entró en vigor el 23 de marzo de 1976) por la Asamblea General de Naciones Unidas. En este texto, sólo se encuentra una referencia indirecta a la prevención de riesgos laborales. Se trata del artículo 6.1 donde se dice que el derecho a la vida es inherente a la persona humana y que este derecho estará protegido por ley. Se ha calificado de derecho supremo respecto del cual no se autoriza suspensión alguna, ni siquiera excepciones que pongan en peligro la vida de la nación. Este derecho no debe ser interpretado en un sentido restrictivo ${ }^{14}$.

Por su mayor contenido social, alcanza mayor protagonismo el Pacto de Derechos Sociales, Económicos. Este Pacto fue aprobado por la Asamblea General de las Naciones Unidas el 16 de diciembre de 1966 (entró en vigor el 3 de enero de 1976). En el campo de la prevención de riesgos laborales, destacan los artículos 7 y 12 del Pacto. En el artículo 7 del Pacto los Estados Partes reconocen el derecho de toda persona al goce de condiciones de trabajo equitativas y satisfactorias que le aseguren en especial: "b) La seguridad y la higiene en el trabajo". Este precepto debe leerse conjuntamente con lo dispuesto en el artículo 12 del Pacto.

El artículo 12 es el más exhaustivo del derecho internacional de los derechos humanos sobre el derecho a la salud. En el apartado primero del precep-

inhumanos y degradantes (art. 5), al derecho a la seguridad y libertad (art. 9), al derecho a la justicia y a un proceso con garantías (art. 10), al principio de no retroactividad (art. 11.2), a la libertad religiosa (art. 18), así como a la idea de los deberes y de los límites de los derechos (art. 29.1), MARTIN-RETORTILLO BAQUER, L., La efectiva aplicabilidad de la Declaración Universal de Derechos Humanos en el Sistema Jurídico Español, Revista de Administración Pública, 200o, núm. 153, pp. 51 y 52.

13 Ratificados por España el 27 de abril de 1977.

14 Así lo ha puesto de manifiesto la Observación No 6 del Comité de Derechos Humanos. $16^{\circ}$ período de sesiones (1982). Las Observaciones Generales facilitan la aplicación del Pacto por parte de los Estados firmantes. El contenido de estas Observaciones se asemeja a la jurisprudencia del Convenio, FERNANDEZ LIESA, C.R., Los Derechos Económicos, Sociales y Culturales en el Orden Internacional, en AA.VV. (Dir. F. M. Mariño Menéndez y C. Fernández Liesa), Política social internacional y europea, Madrid, Ministerio de Trabajo y Asuntos Sociales, 1996, pp. 88 y 89. 
to, se reconoce el derecho de toda persona al disfrute del más alto nivel posible de salud física y mental. Se opta por una definición amplia de la noción del derecho a la salud. El derecho a la salud no debe entenderse como un derecho a estar sano. El derecho a la salud entraña libertades y derechos. Entre los derechos figura el relativo a un sistema de protección de la salud que brinde a las personas oportunidades iguales para disfrutar del más alto nivel posible de salud. El concepto del "más alto nivel posible de salud", a que se hace referencia en el párrafo del artículo 12, tiene en cuenta tanto las condiciones biológicas y socioeconómicas esenciales de la persona como los recursos con que cuenta el Estado.

Para lograr la plena efectividad de este derecho, se establece una lista incompleta y a título orientativo de medidas a que están obligados los Estados firmantes del Pacto: a) La reducción de la mortalidad infantil, y el sano desarrollo de los niños; b) El mejoramiento en todos sus aspectos de la higiene del trabajo y del medio ambiente; c) La prevención y el tratamiento de las enfermedades epidémicas, endémicas, profesionales y de otra índole, y la lucha contra ellas; d) La creación de condiciones que aseguren a todos asistencia médica y servicios médicos en caso de enfermedad.

Se incluyen en el apartado b) del precepto medidas relativas a la prevención de riesgos laborales, porque se ha interpretado el derecho a la salud como un derecho inclusivo, que no sólo abarca la atención a la salud oportuna y apropiada sino también los principales factores determinantes de la salud como las condiciones sanas en el trabajo y el medio ambiente. El mejoramiento de todos los aspectos de la higiene ambiental e industrial" (apartado b) del párrafo 2 del artículo 12) entraña, en particular, la adopción de medidas preventivas en lo que respecta a los accidentes laborales y enfermedades profesionales; la prevención y reducción de la exposición de la población a sustancias nocivas tales como radiaciones y sustancias químicas nocivas $\mathrm{u}$ otros factores ambientales perjudiciales que afectan directa o indirectamente a la salud de los seres humanos. Además, la higiene industrial aspira a reducir al mínimo, en la medida en que ello sea razonablemente viable, las causas de los peligros para la salud resultantes del medio ambiente laboral ${ }^{15}$.

En los Pactos del 1966 subyace una diferenciación entre dos tipos de derechos: los derechos de aplicación inmediata y los derechos de aplicación progresiva. Los primeros serían aquéllos que son de inmediata realización,

15 Observación General Núm. 14 adoptada por el Comité de Derechos Económicos, Sociales y Culturales. $22^{\circ}$ período de sesiones (2000). 
como, por ejemplo, los previstos en los arts. 2.2., 3, 7, 8, 10, 13.2 $2^{\mathrm{a}}, 3$ y 4 y $15 \cdot 3^{16}$. El resto de los derechos serían de aplicación progresiva, entre ellos, el artículo 12.

Específicamente en relación con el artículo 12 del Pacto, si bien establece la aplicación progresiva y reconoce los obstáculos que representan los limitados recursos disponibles, también impone a los Estados Partes diversas obligaciones de efecto inmediato como la obligación de adoptar medidas en aras de la plena realización de lo establecido en dicho precepto. Esas medidas deberán ser deliberadas y concretas e ir dirigidas a la plena realización del derecho a la salud. La realización progresiva del derecho a la salud, a lo largo de un determinado periodo, no debe interpretarse en el sentido de que priva de todo contenido significativo las obligaciones de los Estados Partes. Antes al contrario, la realización progresiva significa que los Estados Partes tienen la obligación concreta y constante de avanzar lo más expedita y eficazmente posible hacia la plena realización del artículo $12^{17}$.

16 FERNANDEZ LIESA pone de manifiesto que se trata de una diferenciación ya superada: $1^{\mathrm{O}}$ Debido al reconocimiento y reafirmación de la indivisibilidad de los derechos desde la Conferencia de Teherán de 1968. $2^{\circ}$. Numerosas Resoluciones de la Asamblea General de Naciones Unidas han reafirmado la indivisibilidad de los Derechos Humanos (la 32/130 (1977), la 39/145 (1984), 41/117 (1986) y la 48/141 (1993)). $3^{\text {o } . ~ L a ~ D e c l a r a c i o ́ n ~}$ de Viena de 1993, en el punto 5, indica que: "Todos los derechos humanos son universales, indivisibles e interdependientes y están relacionados entre sí. La Comunidad Internacional debe tratar los derechos humanos en forma global y de manera justa y equitativa, en pie de igualdad y dándoles a todos el mismo peso. Debe tenerse en cuenta la importancia de las particularidades nacionales y regionales, así como de los diversos patrimonios históricos, culturales y religiosos, pero los Estados tienen el deber, sean cuales fueren sus sistemas políticos, económicos y culturales de promover y proteger todos los derechos humanos y libertades fundamentales”. Sin embargo, el autor reconoce que la formulación unitaria de los derechos por Naciones Unidas encuentra algunas dificultades de aplicación por lo que se refiere a la realización de los derechos económicos, sociales y culturales, en el ámbito nacional e internacional y, también, respecto de la determinación de los criterios de determinación del incumplimiento de las obligaciones y de su contenido, FERNANDEZ LIESA, C.R., Los derechos económicos, sociales y culturales en el orden internacional, cit., pp. 71 a 74 .

$17 \mathrm{Al}$ igual que en el caso de los demás derechos enunciados en el Pacto, existe una fuerte presunción de que no son permisibles las medidas regresivas adoptadas en relación con el derecho a la salud. Si se adoptan cualesquiera medidas deliberadamente regresivas, corresponde al Estado Parte demostrar que se han aplicado tras el examen más exhaustivo de todas las alternativas posibles y que esas medidas están debidamente justificadas por 
Al igual que todos los derechos humanos, el derecho a la salud impone tres tipos o niveles de obligaciones a los Estados Partes: la obligación de respetar, proteger y cumplir. A su vez, la obligación de cumplir comprende la obligación de facilitar, proporcionar y promover. Según las observaciones generales núm. 12 y 13 [explicar de dónde vienen y qué son estas observaciones], la obligación de cumplir incorpora una obligación de facilitar y una obligación de proporcionar. En la presente observación general, la obligación de cumplir también incorpora una obligación de promover habida cuenta de la importancia crítica de la promoción de la salud en la labor realizada por la Organización Mundial de la Salud y otros organismos.

La obligación de respetar exige que los Estados se abstengan de injerirse directa o indirectamente en el disfrute del derecho a la salud. La obligación de proteger requiere que los Estados adopten medidas para impedir que terceros interfieran en la aplicación de las garantías prevista en el artículo 12. Por lo que se refiere a la obligación de proteger, se ha interpretado que la protección jurídica del derecho no se reduce solamente a las amenazas o violaciones provenientes de los agentes estatales sino que incluye también la de los particulares pues, de otro modo, "resultaría incompleto el compromiso de los Estados Partes si se excluyese de la aplicación de los derechos del Pacto el ámbito de las relaciones entre particulares"18 ${ }^{18}$ lo que se vincula, directamente, con las posibles responsabilidades empresariales en esta materia.

Por último, la obligación de cumplir requiere que los Estados adopten medidas apropiadas de carácter legislativo, administrativos, presupuestario, judicial o de otra índole para dar plena efectividad al derecho a la salud. Los Estados también pueden conculcar el derecho a la salud al no adoptar las medidas necesarias dimanantes de las obligaciones legales. Entre las violaciones por actos de omisión figuran el no adoptar medidas apropiadas para dar plena efectividad al derecho universal a disfrutar del más alto nivel posible de salud física y mental, el no contar con una política nacional sobre la seguridad y la salud en el empleo o servicios de salud en el empleo, y el no hacer cumplir las leyes pertinentes.

El mecanismo de control del cumplimiento de las obligaciones previstas en los dos Pactos se base en el examen de los informes presentados por los Esta-

referencia a la totalidad de los derechos enunciados en el Pacto en relación con la plena utilización de los recursos máximos disponibles del Estado Parte. Vid. Observación núm. 13 parr. 9 y 44 y 45 .

18 CANESSA MONTEJO, M.F., Los derechos humanos laborales en el Derecho Internacional, cit., p. 153. 
dos parte (art. 16 del Pacto). Según el artículo 16.2 a del Pacto, estos informes se someten al examen del Consejo Económico y Social de las Naciones Unidas (a partir de 1985 se denomina Comité de derechos económicos, sociales y culturales). La misión de este Comité es presentar al Consejo un informe sobre sus actividades al mismo tiempo que un acta de sus debates sobre los informes de los Estados, pudiendo proponer sugerencias y recomendaciones de carácter general con el fin de ayudar al Consejo y cumplir con sus responsabilidades ${ }^{19}$.

\section{El sistema universal especializado de los derechos humanos laborales: la Organización Internacional del Trabajo}

Se trata, como es sabido, de una organización especializada en la protección de los intereses de los trabajadores. Creada en 1919 a través del Tratado de Versalles (parte XIII), desde su constitución, uno de sus principales objetivos ha sido la humanización del trabajo a través de la mejora de las condiciones laborales. En este sentido, el Preámbulo de la parte XIII del Tratado de Versalles indica: "la urgencia de mejorar las condiciones de trabajo y, especialmente, la protección de los trabajadores contra las enfermedades generales o profesionales y los accidentes que resultan del trabajo, puesto que la falta de adopción de una reglamentación del trabajo verdaderamente humana por cualquiera de las naciones impedirá los esfuerzos de las demás deseosas de mejorar la suerte de los trabajadores en sus propios países”20.

19 El Consejo Económico y Social ha utilizado, desde sus comienzos, el procedimiento previsto por el artículo 18 del Pacto que le permite solicitar a las instituciones especializadas de las Naciones Unidas, informes sobre "los avances realizados en cuanto se refiere a la observación de las disposiciones del presente Pacto que entren en el marco de sus actividades. Finalmente, el Consejo puede "devolver los informes de los Estados y de las instituciones especializadas en derechos humanos, a la Comisión de Derechos Humanos para su estudio y elaboración de recomendaciones de orden general o para información” (art. 19), y puede también "presentar, cada cierto tiempo, a la Asamblea General, los informes que contengan recomendaciones de carácter general y un resumen de la información recibida" de los Estados parte y de las instituciones especializadas, KOJANEC, G., La Carta Social Europea y el Pacto Internacional de las Naciones Unidas relativo a los derechos económicos, Sociales y Culturales, en AA.VV. La Carta Social Europea en la Perspectiva de la Europa del año 2000. Acta del coloquio conmemorativo del XXV Aniversario de la Carta Social Europea, Madrid, Ministerio de Trabajo y Seguridad Social, 1989, pp. 122 a 124.

20 PÉREZ ALENCART, A., El derecho comunitario europeo de la seguridad y la salud en el trabajo, Madrid, Tecnos, 1993, p. 28. 
La Constitución de la Organización Internacional del Trabajo (OIT) de 1919 tiene un contenido institucional, pero también incorpora principios generales ${ }^{21}$. La Constitución de la OIT hace alusión a los derechos humanos de los trabajadores, incluyendo en esta categoría, el derecho a la seguridad y salud en el trabajo. En el fragmento del Preámbulo recién citado y también en su Anexo se refiere a la obligación de proteger adecuadamente la vida y la salud de los trabajadores en todas las ocupaciones. Refuerza esta idea el propio artículo 387 del Tratado de Versalles, precepto en el que se expresa claramente "que el bienestar físico, moral e intelectual de los asalariados industriales es de importancia esencial desde el punto de vista internacional". Por ello "el trabajo no debe considerarse simplemente como un artículo de comercio, estiman que existen métodos y principios para la reglamentación de las condiciones de aquél, que todas las comunidades industriales deberán tratar de aplicar hasta donde lo permitan las circunstancias especiales en que puedan encontrarse".

Conviene agregar en este punto que la OIT ha adoptado un concepto amplio de salud en el trabajo, subrayando que la salud en el trabajo debería perseguir: "la promoción y el mantenimiento del más elevado grado de bienestar físico, mental y social de los trabajadores en todas las ocupaciones; la prevención entre los trabajadores de dolencias causadas por las condiciones de trabajo; la protección de los trabajadores en sus empleos frente a riesgos derivados de factores nocivos para la salud; la colocación y mantenimiento del trabajador en un medio ambiente de trabajo adaptado a sus capacidades fisiológicas y psicológicas; y, resumiendo, la adaptación del trabajo al hombre y de cada hombre a su trabajo" ${ }^{22}$.

No se trata de una declaración solemne sino de un derecho efectivo. El carácter vinculante de la Constitución de la OIT, incluyéndose aquí el Preámbulo y los Principios generales- obliga a los Estados miembros desde que estos adquieren la condición de miembro de la Organización Internacional y con independencia de que estos derechos han sido desarrollados por los Convenios de la organización y su ratificación por parte de los Estados. Ha sido descrito se expresa cuando un Estado decide ser Miembro de la OIT y acepta

21 VALTICOS, N., Derecho internacional del trabajo, Madrid, Tecnos, 1977, p. 143.

22 Noción adoptada por el Comité Conjunto OIT/OMS en su primera sesión de 1950. En su 12 Sesión de 1995, revisó la definición que quedó en los términos expuestos, ALLI, B.O, Principios fundamentales de salud y seguridad en el trabajo, Madrid, Ministerio de Trabajo y Asuntos Sociales, 2002, p. 39. 
la obligatoriedad del instrumento internacional- tanto del Preámbulo como de los Principios Generales- por lo que se encuentra vinculado a respetarlos ${ }^{23}$.

Por su parte, la Declaración de Filadelfia de 1944 reafirma los principios fundamentales de la OIT (el trabajo no es una mercancía; la protección de la vida y salud de los trabajadores) que vinculan a todos los Estados Miembros. La Declaración fue agregada a la Constitución de la OIT como anexo en 1956 (sesión de la Conferencia en la ciudad de Montreal). Por ello, en la sesión de la Conferencia en la ciudad de Montreal (1946) se aprobó que la Declaración fuese agregada a la Constitución de la OIT como anexo. De esta forma, adquiere el valor jurídico de la norma fundamental del organismo internacional ${ }^{24}$.

La Declaración de la OIT relativa a los principios y derechos fundamentales en el trabajo aprobada en 1998 se configura como un texto promocional de los derechos que reconoce ${ }^{25}$. La trascendencia de esta Declaración estriba en

23 Esta tesis ha sido sostenida por VALTICOS respecto de la protección de la libertad sindical. VALTICOS, N., Normas internacionales del trabajo y derechos humanos. ¿Cómo estamos en vísperas del año 20oo?, Revista Internacional del Trabajo, Ginebra, Oficina Internacional del Trabajo, Vol. 117, núm. 2, pp. 157 y 158. El propio Comité de Libertad Sindical ha afirmado esta tesis en numerosas ocasiones: "Cuando un Estado decide ser Miembro de la Organización acepta los principios fundamentales definidos en la Constitución y en la Declaración de Filadelfia, incluidos los relativos a la libertad sindical" (CLS 1996: párrafo 10). Una aplicación concreta del carácter vinculante de la Constitución se suscitó en relación a la Unión Sudafricana. El Comité de Libertad Sindical recibió una queja contra la Unión Sudafricana por la violación de la libertad sindical dentro de su territorio. Sudáfrica cuestionó la competencia del Comité y la aplicación de los convenios internacionales sobre la materia, en razón que no los había ratificado y por ende no se encontraba obligado por ellos. El Comité señaló que la calidad de Miembro de la OIT genera obligaciones derivadas de dicha condición y de las establecidas por la Constitución, siendo una de ellas la consagración del principio de la libertad sindical, por lo que Sudáfrica aun cuando no había ratificado ninguno de los convenios sobre libertad sindical estaba obligado a respetarlos por el propio mandato de la Constitución de la OIT. Vid. el $15^{\circ}$ informe del Comité, caso núm. 102, párrafos 128-132, CANESSA MONTEJO, M.F., Los derechos humanos laborales en el Derecho Internacional, cit., pp.158 y 159.

24 CANESSA MONTEJO, M.F., Los derechos humanos laborales en el Derecho Internacional, cit., pp. 160 y 161.

25 La Declaración no es un texto normativo, CANESSA MONTEJO, M.F., Los derechos humanos laborales en el Derecho Internacional, cit., p. 163. Pone de relieve la escasa efectividad de la Declaración, sobre todo teniendo en cuenta los fracasos precedentes en el control de vulneraciones, DE LA VILLA GIL, L.E., Los derechos humanos y los derechos laborales fundamentales, Revista del Ministerio de Trabajo y Asuntos Sociales, 1999, núm. 17, pp. 282 y 283. 
que establece una nueva jerarquía normativa. Privilegia un grupo de cuatro derechos, los denominados "Core Labour standards": libre asociación, libertad de trabajo y no discriminación. Se produce así un énfasis en las técnicas promocionales de derecho blando.

El proceso de transformación comenzó en 1995 en la Conferencia de Copenhague para el Desarrollo Social. El debate que se generó en noviembre de 1996 puso de manifiesto que no había un consenso claro sobre las nuevas acciones de la OIT. Muchas de las delegaciones se resistían a la idea de un enfoque promocional sobre un grupo de estándares. Los representantes de los trabajadores indicaban que ellos querían discutir las limitaciones de los procedimientos de revisión más que las aproximaciones promocionales. Algunos de los representantes de los trabajadores defendían la idea de una Carta Mundial de los derechos de los trabajadores. Por su parte, el grupo de empleadores insistía en determinados aspectos que debían ser reflejados: 1) la Declaración no debería reflejar nuevas obligaciones para los miembros; 2) no se debería exigir nuevas obligaciones de reportes a los estados miembros; 3) no se debería imponer sobre los estados miembros obligaciones derivadas de Convenios que ellos no habían ratificado libremente. La decisión de la OIT de asegurar determinados derechos esenciales de los trabajadores ha suscitado debate entre los autores ${ }^{26}$.

Con carácter general, se han expuesto argumentos a favor y en contra de la fijación de un núcleo duro de derechos fundamentales. A favor de la distinción entre derechos humanos fundamentales y los otros derechos humanos, se manifiesta VAN BOVEN con los siguientes argumentos: 1) Sirven de base de la comunidad internacional tal como está representada en las Naciones Unidas o en otras organizaciones mundiales o regionales importantes; 2) Los miembros de esas organizaciones deben respetar esos derechos Fundamentales y las organizaciones internacionales están habilitadas a tomar medidas en caso de violación grave de tales derechos; 3) Los derechos fundamentales revisten un carácter supra-positivo en la medida en que puede exigirse a los Estados su respeto aún en la ausencia de obligación convencional o de cualquiera otra aceptación o consentimiento expreso de su parte; 4) Finalmente, esos derechos fundamentales subsisten en cualquier circunstancia, en cualquier tiempo y lugar y no admiten suspensión alguna. Para VAN BOVEN la

26 International trade and labour standards. Can common rules be agreed?: The ILO Director-General speaks out, International Labour Review, 1996, Vol. 135, Núm. 2, p. 231. Se aproxima a una categoría de ius cogens o derechos inviolables, tal y se define en el artículo 53 de la Convención de Viena. 
identificación de este núcleo permite tener una base mínima que se impone a todos, base que puede y debe ir ampliándose.

En contra de la definición de un núcleo duro o intangible de derechos humanos, KLAUS SAMSON señala lo siguiente: 1) Cuestiona el concepto mismo porque conduce a una jerarquía contraria al principio de la indivisibilidad de los Derechos Humanos; 2) La cuestión de las prioridades en la protección de los derechos es eminentemente contingente. Todo criterio a priori puede revelarse erróneo en función de las circunstancias; 3) La importancia de una violación particular, en relación con el objetivo que quiere alcanzarse, depende más de su gravedad que del contenido de la disposición infringida ${ }^{27}$.

Específicamente, por lo que se refiere a la Declaración de la OIT, se han realizado las siguientes críticas: $1^{\circ}$. Los cuatro principios identificados en la Declaración de 1998 representan sólo una parte pequeña de las obligaciones recogidas en los documentos de los que la Declaración se había inspirado. Se trata de una lista muy limitada ${ }^{28}$ que, por ejemplo, no protege los derechos de seguridad y salud en el trabajo ${ }^{29} \cdot 2^{\mathrm{O}}$. Permite la diferenciación entre "worker rights" y "labor standards". Para BLACKWELL, "worker rights son las normas de derechos humanos que gobiernan el camino en el que el trabajo es tratado internacionalmente, sin considerar el nivel de desarrollo del país. De otra parte, los denominados labor standards varían en función del nivel de desarrollo del país ${ }^{30} \cdot 3^{0}$. En definitiva, la selección de los derechos responde a un fenómeno de debilitamiento y no de fortalecimiento de la promoción y de la protección de los Derechos Humanos ${ }^{31}$.

27 Se recogen las dos posturas en el trabajo de SOTTAS, E., El núcleo duro de los derechos humanos desde la perspectiva del derecho constitucional, en AA.VV. (Ed. A. Marzal), El núcleo duro de los derechos humanos, Bosch, 2001, p. 112.

28 ALSTON, P., Core labour standards' and the transformation of the international labour rights regime, European Journal of International Law, 2004.

29 DI MATTEO et al, The Doha Declaration and Beyond: giving a voice to non-trade concerns within the WTO trade regime, Vanderbilt Journal of Transnational Law, 2003, núm. 36, p. 124.

30 BLACKWELL, in Human Rights Program, Harvard Law School, Business and Human Rights: An Interdisciplinary Discusión Held at Harvard Law School in December 1997 (1999), at. 15. Otros autores han dibujado una distinción similar: por ejemplo, R. Freeman, A Hard-Headed Look at Labour Standards in W. Sengenberger and D. Campbell (eds), International Labour Standards and Economic Interdepence (1994). Las referencias han sido tomadas del trabajo de McCRUDDEN, C. y DAVIES, A., A perspectiva on trade and labor rights, Journal of International Economic Law, 2000, p. 50.

31 Esta es la opinión de SOTTAS tras leer las actas de la Conferencia que adoptó la Declaración y los debates y trabajos que durante cuatro años acompañaron de ese docu- 
El derecho a la vida también de los trabajadores pertenece al grupo de los derechos denominados de protección reforzada o bloque compacto de derechos no derogables porque está en juego un atributo inalienable de la persona y, a su vez, se coloca en el valor supremo dentro de la escala de los derechos humanos. Siguiendo este razonamiento, durante un largo periodo de tiempo, se ha dicho que la Declaración de la OIT debería ser objeto de replanteamiento para proponer la inclusión del derecho a la vida de los trabajadores. Con esta propuesta, se reforzaría la posición internacional de este derecho en coherencia con lo dispuesto en la Constitución de la OIT y proyectando sus efectos sobre aquellos países más reacios a la firma de los Convenios vinculados con esta materia.

Con motivo de la celebración del centenario de la OIT, se ha realizado una propuesta de gran interés en esta materia y sobre la que parece oportuno detenerse a reflexionar. En concreto, por parte de la Comisión Mundial de la OIT sobre el Futuro del Trabajo se formula la necesidad de que la seguridad y la salud en el trabajo sea reconocida como un principio y un derecho fundamental del trabajo y que extienda su protección a todos con independencia de su acuerdo contractual o situación laboral (Informe OIT "Trabajar para un futuro más prometedor", 2019).

\section{Bibliografía}

ALLI, B.O, Principios fundamentales de salud y seguridad en el trabajo, Madrid, Ministerio de Trabajo y Asuntos Sociales, 2002.

ALSTON, P., Core labour standards' and the transformation of the international labour rights regime, European Journal of International Law, 2004.

CANESSA MONTEJO, M.F., Los derechos humanos laborales en el Derecho Internacional, Tesis Doctoral, Getafe, Universidad Carlos III de Madrid, 2006.

CARRILLO SALCEDO, J.A., Soberanía de los Estados y derechos humanos en Derecho Internacional contemporáneo, Madrid, Tecnos, 1995.

DE LA VILLA GIL, L.E., Los derechos humanos y los derechos laborales fundamentales, Revista del Ministerio de Trabajo y Asuntos Sociales, 1999.

DI MATTEO et al, The Doha Declaration and Beyond: giving a voice to

mento, SOTTAS, E., El núcleo duro de los derechos humanos desde la perspectiva del derecho constitucional, cit., p. 113. 
non-trade concerns within the WTO trade regime, Vanderbilt Journal of Transnational Law, núm. 36, 2003.

FERNANDEZ LIESA, C.R., Los Derechos Económicos, Sociales y Culturales en el Orden Internacional, en AA.VV. (Dir. F. M. Mariño Menéndez y C. Fernández Liesa), Política social internacional y europea, Madrid, Ministerio de Trabajo y Asuntos Sociales, 1996.

KOJANEC, G., La Carta Social Europea y el Pacto Internacional de las Naciones Unidas relativo a los derechos económicos, Sociales y Culturales, en AA.VV. La Carta Social Europea en la Perspectiva de la Europa del año 2000. Acta del coloquio conmemorativo del XXV Aniversario de la Carta Social Europea, Madrid, Ministerio de Trabajo y Seguridad Social, 1989.

McCRUDDEN, C. y DAVIES, A., A perspectiva on trade and labor rights, Journal of International Economic Law, 2000.

MARTIN-RETORTILLO BAQUER, L., La efectiva aplicabilidad de la Declaración Universal de Derechos Humanos en el Sistema Jurídico Español, Revista de Administración Pública, núm. 153, 2000.

ORAA, J., La Declaración Universal de Derechos Humanos, en AA.VV. (Dir. F. Gómez ISA), La protección internacional de los derechos humanos en los albores del siglo XXI, Bilbao, Universidad de Deusto, 2003.

PÉREZ ALENCART, A., El derecho comunitario europeo de la seguridad y la salud en el trabajo, Madrid, Tecnos, 1993

SAIZ ARNAIZ, A., La apertura constitucional al derecho internacional y europeo de los derechos humanos. El art. 10.2 de la Constitución Española, Madrid, CGPJ, 1999.

SOTTAS, E., El núcleo duro de los derechos humanos desde la perspectiva del derecho constitucional, en AA.VV. (Ed. A. Marzal), El núcleo duro de los derechos humanos, Bosch, 2001

VALTICOS, N., Derecho internacional del trabajo, Madrid, Tecnos, 1977

VAN DER VER, J.J., La liberté, motif juridique dans l'Organisation International du Travail, Revue des Droits de l’Homme, 1975, VII, 4. 



\title{
LAS CLÁUSULAS LABORALES COMO HERRAMIENTA PARA LOGRAR EL OBJETIVO DEL TRABAJO DECENTE
}

\author{
Daniel PÉREZ DEL PRADO \\ Universidad Carlos III de Madrid
}

\begin{abstract}
RESUMEN: El libre comercio se ha situado en el centro del debate político. La renegociación de algunos tratados comerciales o la llamada "guerra comercial" con China quizá sean los ejemplos más paradigmáticos. Aunque los motivos que explican esta situación son muy variados, no debe perderse de vista que aunque el comercio produzca beneficio neto, también genera externalidades negativas en el plano social y laboral que es preciso compensar mediante la adopción de instrumentos adicionales adecuados y eficaces.

Entre éstos destacan la incorporación de cláusulas laborales a los tratados de libre comercio, en cuya virtud se garantizan unos estándares mínimos (frecuentemente los marcados por los convenios de la OIT) entre las partes firmantes. El objeto de este trabajo es analizar hasta qué punto estas cláusulas están cumpliendo la función que tienen encomendada, en qué medida contribuyen a alcanzar el objetivo de trabajo decente y sostenible y cuál es el rol que los agentes sociales pueden jugar a este respecto.
\end{abstract}

PALABRAS CLAVE: libre comercio, tratados comerciales, cláusulas laborales, OIT.

SUMARIO: 1. Introducción: el debate sobre las externalidades negativas del libre comercio en las condiciones de trabajo. 2. La progresiva incorporación de cláusulas laborales en los tratados comerciales internacionales. 2.1. Concepto y morfología de las clausulas laborales. 2.2. La implantación de las cláusulas laborales. 2.3. Efectos y eficacia de las cláusulas laborales desde el plano económico. 3. Las cláusulas laborales como garantía del trabajo decente. 4. Bibliografía.

ABSTRACT: Free trade has been placed on the centre of the political debate. The renegotiation of certain trade agreements or the so-called "trade war" with China maybe are the most important examples. Despide the reasons of this situation are varied, it must take into consideration that in spite of the fact that free trade produces beneficial effects, it also generates negative externalities social and working conditions which must be compensated on by the adoption of some parallel instruments.

The paper focused on one of these tools, the labour provisions included in trade 
agreements, which aims to guarantee certain minimum labour conditions (frequently set by ILO's conventions) among the parties involved. The main objective is to analyse to what extense they are working properly and contributing to achieve the objective of decent and sustainable work and which role the social partners can play concerning it.

KEYWORDS: trade, free trade, labour provisions, ILO.

\section{Introducción: el debate sobre las externalidades negativas del libre comercio en las condiciones de trabajo}

El libre comercio se ha situado en el centro del debate político. La elección de Donald Trump como presidente de los EEUU ha hecho virar los consensos internacionales a favor del libre comercio y la extensión de los acuerdos internacionales que los propician. Su decisión de retirarse del Acuerdo Transpacífico $^{1}$, de renegociar el NAFTA ${ }^{2}$, de suspender ${ }^{3}$ la negociación del Tratado Transatlántico de Libre Comercio entre EEUU y la UE ${ }^{4}$ o la llamada "guerra comercial” con China, probablemente constituyan los ejemplos más paradigmáticos.

Las principales razones esgrimidas son la existencia de prácticas comerciales desleales, el robo de propiedad intelectual y, por lo que aquí respecta, los supuestos efectos perniciosos sobre la clase trabajadora norteamericana, mensaje que caló especialmente, a juzgar por los resultados electorales, en las antiguas ciudades industriales de los estados más afectadas por la globalización.

1 Oficialmente denominado “Acuerdo Transpacífico de Cooperación Económica” (en inglés: Trans-Pacific Partnership, TPP).

2 Tratado de Libre Comercio de América del Norte (TLCAN), más conocido por sus siglas en inglés, NAFTA (North American Free Trade Agreement). El 30 de noviembre de 2018, se firmó entre Estados Unidos, México y Canadá el Tratado entre México, Estados Unidos y Canadá (T-MEC o USMCA por sus siglas en inglés), llamado a sustituir al NAFTA, que seguirá vigente hasta que sus miembros lo ratifiquen.

3 Esa la valoración que le dio la comisaria del ramo, Cecilia Malmström, ante la toma de posesión del nuevo presidente y que, hasta la fecha, no se ha visto modificada. Véase la entrada en el blog oficial de la comisaria: https://ec.europa.eu/commission/commissioners/2014-2019/malmstrom/blog/ttip-assessment-and-pause_en

4 Más conocido por sus siglas en inglés TTIP, Transatlantic Trade and Investment Partnership. 
En este último aspecto, el argumento básico del presidente Trump es que el libre comercio ha deteriorado las condiciones de vida y laborales de los trabajadores norteamericanos, lo que hace necesario la adopción de medidas protectoras hacia la industria del país, así como la reconsideración del conjunto de la política comercial de los EEUU ${ }^{5}$. Parecidos argumentos se dieron relación a la negociación y ratificación del $\mathrm{CETA}^{6}$, que ha sido objeto de fuertes críticas, entre otras cuestiones, por los temores de que un nuevo acuerdo de libre comercio de esta magnitud tuviera efectos devastadores sobre el empleo.

¿Hasta qué punto afecta el libre comercio a las condiciones de trabajo y el bienestar social? De existir efectos negativos, ¿̇resulta posible prevenirlos o compensarlos?

Desde David Ricardo existe consenso entre los economistas acerca de que el efecto neto del libre comercio es positivo ${ }^{8}$. La eliminación de las trabas al comercio repercute en mayor crecimiento económico para las partes implicadas, lo que puede traducirse en mayor bienestar para el conjunto de la ciudadanía. Ahora bien, ni esto último es una consecuencia directa y automática del libre comercio, ni es menos cierto que todo proceso de liberalización de los mercados tiene ganadores y perdedores ${ }^{9}$. La liberalización comercial emprendida en la última década ha permitido que millones de personas salgan de la pobreza, pero sus resultados en términos generales han sido muy desequilibrados ${ }^{10}$.

5 https://www.donaldjtrump.com/policies/trade

6 El Acuerdo Integral sobre Economía y Comercio o Acuerdo Económico y Comercial Global (AECG), más conocido por sus siglas en inglés CETA (Comprehensive Economic and Trade Agreement).

7 http://internacional.elpais.com/internacional/2016/10/22/actualidad/14771242 22_951899.html

8 Desde Ricardo, Ricardo, D., Principios de economía política y tributación, Pirámide, Madrid, 2003., a economistas contemporáneos como Krugman, P. R., "New Thinking about Trade Policy", en Krugman, P. R. (ed.) Strategic Trade Policy and the New International Economics, MIT Press, Cambridge (Massachusetts), 1986, pp. 1-22.. Una explicación sencilla puede verse en Stiglitz, J. E., Microeconomía, $2^{a}$ Edición inglesa, Ariel, Barcelona, 2001, pp. 67-69.

9 Krugman, P. R., "New Thinking about Trade Policy", cit., pp. 1-22. Entre estos últimos frecuentemente se encuentran determinadas categorías de trabajadores, como los poco cualificados y los de determinados sectores industriales.

$10 \mathrm{ONU}$, Impact of globalization on the achievement of the internationally agreed development goals, including the Millennium Development Goals, ONU, Nueva York, 2008, p. 9. 
En el propio proceso de construcción del mercado único europeo tenemos el ejemplo más cercano. Como señaló Jacques Delhors, «la creación de una vasta área económica, basada en la cooperación, es inconcebible -diría inalcanzable- sin la armonización de la legislación social. Nuestro objetivo último ha de ser de un área social europea $»^{11}$. Dicho de otra forma, el desarrollo del mercado único europeo requería la consiguiente compensación en el plano social de las externalidades negativas derivadas del paulatino proceso de integración económica. Estas conclusiones en el plano regional europeo son extrapolables a cualquier otro proceso de integración o cooperación económica, es decir, para que los beneficios del libre comercio alcancen al conjunto de la sociedad y, especialmente a los trabajadores, es preciso adoptar mecanismos correctores concretos que lo permitan.

Entre estos mecanismos destacan la incorporación de cláusulas laborales en los tratados de libre comercio, que tienen por objetivo garantizar unas condiciones mínimas de trabajo entre las partes firmantes, de tal forma que se asegure el proceso de liberalización comercial no conduzca hacia una carrera a la baja en las condiciones de trabajo o, al menos, se impida que se traspasen unos umbrales mínimos garantizados. En este sentido, pueden jugar un papel muy relevante en lo que hace a la consecución del objetivo de trabajo decente en el marco de la Estrategia $2030^{12}$.

\section{La progresiva incorporación de cláusulas laborales en los tra- tados comerciales internacionales ${ }^{13}$. \\ 2.1. Concepto y morfología de las cláusulas laborales}

La incorporación de "cláusulas laborales" en los tratados comerciales internacionales surge con el propósito de evitar que la liberalización comercial derive en situaciones de dumping social. En un contexto de mercados sin ningún tipo de protección o barrera se corre el riesgo de que se empleen las

11 Delors, J., Programa de la Comisión para 1986. Discurso ante el Parlamento Europeo, Parlamento Europeo, Estrasburgo, 1986. EC Bulletin 2/1986, 12.

12 Rivera SÁnchez, J.R., La cláusula laboral en los acuerdos de libre comercio, Tirant lo Blanch, Valencia, 2018, pp. 55-57.

13 Las conclusiones más recientes se encuentran en el estudio OIT, Assessment of Labour Provisions in Trade and Investment Arrangements., ILO, Geneva, 2016. Posteriormente actualizadas en Aissi, J.; Peels, R.; Samaan, D., "Evaluating the effectiveness of labour provisions in trade agreements: An analytical and methodological framework", International Labour Review, vol. 157, 4, 2018, pp. 671-698. 
condiciones de trabajo como un mecanismo para ganar competitividad, de tal forma que se amplíe la cuota de mercado a base de reducir costes laborales o, lo que frecuentemente es lo mismo, empeorando las condiciones de trabajo. De esta forma, se cae en una situación de competencia o carrera a la baja que termina por deteriorar las condiciones laborales de todas las partes implicadas. Ante este tipo de situaciones solo caben dos tipos de alternativas: o el proteccionismo, o la incorporación de cláusulas que establezcan unos suelos mínimos, esto es, que garanticen unas determinadas condiciones de trabajo imprescindibles ${ }^{14}$.

Las cláusulas laborales surgen así como un instrumento jurídico capaz de conjugar los beneficios del libre comercio a la vez que evitan el dumping social. Este tipo de cláusulas se encuentran en diversos instrumentos internacionales, no solamente los tratados comerciales o los de integración económica ${ }^{15}$ (ya sean unilaterales, bilaterales, regionales -y transregionales-) ${ }^{16}$, sino también en los acuerdos internacionales de financiación y los sistemas de preferencias comerciales ${ }^{17}$.

Los estudios que a este respecto ha llevado a cabo la OIT entienden por "cláusula laboral": a) cualquier tipo de norma que tenga que ver con las relaciones laborales (frecuentemente los propios convenios de la OIT) o con la garantía de unas condiciones mínimas de trabajo o empleo; b) cualquier mecanismo destinado a asegurar el cumplimiento de tales normas, ya sea bajo la ley nacional o por alguna de las cláusulas incorporadas en el tratado comercial y; c) cualquier marco destinado a actividades de cooperación, diálogo y/o control de asuntos laborales ${ }^{18}$. Por consiguiente, el concepto de

14 Valor Martínez, C., "Cláusulas sociales: análisis de la afinidad de objetivos con el movimiento por el comercio justo”, Boletín económico de ICE, Información Comercial Española, 2882, 2006, p. 40.

15 Denominados así porque van más allá de cuestiones comerciales, como por ejemplo los programas de infraestructuras.

16 Las cláusulas laborales pueden estar incluidas en el propio instrumento o en documentos secundarios, como acuerdos complementarios o memorándums de entendimiento (estos últimos no suelen ser jurídicamente vinculantes).

17 Lobejon Herrero, L. F., "Pasado, presente y futuro de la cláusula social. El papel de la Organización Mundial del Comercio.”, Información Comercial Española, ICE: Revista de economía, vol. 843, pp. 154-157.

18 Esta delimitación arranca en OIT, Informe sobre el trabajo en el mundo 2009, International Labour Office, Geneva, 2010, pp. 72-73. Y se han mantenido en estudios posteriores: OIT, Dimensiones sociales de los acuerdos de libre comercio., International 
"cláusula laboral" es muy amplio y flexible, ya que no solamente tiene que ver con normas que regulen o aseguren condiciones de trabajo y empleo (regulación sustantiva estricta), sino también con aquellas que van dirigidas a determinar el cumplimiento o aplicación de tales normas (regulación instrumental), o que tienen que ver con mecanismos de regulación blanda o soft law (regulación sustantiva blanda o flexible). La causa fundamental de esta amplia delimitación está relacionada con que, en la experiencia práctica, son muy variadas los tipos de normas laborales que podemos encontrar en los tratados comerciales.

De una parte, las disposiciones laborales que tienen que ver con la regulación sustantiva de condiciones de trabajo pueden dividirse según contengan normas jurídicamente vinculantes o simplemente materialicen algún compromiso político. En esta clasificación se observa claramente la distinción entre hard y soft law. En el primer ámbito, las obligaciones impuestas pueden serlo en relación con normas de Derecho internacional, como los principios y derechos fundamentales del trabajo a que se refiere la Declaración de la OIT de 1998, o a los propios convenios de la OIT; o en relación a las propias legislaciones laborales nacionales. En el segundo se encuentran frecuentemente cláusulas que obligan a los estados firmantes a aumentar progresivamente el nivel de protección de sus legislaciones laborales o, al menos, a no reducirlo con el objetivo de fomentar las exportaciones o las inversiones. De esta forma, no se impone al estado la aplicación de una determinada norma en relación a una específica cuestión laboral sino un objetivo genérico que, en un plazo determinado de tiempo, ha de ser alcanzado.

En el caso particular de la UE $\mathrm{UE}^{19}$, los acuerdos más recientes (llamados de cuarta generación) tienen como objetivo fundamental la protección de los derechos de los trabajadores en el marco de la estrategia de desarrollo sostenible. Asimismo, como garantía de mínimos, además de la Declaración de la OIT de 1998, se vienen incluyendo la Declaración Ministerial del Consejo Económico y Social de las Naciones Unidas (ECOSOC) sobre generación de

Labour Office, Geneva, 2013, p. 9. OIT, Assessment of Labour Provisions in Trade and Investment Arrangements., cit., p. 21. No obstante, el primer estudio amplio sobre la materia fue OECD, Trade, Employment and Labour Standards, Organisation for Economic Co-operation and Development, Paris, 1996. Para una aproximación básica al concepto de “cláusula laboral”, vid. Lim, H., The Social Clause: Issues and Challenges, OIT, Geneva. (Disponible online)

19 OIT, Assessment of Labour Provisions in Trade and Investment Arrangements., cit., p. 41. 
empleo pleno y productivo y trabajo decente para todos de 2006 y los ocho convenios fundamentales de la $\mathrm{OIT}^{20}$.

Sea cual fuere el tipo de regulación sustantiva a que nos refiramos, buena parte de su eficacia práctica dependerá de la previsión de mecanismos de aplicación, seguimiento y control. En este ámbito, la variedad también es amplia y va desde aquellas cláusulas que se aplican a determinadas relaciones comerciales entre las partes o a toda relación comercial, a aquellas que, de forma más amplia, se aplican a cuestiones laborales, independientemente de su vinculación con las relaciones comerciales ${ }^{21}$. En concreto, se han distinguido los siguientes cinco tipos ${ }^{22}$ :

En primer lugar, nos encontraríamos con las medidas previas a la ratificación, que consisten en la imposición de reformas legales o institucionales como prerrequisito indispensable para la ratificación del acuerdo. Por su propia naturaleza no forman parte del tratado comercial, sino que se trata de requisitos previos a su firma. Estas condiciones suelen basarse en la homologación de las condiciones laborales a los estándares mínimos internacionales, aunque pueden consistir también en la mejora de la capacidad técnica de aplicación del acuerdo de una de las partes (normalmente la menos desarrollada).

En segundo lugar, nos encontramos con la cooperación técnica, que se refiere a cualquier tipo de medida que permite proveer asistencia técnica a la contraparte. Normalmente está dirigida al Estado en su conjunto, aunque también puede centrarse en otros sujetos, como empresas o agentes sociales.

El tercer tipo de cláusulas son los mecanismos de control y significan una re-

20 Los convenios de la OIT calificados como fundamentales y conocidos bajo el término «normas fundamentales» en el trabajo son: Convenio Relativo a la Libertad Sindical y a la Protección del Derecho de Sindicación, 1948 (núm. 87), Convenio Relativo a la aplicación de los principios del Derecho de Sindicación y de Negociación Colectiva, 1949 (núm. 98), Convenio Relativo al Trabajo Forzoso u Obligatorio, 1930 (núm. 29), Convenio Relativo a la Abolición del Trabajo Forzoso, 1957 (núm. 105), Convenio sobre la Edad Mínima de Admisión al Empleo, 1973 (núm. 138), Convenio sobre la Prohibición de las Peores Formas de Trabajo Infantil y la Acción Inmediata para su Eliminación, 1999 (núm. 182), Convenio Relativo a la Igualdad de Remuneración entre la Mano de Obra Masculina y la Mano de Obra Femenina por un Trabajo de Igual Valor, 1951 (núm. 100) y Convenio Relativo a la Discriminación en Materia de Empleo y Ocupación, 1958 (núm. 111).

21 OIT, Informe sobre el trabajo en el mundo 2009, cit., pp. 74-75.

22 OIT, Assessment of Labour Provisions in Trade and Investment Arrangements., cit., pp. $72-73$. 
visión de las progresiones realizadas en relación a determinados objetivos durante un cierto tiempo. Normalmente estas medidas se centran en incrementar la transparencia e informar a los actores intervinientes acerca del estado de situación de diversas áreas relacionadas con lo laboral. Los mecanismos de control pueden tomar la forma de informes parciales progresivos, la participación de sujetos implicados mediante la posibilidad de formular peticiones o quejas o la incorporación de colaboradores externos públicos o privados.

En cuarto lugar, los acuerdos de disputas o de resolución de conflictos pueden tomar diversas formas: las consultas intergubernamentales, el uso de paneles de expertos, el recurso al arbitraje internacional o el empleo de la amenaza de sanciones, frecuentemente incorporados en los acuerdos con EEUU y Canadá, son los más frecuentes. Aunque normalmente están pensados como instrumentos de reacción frente a incumplimientos por parte de los Estados, se han previsto también formas particulares a nivel de empresa para el caso de que los incumplimientos se produzcan por sujetos particulares. En todo caso, la adopción de estos últimos mecanismos de control, muy desarrollados por parte de Canadá y EEUU, contrasta con la preferencia europea por otros de naturaleza blanda, basados en la consulta y la persuasión política y, en caso de no obtener un resultado satisfactorio, en la intervención de un tercero independiente ${ }^{23}$. La única excepción a este respecto hasta la fecha has sido el acuerdo CARIFORUM-UE ${ }^{24}$.

Por último, los acuerdos comerciales han incorporados (des)incentivos económicos, que consisten en la imposición de un coste o un beneficio en caso de incumplimiento o cumplimiento de las obligaciones laborales previstas en el tratado, tales como la imposición de multas pecuniarias en el primer caso o el incremento de las cuotas de exportación en el segundo. Los incentivos y desincentivos económicos pueden aplicados a nivel estatal o empresarial y suelen combinarse con otras formas de control.

A pesar de esta amplia variedad de mecanismos, una de las críticas más habituales en relación con las cláusulas laborales tiene que ver precisamente con su escasa efectividad ${ }^{25}$. EEUU ha sido quizá el país que más esfuerzos ha

23 Véase el caso del propio CETA en el apartado 3.

24 OIT, Assessment of Labour Provisions in Trade and Investment Arrangements., cit., p. 41.

25 Lo que se achaca a los complejos procedimientos para su aplicación y la lejanía con el nivel de aplicación. También se critica su utilización política, esto es, al margen de las condiciones de trabajo y en función de intereses de carácter político. Muntaner, S., "Las cláusulas sociales en el libre comercio: del TTIP al caso de Hunduras”, SEGÚN ANTONIO 
dedicado a evaluar en qué medida estos mecanismos jurídicos están cumpliendo su función, siendo los resultados obtenidos muy limitados ${ }^{26}$. Quizá ello explique el giro actual en su política comercial pues, como vimos, es la vía alternativa simple ante el dumping social. Sea como fuere, a pesar de estas evaluaciones, lo cierto es que su uso ha experimentado un notable avance en los últimos años. $\mathrm{Al}$ análisis de su evolución reciente dedicaremos las páginas que siguen.

\subsection{La implantación de las cláusulas laborales}

Dentro de estos parámetros, la evolución experimentada por las cláusulas laborales desde el plano cuantitativo es ciertamente notable. Aunque pueden encontrarse algunas referencias previas, la primera vez que se introdujeron este tipo de cláusulas con carácter imperativo fue en 1994, en el Acuerdo de Cooperación Laboral de América del Norte (ACLAN), vinculado al NAFTA. Desde ese momento y hasta diciembre de 2015, había 75 tratados comerciales en vigor (pertinentes a 107 economías) con cláusulas laborales, de los cuales, casi la mitad de ellos fueron suscritos después de 2008. Estos suponen más de un cuarto (el $28 \%$ para ser más exactos) de los tratados que han sido notificados a la Organización Mundial del Comercio (OMC) y que están en vigor ${ }^{27}$.

Como puede observarse en el siguiente gráfico, la tendencia hasta 2009 es claramente creciente, tanto en lo que se refiere al número total de tratados comerciales firmados, como en lo que hace a aquellos que incluyen cláusulas

BAYLOS..., 8/04/2015, http://baylos.blogspot.com.es/2015/04/las-clausulas-socialesen-el-libre.html. En el mismo sentido, Doumbia-Henry, C.; Gravel, E., "Acuerdos de libre comercio y derechos laborales. Evolución reciente", Revista Internacional del Trabajo, vol. 125, 3, 2006, p. 221.

26 Guamán Hernández, A., "Cláusulas laborales en los acuerdos de libre comercio de nueva generación: una especial referencia al contenido laboral del TPP, CETA y TTIP”, Estudios financieros. Revista de trabajo y seguridad social: Comentarios, casos prácticos : recursos humanos, 398, 2016, p. 94. Gutiérrez Hurtado, F. J.; Lobejón Herrero, L. F., "Cláusulas sociales, comercio internacional y derechos laborales. La perspectiva de los países subdesarrollados”, Revista de Economía Crítica, vol. 7, [object Attr], 2009, pp. 60-62. Algunos estudios han subrayado que, teniendo en cuenta los distintos tipos de medidas, son más efectivas las de control y cooperación que las de corte sancionador. VALOR MarTínez, C., "Cláusulas sociales", cit., p. 45.

27 OIT, Assessment of Labour Provisions in Trade and Investment Arrangements., cit., p. 22. 
laborales. Sin embargo, la crisis económica parece haber afectado en cierta medida a la negociación comercial internacional, pues se observa que se ha retrocedido a los niveles previos a 2006. No obstante, esto ha beneficiado a los acuerdos con cláusulas laborales. Más del 80 por ciento de los acuerdos vigentes desde 2013 contienen ese tipo de disposiciones. Esta última cifra tiene su origen en que la mayoría de los acuerdos comerciales suscritos lo fueron con los principales proponentes de este tipo de disposiciones, como la Unión Europea, Estados Unidos y Canadá ${ }^{28}$. De los siete acuerdos comerciales que se suscribieron en 2013, cuatro no tuvieron a estos tres sujetos como intervinientes (Costa Rica-Singapur, República de Corea-Turquía, Malasia-Australia y Nueva Zelanda-Taiwán); de los nueve de 2014, cuatro tuvieron otros actores (Australia-República de Corea, Hong Kong-Chile, Islandia-China y Suiza-China) y en 2015, la misma relación fue 4/2.

\section{Gráfico 1. Número de tratados comerciales con y sin cláusulas laborales, 1995-2015.}

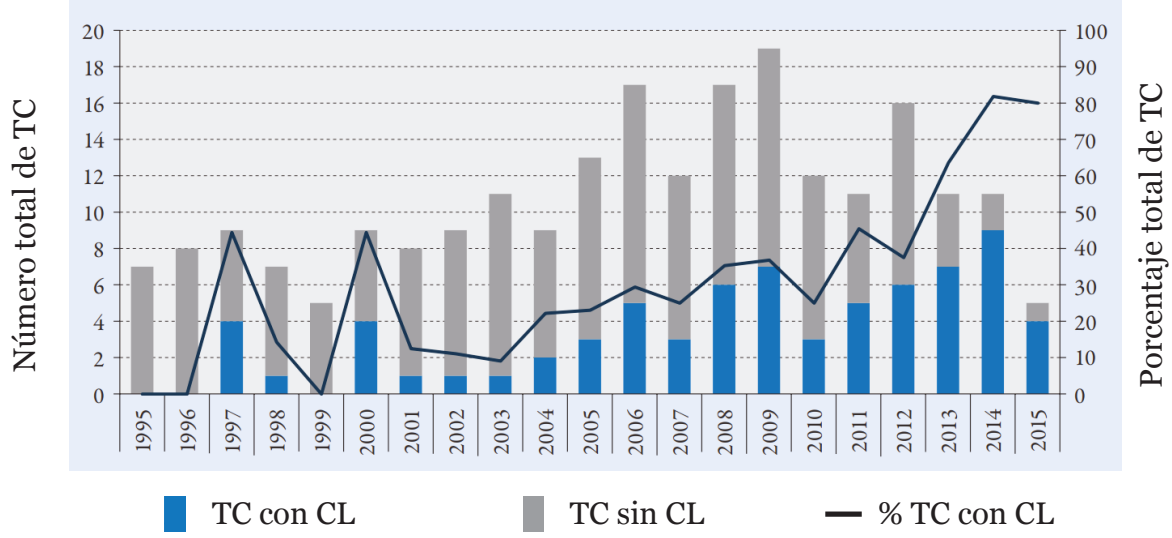

Fuente: OIT, 2016.

De hecho, si observamos el detalle de tratados comerciales con cláusulas laborales que han entrado en vigor (Gráfico 2), vemos que el avance es muy notable a partir de 2013. Así, de una cifra media en torno al $36 \%$ hasta 2012, se pasa a más del 60\% en 2013, para mantener la cota del $80 \%$ desde entonces.

28 Ibid. 


\section{Gráfico 2. Acuerdos comerciales con cláusulas laborales (\% res- pecto del total).}

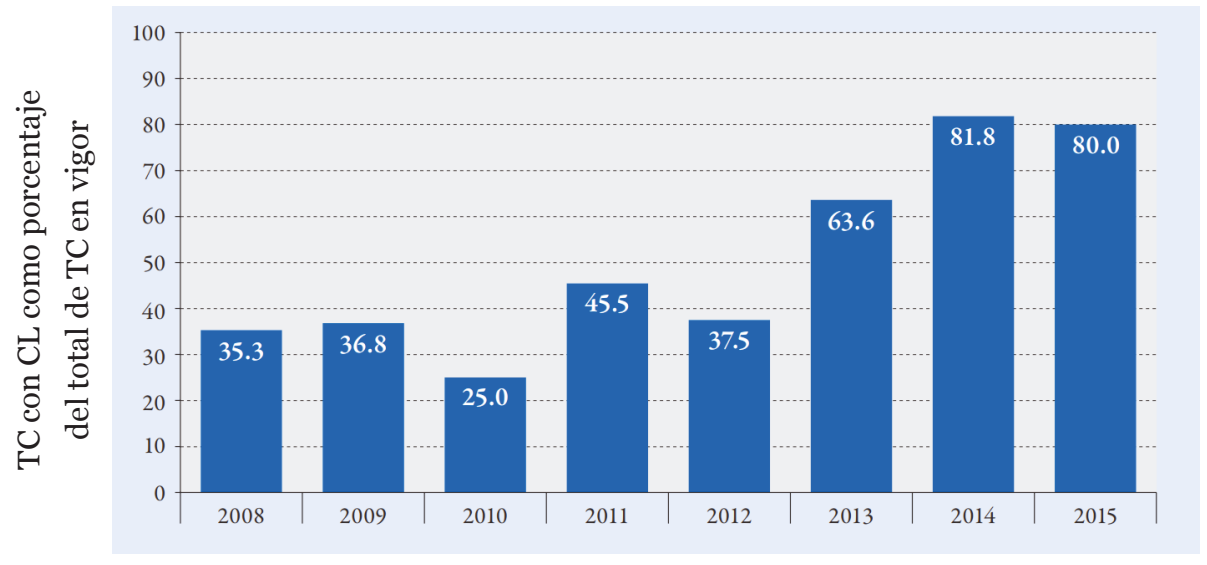

Fuente: OIT, 2016.

Por otra parte, al igual que en el caso de los acuerdos comerciales, en los acuerdos internacionales de inversión (AII) también son cada vez más habituales las referencias a las normas del trabajo. Estos tratados, denominados en España "Acuerdos de promoción y protección recíproca de inversiones" (APPRI) son tratados bilaterales ${ }^{29}$ de naturaleza recíproca que contienen medidas y cláusulas destinadas a proteger, en el plano del derecho internacional, las inversiones realizadas por los inversores de cada Estado Parte en el territorio del otro Estado Parte. Su objetivo es proporcionar un ambiente estable y favorable a la inversión, frecuentemente con Estados no miembros de la OCDE, que permita reducir los factores de incertidumbre política y jurídica que a veces afectan al desarrollo de los proyectos de inversión a los que se suele enfrentar la empresa en el exterior ${ }^{30}$.

29 La denominación "Acuerdo Internacional de Inversión" es directa traducción de la inglesa, International Investment Agreements -IIA-. También se emplea la designación Bilateral Investment Treaty (BIT). En España se prefiere la denominación Acuerdos de promoción y protección recíproca de inversiones. Puede consultarse los que nuestro país tiene suscritos y en vigor en: http://www.comercio.es/es-ES/inversiones-exteriores/ acuerdos-internacionales/acuerdos-promocion-proteccion-reciproca-inversiones-appris/ Paginas/lista-appri-vigor.aspx

30 Secretaría de Estado de Comercio, Ministerio de Economía, Industria y Competitividad. Más información en: http://www.comercio.es/es-es/inversiones-exteriores/ 
Pues bien, 14 de los 21 acuerdos de este tipo suscritos en 2015 hacen referencia a la protección de los derechos laborales, incluso a instrumentos de la $\mathrm{OIT}^{31}$, lo que supone cerca del 70\% del total, treinta puntos más que el año anterior. De hecho, tal y como muestra el siguiente gráfico, se trata de una tendencia que se viene consolidando en los últimos años y que es similar a la detectada en los tratados comerciales. La mayoría de estos tratados son acuerdos norte-sur, pero un tercio de los que se firmaron con cláusulas laborales lo han sido entre Estados parte del sur ${ }^{32}$.

\section{Gráfico 3. Acuerdos internacionales de inversión con cláusulas laborales (\% respecto del total firmados).}

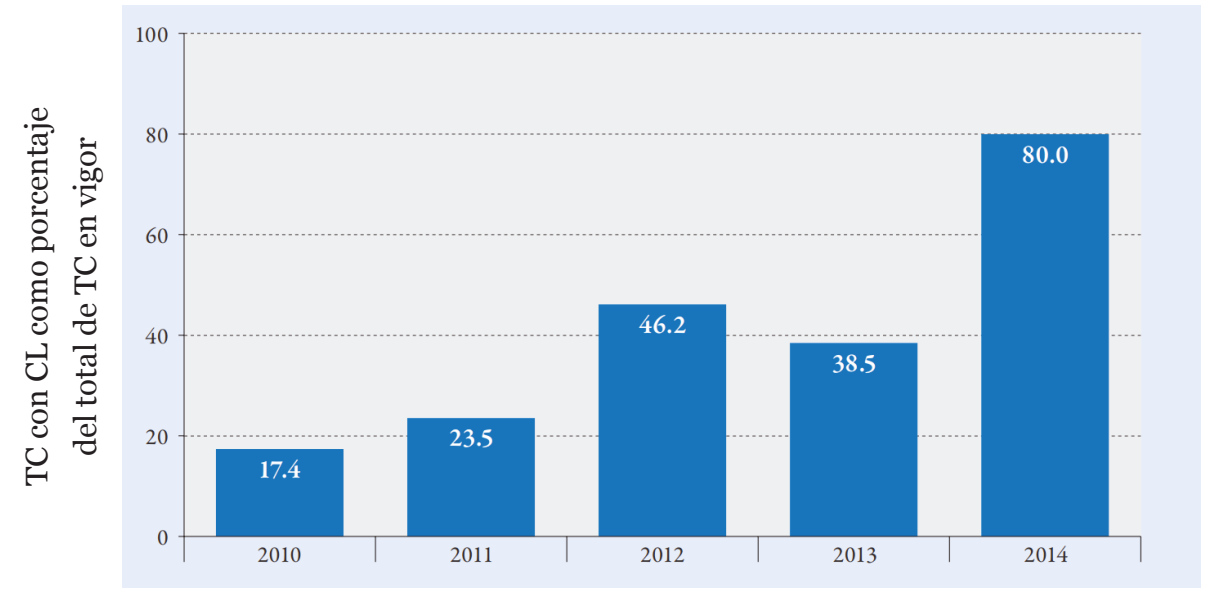

Fuente: OIT, 2016.

En suma, las cláusulas laborales han venido ganando terreno de forma muy notable en el comercio internacional impulsadas por EEUU, Unión Europea y Canadá. Si a ello le unimos que su uso se encuentra plenamente consolidado, podemos preguntarnos qué tipo de efectos han producido y, como señalábamos anteriormente, a qué se debe su escasa eficacia.

acuerdos-internacionales/acuerdos-promocion-proteccion-reciproca-inversiones-appris/ paginas/contenidos-y-objetivos.aspx

31 UNCTAD (ED.), Investor nationality: policy challenges, United Nations, New York Geneva, 2016, p. 113.

32 OIT, Assessment of Labour Provisions in Trade and Investment Arrangements., cit., p. 27. 


\subsection{Efectos y eficacia de las cláusulas laborales desde el plano económico.}

Dada esta continua y amplia expansión de las cláusulas laborales en los tratados internacionales, la pregunta que surge inmediatamente es qué tipo de efectos pueden estar produciendo ${ }^{33}$. Dos son las áreas principales a observar. De una parte, el impacto sobre el propio comercio internacional. De otra, sobre las condiciones laborales y de empleo.

Por lo que hace a lo primero, desde un punto de vista teórico, la incorporación de cláusulas laborales se asocia con costes adicionales para las empresas relacionados con la consecución de los estándares laborales impuestos. Si estos costes se trasladan, al menos parcialmente, a los consumidores, el resultado será un encarecimiento del producto final o, lo que es lo mismo, una caída de las exportaciones y, por consiguiente, una disminución de las transacciones comerciales. Sin embargo, además de éste, existen otros efectos a los que se suele prestar menos atención. Tal es el caso de la productividad. Si las cláusulas laborales tienden a mejorar las condiciones de trabajo, esto se puede traducir en que los trabajadores sean más productivos, impulsando la competitividad de las empresas. Ello produciría el efecto opuesto, pues aumentaría las exportaciones y el conjunto de transacciones comerciales sin incrementar los costes o, incluso, reduciéndolos en términos relativos. En un sentido similar, no hay que descartar el llamado "efecto reputacional" derivado de la preferencia de los consumidores por productos que hayan sido producidos garantizando condiciones de trabajo justas y decentes. La especial atención que los llamados acuerdos marco internacionales (AMIs) prestan a estos asuntos es una buena muestra de la importancia que le conceden las grandes empresas multinacionales ${ }^{34}$.

Pues bien, sobre la base del análisis empírico, a nivel macro, no se ha encontrado evidencia que corrobore la afirmación de que la inclusión cláusulas laborales reduzca o desvíe los flujos comerciales hacia países no signatarios del acuerdo. Dicho de otra forma, los acuerdos comerciales impulsan el co-

33 Ibid., pp. 76-87.

34 Sobre esta cuestión, véase Correa CARrasco, M., Acuerdos marco internacionales: de la responsabilidad Social Empresarial a la autonomía colectiva transnacional, Tirant lo Blanch, Valencia, 2016. En un marco más amplio, Gordo GonzÁlez, L., La representación de los trabajadores en las empresas transnacionales, Tirant lo Blanch, Valencia, 2017 . 
mercio entre quienes los suscriben de forma similar, independientemente de la existencia de este tipo de cláusulas. Según las estimaciones, un tratado comercial con disposiciones laborales aumenta el valor del comercio en un promedio del $28 \%$, mientras que uno que carece de ellas aumenta el comercio en un $26 \%{ }^{35}$.

En lo que respecta a lo segundo, el objetivo fundamental de la inclusión de disposiciones laborales en los tratados comerciales es doble. De una parte, se trata de garantizar unas mínimas condiciones laborales en todos los países. Pero de otra, también con ello se persiguen unas condiciones de competencia similares, de tal forma que la relajación o eliminación de las barreras comerciales no sitúe a unos países en desventaja frente a otros, al menos, en lo que a costes laborales se refiere. De esta forma se logra no solamente un marco de competencia más justo, sino que se evitan "carreras a la baja" en condiciones de trabajo y empleo.

Sin embargo, éste es precisamente uno de los elementos que enfrenta a los países desarrollados con los que se encuentran en vías de desarrollo. Para estos últimos, la existencia de costes laborales más bajos en lo que les otorga una ventaja competitiva frente aquellos, por lo que se oponen a la incorporación de estos mecanismos con carácter generalizado en el marco de la OMC, ya que eso supondría tanto como eliminar o reducir su principal vía para competir. Desde su punto de vista, las cláusulas laborales son una medida proteccionista impuesta por los desarrollados ${ }^{36}$. Frente a esto se suelen esgrimir dos tipos de argumentos, unos de carácter moral y otros de tipo económico ${ }^{37}$.

Los de carácter moral tienen que ver con el hecho de que los derechos laborales básicos conectan directamente con la dignidad de las personas y, por consiguiente, debieran estar por encima de cualquier tipo de interés económico o comercial. Pero, adicionalmente, del lado económico también existen buenas razones para apoyar la incorporación de cláusulas laborales en los tratados comerciales. Algunas son de carácter lógico y otras de naturaleza empírica.

Por lo que hace a las primeras, se ha dicho que las situaciones de competencia a la baja en lo que hace a los costes laborales es un caso claro de

35 OIT, Assessment of Labour Provisions in Trade and Investment Arrangements., cit., p. 86.

36 Gutiérrez Hurtado, F. J.; Lobejón Herrero, L. F., “Cláusulas sociales, comercio internacional y derechos laborales. La perspectiva de los países subdesarrollados”, cit., p. 58.

37 VALOR Martínez, C., “Cláusulas sociales”, cit., pp. 40-42. 
"dilema del prisionero", por lo que las estrategias no cooperativas conducen necesariamente a resultados subóptimos ${ }^{38}$. La cláusula laboral tendría la virtud, por diversos medios, de conducir a los diversos países implicados a la cooperación, alcanzando una situación de equilibrio óptima. De esta forma, se articularía un tipo de competencia "constructiva", que fomente la inversión generando confianza en los inversores (pues está garantizada la estabilidad social), el dinamismo, la retención del talento y la mejora de las cualificaciones profesionales ${ }^{39}$.

Por lo que respecta a las segundas, los resultados indican que, en promedio, los acuerdos comerciales que incluyen cláusulas laborales inciden positivamente en la tasa de participación de la fuerza laboral, esto es, la población activa se incrementa, recibiendo una mayor proporción de población en edad de trabajar. Este incremento sería especialmente significativo en el caso de las mujeres ${ }^{40}$. Un elemento que puede explicar la repercusión positiva sobre las tasas de participación es que el diálogo sobre políticas de empleo y sensibilización hacia determinados colectivos puede suscitar expectativas de mejores condiciones de trabajo ${ }^{41}$, lo cual a su vez aumenta el deseo de incorporarse al mercado laboral.

Desde la perspectiva global, el análisis transnacional no presenta impactos adicionales de las cláusulas laborales en otras variables relacionadas el mercado de trabajo ${ }^{42}$. Sin embargo, existe la posibilidad de que las disposiciones laborales produzcan efectos a nivel nacional, por lo menos en algunos países en función de su entramado institucional. La evidencia sugiere que las disposiciones laborales constituyen solo uno de los instrumentos para promover mejoras en las normas laborales y que el impacto no está claro, pudiendo ser

38 FERnÁndez Scrimieri, B., "Derechos sociales y globalización: soluciones multilaterales”, Información Comercial Española, ICE: Revista de economía, 785, 2000, p. 77.

39 Doumbia-Henry, C.; Gravel, E., "Acuerdos de libre comercio y derechos laborales. Evolución reciente", cit., pp. 224-225.

40 OIT, Assessment of Labour Provisions in Trade and Investment Arrangements., cit., pp. 76-84.

41 En algunos tratados se hace especial hincapié en la incorporación de disposiciones laborales en la igualdad de género (sobre todo a través del principio de no discriminación en el empleo y la ocupación).

42 Esto incluye efectos sobre los salarios de los trabajadores poco cualificados en los países desarrollados. Maskus, K. E., Should Core Labor Standards Be Imposed Through International Trade Policy?, World Bank Publications, 1999. 
positivos a corto plazo, pero negativos en el largo ${ }^{43}$. De ser así, los mecanismos de aplicación a escala nacional constituirían elementos fundamentales para el éxito en la aplicación de las cláusulas laborales, lo que debería tenerse muy en cuenta en el plano práctico durante la negociación y en la gestión de los acuerdos ${ }^{44}$.

Un aspecto importante que indican las investigaciones es que la eficacia de las disposiciones laborales depende del grado de participación de las partes interesadas y, en particular, de los interlocutores sociales, en la elaboración y puesta en práctica de los acuerdos comerciales ${ }^{45}$. Esto se traduce en una tendencia general a tratar de dotar de mayor transparencia a las negociaciones comerciales, las cuales tradicionalmente han tenido lugar entre gobiernos, sin la plena participación de otros agentes implicados. Las referencias explícitas a la participación de las partes interesadas en los acuerdos comerciales se han vuelto más habituales y exhaustivas ${ }^{46}$, lo cual obedece, en parte, a la mayor variedad de cuestiones abarcadas en los acuerdos de comercio, las cuales pueden incluso abarcar las normas del trabajo, la protección del medio ambiente, la salud y seguridad, entre otras cuestiones.

De lo dicho hasta aquí se desprende que la experiencia en cuanto a la incorporación de cláusulas laborales en los tratados comerciales es positiva y ello se ha traducido en un paulatino aumento. Sin embargo, esto no ha impedido, como se señaló al principio, que la liberalización del comercio internacional esté siendo puesta en tela de juicio por algunos sectores.

\section{Las cláusulas laborales como garantía del trabajo decente}

Aunque la mayoría de los economistas insistan en que la liberalización del comercio sea positiva para todos los sujetos implicados, esto no implica que no haya ganadores y perdedores. Entre estos últimos frecuentemente han estado determinados grupos de trabajadores que han visto, en el caso de los países desarrollados, empeorar sus condiciones laborales, cuando no perder directamente sus trabajos. Son estos efectos colaterales perversos, obviados

43 S. Marshall; C. Fenwick, "Labour law and trade policy", en Labour Regulation and Development, Edward Elgar Publishing, 2016, p. 115.

44 A este respecto véase OIT, Handbook on assessment of labour provisions in trade and investmnt arrangements, OIT, Geneva, 2016.

45 OIT, Assessment of Labour Provisions in Trade and Investment Arrangements., cit., pp. 130-139.

46 Un ejemplo claro, de nuevo, es el CETA. Véase el apartado 3. 
probablemente porque se pensó que la compensación llegaría sola, los que explican el sentimiento de desafección que se observa en diversos países de nuestro entorno en relación a los tratados de libre comercio.

Para que los beneficios del comercio internacional sean repartidos y alcancen a todas las capas sociales es preciso que se adopten mecanismos que permitan que todos ganen. Entre estos instrumentos, sin duda que las cláusulas laborales muestran un enorme potencial, hasta el punto que podría decirse que de su éxito depende en buena que el libre comercio se siga abriendo paso entre las diversas economías del globo y, de sus deficiencias, la aparición de nuevas tensiones proteccionistas.

En efecto, las cláusulas laborales han experimentado un crecimiento muy notable en la última década, lo que ha permitido que hoy estén presentes en la mayoría de los acuerdos internacionales de comercio e inversión que se firman cada año. Al margen de lo cuantitativo, en lo cualitativo también se observa una notable evolución, siendo muy amplia tanto la gama de cláusulas que se encuentran en los textos internacionales, como los mecanismos previstos para garantizar su aplicabilidad, lo que incluye cada vez más herramientas que doten a estos acuerdos de más trasparencia y propicien una mayor intervención de agentes sociales y organismos internacionales, como la OIT, entre otros sujetos implicados. En buena medida el desarrollo del libre comercio en las últimas dos décadas ha estado amparado en la incorporación de estos mecanismos jurídicos, al permitir a los gobiernos justificar que los efectos no deseados podrían ser compensados.

Sin embargo, con este bagaje a sus espaldas, hoy son puestas en tela de juicio, lo que alcanza a las políticas de liberalización comercial con carácter general. El principal argumento empleado es que son ineficaces y que, por tanto, no evitan el dumping social. ¿Qué nos dicen los estudios sobre este punto?

De una parte, en lo que hace a su hipotético impacto sobre los flujos comerciales, a nivel macro, no se ha encontrado evidencia que corrobore la afirmación de que inclusión cláusulas laborales reduzca o desvíe los flujos comerciales hacia países no signatarios del acuerdo. Dicho de otra forma, los acuerdos comerciales impulsan el comercio entre quienes los suscriben de forma similar, independientemente de la existencia de este tipo de cláusulas.

De otra, en lo que respecta a sus efectos en el mercado de trabajo, los resultados indican que, en promedio, los acuerdos comerciales que incluyen cláusulas laborales inciden positivamente en la tasa de participación de la 
fuerza laboral, esto es, la población activa se incrementa, recibiendo una mayor proporción de población en edad de trabajar. Este incremento sería especialmente significativo en el caso de las mujeres. Desde la perspectiva global, el análisis transnacional no presenta impactos adicionales de las cláusulas laborales en otras variables relacionadas con el mercado de trabajo, al margen de observarse una interrelación importante con las regulaciones nacionales, reforzándose mutuamente, y que su eficacia final depende en buena medida de la intervención de los agentes sociales.

Sobre esta base cabe hacer varias deducciones importantes. En primer lugar, los efectos sobre las condiciones de trabajo son limitados y fundamentalmente se producen en los países en desarrollo. Por consiguiente, se hace preciso reforzar su eficacia de tal forma que redunden en una mejora relevante de las condiciones de trabajo. Sobre esta base, su impacto en el mercado de trabajo de los países desarrollados en el corto plazo ha de ser necesariamente también limitado, por lo que apenas estarían contribuyendo a prevenir el dumping social.

Así las cosas, se impone, de una parte, la adopción de medidas adicionales en las economías desarrolladas que permitan que los beneficios del libre comercio se repartan en el conjunto de la sociedad. Estas medidas han de tener una base tanto nacional como supranacional o internacional y tienen que ver con el mejor reparto de la renta y la riqueza, la lucha contra la desigualdad material, la mejora de los servicios del Estado del bienestar y el impulso de nuevas actividades y sectores económicos. «A menos que los beneficios se distribuyan rápidamente entre la población, será cada vez más difícil asegurar la viabilidad y legitimidad social de la integración y globalización económicas» ${ }^{47}$.

De otra, es preciso seguir avanzando en la configuración jurídica de las cláusulas laborales y, en particular, en los mecanismos que garantizan su eficacia. En este particular, un debate irresuelto es precisamente el del encaje de las cláusulas que, gobernando cuestiones laborales, se insertan en tratados comerciales $^{48}$. Cerrada la vía de la $\mathrm{OMC}$ por el momento ${ }^{49}$, se hace preciso re-

47 Doumbia-Henry, C.; Gravel, E., "Acuerdos de libre comercio y derechos laborales. Evolución reciente”, cit., p. 206.

48 Elliott, K. A., The ILO and Enforcement of Core Labor Standards, Peterson Institute for International Economics, 2000, pp. 2-7. STERN, R., Labor Standards and Trade Agreements, Research Seminar in International Economics, University of Michigan, 2003.

49 BÉzou, C., "Le commerce, les clauses sociales et les normes du travail”, en Deblock, C. (ed.) L'Organisation mondiale du commerce: où s'en va la mondialisation?, Les Editions Fides, 2002, pp. 255-266. 
forzar la de la OIT, que es además la más apropiada. En efecto, la garantía de los derechos laborales no debería estar al albur del contenido de los tratados comerciales, sino que estos deberían remitirse a un sistema más complejo en manos de quien está en mejores condiciones para garantizar los derechos laborales a nivel global, que es la OIT. Su carácter internacional y tripartito, le permite actuar como un tercero ajeno a las partes; su especialización en asuntos laborales le confiere la base técnica suficiente como para afrontar con éxito la importante tarea de conjugar intereses sociales y económicos generales de los países implicados con los particulares de cada uno de ellos. Desde esta perspectiva, la cláusula laboral no sería más que un mecanismo de inclusión de esa relación comercial en un sistema más complejo, sustentado, amparado y conducido por la OIT $^{50}$.

En ambos casos, el papel de los agentes sociales, representantes de los trabajadores y de los empresarios, resulta crucial. Tal y como tuvimos ocasión de ver, su participación es un elemento esencial en lo que hace a la eficacia de este tipo de cláusulas. En el caso de la OIT, su naturaleza tripartita hace que esta implicación resulte inevitable. Impulsar el papel de la OIT en la mejora de la eficacia de estas cláusulas supone también insertar a los agentes sociales en los trabajos para su mejora técnica. Sin embargo, esto no resulta tan obvio en el plano nacional. Al contrario, para que su involucración sea posible es necesaria la concurrencia de, al menos, dos voluntades. De una parte, la de los propios Estados, que han de ser conscientes de que la participación institucional en los procesos de negociación y control de los tratados no solamente es deseable en sí misma por cuanto dota de una mayor trasparencia y representatividad a estos procesos, sino imprescindible desde el plano de su eficacia. De otra, los propios agentes sociales han de también asumir la importancia creciente que este tipo de acuerdos internacionales tienen para las condiciones de trabajo en el país y, por consiguiente, que han de estar preparados en el plano teórico y práctico y han de reivindicar su participación efectiva no solamente durante la negociación, sino también y muy especialmente en los mecanismos de control que se pudieran acordar.

Finalmente, desde un prisma más general, las cláusulas laborales en los acuerdos comerciales internacionales ponen al descubierto los déficits del desarrollo económico y subrayan la oportunidad actual del papel tradicional de

50 Pérez del Prado, D., "Cláusulas laborales y libre comercio: el papel de la OIT Dialnet”, en Futuro del Trabajo: Trabajo decente para todos, Ministerio de Trabajo y Seguridad Social, Madrid, 2017. 
la Ley laboral. El Derecho del trabajo nació con el objetivo de poner límite a los abusos que el simple interés empresarial, sin la más mínima limitación, producía. Buena parte de los problemas derivados de la globalización o, simplemente, de la última crisis económica, han venido dados precisamente por la falta de regulación y límites ${ }^{51}$. Es probable que las cláusulas aquí estudiadas, como tantos otros ejemplos en el amplio y muy vacío Derecho del trabajo internacional (o supranacional) contribuyan a compensar en buena medida estos graves desequilibrios. Ahora, como entonces, se impone la necesidad de intervenir, no solamente como garantía del trabajo decente, sino para construir un desarrollo económico mucho más eficiente y sostenible para todas las partes implicadas.

\section{Bibliografía}

Aissi, J.; Peels, R.; Samaan, D., "Evaluating the effectiveness of labour provisions IN TRADE AGREEMENTS: AN ANALYTICAL AND METHODOLOGICAL FRAMEWORK", INTERNATIONAL Labour Review, vol. 157, 4, 2018, PP. 671-698.

Araoz SÁnchez-Dopico, I., "Insuficiencias de la regulación del derecho a la educación inclusiva en la legislación española”, en Cayo Pérez Bueno, L. (ed.) 20o32012: 10 años de legislación sobre no discriminación de personas con discapacidad en España: estudios en homenaje a Miguel Ángel Cabra de Luna, Cinca, Madrid, 2012, pp. 325-340.

ARRIETA IDIAKEZ, F. J., "La formación dual en el ámbito universitario como alternativa a los retos planteados por la industria 4.0 en cuanto a la empleabilidad de los jóvenes”, en Mella Méndez, L. (ed.), 2018.

BÉzou, C., "Le commerce, les clauses sociales et les normes du travail", en Deblock, C. (ed.) L'Organisation mondiale du commerce: où s'en va la mondialisation?, Les Editions Fides, 2002.

Calero Martínez, J.; Fernández Gutierrez, M., "Programas de gasto destinado a la educación inclusiva de personas con discapacidad: descripción y estimación del coste de nuevas medidas", en Casanova Rodríguez, M. J. (ed.) Educación y personas con discapacidad: presente y futuro, ONCE, Madrid, 2009, pp. 237-265.

Casanova Rodríguez, M. A, "De la educación especial a la inclusión educativa. Estado de la cuestión y retos pendiente", Participación educativa. Revista cuatrimestral del Consejo Escolar del Estado, vol. 11, 2011.

51 Subrayando la conexión entre el papel primigenio del Derecho del Trabajo y cómo puede extender al momento actual de un hipotético nacimiento de un Derecho del Trabajo a nivel supranacional Doumbia-Henry, C.; Gravel, E., "Acuerdos de libre comercio y derechos laborales. Evolución reciente", cit., p. 207. 
Comité sobre los Derechos de las Personas con Discapacidad, Comentario general $n^{\circ} 4$ (2016). Artículo 24. Derecho a la Educación Inclusiva., Naciones Unidas. Convención sobre los Derechos de las Personas con Discapacidad, 2016.

Correa Carrasco, M., Acuerdos marco internacionales: de la responsabilidad Social Empresarial a la autonomía colectiva transnacional, Tirant lo Blanch, Valencia, 2016.

De Araoz SÁnchez-Dopico, I., "La configuración del derecho a la educación inclusiva”, en Pérez Cayo, L. (ed.) Discapacidad, Tercer Sector e Inclusión Social, CERMI, Madrid, 2010.

De Asís Roig, R., "El encaje de la Convención Internacional sobre los Derechos de las Personas con Discapacidad”, en Arenas Escribano, F., Cabra de Luna, M. A. (eds.) Comentarios al Texto Refundido de la Ley General de derechos de las personas con discapacidad y de su inclusión social, La Ley; CERMI, Madrid, 2015.

De Asís Roig, R. (Dir.)., Impacto de la aplicación de la Convención de Naciones Unidas para los derechos de las personas con discapacidad en la regulación de los centros especiales de empleo, Universidad Carlos III de Madrid. Instituto Bartolomé de las Casas, Getafe, 2015.

Delors, J., Programa de la Comisión para 1986. Discurso ante el Parlamento Europeo, Parlamento Europeo, Estrasburgo, 1986.

Doumbia-Henry, C.; Gravel, E., "Acuerdos de libre comercio y derechos laborales. Evolución reciente", Revista Internacional del Trabajo, vol. 125, n. ${ }^{\circ} 3,2006$, pp. 207-231.

ELLIOTt, K. A., The ILO and Enforcement of Core Labor Standards, Peterson Institute for International Economics, 2000.

FERnÁndez SCRIMIERI, B., "Derechos sociales y globalización: soluciones multilaterales”, Información Comercial Española, ICE: Revista de economía, n. ${ }^{\circ} 785$, 2000, pp. 69-80.

Gordo GonZÁlez, L., La representación de los trabajadores en las empresas transnacionales, Tirant lo Blanch, Valencia, 2017.

Guamán Hernández, A., "Cláusulas laborales en los acuerdos de libre comercio de nueva generación: una especial referencia al contenido laboral del TPP, CETA y TTIP”, Estudios financieros. Revista de trabajo y seguridad social: Comentarios, casos prácticos: recursos humanos, n. ${ }^{\circ}$ 398, 2016, pp. 83-112.

Guerrero Romera, C., Formación ocupacional de las personas con discapacidad psíquica, Ariel, Barcelona, 2002.

Gutiérrez Hurtado, F. J.; Lobejón Herrero, L. F., “Cláusulas sociales, comercio internacional y derechos laborales. La perspectiva de los países subdesarro-

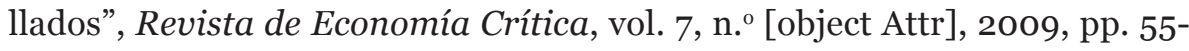
73 . 
Huete García, A., "Las personas con discapacidad en la escuela. Luces y sombras del proceso de inclusión educativa en España”, Panorama Social, vol. 26, 2017.

Huete García, A.; Jiménez Lara, A. (eds.), Informe Olivenza 2016 sobre la situación de la discapacidad en España, Observatorio Estatal de la Discapacidad, Olivenza, 2016.

KPMG, Presente y futuro de los centros especiales de empleo, Fondo Social Europeo; Ministerio de Empleo y Seguridad Social; Fundación Once, Madrid, 2013.

Krugman, P. R., "New Thinking about Trade Policy", en Krugman, P. R. (ed.) Strategic Trade Policy and the New International Economics, MIT Press, Cambridge (Massachusetts), 1986, pp. 1-22.

Lema AÑon, C., "El impacto en la educación de la Convención de la ONU sobre los Derechos de las Personas con Discapacidad", en Casanova Rodríguez, M. J. (ed.) Educación y personas con discapacidad: presente y futuro, ONCE, Madrid, 2009, pp. 31-35.

Lim, H., The Social Clause: Issues and Challenges, OIT, Geneva.

Lobejon Herrero, L. F., "Pasado, presente y futuro de la cláusula social. El papel de la Organización Mundial del Comercio.”, Información Comercial Española, ICE: Revista de economía, vol. 843.

Marshall, S.; Fenwick, C., "Labour law and trade policy”, en Labour Regulation and Development, Edward Elgar Publishing, 2016.

Maskus, K. E., Should Core Labor Standards Be Imposed Through International Trade Policy?, World Bank Publications, 1999.

Muntaner, S., "Las cláusulas sociales en el libre comercio: del TTIP al caso de Hunduras", SEGÚN ANTONIO BAYLOS..., fecha de consulta 7 febrero 2017, en http://baylos.blogspot.com.es/2015/04/las-clausulas-sociales-en-el-libre. html.

ODISMET, Informe general. La situación de las personas con discapacidad en el mercado laboral, Fundación ONCE, Madrid, 2015.

OECD, Trade, Employment and Labour Standards, Organisation for Economic Co-operation and Development, Paris, 1996.

OIT, Assessment of Labour Provisions in Trade and Investment Arrangements, ILO, Geneva, 2016.

OIT, Dimensiones sociales de los acuerdos de libre comercio., International Labour Office, Geneva, 2013.

OIT, Handbook on assessment of labour provisions in trade and investmnt arrangements, OIT, Geneva, 2016.

OIT, Informe sobre el trabajo en el mundo 2009, International Labour Office, Geneva, 2010. 
ONU, Impact of globalization on the achievement of the internationally agreed development goals, including the Millennium Development Goals, ONU, Nueva York, 2008.

Pérez Del Prado, D., "Cláusulas laborales y libre comercio: el papel de la OIT Dialnet", en Futuro del Trabajo: Trabajo decente para todos, Ministerio de Trabajo y Seguridad Social, Madrid, 2017.

Plena INCLUSIÓn MADRID, La formación como oportunidad de inclusión de las personas con discapacidad intelectual, Plena Inclusión Madrid, Madrid, 2017.

Polonio DE Dios, G., "La discapacidad desde la perspectiva del estado social", 2016, Universidad de Córdoba, Córdoba.

Ricardo, D., Principios de economía política y tributación, Pirámide, Madrid, 2003.

Rivera SÁnchez, J.R., La cláusula laboral en los acuerdos de libre comercio, Tirant lo Blanch, Valencia, 2018.

Rodríguez, V., "El empleo de las personas con discapacidad en España: quo venis, quo vadis", Panorama Social, vol. 26, 2017.

Sanz Escudero, M. J., "Trayectoria del CERMI en materia educativa", Participación educativa. Revista cuatrimestral del Consejo Escolar del Estado, vol. 11, 2011.

Servicio Público Empleo Estatal, Informe del Mercado de Trabajo de las Personas con Discapacidad Estatal. Datos 2015., Ministerio de Empleo y Seguridad Social, Madrid, 2016.

Stern, R., Labor Standards and Trade Agreements, Research Seminar in International Economics, University of Michigan, 2003.

Stiglitz, J. E., Microeconomía, $2^{a}$ Edición inglesa, Ariel, Barcelona, 2001.

UNCTAD (ed.), Investor nationality: policy challenges, United Nations, New York Geneva, 2016.

VALDÉs DAL-RÉ, F., "Derechos en serio y personas con discapacidad: una sociedad para todos”, en Lahera Forteza, J., Valdés Dal-Ré, F. (eds.) Relaciones laborales de las personas con discapacidad, Biblioteca Nueva, Madrid, 2005.

VAlor MarTínez, C., "Cláusulas sociales: análisis de la afinidad de objetivos con el movimiento por el comercio justo", Boletín económico de ICE, Información Comercial Española, n. ${ }^{\circ}$ 2882, 2006, pp. 39-54. 



\title{
UNA ESTRATEGIA GLOBAL PARA LA FORMALIZACIÓN \\ EMPRESARIAL Y LABORAL
}

\author{
Marta GARCÍA MANDALONIZ \\ Universidad Carlos III de Madrid
}

\begin{abstract}
RESUMEN: Se reivindica una estrategia global para la formalización y productividad de la empresa para la creación de empleo formal decente y de calidad. Se apuesta para la formalización empresarial por una normativa simplificada que reduzca los trámites, costes y plazos de la inscripción registral. Para la promoción de la formalización laboral, una vez registrada la empresa, se reflexiona sobre la adopción de incentivos fiscales y laborales. Con incentivación, además de con información y concienciación, puede minorarse la informalidad en el empleo si se acompaña de un régimen eficaz de inspección laboral. La formalización laboral conlleva la garantía de los derechos laborales y la protección social como camino para avanzar hacia un trabajo decente.
\end{abstract}

Palabras clave: Empleo informal, informalidad empresarial, registro electrónico empresarial, incentivos, sensibilización.

SUMARIO: 1. Un entorno de informalidad: las causas y los efectos. 1.1. Los efectos de la informalidad. 1.2. Las causas de la informalidad. 2. La informalidad versus la formalidad: un entorno de competencia desleal. 3. Las desventajas de la informalidad son las ventajas de la formalidad: para el empresario, el trabajador, el Estado y la sociedad. 4. Los componentes clave de una estrategia hacia la formalización. 4.1. Un sistema electrónico eficiente de inscripción empresarial. 4.2. Un sistema de incentivos fiscales y laborales. 4.3. Un conjunto de medidas de sensibilización para desenraizar la cultura de la informalidad. 5. Hacia la formalización en un entorno digital y global. 6. Bibliografía.

\section{A Global Strategy for business and labor formalizacion}

ABSTRACT: A comprehensive strategy for the formalization and productivity of the company for the creation of decent and quality formal employment is demanded. For the formalization of business is demanded a simplified regulation that reduces the procedures, costs and deadlines of business registration. For the promotion of labor formalization, once the company is registered, we reflect on the adoption of tax and labor incentives. With incentives, as well as information and awareness-raising, informality can be reduced if accompanied by an effective 
inspection regime. Formalization means guarantee labor rights and social protection to move towards decent work.

Keywords: Informal employment, business informality, electronic business registry, incentives, awareness raising.

\section{Un entorno de informalidad: las causas y los efectos}

"El empleo independiente, las microempresas y las pequeñas firmas tienen un rol infinitamente más importante como proveedores de trabajo de lo que siempre se creyó". Las "pequeñas unidades económicas representan el setenta por ciento del empleo total. Son las que más trabajo generan”, aunque "un sesenta y dos por ciento del empleo corresponde al sector informal". "Las políticas y los programas de creación y calidad del empleo, sobre productividad empresarial y formalización deben centrarse más en estas pequeñas unidades económicas”. El papel de las pequeñas unidades económicas resulta clave en el avance hacia la consecución del trabajo decente como objetivo de desarrollo sostenible ${ }^{1}$. Estas palabras y cifras integran el reciente informe que la Organización Internacional del Trabajo (OIT) ha publicado, en el centenario de su aniversario, el 10 de octubre de 2019, bajo el título: "Lo pequeño importa: datos mundiales sobre las contribuciones al empleo de los trabajadores independientes, las microempresas y las pymes" ${ }^{2}$.

En ellas vislumbramos un cambio en el foco de atención del empleo y, en particular, del empleo informal. Si en el pasado había sido cambiado desde las pequeñas unidades económicas (trabajadores autónomos, micro y pequeñas empresas) hasta los empleados ${ }^{3}$, vuelve a ponerse la atención en aquellas

1 Además de contribuir al objetivo de desarrollo sostenible (ODS) número 8 (trabajo decente y crecimiento económico), también contribuye a los ODS 1 (fin de la pobreza) y 10 (reducción de las desigualdades) en especial. Así se indica en la página iii del preámbulo del informe de la OIT que se referenciará en la nota a pie de página siguiente.

2 Informe publicado el 10 de octubre de 2019, bajo el título descrito en el texto principal, con cincuenta y seis páginas y un resumen ejecutivo. Está basado en datos recopilados en noventa y nueve países (excepto de América del Norte) durante el período de 2009 a 2018. Las palabras que transcribimos en el primer párrafo de nuestro texto principal fueron resaltadas en las diversas noticias de prensa que distintos medios de comunicación publicaron sobre este informe de la OIT el jueves 10 de octubre de 2019.

3 Vid. DÍAZ ANDRADE, E.; GÁLVEZ PÉREZ, T.: Informalidad laboral: concepto y mediciones, Parte 1, Taller de coyuntura. Departamento de Estudios. Dirección de Trabajo, septiembre 2015, p. 3 . 
unidades para transitar desde la informalidad hacia la formalidad laboral. Si antes no importaba tanto para la noción de la informalidad laboral si la empresa era o no una empresa registrada 4 , por ende, era o no una empresa formal, ahora importa más la formalización y la productividad de la micro y pequeña empresa para la "creación y calidad del empleo"s formal.

El sector informal puede ser observado desde dos perspectivas: desde la informalidad de la empresa y desde la informalidad del trabajo. Existiendo informalidad empresarial habrá informalidad laboral. No siempre la situación contraria se producirá. Una empresa formalizada, por estar previamente registrada, pudiera albergar empleo informal ${ }^{6}$. Habiendo formalidad empresarial habría de haber formalidad laboral, pero habrá empleo informal en el caso de incumplimiento de la regulación laboral que, con las correspondientes inspecciones, habrá que vigilar para corregir y sancionar.

Hay que detener el problema de la informalidad de la empresa para simultáneamente contener el grave problema de la informalidad del trabajo. Aun contenido aquél, pudiera no contenerse éste, en tanto lamentablemente sigue habiendo empleo informal en el sector formal. La informalidad laboral insertada en la formalidad empresarial habrá que atajarla porque conduce a la precarización del empleo ${ }^{7}$, y la precarización a la vulnerabili$\mathrm{dad}^{8}$. A su vez, la informalidad laboral lastra la productividad empresarial. A más informalidad laboral, menos productividad empresarial. A contra-

4 Ídem.

5 En las palabras del informe de la OIT, de 10 de octubre de 2019, transcritas en el primer párrafo del texto principal.

6 Dentro de la "informalidad laboral" la diferencia y la definición del "empleo en el sector informal" o empleo en una empresa informal (en empresas de hogares no constituidas como sociedades) y el "empleo informal", incluso en una empresa formal, se haría en: ORGANIZACIÓN INTERNACIONAL DEL TRABAJO: Panorama laboral 2008. América Latina y El Caribe. Ginebra: OIT, 13 enero 2009, p. 19. Anteriormente, una definición y una clasificación se habían recogido en las Directrices sobre una definición estadística del empleo informal del Anexo "Informe del Grupo de Trabajo sobre el empleo informal” del capítulo 3 del siguiente documento: ORGANIZACIÓN INTERNACIONAL DEL TRABAJO: Informe de la Conferencia. Decimoséptima Conferencia Internacional de Estadísticos del Trabajo. Ginebra, OIT, 24 noviembre a 3 diciembre 2003, pp. 13 y siguientes.

7 Definido el "empleo precario" en: DÍAZ ANDRADE, E.; GÁLVEZ PÉREZ, T.: Informalidad laboral..., op. cit., p. 9, como el empleo de "asalariados del sector formal con condiciones precarias de contratación".

8 Ibidem, p. 18. 
rio, a más productividad y competitividad empresarial, menos informalidad laboral ${ }^{9}$.

Ambos puntos de vista (el laboral y el empresarial) de un mismo fenómeno (el amplio y complejo de la informalidad) ${ }^{10}$ no son contrapuestos ni siquiera independientes, sino interrelacionados. Por la interrelación, la transición desde la informalidad hasta la formalidad ha de ser conjunta en el camino que dirige hacia un trabajo formal y decente y a un crecimiento productivo empresarial ${ }^{11}$. Aun cuando el empleo informal y la empresa informal tengan dinámicas distintas y aun cuando formen un "conjunto heterogéneo"12 dentro del sector económico informal, debido a esa estrecha interrelación vamos a analizarlos en esta investigación de manera articulada. Pese a la interconexión, nos centraremos en las microempresas y las pequeñas empresas, como en ellas propone centrar el nombrado informe de la OIT las políticas y los programas para el empleo, la productividad y la formalidad.

\subsection{Los efectos de la informalidad}

La informalidad empresarial conlleva, de entrada, el no registro de la empresa. Sin el previo registro, no se obtienen los consiguientes permisos ni licencias administrativas para la puesta en marcha de la actividad empresarial. Sin registros ni permisos, la informalidad empresarial se traduce en la práctica en el impago de impuestos o tasas; habitualmente, en la falta de una adecuada contabilidad de los correspondientes gastos e ingresos de la empresa ${ }^{13}$;

9 Vid., ad ex., OTÁROLA PEÑARANDA, F. R. (et al.): Estrategia sectorial para la formalización laboral 2014-2016. Perú: Ministerio de Trabajo y Promoción del Empleo, 2014, pp. 9, 74 .

10 Que la informalidad es un "fenómeno amplio y complejo" se indicaría, por ejemplo, en: DÍAZ ANDRADE, E.; GÁLVEZ PÉREZ, T.: Informalidad laboral..., op. cit., p. 5 .

11 En la 104 ${ }^{\mathrm{a}}$ reunión de la Conferencia Internacional del Trabajo, celebrada en Ginebra, del 1 al 13 de junio de 2015, se habló de la "transición de los trabajadores y las empresas desde la informalidad hasta la formalidad para un trabajo decente y un desarrollo incluyente"; conforme al documento sobre: "La transición de la economía informal a la economía formal. Proyecto de recomendación"; cuya cita se recoge en: ibidem, p. 3.

12 En ibidem, p. 18, se habló de "conjunto heterogéneo de formas de producción y empleo” y, aunque se indicó su interrelación, se resaltaron sus distintas dinámicas.

13 Como se comentaría en: ORGANIZACIÓN INTERNACIONAL DEL TRABAJO: Panorama laboral 20o8..., op. cit., p. 19, las empresas informales "no llevan registros contables, sea por motivos económicos, desconocimiento, u otras razones". 
y, en lo que aquí más importa, en un empleo informal porque se incumple la regulación laboral y porque no hay protección social de los trabajadores. Sin registros y sin estar la empresa bajo la regulación, no hay protección ni derechos para el trabajador ${ }^{14}$.

Las consecuencias directas de esta doble situación de informalidad, empresarial y laboral, son múltiples y variadas ${ }^{15}$. Una de ellas, quizás la primera, es sobrellevar la posibilidad de recibir una sanción administrativa, en el supuesto de que exista un sistema eficaz de inspección o fiscalización con imposición de multas o sanciones para detener la informalidad empresarial y laboral en la región de que se trate.

A esta posibilidad, más real cuanto más eficaz sea el sistema sancionador, se suman varias imposibilidades o, cuanto menos, dificultades. Una de esas imposibilidades o dificultades es el óptimo acceso de la empresa al sistema bancario y a otras fuentes de financiación. Su resultado es una escasez de recursos económicos con los que hacer subsistir y crecer la empresa. Las fuentes financieras ajenas, bancarias y extra-bancarias -privadas (microfinanzas o capital riesgo) y públicas (ayudas estatales, no solo subvenciones)-, se cierran ante una empresa no registrada que realiza sus actividades en la economía informal o sumergida. Los recursos propios externos, procedentes de familiares o amigos (2 de las " $3 \mathrm{~F}$ ": "family, friends \& fool"), y los recursos propios internos (o autofinanciación) procedentes de los beneficios empresariales no distribuidos, son las únicas fuentes financieras con las que actuar en el tráfico comercial para una empresa sin registros ni permisos. Cuando escasean y habitualmente escasean los recursos procedentes de uno u otro frente, la supervivencia de la empresa puede tambalearse. Con ella, también se pone en riesgo el sustento personal y familiar del empleador y de los empleados.

Sin posibilidad de fácil acceso a los recursos financieros externos y, en particular, ni al sistema bancario ni a los programas de ayudas públicas, se merma el crecimiento y la expansión a mercados más allá de los locales o regionales. No puede accederse al mercado internacional ni, en ocasiones, tampoco al nacional externo al regional. Tampoco puede accederse a las licitaciones

14 Vid. OTÁROLA PEÑARANDA, F. R. (et al.): Estrategia sectorial..., op. cit., pp. 36 y siguientes.

15 De modo más extenso se contiene información, respecto de las causas y los efectos, en la presentación que el gerente de formalización del Ministerio de Comercio, Industria y Turismo de la República de Colombia, D. ARANGO, hiciera en agosto de 2011, para presentar la "Estrategia para la formalización" del Gobierno. 
públicas. Se cierra la puerta a los contratos públicos y muchas veces también a los contratos privados, salvo que la contratación privada se restrinja a otras empresas igualmente informales. Un menor acceso a la financiación ajena, pública o privada, y una menor contratación, pública o privada, ocasiona una menor productividad y competitividad empresarial.

A las anteriores consecuencias negativas derivadas de la informalidad empresarial habrían de sumarse las derivadas directamente de la informalidad laboral dentro de la empresa informal o, en su caso, de la empresa formal. En un entorno de empleo informal, el trabajador ni es contratado con las garantías ni, en consecuencia, con los derechos legales que le corresponderían, ni es remunerado con un salario adecuado a las horas laborales (ordinarias o extraordinarias) trabajadas, sin recibir ni el salario mínimo (o, a veces, siquiera remuneración) y con inestabilidad de ingresos. La informalidad laboral provoca la inestabilidad de ingresos y de horarios, sin derechos que poder reclamar por pensiones de desempleo, incapacidad o jubilación, sin seguros por riesgos profesionales, y sin representatividad a través de los representantes de los trabajadores. Sin protección social, sin garantías ante las contingencias, sin respeto de los derechos, con un empleo informal hay vulnerabilidad labora ${ }^{16}$. No hay un trabajo decente.

\subsection{Las causas de la informalidad}

Ante los efectos, las causas. Ante tantas consecuencias negativas para la empresa y para el trabajador -aparte de las que luego habrá que referenciar para el Estado y la sociedad-, hay que tratar de averiguar las causas que llevan a comenzar y a continuar la actividad empresarial fuera de la formalidad, esto es, fuera de la reglamentación. Las causas pueden ser muy diversas, en función del país y, dentro de él, de la región y el sector económico en el que se desarrolle la actividad empresarial. Sin poder recoger ni atender aquí a tanta diversidad, tan solo se describirán algunas de las causas generales más conocidas y frecuentes que conducen y mantienen en la informalidad a la empresa y a los trabajadores.

La informalidad es por necesidad o por sobrevivencia ${ }^{17}$, en primer lugar.

16 Para el efecto de la vulnerabilidad laboral derivado del empleo informal, léase, por ejemplo: DÍAZ ANDRADE, E.; GÁLVEZ PÉREZ, T.: Informalidad laboral..., op. cit., pp. 18.

17 Por sobrevivencia por marginalidad, se calificaría en: OTÁROLA PEÑARANDA, F. R. (et al.): Estrategia sectorial..., op. cit., p. 9. 
La pobreza y la marginalidad por la falta de alfabetización y de recursos serían las causas más profundas y estructurales que contrarrestar en los esfuerzos de los gobiernos regionales y nacionales que apuesten por promover y extender la formalización. Programas de alfabetización y de cultura empresarial y financiera, en general, y facilitación del acceso a recursos económicos de no elevado coste, en particular, debieran ponerse en funcionamiento para la progresión hacia la formalización.

La informalidad es por conveniencia o con intencionalidad, en segundo lugar. En paralelo a las anteriores causas, se halla la "cultura de la informalidad"18. Una cultura, la de la informalidad, que habría que ir desterrando y cambiando hacia la opuesta cultura de la formalidad con medidas de información y de formación, de orientación y sensibilización. Con estas medidas se trataría de hacer comprender al empresariado los riesgos y los problemas que derivan de la elusión de las obligaciones legales fiscales y laborales y, al contrario, las ventajas particulares y generales de desarrollar la actividad dentro de la legalidad.

Junto con las mencionadas causas estructurales, otras causas, esta vez legislativas, se agrupan en la comprensión del porqué de la existencia y subsistencia de la informalidad empresarial. Entre ellas, sobresalen las barreras legales y administrativas que obstaculizan el proceso del emprendimiento formalizado ${ }^{19}$. La acumulación de procedimientos, los altos costes y los largos plazos para registrar una empresa, así como para solicitar y obtener los debidos permisos o licencias, en función de la actividad empresarial de que se trate, pueden provocar el desistimiento (por hastío) de la puesta en marcha de la empresa en el sector económico reglamentado. Si a la burocracia se añaden para los emprendedores (sobre todo, de recursos más bajos) unos elevados costes tributarios, laborales y de Seguridad Social pudiera no interesar (en una balanza de beneficios y costes) emprender formalmente, pese al riesgo de ser inspeccionado y, en consecuencia, sancionado por emprender informalmente.

18 A la "cultura de la informalidad" se refiere expresamente la citada presentación sobre la estrategia de formalización del Ministerio del Ministerio de Comercio, Industria y Turismo de la República de Colombia. Vid. supra la nota a pie de página número 15.

19 En la "heterogeneidad de la informalidad empresarial" clasificada en: OTÁROLA PEÑARANDA, F. R. (et al.): Estrategia sectorial..., op. cit., p. 9, junto a la informalidad por sobrevivencia y por elusión de las obligaciones fiscales o laborales, se agrupó la informalidad por la "complejidad del proceso". 


\section{La informalidad versus la formalidad: un entorno de compe- tencia deleal}

La informalidad acarrea desventajas. Algunas de las más comunes para la empresa -para su subsistencia, crecimiento y expansión-, así como para el trabajador -para sus derechos y protección-, han sido anunciadas en el epígrafe anterior. Algunas otras, las que afectan al Estado y a la sociedad, se relatarán en este y en el siguiente epígrafe.

No pagando las empresas informales las tasas ni impuestos, disminuyen los ingresos públicos con los que compensar los gastos públicos. De ser elevado el porcentaje de informalidad empresarial en el país, las empresas formales pudieran tener que soportar una superior carga fiscal, para hacer frente a aquella disminución de los ingresos públicos, que la que habrían de soportar (porque se distribuiría entre todas las empresas) en la hipótesis de que todas o la mayoría de las empresas actuaran en la economía formal ${ }^{\mathbf{2 0}}$.

Entre las empresas formales y las informales pudieran producirse tensiones, no solo en materia fiscal, sino de competencia desleal ${ }^{21}$. En la economía no reglamentada ni se pagan las cuotas tributarias ni tampoco se efectúan los pagos de las cotizaciones a la Seguridad Social mientras que en la economía reglamentada el empresario (formalizado como trabajador autónomo o como sociedad mercantil regular) está sometido a la fiscalidad y a la cotización laboral. Existiendo una violación de las normas administrativas, laborales y fiscales por parte de las empresas informales se podría estar consiguiendo una ventaja competitiva que, de ser significativa, pudiera dar lugar a actos de competencia desleal, contrarios al principio de buena fe que ha de perseguirse en el mercado. De ser así, pudieran plantearse denuncias o demandas por competencia desleal. En tal caso, las autoridades judiciales en materia de

20 Esta observación halló eco en la reseñada presentación del gerente de formalización del Ministerio de Comercio colombiano.

21 Aunque referidas a la moneda social, planteábamos tensiones similares de competencia desleal entre la economía formal y la informal en: HERNÁNDEZ-BEJARANO, M.; GARCÍA MANDALONIZ, M.: "La moneda y criptomoneda social para el desarrollo de la economía social y sostenible”, en prensa en una obra colectiva de la oficina española de la OIT. Esta obra colectiva será el resultado de un triple encuentro interuniversitario organizado sobre la iniciativa del futuro del trabajo para conmemorar el centenario de la OIT. El trabajo de ambas autoras incluido en ese libro colectivo es el reflejo escrito de una comunicación presentada en el tercer encuentro interuniversitario que tuvo lugar en la Universidad de Sevilla en febrero de 2019. 
competencia tendrían que resolver los conflictos planteados en las relaciones entre las empresas formales e informales. En su caso, sancionando por actos de competencia desleal, la normativa de la competencia pudiera contribuir a reducir el incumplimiento de la regulación y, con ello, el mercado informal. La informalidad daña una competencia saneada. Por ello, el derecho y la política de la competencia habrían de examinar y, en su caso, sancionar las actuaciones anticompetitivas de las empresas informales cuando se dieran los requisitos legales para su calificación como actos de competencia desleal. La informalidad puede dañar la competencia y, visto de un modo global, afectar a la productividad ${ }^{22}$, la eficiencia económica y la competitividad ${ }^{23}$ de un país.

\section{Las desventajas de la informalidad son las ventajas de la for- malidad: para el empresario, el trabajador, el Estado y la sociedad}

Por aquellos daños y afectaciones, el avance hacia la formalidad empresarial es en pro de la consecución de las ventajas que acarrea la formalización para el empresario y los empleados, desde el interior de la empresa; y, desde el exterior, para el Estado y la sociedad.

Desde el primer punto de vista, el interno a la empresa, la posibilidad de incrementar los recursos financieros ajenos, por el acceso al crédito y a otros contratos bancarios o alternativos a los bancarios, sería ventaja que no desdeñar. A ellas podría sumarse la reseñada posibilidad de licitación en contratos públicos y del incremento de los contratos privados. La apertura hacia nuevos mercados y, sobre todo, la seguridad jurídica, al no estar sometida la empresa a la presión de verse sancionada, tras la correspondiente fiscalización de las autoridades competentes, serían ventajas notorias para la empresa derivadas de una situación de formalización.

También desde un foco interno, para los trabajadores que en ella realicen un trabajo por cuenta ajena, la formalización (empresarial y) laboral conlleva, gracias a las correspondientes cotizaciones, la inclusión en el sistema de la Seguridad Social y, por ende, subsidios por accidente o enfermedad, desempleo o

22 Para aumentar la productividad se planteó reducir la informalidad en los planes de formalización y productividad que presentó Colombia ante la OCDE el 13 de febrero de 2019. En la misma dirección camina el pacto por el emprendimiento, la formalización y la productividad (PND), como parte del Plan Nacional de Desarrollo 2018-2022: "Pacto por Colombia. Pacto por Equidad".

23 De conformidad con "The Global Competitiveness Index 4.o 2018 Rankings", Colombia ocupaba en competitividad la posición sesenta de los ciento cuarenta países analizados. 
jubilación. A ello puede unirse la estabilidad de los ingresos, la formación y la capacitación, las oportunidades de especialización y de ascenso laboral, y la garantía de los derechos. Estas ventajas de la formalidad laboral habría que propagarlas entre los trabajadores de los sectores económicos que sufren mayor informalidad laboral para su conocimiento y su reivindicación. Han de conocer que la formalidad laboral provoca su empoderamiento económico ${ }^{24}$. Un trabajo con protección social y garantía de los derechos es un trabajo formal decente y de calidad ${ }^{25}$. Dar un trabajo de calidad atrae al talento hacia la empresa y, a su vez, el talento laboral deriva en más productividad empresarial ${ }^{26}$. En este círculo virtuoso ha de estimularse la generación de empleo formal facilitando programas de capacitación y formación técnica de los trabajadore ${ }^{27}$. Más formación y capacitación, más conocimiento productivo. Más conocimiento productivo de los trabajadores, más "sofisticación del aparato productivo". Más diversidad y sofisticación de las actividades productivas, más crecimiento del empleo formal y, con él, "sectores económicos más sofisticados" 28 .

Desde el punto de vista externo a la empresa, una de las mayores ventajas de la formalización para el Estado es, precisamente, la generación de empleo y autoempleo formal de calidad. Otra es la ampliación de la base tributaria ${ }^{29}$ y, en consecuencia, el incremento de los ingresos públicos. A la creación de

$24 \mathrm{Al}$ empoderamiento económico y a la emancipación de las personas de los sectores más desventajados de la sociedad, como efecto de la formalización empresarial y laboral, se referiría el Grupo de Trabajo I de la Comisión de Naciones Unidas para el Derecho Mercantil Internacional (CNUDMI) en el documento, de 10 de mayo de 2018, rubricado: "Creación de un entorno jurídico propicio para el funcionamiento de las microempresas y las pequeñas y medianas empresas (mipyme)".

25 Hacia el trabajo decente y de calidad, con garantía de los derechos y la protección social para los trabajadores, camina el Ministerio de Trabajo de Colombia con el establecimiento de una Red Nacional de Formalización Laboral, formada como una alianza entre las entidades privadas y públicas.

26 Como se indica por la CNUDMI en el documento que hemos citado en la nota a pie de página número 24, en su apartado de oportunidades de especialización laboral.

27 Vid., ad ex., OTÁROLA PEÑARANDA, F. R. (et al.): Estrategia sectorial..., op. cit., p. 50 .

28 En ideas y expresiones entrecomilladas tomadas de: LORA, E.: "La formalización del empleo en las ciudades colombianas". Dinero.com, 9 noviembre 2017 (sección opinión) (después también en la siguiente publicación: asesorías especializadas blogspost, 16 noviembre 2017).

29 Así lo recuerda y resalta la CNUDMI en el documento que insta a la reducción de los obstáculos jurídicos que afectan a las mipyme. 
empleo formal y al aumento de los ingresos públicos se unen ventajas, en general, para la sociedad: la protección de los consumidores, la confianza en el comercio y en el mercado, y el crecimiento del tejido económico-productivo ${ }^{30}$.

\section{Los componentes clave de una estrategia hacia la formaliza- ción}

Para alcanzar las ventajas que para unos (empresarios y trabajadores) y otros (Estado y sociedad) se desprenden de la formalidad empresarial (y laboral), la Comisión de Naciones Unidas para el Derecho Mercantil Internacional (CNUDMI) ha venido desarrollando tareas para favorecer un emprendimiento formalizado ${ }^{31}$.

La CNUDMI pretende contribuir a avanzar en la facilitación de la formalización por su traducción en visibilidad en los mercados, ante los consumidores y el Estado; en accesibilidad al sistema bancario y a otras instituciones financieras; en extensión de las oportunidades de negocio y, en consecuencia, de expansión e internacionalización; y en amplificación de la rentabilidad, la productividad y la competitividad empresarial ${ }^{32}$. Para esa facilitación de la formalización, insta a instaurar un "entorno jurídico propicio" 33 , caracterizado por la reducción de las trabas a través de la simplificación de la regulación.

Con ese fin, publicaba, el 10 de mayo de 2018, un documento rubricado: "Creación de un entorno jurídico propicio para el funcionamiento de las microempresas y las pequeñas y medianas empresas (mipyme)"34. En su prefacio insistía en la situación de desventaja que sufren las mipyme frente a las grandes empresas, así como en la necesaria labor de la CNUDMI para incentivar su formalización y funcionamiento ${ }^{35}$. Por un "entorno empresarial sólido

30 También son estas ventajas citadas y destacadas por la CNUDMI en aquel documento.

31 A través de su Grupo de Trabajo I sobre las microempresas, las pequeñas y medianas empresas.

32 Conforme detalla la Nota de la Secretaría de la CNUDMI titulada: "Reducción de los obstáculos jurídicos que afectan a las microempresas y pequeñas y medianas empresas", de 17 de julio de 2017, pp. 12-13 (correspondiente al 29º Período de sesiones del Grupo de Trabajo I).

33 En la expresión de la rúbrica del documento del Grupo de Trabajo I de la CNUDMI: "Creación de un entorno jurídico propicio para el funcionamiento de las microempresas y las pequeñas y medianas empresas (mipyme)”.

34 A/CN.9/941.

35 Anexo. Introducción, p. 3. 
para todas las empresas" entiende este organismo internacional "las políticas, las leyes, las instituciones y los reglamentos que rigen las actividades empresariales, y los mecanismos administrativos y de aplicación”. Para hacer sólido ese entorno empresarial han de adoptarse "medidas para simplificar y hacer más atractivo para las mipyme el ingreso en el sector reglamentado". Entre las medidas de simplificación sobresalen las legislativas o reglamentarias ${ }^{36}$.

En las fronteras de la Unión Europea ${ }^{37}$, la Comisión europea propuso, a través de la Small Business Act (SBA) ${ }^{38}$ de 2008, actuar con el firme propósito de simplificar la regulación, conforme a la regla de "pensar primero a pequeña escala”. Para traducir este principio a la práctica, de un lado ${ }^{39}$, planteó reducir ${ }^{40}$ la carga administrativa, con una normativa redactada con claridad y sencillez, y evaluaciones periódicas de la incidencia de las iniciativas legislativas mediante el "sme test" 41 , en español, "test de la mipyme". De otro lado, formuló la necesidad de consultar a los interesados, incluidas

36 En el programa "Estado simple, campaña Colombia ágil” se comenta que los excesos de regulación y tramitación afectan principalmente a las mipyme. Por ello, es conveniente cambiar las "regulaciones obsoletas, inconsistentes o repetitivas" por otras más simplificadas. Porque la simplicidad legislativa conduce hacia la formalidad, un paso legislativo importante hacia la formalización se dio en Colombia con la publicación de la Ley 1429, de 29 de diciembre de 2010, de formalización y generación de empleo (Diario Oficial 47.937, de 29 de diciembre de 2010). En esa ley se incluyeron, por ejemplo, beneficios fiscales (a modo de pagos progresivos de los impuestos) para las nuevas empresas formalizadas desde el origen y también para las empresas inicialmente informales que se formalizaran. También los beneficios allegaron a la matricula mercantil.

37 Varias de las alusiones que haremos en este epígrafe (en el texto principal o en las notas a pie de página) al marco europeo tuvimos ocasión de reflejarlas con anterioridad, a otros efectos, en nuestra siguiente publicación: GARCÍA MANDALONIZ, M.: "La estrategia europea en favor de las pequeñas y medianas empresas y su implementación en España”, Derecho comercial y de las obligaciones: revista de doctrina, jurisprudencia, legislación y práctica, núm. 285, 2017, pp. 827-848.

38 Communication for the Commission to the Council, the European Parliament, the European Economic and Social Committee and the Committee of the Regions "Think Small First": a "Small Business Act" for Europe (SBA) (SEC (2008) 2101) (SEC (2008) 2102) (COM (2008) 394 final, 25 junio 2008, 24 pp.).

39 En las páginas 8 y 9 de la SBA.

40 En un veinticinco por ciento.

41 Algunos Estados miembros (como Bélgica, Dinamarca, Alemania, Luxemburgo, Polonia, Eslovenia, Finlandia, Suecia y Reino Unido) fueron citados como territorios donde se había integrado la prueba de las PYMES en los procesos de toma de decisiones, en el listado incluido en la página 5 de la revisión de la SBA. 
las organizaciones empresariales (y, añadimos, sindicales) antes de elaborar cualquier proyecto de legislación con repercusiones sobre las microempresas y las pequeñas empresas ${ }^{42}$. Además, planteó utilizar medidas específicas, tales como derogaciones, periodos de transición y exenciones, entre otras, de las obligaciones de informar o declarar. También instón ${ }^{43}$ a la reducción ${ }^{44}$ de los plazos de concesión de licencias y otras autorizaciones administrativas necesarias para comenzar una actividad empresarial ${ }^{45}$. En definitiva, trató de permeabilizar a las Administraciones Públicas ante los requerimientos de las mipyme, simplificando las licencias y promoviendo la Administración electrónica para conferir agilidad ${ }^{46}$ en la tramitación de los primeros pasos de la vida empresarial ${ }^{47}$.

En febrero de $2011^{48}$ se revisaba esa "ley" de la pequeña empresa en Europa. Mediante dicha revisión se evaluaron los progresos alcanzados, se detectaron los obstáculos persistentes y los desafíos pendientes y se examinaron las nuevas necesidades que presentaban las mipyme ${ }^{49}$. La aplicación de la máxima de "pensar primero a pequeña escala" siguió siendo la "piedra de toque" 50 . Su concreción para la simplificación del entorno reglamentario y administrativo suponía formular normas aplicando el "principio de solo una vez" ${ }^{1}$. Conforme a este principio, las autoridades nacionales han de abstenerse de solicitar los datos, documentos o certificados que las empresas han

$42 \mathrm{Al}$ menos, ocho semanas.

43 En la Comunicación de la Comisión al Parlamento Europeo, al Consejo, al Comité Económico y Social Europeo y al Comité de las Regiones: "Plan de acción sobre emprendimiento 2020. Relanzar el espíritu emprendedor en Europa” (COM (2012) 795 final, 9 enero 2013, 36 pp.).

44 A un mes.

45 Los Países Bajos fueron puestos como ejemplo de buena práctica de reducción de las cargas administrativas en la página 23, correspondiente al Anexo, del texto revisado de la SBA.

46 Acortando a menos de una semana.

47 En palabras subrayadas en negrita en la recomendación cuatro del apartado IV de la SBA (p. 11).

48 Comunicación de la Comisión al Parlamento Europeo, al Consejo, al Comité Económico y Social Europeo y al Comité de las Regiones: Revisión de la "Small Business Act" para Europa (COM (2011) 78 final, 23 febrero 2011, 28 pp.).

49 Conforme se comenta en la introducción de esta revisión (p. 2) (también en p. 3).

50 En la expresión empleada en la página 5 del Plan de Acción sobre emprendimiento 2020. Vid. supra nota a pie de página número 43.

51 Páginas 7 y 8 de la SBA revisada. 
puesto a su disposición en otros procedimientos ${ }^{2}$. También han de llevar a cabo comprobaciones de aptitud para evaluar si el marco reglamentario es adecuado al objetivo marcado y, si de esta evaluación se desprendiera que no lo es, para afrontar cómo deben solucionarse las dificultades detectadas ${ }^{53}$. Asimismo, tienen que llevarse a cabo controles de eficacia que identifiquen y, si es necesario, resuelvan los problemas derivados de la interacción de las normas que sean aplicables de manera simultánea a un sector ${ }^{54}$.

Complementando la revisión de la SBA, la red europea de enviados de las pymes (o "Sme-Envoy Networking") elaboraba, en 2017, un plan de acción de las mipyme. A modo de extenso documento de trabajo ${ }^{55}$, comenzaba con la necesidad de profundizar en las acciones para fortalecer una "mejor regulación”. Porque la burocracia administrativa y regulatoria representa mayores costes para las pequeñas que para las grandes empresas, al no gozar aquellas de los beneficios de las economías de escala, hay que generalizar e intensificar los progresos hacia una mejor regulación. En ese avance, el incremento de la transparencia legislativa, la aplicación del principio de pensar primero a pequeña escala a la regulación, el "sme test" y el principio de solo una vez ("only once") han de ser intensificados porque siguen perviviendo algunos de los obstáculos para su plena consecución ${ }^{56}$.

En conjunto, la prueba de la pyme, el principio de solo una vez, la comprobación de actitud y el control de eficacia, junto con la minoración de la obligación de presentar documentación o el establecimiento de un interlocutor único empresarial ${ }^{57}$, persiguen en la geografía europea y pueden perseguir fuera de ella el logro de una normativa simplificada "a escala pyme" que desbanque la sobrerregulación ${ }^{58}$. Para desbancarla, se requieren medidas dirigidas a tornar la hiper-regulación en hipo-regulación pensando en las mipyme y promocionando su participación y coordinación con las instituciones y las

52 En la descripción que de este "principio de solo una vez" se realiza en la página 8 de la SBA revisada en 2011.

53 En la página 7, además de la página 9, de la revisión de la SBA.

54 Página 9 de la revisión de la SBA.

55 Con 76 páginas en total se publicaba, en 2017, el European SME Action Programme del SME-Envoy Network.

56 Páginas 5 y siguientes del European SME - Action Programme.

57 La Comisión invitó a los Estados a que establecieran un interlocutor único (por ejemplo, con ventanillas únicas empresariales) y a que minorasen las obligaciones de presentar informes, en la página 9 de la SBA modificada.

58 En la página 7 de la revisión de la SBA. 
autoridades políticas y legislativas, como recomienda a los gobiernos la OIT en su informe de 10 octubre de $2019^{59}$.

\subsection{Un sistema electrónico eficiente de inscripción empresarial}

Entre las medidas legislativas simplificadoras, se precisaría, en primer lugar, derribar las barreras jurídicas que puedan obstaculizar -por número de trámites, permisos, costes y tiempos- un rápido y fácil registro y puesta en marcha de una empresa ${ }^{60}$. La propuesta de la CNUDMI de acabar con la "reglamentación onerosa y [...] los costosos procedimientos que imponen los Estados a las empresas para ingresar en el sector reglamentado" tiene la vista puesta en "el crecimiento económico, la protección social y la inclusión” 61.

Para pasar de la informalidad a la formalidad es obligatoria la inscripción de las empresas ante las autoridades competentes, esto es, ante el registro mercantil y los organismos tributarios y de la Seguridad Social ${ }^{62}$. La tendencia marcada por la CNUDMI se dirige hacia un sistema de inscripción exclusivamente electrónico basado en la eficiencia para una ágil formalización del emprendimiento en la presente era de la conexión digital ${ }^{63}$. A fin de facilitar la máxima rapidez en la formalización del emprendimiento, la CNUDMI ${ }^{64}$, en su Guía Legislativa sobre los principios fundamentales de la inscripción registral de las empresas, invita a los Estados a que prevean un sistema de inscripción registral de acceso electrónico directo por parte del usuario. El

59 Conforme se recoge en las notas de prensa que extractan el informe de la OIT de 10 de octubre de 2019 que citábamos al inicio de la presente investigación.

60 Según el antedicho ranking del índice global de competitividad 4.o de 2018, Colombia se situaba, en cuanto al coste de comenzar una empresa, en la posición noventa y una de las ciento cuarenta economías clasificadas y, en el tiempo de empezar una empresa, en el número sesenta y ocho.

61 Conforme a la página 10 de aquel documento citado de la CNUDMI.

62 Página 7 del documento sobre un entorno jurídico propicio de la CNUDMI.

63 Como tuvimos ocasión de remarcar en estos dos capítulos de libro: GARCÍA MANDALONIZ, M.: "Hacia un sistema único de constitución de sociedades mercantiles electrónico y eficiente”, en MADRID PARRA, A. (Dir.): Derecho mercantil y tecnología. Aranzadi, 2018, pp. 857-895; GARCÍA MANDALONIZ, M.: "Fomentando la formalización del emprendimiento femenino con un registro electrónico de empresas y una entidad de responsabilidad limitada simplificada”, en BLÁZQUEZ AGUADO, E. M. ${ }^{\text {a }}$ (Dir.): Los ODS como punto de partida para el fomento de la calidad del empleo femenino. Dykinson, 2018, pp. 131-173.

64 A/CN.9/WG.I/WP.93, p. 21. 
acceso electrónico directo aumenta la eficiencia del proceso, en tanto incrementa las posibilidades de acceder al registro y, a la vez, reduce los costos de funcionamiento y mantenimiento del sistema de inscripción registral ${ }^{65}$.

Por la inscripción en línea también se decantaría en la Unión Europea el grupo informal de expertos en derecho de sociedades (ICLEG, en sus siglas en lengua inglesa $)^{66}$ en un informe sobre la digitalización del derecho de sociedades en la Unión Europea, fechado en marzo de 2016. El marco general predecesor sería la conferencia de 2015 sobre el derecho de sociedades en la era digital y el marco sucesor el programa de trabajo de la Comisión europea para $2017^{67}$, donde se anunció una iniciativa legislativa de derecho societario facilitadora del uso de las tecnologías digitales durante el ciclo de vida empresarial para una base industrial fortalecida en un mercado único europeo digital conectado. Esa iniciativa legislativa ha desembocado en la aprobación y publicación de la Directiva (UE) 2019/1151 del Parlamento Europeo y del Consejo, de 20 de junio de $2019^{68}$, sobre la digitalización del derecho de sociedades. En ella se prevé un proceso "íntegramente en línea" para "el funcionamiento eficaz, la modernización y la racionalización administrativa"

De regreso al ámbito internacional, hacia un sistema de registro on-line se encamina derechamente la CNUDMI en la citada Guía Legislativa sobre los principios fundamentales de inscripción registral de empresas. Esta Guía propone un itinerario que transita hasta un sistema único electrónico de constitución de las sociedades mercantiles. Las razones esgrimidas entroncan con la integridad de los datos, la seguridad de la información, la transparencia del

65 En palabras redactadas en la página 69 de la Nota de la Secretaría de la CNUDMI, de 17 de julio de 2017, titulada: "Reducción de los obstáculos jurídicos que afectan a las microempresas y pequeñas y medianas empresas” (correspondiente al $29^{\circ}$ Período de sesiones del Grupo de Trabajo I).

66 El Informal Company Law Expert Group (ICLEG) está registrado, desde el 26 de mayo de 2014, para trabajar en nuevas iniciativas sobre el derecho de sociedades en Europa.

67 COM (2016) 710 final, 25 octubre 2016; Anexo de la Comunicación de la Comisión al Parlamento Europeo, al Consejo, al Comité Económico y Social y al Comité de las Regiones (SWD (2016) 400 final).

68 DOUE L 186, 11 julio 2019, pp. 80-104. A través de esta Directiva de 2019 se modifica la Directiva (UE) 2017/1132 del Parlamento Europeo y del Consejo, de 14 de junio de 2017, "en lo que respecta a la utilización de herramientas y procesos digitales en el ámbito del derecho de sociedades" (DOUE L 169, 30 junio 2017, pp. 46 y siguientes).

69 Considerando $2^{\circ}$ de la Directiva (UE) 2019/1151. 
sistema registral, la verificación del cumplimiento de los requisitos legales por parte de las empresas y la evitación de almacenamiento de información innecesaria o redundante ${ }^{70}$.

El sistema de inscripción registral empresarial no solo ha de ser electrónico sino también eficiente. La antedicha Guía Legislativa no solo respalda la transición hacia un sistema de inscripción de empresas exclusivamente digital, sino que lo encamina hacia la eficiencia. La eficiencia se regiría por los siguientes principios fundamentales ${ }^{71}$ : el primero, un trámite de inscripción sencillo, rápido, económico, fácil de aplicar y accesible al público; el segundo, una información registrada de las entidades mercantiles fácil de consultar y extraer; y el tercero y último, una información registrada fiable, actualizada e inalterada. En suma, se aglutinan la simplificación, la rapidez, la economicidad y la facilidad con la actualización y la fiabilidad ${ }^{72}$. Bajo estos principios, las ventajas son la reducción del tiempo y la disminución de la posibilidad de fraude y del riesgo de que el sistema registral incurra en responsabilidad debido a la disminución de la probabilidad de cometer error en el ingreso de los datos correspondientes a la inscripción o a la búsqueda de la información ${ }^{73}$.

70 Página 27 de la versión de 17 de julio de 2017 del proyecto de Guía Legislativa de la CNUDMI sobre los principios fundamentales de un registro de empresas. También en el proyecto revisado de Guía Legislativa, fechado el 2 de enero de 2018 (A/CN.9/W.G.I/ W.P.109), en las páginas 15 y siguientes. La reducción del tiempo, la transparencia de la información, el acceso en tiempo real, la simplificación del proceso, la mejor disponibilidad del servicio, la facilidad de uso de una interfaz única, la precisión y seguridad de los datos y la disminución del costo también habían sido motivaciones destacadas en la postura favorable hacia un registro de empresas on-line que se adoptara una década atrás, en junio de 2007 , en el documento donde el Banco Mundial formulaba recomendaciones basadas en las "good practices for electronic business registries”. Todo ello según: LEWIN, A. (et al.): Implementing electronic business registry ( $e-B R$ ) services. Recommendations for policy makers based on the experience of EU accession countries. The World Bank, june 2007, pp. 17-19; conforme citábamos en los dos capítulos de libro referenciados en la nota a pie de página 63 .

71 Proyecto de Guía Legislativa sobre los principios fundamentales de la inscripción registral de las empresas: Notas de la Secretaría de 5 de agosto de 2015 (A/CN.9/WG.I/ WP.93), pp. 7-8; y en posteriores Notas, como la de 2 de enero de 2018 (A/CN.9/W.G.I/ WP.109), pp. 15 y siguientes.

72 La versión de 17 de julio de 2017 del proyecto de Guía Legislativa se marcó (en la p. 9) como objetivo: "simplificar los trámites registrales y lograr que sean rápidos, económicos y fáciles de utilizar para los usuarios”, así como conseguir la fiabilidad que derive en un sistema "digno de confianza" (p. 14).

73 A/CN.9/WG.I/WP.93, p. 20. 
En los términos de eficiencia previstos por la CNUDMI ${ }^{74}$, habría un número mínimo de trámites, con unos plazos breves y precisos. Amén de simple y breve, para conseguir la eficiencia es conveniente que el procedimiento electrónico sea de nulo o bajo coste para el usuario emprendedor si pretende favorecerse su formalización.

La tecnología actual puede ser apta para configurar un proceso electrónico eficiente. En ese proceso cumplirían un papel principal, de un lado, los formularios tipo autorrellenables ${ }^{75} \mathrm{y}$, de otro lado, la ventanilla única empresarial en su formato virtual. Alusión general a estas ventanillas únicas, como interlocutor único para la simplificación de la vida empresarial, hubo en la Small Business Act, donde se describieron como lugares donde "obtener toda la información pertinente y cumplimentar por vía electrónica todas las formalidades y los procedimientos necesarios" ${ }^{76}$. Nueva alusión, como interfaz única para la inscripción, hay en la documentación que plasma los trabajos que la CNUDMI ha llevado a cabo para formular la Guía Legislativa sobre los principios fundamentales del registro de empresas ${ }^{77}$.

Con tecnologías que presten servicios registrales con confianza, veracidad y validez conforme a la legislación interna; con identificación digital del emprendedor; y con una ventanilla única empresarial virtual accesible desde cualquier dispositivo móvil y cualquier territorio de la geografía se caminaría en dirección hacia un sistema único electrónico y eficiente de inscripción registral con el que promover la formalización empresarial.

74 Página 19 de la Nota de la Secretaría de la CNUDMI de 17 de julio de 2017.

75 Consúltese la Nota de la Secretaría de la CNUDMI de 10 de agosto de 2015, pp. 9-10.

76 La alusión a las ventanillas únicas empresariales se plasmó en la página 11 de la redacción originaria de la SBA. En el desarrollo de las ventanillas únicas empresariales, como "portales de administración electrónica de fácil utilización para el usuario", se incidiría después, en la revisión de 2011 de la SBA (p. 8). La creación de ventanillas únicas empresariales, configurando la denominada “Red EUGO”, era una de las obligaciones establecidas en la Directiva 2006/123/CE del Parlamento Europeo y del Consejo, de 12 de diciembre de 2006, relativa a los servicios en el mercado interior (DO L 376, 27 diciembre 2006, pp. 36-68), más conocida como: "Directiva de Servicios”. Con posterioridad su impulso se ha ido manteniendo por el Plan de Acción Europeo e-Government 2011-2015 (SEC (2010) 1539 final; COM (2010) 743 final, 15 diciembre 2010, 16 pp.), por la Agenda Digital en Europa y por las Agendas Digitales de los Estados miembros.

77 Así, en la Nota de la Secretaría de la CNUDMI de 10 de agosto de 2015, pp. 3-6; o en la posterior de 17 de julio de 2017, pp. 5, 8, 34 y siguientes. 


\subsection{Un sistema de incentivos fiscales y laborales}

Para tratar de conseguir un ecosistema global y eficiente de formalización, resultaría imprescindible acometer una serie de cambios en el momento inicial del registro empresarial, con el mínimo de costes en la matricula mercantil y con la máxima reducción de los procedimientos y los plazos, a través de una ventanilla única empresarial virtual accesible desde cualquier lugar.

Además de remover obstáculos, hay que añadir incentivos. Podría pensarse actuar en los primeros años de la actividad empresarial, con beneficios tributarios para los emprendedores, a modo de exoneraciones o moratorias en el pago de los tributos. En los beneficios tributarios creemos que podría interesar incidir si se pretende reducir el coste de la formalización. Pero, porque los efectos de los incentivos fiscales para las nuevas empresas formalizadas pudieran ser más en el corto que en el largo plazo, en el que tenderían a descender o desaparecer, habría que conjuntarlos con incentivos fiscales para otros agentes económicos. Beneficios tributarios para los business angels y las entidades de venture capital interesadas en invertir en las fases incipientes de los proyectos empresariales innovadores podrían ser de utilidad para que las empresas nuevas e innovadoras obtuvieran financiación alternativa a la bancaria y, gracias a ella, para promover su mantenimiento en la economía formal.

Aparte de beneficios fiscales bien a las nuevas empresas formalizadas o bien a los inversores que invirtieran en ellas, otro tipo de incentivos podrían estudiarse desde el terreno laboral y de la Seguridad Social. Podría reflexionarse acerca de la minoración de los costos laborales para las empresas formales $^{78}$. El recorte de las cotizaciones a la Seguridad Social podría tener, no obstante, el efecto indeseado de la reducción de la protección social ${ }^{79}$. La reducción de los costes laborales o de las cotizaciones de la Seguridad Social parecería, en cualquier caso, insuficiente para por sí sola hacer pasar a la empresa de la informalidad a la formalidad ${ }^{80}$. No en recortes sino en subsidios podría meditarse para el fomento de la contratación de trabajadores de colectivos desfavorecidos o vulnerables ${ }^{81} \mathrm{y}$, en especial, de jóvenes, mujeres con familias monoparentales, mayores todavía no en edad de jubilación o personas con discapacidad.

78 Vid. OTÁROLA PEÑARANDA, F. R. (et al.): Estrategia sectorial..., op. cit., p. 57.

79 Como se alerta en ídem.

80 Ídem.

81 Ibidem, p. 70. 
En su conjunto, las medidas a adoptar convendría que tuvieran una cuádruple vertiente legislativa: la comercial, la administrativa, la fiscal y la laboral. Con medidas de simplificación legislativa, de reducción de los plazos y costes de la inscripción, y de incentivación fiscal y laboral podría incrementarse el porcentaje de empresas formalizadas, si consiguiera reducirse el costo de la legalidad y aumentar el beneficio de realizar la actividad económica dentro de ella. Una reglamentación onerosa para el ingreso y el mantenimiento en el sector reglamentado ha de ser mutada por una reglamentación de sencillo y bajo coste de cumplimiento ${ }^{82}$.

\subsection{Un conjunto de medidas de sensibilización para desenrai- zar la cultura de la informalidad}

No solo desde la vertiente legislativa sino también desde la extra-legislativa pueden darse pasos que encaminen hacia la formalización empresarial y laboral. Las modificaciones de la legislación, para su simplificación y agilidad, las consideramos condición necesaria, pero no suficiente para sustituir los efectos negativos que provoca la informalidad por los efectos positivos que conlleva la formalidad. Junto con una revisión de la legislación vigente para dotarla de simplicidad y efectividad, parece conveniente indagar en otras vías de resolución del problema que nos atañe.

Al lado de una legislación incentivadora "sencilla y directa" 83 han de idearse e instaurarse otros mecanismos para la formalización del emprendimiento $^{84}$. Desde el ámbito externo a la empresa, una política nacional y regional eficaz incluiría la promoción del emprendimiento formalizado, la formación en las capacidades y habilidades emprendedoras ${ }^{85}$ y el estímulo del acceso a los canales financieros. Desde el ámbito interno a la empresa, podríamos enunciar la necesaria optimización en la utilización de los recursos existentes y la deseable eficiencia y estrategia en la gestión económico-financiera de cara al aumento de la productividad. La formalización llevaría consigo el acceso al sistema financiero y, con él, la disponibilidad de los recursos económicos

82 Léase la Nota de la Secretaría de CNUDMI de 10 de abril de 2018, p. 10.

83 Ídem.

84 El párrafo 23 (p. 12) de la Nota de la Secretaría de CNUDMI de 10 de abril de 2018 alude a la necesidad de incentivos para la inscripción empresarial, añadiendo un listado ejemplificativo que, en parte, transcribiremos, a continuación, en el texto principal.

85 Vid. OTÁROLA PEÑARANDA, F. R. (et al.): Estrategia sectorial..., op. cit., p. 51. 
podría aumentar la productividad ${ }^{86}$. Sería buscar la formalización para la financiación y la financiación para la productividad. Pero, también el ítem contrario se podría dar, en el sentido de que la productividad conduciría hacia la formalidad ${ }^{87}$. En efecto, un considerable aumento de la productividad discurriría hacia la necesidad de la empresa de formalizarse para seguir ganando en productividad y para abrirse hacia nuevos mercados internos y externos. La ganancia de productividad provocaría un crecimiento a largo plazo, y viceversa; en el nexo causal que entre uno y otro extremo se establece ${ }^{88}$.

Desde una óptica externa a la empresa, se requeriría la mejora del contexto económico-financiero del país, con el consiguiente incremento del acceso al crédito bancario y al resto de vías de financiación empresarial, públicas o privadas, para posibilitar que las nuevas empresas dispusieran de medios bancarios y alternativos a los bancarios (microcréditos, crowdfunding, seed capital o venture capital) con los que atender sus proyectos de inversión o de internacionalización ${ }^{89}$.

Aun en una situación macroeconómica idílica, probablemente seguiría existiendo un elevado porcentaje de casos en los que la informalidad sería intencional, si no se actúa para transformar la nombrada cultura de la informalidad en la ansiada cultura de la formalidad. Programas de información, formación y sensibilización se alzan en pilar básico de cualquier estrategia global conducente hacia la formalidad ${ }^{90}$. Se ha de concienciar a la sociedad, en general, y al sector empresarial y laboral, en particular, de la problemática de la informalidad y de las desfavorables consecuencias que ocasiona para el tejido productivo, en general, y para las mipyme, en especial. Esta sería una

86 Acceso a los servicios financieros para promover la productividad empresarial, se comentaría en ídem.

87 LORA, E.: “La formalización del empleo...”, op. cit., opinó que el aumento de la productividad conduce a la empresa hacia la formalización. Más que en la formalidad para el aumento de la productividad apostó por más productividad para más formalidad.

88 El nexo causal entre la productividad y el crecimiento a largo plazo se destacó en el Informe Global de Competitividad del World Economic Forum, de 16 de octubre de 2018, publicado en Ginebra-Suiza y suscrito por K. SCHWAB y X. SALA Y MARTÍN.

89 En el índice global de competitividad 4.0 de 2018, elaborado por el profesor K. SCHWAB, Colombia se situaba en el puesto 84 de 140 economías en cuanto a la financiación de las mipyme.

90 Como se refleja, por ejemplo, en: OTÁROLA PEÑARANDA, F. R. (et al.): Estrategia sectorial..., op. cit., p. 5, donde se refiere a "acciones de sensibilización" para la "cultura del cumplimiento de las normas”. También en las páginas 58 y siguientes. 
de las líneas de actuación que debieran acometerse para en el largo plazo acabar o, al menos, minorar la lacra de la informalidad por conveniencia o intencional.

Informar y formar a las empresas en la cultura de la formalidad es la doble medida que tendría que fomentarse para obtener efectos positivos dentro de esta última línea de actuación. Con información y formación, se precisaría una continua labor de mentalización a las empresas sobre la necesidad de cumplir atendiendo a la reglamentación. Debiera modificarse un cambio de mentalidad susceptible de abrir paso a una nueva situación, más próxima a la existente en aquellos países donde, aun perviviendo (siempre pervive) la informalidad, apenas representa un problema para la productividad y competitividad económica ${ }^{91}$. Para la "re-mentalización" propuesta, la CNUDMI expondría que habría que adoptar medidas dirigidas a "facilitar, explicar y atraer". Se trataría de facilitar la reglamentación, "explicar el significado de funcionar en el sector reglamentado de la economía” y atraer a las empresas hacia dicho mercado, una vez hayan sido informadas con claridad sobre las ventajas y sobre los requisitos que han de cumplir y cómo han de cumplirlos.

Rondas de reuniones informativas, charlas, talleres o seminarios; publicaciones especializadas y folletos informativos; certificación de "buenas prácticas comerciales laborales"92; y campañas promocionales institucionales por diversos canales de comunicación y, entre ellas, por las redes sociales ayudarían a establecer lo que desde estas líneas gráficamente quisiéramos denominar la "medida fea" por referirse a las primeras letras de los vocablos que empleara la CNUDMI: "facilitación, explicación y atracción”. Para su efectividad podría pensarse en la comunicación de ejemplos exitosos de empresas antes informales. Podrían ejemplificarse casos de empresarios de éxito que hubieran decidido registrar la empresa y cumplir de manera sistemática la normativa vigente, si prestasen el consentimiento para el tratamiento de sus datos personales. El resultado de esta "medida fea" sería una comunicación clara para un fácil entendimiento para obtener la sensibilización necesaria para desenraizar la enraizada cultura de la informalidad.

91 De conformidad con el nombrado informe de la OIT, de 10 de octubre de 2019, en aquellos países con más elevados ingresos (como, por ejemplo, Austria o Bélgica) la tasa de la informalidad es menor al $5 \%$, según publicaron las noticias de prensa que en distintos medios de comunicación aludieron en tal fecha a este informe.

92 A esta certificación se referiría el siguiente documento: OTÁROLA PEÑARANDA, F. R. (et al.): Estrategia sectorial..., op. cit., p. 75. 
Para desenraizarla, podría servir proporcionar mecanismos de orientación y asistencia para la elaboración del plan de negocio, con una mentorización y una asesoría empresarial de calidad a bajo coste o sin coste, y con el suministro de infraestructura tecnológica también a bajo coste ${ }^{93}$ para quienes han emprendido formalmente por necesidad, como intento de sustento económico personal y familiar. Las "redes de mentores" 94 serían el refuerzo de la alfabetización empresarial y financiera hacia el incremento de las posibilidades de emprendimiento y de subsistencia en el emprendimiento, como fórmula de autoempleo y de empleo formal.

Para acabar con la informalidad por necesidad confiamos a largo plazo en la información, la formación y la asesoría, pero estas medidas probablemente no sean por sí solas suficientemente disuasorias para terminar con la informalidad por conveniencia. Por ello, sería asesoría y mentoría para quienes no tienen capacidad de cumplir, por marginalidad, para sobrevivir. Y sensibilización y fiscalización para quienes tienen capacidad de cumplir, pero no cumplen para evadir. Para estos sería útil el reforzamiento del control y la inspección laboral ${ }^{95}$ en aquellos sectores económicos (por ejemplo, el del hogar, el del comercio o los servicios) y en aquellas regiones donde la tasa de informalidad sea más acusada. En este refuerzo del control y la fiscalización, resultaría insoslayable la eficaz aplicación del régimen de infracciones y sanciones.

En definitiva, labores de concienciación con información y formación, y un sistema de acompañamiento y tutorización a las mipyme en sus primeras etapas, aparte de la aplicación efectiva de un régimen sancionador previa inspección, sería la batería de propuestas extra-legislativas que, a modo de ensayo, han sido anunciadas con somero.

De esta batería convendría hacer partícipes a las Cámaras de Comercio y a las asociaciones empresariales y sindicales para que coadyuven junto con las autoridades competentes en pro de la formalización empresarial y laboral.

93 También el documento de la CNUDMI sobre la creación de un entorno jurídico propicio para el funcionamiento de las MIPYME contemplaría estos y otros incentivos estatales para "atraer a las MIPYME para que funcionen en el sector de la economía formal" (pp. 13-14).

94 Tomando como analogía, en particular, la red de mentoría y el "club de líderes ciberemprendedores" y, en general, el ecosistema de ciberemprendimiento planteado en el Plan de acción sobre emprendimiento 2020 en la Unión Europea, pp. 15-17.

95 Vid. OTÁROLA PEÑARANDA, F. R. (et al.): Estrategia sectorial..., op. cit., p. 58. 
En coordinación intersectorial ${ }^{96}$, las asociaciones empresariales y las organizaciones sindicales desempeñarían un papel clave para involucrar y hacer partícipes a las empresas y a los trabajadores de esa necesaria cultura de la formalidad empresarial y laboral. Se requiere cooperación y coordinación entre organismos públicos y privados para transitar hacia la formalidad.

La colaboración hacia la consecución de este primordial objetivo también pudiera provenir de las propias empresas formalizadas ${ }^{97}$ mediante la exigencia de formalidad empresarial y laboral a las empresas (clientes y proveedores) con quienes pretendan contratar. Se trataría de conseguir que todos y cada uno de los eslabones de la cadena cumplieran la legislación para conseguir una cadena de valor formalizada que pudiera enlazar con otras cadenas de valor que actuaran igualmente bajo la reglamentación. En suma, engarces de cadenas de valor reglamentadas para alcanzar el propósito final de reducir las tasas de informalidad en las regiones y en los sectores más afectados por esta lacra, con el fin último de contribuir al crecimiento económico del país.

\section{Hacia la formalización en un entorno digital y global}

Se ha insistido en que, a la optimización, por simplificación e incentivación, del entorno regulatorio habría que añadir medidas complementarias tan necesarias como las de financiamiento o las de favorecimiento de la cultura del emprendimiento, hasta conseguir una estrategia global de formalización empresarial y laboral.

A ellas podrían unirse las de promoción de círculos de interacción entre los agentes económicos para el crecimiento y la inversión en las nuevas empresas formalizadas ${ }^{98}$. En este sentido, entre los distintos agentes económi-

$96 \mathrm{Al}$ respecto, léase supra la nota a pie de página número 25. Además, a "la coordinación intersectorial” se aludiría en: ibidem, pp. 56 y 75 y siguientes.

97 Ibidem, p. 56.

98 La interacción entre los agentes del ecosistema empresarial mediante redes y plataformas tecnológicas de conexión para el crecimiento de las pequeñas empresas fue el eje central del "UNCITRAL Colloquium on contractual networks and other forms of inter-firm cooperation”, New York, 25-26 March 2019. En el sentido expresado en el texto principal, atiéndase, en especial, en dicho coloquio a las dos siguientes ponencias: LINE CARPENTIER, C.: "MSMEs and the Suistainable Development Goals", en UNCITRAL Colloquium on contractual networks and other forms of inter-firm cooperation. New York, 25 March 2019; VERMEULEN, E.: "Platform economy: how the new economy is shaping 
cos (empresarios, clientes, proveedores o inversores) sería idóneo instaurar e impulsar redes y plataformas tecnológicas de conexión para la promoción del mentoring y del networking, de las relaciones comerciales verticales $\mathrm{u}$ horizontales de cooperación, o de la innovación e internacionalización conjunta ${ }^{99}$. Las plataformas de conexión e interacción para establecer un ecosistema que ayude en las etapas del nacimiento y el crecimiento empresarial serían útiles no solo para la subsistencia sino para el liderazgo comercial de las mipyme mediante la inversión, la expansión y la utilización conjunta de la tecnología ${ }^{100}$. La formación de clúster de mipyme facilitada a través de esas plataformas de conexión podría conducir hacia la "eficiencia colectiva"101 en un mercado cada vez más competitivo, por cada vez más digitalizado y globalizado.

La moderna era de la digitalización y la globalización trae consigo nuevas posibilidades y necesidades para las nuevas empresas. El emprendimiento no solo ha de ser formal sino de alto potencial de crecimiento. El emprendimiento innovador de alto potencial de crecimiento ha de ser apoyado y acompañado para conseguir su inversión-financiación y, con ella, su expansión en los mercados internacionales. Una estrategia global público-privada de favorecimiento de la formalización del emprendimiento ha de centrar también sus esfuerzos en aquellas empresas y sectores de mayor innovación. Esfuerzos para el acompañamiento, esfuerzos para el reforzamiento del financiamiento, y esfuerzos regulatorios encaminados a obtener una legislación más simple y transparente y mejor aplicada.

En los esfuerzos regulatorios, el gran reto pendiente es conseguir una legislación suficientemente simplificada y efectiva en pro de la formalización empresarial y laboral hacia la consecución del trabajo decente y de la productividad y competitividad empresarial. Hacia este gran desafío hay que continuar dando pasos para avanzar hacia más cohesión social.

contract practices of MSMEs", en UNCITRAL Colloquium on contractual networks and other forms of inter-firm cooperation. New York, 25 March 2019.

99 Ídem.

100 Ídem.

101 Hacia la "eficiencia colectiva" en expresión de JAPPIE, R.: "SMEs and sustainable development: challenges \& opportunities”, en UNCITRAL Colloquium on contractual networks and other forms of inter-firm cooperation. New York, 25 March 2019; donde incidiría en la "eficiencia colectiva" derivada de "joint actions", con clúster capaces de facilitar y estrechar lazos de innovación entre las pequeñas compañías. 


\section{Bibliografía}

ARANGO, D.: “Estrategia para la formalización”. Ministerio de Comercio, Industria y Turismo de la República de Colombia, agosto 2011.

COMISIÓN DE NACIONES UNIDAS PARA EL DERECHO MERCANTIL INTERNACIONAL: Creación de un entorno jurídico propicio para el funcionamiento de las microempresas y las pequeñas y medianas empresas (mipyme). CNUDMI, 10 mayo 2018.

DÍAZ ANDRADE, E.; GÁLVEZ PÉREZ, T.: Informalidad laboral: concepto y mediciones, Parte 1, Taller de coyuntura. Departamento de Estudios. Dirección de Trabajo, septiembre 2015.

GARCÍA MANDALONIZ, M.: "La estrategia europea en favor de las pequeñas y medianas empresas y su implementación en España”, Derecho comercial y de las obligaciones: revista de doctrina, jurisprudencia, legislación y práctica, núm. 285, 2017.

"Hacia un sistema único de constitución de sociedades mercantiles electrónico y eficiente", en MADRID PARRA, A. (Dir.): Derecho mercantil y tecnología. Aranzadi, 2018.

"Fomentando la formalización del emprendimiento femenino con un registro electrónico de empresas y una entidad de responsabilidad limitada simplificada”, en BLÁZQUEZ AGUADO, E. M. ${ }^{a}$ (Dir.): Los ODS como punto de partida para el fomento de la calidad del empleo femenino. Dykinson, 2018

HERNÁNDEZ-BEJARANO, M.; GARCÍA MANDALONIZ, M.: "La moneda y criptomoneda social para el desarrollo de la economía social y sostenible", en Encuentro interuniversitario sobre la iniciativa del futuro del trabajo. OIT (en prensa).

JAPPIE, R.: "SMEs and sustainable development: challenges \& opportunities", en UNCITRAL Colloquium on contractual networks and other forms of interfirm cooperation. New York, 25 March 2019.

LEWIN, A. (et al.): Implementing electronic business registry (e-BR) services. Recommendations for policy makers based on the experience of EU accession countries. The World Bank, june 2007.

LINE CARPENTIER, C.: "MSMEs and the Suistainable Development Goals", en UNCITRAL Colloquium on contractual networks and other forms of interfirm cooperation. New York, 25 March 2019.

LORA, E.: "La formalización del empleo en las ciudades colombianas". Dinero. com, 9 noviembre 2017 (sección opinión).

ORGANIZACIÓN INTERNACIONAL DEL TRABAJO: Informe de la Conferencia. Decimoséptima Conferencia Internacional de Estadísticos del Trabajo. Ginebra, OIT, 24 noviembre a 3 diciembre 2003. 
_ Panorama laboral 2008. América Latina y El Caribe. OIT, 13 enero 2009. "Lo pequeño importa: Datos mundiales sobre las contribuciones al empleo de los trabajadores independientes, las microempresas y las pymes". Ginebra, OIT 10 octubre 2019.

OTÁROLA PEÑARANDA, F. R. (et al.): Estrategia sectorial para la formalización laboral 2014-2016. Perú, Ministerio de Trabajo y Promoción del Empleo, 2014.

VERMEULEN, E.: "Platform economy: how the new economy is shaping contract practices of MSMEs", en UNCITRAL Colloquium on contractual networks and other forms of inter-firm cooperation. New York, 25 March 2019. 



\title{
TRABAJO DECENTE E IGUALDAD DE GÉNERO. DÉFICITS DE TRABAJO DECENTE Y ACCIÓN SINDICAL
}

\author{
Ofelia DE FELIPE VILA \\ Técnica de desarrollo del Instituto Paz y Solidaridad \\ de la Fundación $1^{0}$ de Mayo de $\mathrm{CCOO}$
}

\begin{abstract}
RESUMEN: se persigue clarificar una serie de conceptos contenidos en la Agenda 2030, como Trabajo Decente e Igualdad de Género, así como el origen de los mismos. Al mismo tiempo, se explica la contribución e importancia de la participación sindical para la consecución efectiva de la Agenda 2030, en concreto de sus objetivos y metas relacionados con el trabajo decente y la igualdad de género.
\end{abstract}

Palabras clave: trabajo decente, igualdad de género, Agenda 2030, ODS, organizaciones sindicales, globalización, discriminación, cadenas de cuidado.

SUMARIO: 1. Relación entre trabajo decente e igualdad de género. 2. El estado del trabajo en el mundo. 3. El impacto de la globalización. 4. Las cadenas globales de cuidado. 5. Pistas para la acción sindical internacional. 6. El compromiso sindical con el trabajo decente, igualdad de género y Agenda 2030.

\section{Decent work and gender equality: deficits and collective action}

\begin{abstract}
: this article seeks to clarify a series of concepts contained in the 2030 Agenda, such as Decent Work and Gender Equality, as well as their origin. At the same time, the contribution and importance of trade union participation for the effective achievement of the 2030 Agenda is explained, specifically its objectives and goals related to decent work and gender equality.
\end{abstract}

Keywords: decent work, gender equality, 2030 Agenda, SDG, trade union organizations, globalization, discrimination, global care chains.

\section{Relación entre trabajo decente e igualdad de género}

Los Derechos Laborales son Derechos Humanos de las personas en su lugar de trabajo, y así aparecen consagrados en la Declaración Universal de los 
Derechos Humanos ${ }^{1}$. Resulta innegable que la mejora de las condiciones de trabajo de las personas, y unas relaciones de empleo justas, constituyen herramientas potentes para reducir las desigualdades ${ }^{2}$.

Desde 2015 el Trabajo decente ha pasado a ser parte integrante de la recientemente aprobada Agenda de Desarrollo Sostenible en el seno de las Naciones Unidas. El Trabajo Decente supone que hombres y mujeres tienen la oportunidad de un empleo productivo en libertad, equidad, seguridad y con dignidad. El logro de incluir el trabajo decente en un acuerdo global como la Agenda 2030 es el resultado de un amplio trabajo de consultas y presión por parte tanto de la Organización Internacional del Trabajo, como de la sociedad civil, entre la que destacan las organizaciones sindicales.

El concepto de Trabajo Decente y los elementos que lo componen fueron definidos en 1999 por el director de la OIT Juan Somavía. El programa de Trabajo Decente de la OIT se construye sobre 4 pilares. El primero es la Creación de empleo, promover empleo y generar oportunidades para que hombres y mujeres trabajen en libertad, igualdad, seguridad y dignidad. El segundo pilar se articula sobre Derechos en el trabajo, que supone la garantía no sólo de los derechos laborales, sino también de la libertad sindical, de asociación y negociación colectiva; la eliminación del trabajo forzoso y del trabajo infantil; la superación de la discriminación, y la igualdad de trato y de oportunidades. El tercer pilar está construido sobre la existencia de Diálogo social, que implica la cooperación entre gobiernos, organizaciones empresariales y sindicales para alcanzar consensos en la aplicación y el desarrollo normativo, y políticas que favorezcan el trabajo decente. Por último, el cuarto pilar es la Protección social, que requiere de la existencia de sistemas de Seguridad Social adecua$\operatorname{dos}^{3}$ con prestaciones de desempleo, jubilación, invalidez, maternidad, etc.

El quinto pilar transversal a todos los anteriores es la Igualdad de Género y la lucha contra la discriminación. Esta transversalidad de género en el Trabajo Decente implica que cualquier acción que se emprenda en el marco del Trabajo Decente se debe hacer partiendo de un análisis de género, así como

1 Artículo 23 de la "Declaración Universal de Derechos Humanos" adoptada por la Asamblea General de las Naciones Unidas en 1948

2 JALLES D’OREY, M. A., “¿Cómo apoyan los donantes el Programa de Trabajo Decente? Informe sobre cinco donantes”, del Instituto de Desarrollo de Ultramar (Overseas Development Institute), para la Red Sindical de Cooperación al Desarrollo - Confederación Sindical Internacional (RSCD-CSI). 2017.

3 Acordes a los mínimos establecidos por El Convenio sobre la seguridad social (norma mínima), 1952 (núm. 102). 
que todas las acciones deben ser ideadas, ejecutadas y evaluadas teniendo en cuenta su diferenciado impacto en mujeres y hombres. Así se recoge en el documento de la OIT resultado de la Conferencia Internacional del Trabajo del $2009^{4}$, en el que se alude a la doble estrategia que conjuga acciones positivas y la transversalidad de género para lograr la Igualdad entre hombres y mujeres.

La Agenda 2030 de Desarrollo Sostenible también adopta esta estrategia, y transversaliza el enfoque de género. Es decir, analiza todas las cuestiones con esta perspectiva, al tiempo que marca metas en todos los ODS para promover la igualdad de manera permanente.

Por tanto, la Igualdad de Género en el centro del Trabajo Decente debe suponer en primer lugar, la Garantía y promoción de derechos y principios y normas básicas laborales, como parte de los derechos humanos, asegurando el respeto a los derechos de las trabajadoras. De acuerdo al segundo pilar, debe implicar la Creación de empleo, en igualdad de oportunidades y acceso entre hombres y mujeres. En cuanto al tercer pilar del Trabajo Decente, se debe asegurar que el Diálogo social, como motor de desarrollo, se lleve a cabo garantizando una adecuada representación de las trabajadoras. En cuanto a la Protección social, es necesario asegurar las prestaciones y protección de la salud y derechos reproductivos de las mujeres.

\section{Estado del trabajo en el mundo}

La OIT, en su Informe anual sobre el Estado del Trabajo en el Mundo, recoge la siguiente situación del Trabajo Decente en el mundo: 2.00o millones de personas, dos tercios de quienes trabajan en el mundo, sufren de trabajo sin contrato y sin derechos, de discriminación, remuneración por debajo de sus capacidades, y sobreexposición a accidentes o enfermedades laborales. El $80 \%$ de la población mundial no tiene una cobertura adecuada de seguridad social y más del 50\% no tiene protección frente al desempleo, enfermedad, discapacidad, vejez o maternidad. Más de 200 millones de personas ni siquiera tienen trabajo, 30 millones más que antes de la crisis, de ellas 74 millones son jóvenes. 168 millones de niñas y niños se encuentran atrapados en el trabajo infantil perdiendo su vida, su salud y su futuro. 21 millones de personas son explotadas en condiciones de trabajo forzoso.

Como conclusiones principales del Informe 2019 de la OIT, es necesario

4 Resolución de la OIT relativa a la igualdad de género como eje del trabajo decente, 2009. 
subrayar la persistencia de una gran brecha de género en el mundo, la generalización de los déficits de trabajo decente, y la mayor prevalencia de la subutilización de la fuerza de trabajo entre las mujeres.

Además, en el 2016 la OIT publicó un Informe específico sobre la situación de las mujeres en el trabajo. Pretendía subrayar que, en el mundo laboral, entre hombres y mujeres, pese a algunos avances logrados, persisten considerables diferencias y discriminaciones ${ }^{5}$ : En 2015, 586 millones de mujeres eran trabajadoras por cuenta propia o familiares, no remuneradas. El $38 \%$ de las mujeres en el mercado laboral no cuentan con protección social, alcanzando el 63,2\% en África subsahariana y el 74,2\% en Asia Meridional, donde el trabajo informal es la forma de empleo dominante. Tanto en los países desarrollados, como en los países en desarrollo, las mujeres trabajan mayor número de horas al día que los hombres, sea en el trabajo remunerado como en el no remunerado. En más de 100 países, la cobertura de pensiones es inferior para las mujeres en comparación con los hombres, debido a las condiciones laborales precarias o no remuneradas que han afrontado durante su vida laboral. A nivel mundial, en términos de salarios, las mujeres ganan un promedio del $77 \%$ de lo que ganan los hombres.

\section{Impacto de género en la Globalización}

La globalización es un fenómeno complejo, entre cuyas características fundamentales están la liberalización del comercio internacional, la expansión de la inversión extranjera y la aparición de flujos financieros masivos transfronterizos. El resultado ha sido un boom en la "deslocalización" de las tareas de producción. El impacto de la globalización y la reestructuración de la plantilla han tenido consecuencias importantes para el género y las políticas relacionadas con la igualdad en todo el mundo.

Los inversores y compañías multinacionales han tenido gran libertad de movimiento de capitales, creando puestos de trabajo en los países con menores costes laborales. Las mujeres son las primeras en sentir los efectos porque el capital internacional tiende a invertir en mano de obra femenina debido a que los salarios son más bajos para ellas. Los empleadores adoptan políticas laborales más flexibles y formas menos seguras de empleo, como a tiempo parcial o temporal, donde las mujeres son mayoría.

Otro fenómeno es la informalización del mercado de trabajo. En algunos

5 OIT, “Las mujeres en el trabajo. Tendencias 2016”, 2017. 
países en desarrollo, más del 90\% de la población activa se encuentra en la economía informal. Las condiciones de trabajo son a menudo peligrosas, existe poca o ninguna seguridad de empleo o ingresos, y las personas trabajadoras están excluidas de la protección social

En los últimos 20 años se ha consolidado un nuevo modelo basado en las empresas de externalización de producción a través de las cadenas de suministro globales a bajo coste y trabajo "flexible". En muchos países, las leyes nacionales del trabajo se han debilitado o no se aplican.

En este contexto, las mujeres se encuentran concentradas en determinados sectores laborales como el Textil, donde son más de 3/4 partes del sector de la confección (90\% en Camboya, 85\% en Bangladesh, 70\% en China). También en el sector turístico, en especial en la hostelería y restauración, las mujeres son el 70 \%, sobretodo en puestos de nivel inferior. El sector de cuidados aglutina en los países desarrollados al 85\% de mujeres como mano de obra. En razón de ello, la $12^{\text {a }}$ Jornada Mundial por el Trabajo Decente, celebrada el pasado 7 de Octubre de 2019, ha realizado una llamada a la inversión en el sector de cuidados para lograr la Igualdad de género ${ }^{6}$.

Como resultado de la globalización, liberalización y externalización, millones de personas trabajadoras trabajan de manera precaria: con contratos a corto plazo, con un acceso limitado a la protección social, largas horas de trabajo en condiciones insalubres, intentos de organizarse y reclamar que se cumplan sus derechos. Aplicando la perspectiva de género, se puede observar que además existe segregación laboral (cuyo origen está en la división sexual del trabajo: las mujeres tradicionalmente han ocupado el espacio privado y desarrollado tareas y actividades en este marco, como el cuidado y la atención de otras personas, el mantenimiento del hogar, etc, mientras que los hombres se han dedicado de forma general al trabajo productivo, en el espacio público, lo que implica tanto los trabajos remunerados como la actividad política y social.

La incorporación de las mujeres al mercado laboral ha reproducido en cierta forma esta división de tareas, si bien desde el marco común del trabajo

6 El origen de la Jornada Mundial por el Trabajo Decente se sitúa en 2008, cuando el Secretario General Guy Ryder de la Confederación Sindical Internacional, en el congreso fundacional se aprobó poner en marcha una jornada de acción mundial para «fortalecer la lucha internacional por los derechos de los trabajadores y contra la pobreza». Se trata de un proceso histórico para unificar y comprometer en una acción global a 331 centrales sindicales nacionales. 
asalariado o remunerado: las mujeres destacan de forma patente en sectores como: hogares privados con servicios doméstico, servicios sociales y sanitarios, enseñanza, hoteles y restaurantes y comercios, etc. donde predominan tareas de cuidado de otras personas, prolongando de alguna manera la actividad del espacio privado, mientras que los hombres aparecen ocupando el grueso de la fuerza laboral en construcción, agricultura y ganadería, pesca, transporte, almacenamientos y comunicaciones. Esto es lo que se conoce como "segregación horizontal" que hace referencia al grado en que mujeres y hombres se encuentran en diferentes sectores de actividad o sectores ocupacionales. Se observa como los sectores en los que se concentran la mayoría de mujeres se caracterizan por brindar pocas oportunidades de promoción profesional, peores remuneraciones y menor prestigio social.

La "segregación vertical", se refiere a la desigual distribución de mujeres y hombres en las posiciones jerárquicas dentro del mismo sector ocupacional e incluso dentro de las mismas empresas, tendiendo las mujeres a ocupar los puestos de menor escala jerárquica o funcional, y consecuentemente recibiendo los salarios más bajos. Como consecuencia de esta doble segregación, aparece la "brecha salarial", es decir el porcentaje de los ingresos de las mujeres respecto al de los hombres en términos estadísticos.

\section{Las cadenas globales de cuidado}

En cuanto a las Cadenas Globales de Cuidado, se trata de un sector infravalorado, con salarios bajos y malas condiciones laborales, donde la mano de obra es mayoritariamente femenina. Las Mujeres representan más de 3/4 partes del trabajo de cuidados no remunerado en el mundo, lo que equivale a un 13\% del PIB o 10 billones de USD al año. Se estima que invirtiendo un $2 \%$ del PIB en cuidados, se podrían crear 42 millones puestos de trabajo en 6 países en desarrollo7.

La OIT avanza además que en España se podrían generar un millón de empleos en el sector de cuidados, atendiendo «los déficits actuales en la prestación de servicios de cuidado y su calidad». El Trabajo de cuidados, comprende dos tipos de actividades, el cuidado directo, personal y relacional, como dar de comer a un bebé o cuidar de un familiar enfermo; y el cuidado indirecto, como cocinar y limpiar. El trabajo de cuidados en España se estima

7 OIT, El trabajo de cuidados y los trabajadores del cuidado para un futuro con trabajo decente, 2016. 
representa un 14,9\% del PIB. El escenario que maneja la OIT es que España en el año 2030, se situará en la posición 22 de los países con mayores ratios de dependencia de cuidados de personas mayores, con 9,1\%.

En estas cadenas globales de cuidado se da la conjunción de múltiples elementos, como es la división sexual del trabajo, la crisis global, la migración como opción para muchas mujeres, que se insertan en el sector de cuidados en los países de destino. Todo ello se asienta sobre la consideración de trabajo de cuidados como una condición innata femenina, que además es desvalorizado, no profesionalizado, no reconocido, y por lo tanto no remunerado adecuadamente... La consecuencia directa es que tenemos un sector de cuidados feminizado, precarizado, e invisibilizado, con explotación laboral de mujeres migrantes. Estas cadenas si bien están protagonizadas por mujeres, se encuentran construidas sobre ausencias: de instituciones (ni servicios ni prestaciones), de empresas y de hombres ${ }^{8}$.

Todo ello conforma un déficit de trabajo decente gravísimo. En el contexto actual los riesgos de continuar aumentando los déficits de trabajo decente son muy elevados. La crisis mundial del empleo es uno de los mayores riesgos. La falta prolongada de oportunidades de trabajo, la insuficiencia de inversiones y el bajo consumo, erosionan el contrato social básico de las sociedades democráticas. En este sentido, es más que necesario recordar que el trabajo decente es un elemento que contribuye a alcanzar la paz, la justicia y la igualdad a nivel global.

\section{Pistas para la acción sindical internacional}

Desde la perspectiva de la acción sindical, varias serían las áreas de trabajo:

En primer lugar, en materia de igualdad en el empleo, es necesario destacar que la participación de las mujeres en el mercado laboral tiene un gran impacto en la economía, y en su propia autonomía y empoderamiento. Para lograr una plena participación de las mujeres, en igualdad de oportunidades que los hombres, y con garantía de sus derechos, es necesario realizar esfuerzos conjuntos desde gobiernos, interlocutores sociales y sociedad civil, encaminados a : Proteger y promover los derechos laborales de las mujeres con servicios de asesoramiento y asistencia jurídica. Mejorar las competencias y cualificaciones profesionales de las mujeres. Evitar la discriminación

8 PÉREZ OROZCO, A., "Cadenas Globales de Cuidado: preguntas para una crisis”, Miradas Norte, 2010. 
de género en el lugar de trabajo (derechos laborales, remuneración, horario laboral, salud y seguridad, así como otras condiciones...). Facilitar el acceso de las mujeres a sectores laborales cerrados para ellas. Garantía de los derechos individuales de las mujeres migrantes. Vigilancia sobre el respeto de los derechos de las trabajadoras temporeras. Promoción de trabajo decente para las trabajadoras en el empleo doméstico

En segundo lugar, por lo que hace a la igualdad en la participación y toma de decisiones, el apoyo a organizaciones sindicales democráticas, paritarias y transparentes en esta línea es clave para mejorar la representatividad de las mujeres, su contribución a la igualdad de género y la mejora de la participación de las mujeres en las organizaciones sindicales y en los espacios de diálogo social y de representación. Se trata de promover una mayor presencia de mujeres sindicalistas en puestos de toma de decisiones y en los espacios de diálogo social, fomentar el análisis y la reflexión sobre estrategias para la igualdad de participación e influencia de las mujeres en las organizaciones sindicales, al tiempo que se asegura el apoyo a organizaciones en sus esfuerzos de sensibilización sobre la igualdad entre hombres y mujeres, y el empoderamiento de las mujeres.

En tercer lugar, también hay que trabajar para la igualdad en los marcos normativos. A este especto, las autoridades nacionales son las responsables de la adopción y aplicación de marcos legislativos acordes con la normativa internacional y garantes de los derechos de las mujeres y de la igualdad. La incidencia de las organizaciones para la adecuación del marco normativo nacional a los estándares reconocidos por la legislación internacional en materia de igualdad sobre las autoridades, es muy importante. Es prioritario en este ámbito la promoción de una ratificación universal de normas clave, como la Convención de las Naciones Unidas sobre la eliminación de todas las formas de discriminación contra la mujer (CEDAW), y los Convenios fundamentales y de gobernanza de la OIT, así como todas las normas emanadas de la OIT relacionadas con los ejes estratégicos y el eje transversal sobre no discriminación que forman parte del Trabajo Decente. Especial atención merece la ratificación del Convenio 189 de la OIT sobre el Trabajo Decente para las Trabajadoras y los Trabajadores Domésticos.

Por último, hay que tejer alianzas por la igualdad. La acción colectiva de las organizaciones diversas de la sociedad civil y de los agentes sociales para tejer redes y establecer alianzas estratégicas permitirán afrontar los retos y obstáculos que impiden que las mujeres puedan acceder o permanecer en 
el trabajo, contribuyendo entre todos los actores a promover soluciones basadas en normas laborales que garanticen salarios y condiciones laborales dignas de acuerdo con los convenios de la OIT, prestando especial atención a trabajadoras del sector informal, trabajadoras migrantes y trabajadores del empleo doméstico, la eliminación del acoso sexual en el lugar de trabajo, con medidas de protección y seguridad social, y la protección de las trabajadoras en territorios ocupados y zonas de conflicto.

\section{El compromiso sindical con el trabajo decente, igualdad de género y Agenda 2030}

Las organizaciones sindicales, entre ellas $\mathrm{CCOO}$, desempeñan un papel clave para lograr el Trabajo Decente en cada país, y la promoción de la igualdad entre hombres y mujeres, en particular en el ámbito laboral. Su acción internacionalista y solidaria, llevada a cabo en cooperación al desarrollo durante años, ha perseguido como objetivo la mejora de las condiciones de vida de la población trabajadora en otros países. En paralelo, se ha realizado una importante labor de sensibilización de la población trabajadora española para la construcción de una ciudadanía consciente y crítica con la situación de desigualdad global.

Si bien la aprobación de la Agenda 2030 en la Cumbre de las Naciones Unidas no fue fácil, con 13 rondas de negociaciones entre 2013 y 2014, más otras 8 rondas en 2015 previas a su aprobación, su adopción por los 193 Estados Miembros de las Naciones Unidas, entre ellos España, se considera un importante logro. Forman también parte de esta Agenda, la Agenda de Acción de Addis Abeba (un marco financiero y no financiero de ejecución) y el Acuerdo de París sobre el clima (un tratado mundial para el cambio climático). En su elaboración y adopción, una amplia variedad de actores participan, entre ellos la OIT y las organizaciones sindicales, coordinadas pro al Confederación Sindical Internacional.

Por tanto, desde su origen se da un fuerte compromiso de las organizaciones sindicales, y en concreto de CCOO con la Agenda 2030 y sus ODS. La apropiación se muestra en las contribuciones a los planes desarrollo A2030 y la participación Consejos y diálogos sociedad civil por parte de la organización; la difusión de información y formación en la materia, la creación de grupos de trabajo específicos, y la realización y publicación de un Informe de seguimiento sindical 2018 y 2019. 
Las prioridades sindicales se encuentran centradas inicialmente en los siguientes ODS y metas:

- Objetivo 1. Poner fin a la pobreza en todas sus formas en todo el mundo

- Objetivo 3. Garantizar una vida sana y promover el bienestar de todos y todas a todas las edades

- Objetivo 4. Garantizar una educación inclusiva y equitativa de calidad y promover oportunidades de aprendizaje permanente para todos y todas

- Objetivo 5. Lograr la igualdad entre los géneros y empoderar a todas las mujeres y las niñas

- Meta 5.4. Reconocer y valorar los cuidados y el trabajo doméstico no remunerados mediante servicios públicos, infraestructuras y políticas de protección social, y promoviendo la responsabilidad compartida en el hogar y la familia, según proceda en cada país

- Meta 5.5. Asegurar la participación plena y efectiva de las mujeres y la igualdad de oportunidades de liderazgo a todos los niveles decisorios en la vida política, económica y pública

- Objetivo 8. Promover el crecimiento económico sostenido, inclusivo y sostenible, el empleo pleno y productivo y el trabajo decente para todos y todas

- Meta 8.5. Para 2030, lograr el empleo pleno y productivo y garantizar un trabajo decente para todos los hombres y mujeres, incluidas las personas jóvenes y las personas con discapacidad, y la igualdad de remuneración por trabajo de igual valor

- Meta 8.8. Proteger los derechos laborales y promover un entorno de trabajo seguro y protegido para todos los trabajadores y todas las trabajadoras, incluidos los trabajadores migrantes, en particular las mujeres migrantes y las personas con empleos precarios

- Objetivo 10. Reducir la desigualdad en y entre los países

- Meta 10.4. Adoptar políticas, en especial fiscales, salariales y de protección social, y lograr progresivamente una mayor igualdad

- Meta 10.7. Facilitar la migración y la movilidad ordenadas, seguras, regulares y responsables de las personas, entre otras cosas mediante la aplicación de políticas migratorias planificadas y bien gestionadas

- Objetivo 13. Adoptar medidas urgentes para combatir el cambio climático y sus efectos

- Objetivo 16. Promover sociedades pacíficas e inclusivas para el desarrollo sostenible, facilitar el acceso a la justicia para todos y todas y crear instituciones eficaces, responsables e inclusivas a todos los niveles 
- Objetivo 17. Fortalecer los medios de implementación y revitalizar la Alianza Mundial para el Desarrollo Sostenible

A nivel nacional, los derechos sindicales y las cuestiones relacionadas con la negociación colectiva (remuneración adecuada, protección social y lucha contra la discriminación) ocupan un lugar central de la acción sindical. Las organizaciones sindicales tienen una importante función en la difusión de los derechos entre las trabajadoras y los trabajadores, y en la presión a los gobiernos para la ratificación de convenios internacionales, adaptación de la legislación y desarrollo de políticas públicas.

Sin embargo, las organizaciones sindicales afrontan muchas dificultades en razón de la persistencia y agravamiento de las violaciones a la libertad sindical. La Confederación Sindical Internacional, a la que pertenece CCOO, realiza anualmente un informe sobre las violaciones de derechos sindicales en el mundo9. Las regiones donde se dan en mayor medida y crudeza son Oriente Próximo y Norte de África. Sin embargo, en Europa y en concreto en España, hemos visto graves retrocesos en este ámbito en los últimos años, llegando aquí a criminalizar y sancionar penalmente el ejercicio del derecho de huelga por parte de sindicalistas.

En este contexto, se hace más necesario que nunca, promover un mayor respeto de la libertad sindical en el mundo, porque forma parte de los Derechos Humanos reconocidos internacionalmente, y porque resulta indispensable en la promoción del trabajo decente y de la igualdad entre hombres y mujeres. Sin libertad sindical, es decir, sin organizaciones sindicales igualitarias, autónomas, representativas y dotadas de las garantías necesarias para la promoción de los derechos de las personas trabajadoras, no se alcanzará el objetivo del trabajo decente ni el de la igualdad entre hombres y mujeres. La relación entre libertad sindical, trabajo decente, igualdad y desarrollo sostenible es esencial.

\section{Bibliografía}

JALLES D’OREY, M. A., “¿Cómo apoyan los donantes el Programa de Trabajo Decente? Informe sobre cinco donantes", del Instituto de Desarrollo de Ultramar (Overseas Development Institute), para la Red Sindical de Cooperación al Desarrollo - Confederación Sindical Internacional (RSCD-CSI). 2017.

9 Informe sobre las violaciones de los derechos sindicales de la Confederación Sindical Internacional, 2019 
OIT, El trabajo de cuidados y los trabajadores del cuidado para un futuro con trabajo decente, 2016.

OIT, “Las mujeres en el trabajo. Tendencias 2016”, 2017.

PÉREZ OROZCO, A., "Cadenas Globales de Cuidado: preguntas para una crisis”, Miradas Norte, 2010. 